MARIANA ABRANTES GIANNOTTI

DESENVOLVIMENTO DE ONTOLOGIAS PARA SISTEMAS DE APOIO A LOGÍSTICA HUMANITÁRIA BASEADOS EM SERVIÇOS DE INFORMAÇÕES GEOGRÁFICAS: UMA APLICAÇÃO PARA BANCOS DE ALIMENTOS 
MARIANA ABRANTES GIANNOTTI

DESENVOLVIMENTO DE ONTOLOGIAS PARA SISTEMAS DE APOIO A LOGÍSTICA HUMANITÁRIA BASEADOS EM SERVIÇOS DE INFORMAÇÕES GEOGRÁFICAS: UMA APLICAÇÃO PARA BANCOS DE ALIMENTOS

Tese apresentada à Escola Politécnica da Universidade de São Paulo para obtenção de título de Doutorado em Engenharia.

SÃo PAULO 


\section{DESENVOLVIMENTO DE ONTOLOGIAS PARA SISTEMAS DE APOIO A LOGÍSTICA HUMANITÁRIA BASEADOS EM SERVIÇOS DE INFORMAÇÕES GEOGRÁFICAS: UMA APLICAÇÃO PARA BANCOS DE ALIMENTOS}

Tese apresentada à Escola Politécnica da Universidade de São Paulo para obtenção de título de Doutorado em Engenharia. Área de Concentração: Engenharia de Transportes - Informações Espaciais.

Orientador: Prof. Livre-Docente José Alberto Quintanilha 
Este exemplar foi revisado e alterado em relação à versão original, sob responsabilidade única do autor e com a anuência de seu orientador.

São Paulo, 25 de novembro de 2010.

Assinatura do autor

Assinatura do orientador

FICHA CATALOGRÁFICA

Giannotti, Mariana Abrantes

Desenvolvimento de ontologias para sistemas de apoio à logística humanitária baseados em serviços WEB de informações geográficas / M.A. Giannotti. -- ed.rev. -- São Paulo, 2010. $196 \mathrm{p}$.

Tese (Doutorado) - Escola Politécnica da Universidade de São Paulo. Departamento de Engenharia de Transportes.

1. Geoprocessamento 2. Logística 3. Ontologia I. Universidade de São Paulo. Escola Politécnica. Departamento de Engenharia de Transportes II. $t$. 
Ao meu companheiro, cujo amor, paciência e carinho me deram estrutura e força para continuar na batalha.

Ao meu filho que chegou durante este doutorado e trouxe outro sentido à minha vida.

Aos meus familiares pelo apoio incondicional, em especial ao meu pai que me ensinou a lutar pelos meus sonhos, à minha mãe por toda sua ajuda indispensável, ao meu irmão pela torcida, ajuda e incentivo e à minha afilhada querida que tantas vezes me ajudou a cuidar de meu filho para que eu pudesse terminar esse trabalho. 


\section{AGRADECIMENTOS}

Ao Professor José Alberto Quintanilha pela orientação e pela confiança. Ao Professor Robert Laurini pela co-orientação, pelo apoio e por ter viabilizado meu grande sonho de morar na França.

Ao Laboratório de Geoprocessamento (LabGeo/EP/USP), ao Departamento de Engenharia de Transportes da Escola Politécnica de São Paulo e a toda sua equipe de alunos, funcionários e professores pelo grande apoio. Em especial ao Prof. Marcos Rodrigues, à Alessandra, à Claudia, ao Jun, à Patrícia, ao Rafael, à Silvia, ao Henrique, ao Vinícius, ao Daniel Gorni e ao Daniel Bevilacqua.

Ao Laboratório LIRIS (Laboratoire d'InfoRmatique en Image et Systèmes d'information) pela infraestrutura e aos amigos que fiz durante a temporada nesta instituição, em especial à Rosa, à Armelle e à Sam.

Ao MESA Brasil SESC, que me deu a oportunidade de conhecer melhor sobre os bancos de alimentos no Brasil.

À Federação Européia de Banco de Alimentos, em especial à Aude Auston que foi muito solicita e me abriu as portas para conhecer um pouco mais sobre os bancos de alimentos na Europa.

Aos meus amigos, em especial à Vera a amiga de sempre, à Kanta, à Laura e às minhas outras irmãs pé-de-meienses e à Cibele que me apresentou pela primeira vez um banco de alimentos e me abriu perspectivas que resultaram na realização deste trabalho.

À Coordenação de Aperfeiçoamento de Pessoal de Nível Superior (CAPES) pelo financiamento desta pesquisa.

Ao Conselho Nacional de Desenvolvimento Científico e Tecnológico (CNPq) pelo financiamento de meu estágio no exterior. 
"Se encontrarmos meios de permitir que as pessoas se encontrem e trabalhem juntas, poderemos nos sair muito melhor do que se cada um trabalhar separadamente" Elinor Ostrom 


\section{RESUMO}

Com o advento da Internet, novas tecnologias de Geoprocessamento têm sido criadas para tratar, trocar, disponibilizar e acessar informações e dados espaciais como as Infraestruturas de Dados Espaciais, os Geobrowsers e os Serviços de Informações Geográficas. O número de aplicações que lida com atributos espaciais não somente cresceu como também se diversificou, no entanto problemas de interoperabilidade semântica ainda limitam a evolução nessa área. Ontologias formalizam o conhecimento necessário para organizar e permitir o uso de dados de diferentes fontes, pois são modelos de referência robustos devido à sua expressividade e capacidade de serem compartilhados pela internet. Nesta tese, ontologias foram desenvolvidas para aumentar a interoperabilidade semântica em sistemas de apoio à logística humanitária que utilizam serviços de informações geográficas. A aplicação de logística humanitária estudada foi a operação de bancos de alimentos. O conhecimento relativo aos processos logísticos, problemas logísticos de bancos de alimentos e serviços de informações geográficas úteis para os métodos de solução desses problemas foram formalizados em uma rede de ontologias. O número de serviços de informações geográficas disponíveis ainda é pequeno, mas a composição de serviços de informações geográficas em cadeias, formando novos serviços, abre uma perspectiva para que operações espaciais, não fiquem mais restritas às soluções proprietárias e possam ser melhor exploradas. As

ontologias propostas neste trabalho podem ser usadas como base para o desenvolvimento de sistemas em que serviços de informações geográficas podem ser acoplados, na medida em que forem sendo disponibilizados.

Palavras-chave: Logística, Ontologia, Geoprocessamento. 


\begin{abstract}
With the advent of Internet, new technologies from GIS field have been created to access and exchange spatial data and information, such as Spatial Data Infrastructures, Geobrowsers and Geographic Information Services. The number of applications dealing with spatial attributes is growing and is also diversifying. However semantic interoperability problems still limit progress in this area. Ontologies formalize the knowledge necessary to organize and allow the use of data from different sources due to its expressiveness and ability to be shared over the Internet. In this thesis, ontologies have been developed to increase the semantic interoperability of humanitarian logistics support systems that use geographic information services. The application of humanitarian logistics operation studied was the food banks operation. The knowledge on logistics processes, logistics problems of food banks and geographic information services useful for the methods for solving these problems have been formalized into a network of ontologies. The number of geographical information services available is still small, but the composition of geographic information services in chains, creating new services, opens a perspective for new methods of spatial operations, which are not limited to proprietary solutions form GIS softwares available in the market. The ontologies proposed in this thesis can be used as a basis for developing systems in which geographic information services can be coupled, as it becomes available.
\end{abstract}

Keywords: Logistic, Ontologies, Geoprocessing Services. 


\section{LISTA DE ILUSTRAÇÕES}

Figura 1.1 - Fluxograma.

Figura 2.1 - Componentes do IDE. Fonte: Rajabifard et al. (2002).

Figura 2.2 - Semântica e iniciativas recentes relacionadas ao geoprocessamento. .38

Figura 2.3 - Configuração da digital earth (Davis et al., 2009). .39

Figura 2.4 - Arquitetura para sistemas de apoio a logística humanitária. 40

Figura 3.1 - Triângulo do planejamento logístico. Fonte: Ballou, 2001 43

Figura 3.2 - Fluxograma da operação de bancos de alimentos. 55

Figura 3.3 - Cadeia de suprimentos onde se insere a ação de bancos de alimentos. 60

Figura 3.4 - Alimento sendo empacotado e identificado por um banco de alimentos. Fonte: Prefeitura de Belo Horizonte, MG, Brasil.

Figura 3.5 - Fluxos das cadeias de suprimentos empresarial, humanitária e dos bancos de alimentos. Fonte: Adaptado de Blanco e Goentzel (2006). .64

Figura 3.6 - Operação de bancos de alimentos. 67

Figura 4.1 - Triângulo semântico (Fonte: Kuhn, 2005). .72

Figura 4.2 - llustração sobre a integração entre ontologias pelo estabelecimento de relacionamentos entre classes. 75

Figura 4.3 - Classificação de ontologias (Guarino, 1998). 76

Figura 4.4 - Processo de desenvolvimento de ontologias. Fonte: Goméz-Perez et al. (2003). .79 
Figura 4.5 - Ilustração de metodologia para SIG orientados por ontologia. (Adaptado de Fonseca et al., 2000). .83

Figura 4.6 - Ontologia proposta por Pawlszcyk et al. (2004) ...................................92

Figura 4.7 - Estrutura modular da ontologia proposta por Ye et al. (2008). .93

Figura 4.8 - Representação gráfica das classes e relações básicas da ontologia proposta por Ye et al. (2008). .94

Figura 4.9 - Hierarquias de estrutura formalizada pela ontologia elaborada para produtos manufaturados na cadeia de suprimentos. .95

Figura 4.10 - Hierarquias de abstração formalizada pela ontologia elaborada para produtos manufaturados na cadeia de suprimentos. 96

Figura 4.11 - Relacionamento entre classes de uma ontologia de inventário em logística (Jingbing et al., 2008). 97

Figura 4.12 - Ontologia logística baseada em contexto e condições (ou estados) proposta por Peng et al. (2007). 98

Figura 4:13 - Detalhamento da classe de contexto localização proposta por Peng et al. (2007). 99

Figura 4.14 - Detalhamento da classe condições (ou estados) proposta por Peng et al. (2007) 99

Figura 4.15 - Modelagem do contexto em operações de atendimento à situação de emergência. Smirnov et al. (2009). 101

Figura 4.16 - Modelagem do contexto através de ontologias proposto por Smirnov et al. (2007) 102

Figura 4.17 - Exemplo de mineração de regras influenciando a decisão do usuário (adaptado de Smirnov et al., 2007). 103

Figura 4.18 - Representação gráfica da ontologia da Cadeia de Suprimentos. .....106

Figura 4.19 - Classes de Processos Logísticos. 107 
Figura 4.20 - Classes de Problemas Logísticos. 108

Figura 5.1 - Agenda de pesquisa para serviços de informações geográficas 116

Figura 5.2 - Elementos relacionados à composição de serviços (Lemmens et al., 2007)

Figura 5.3 - Cadeia de serviços WPS para aplicação de análise de mercado imobiliário (Stollberg e Zipf, 2008).

Figura 5.4 - Arquitetura baseada em composição de serviços para aplicação de cálculo de risco de incêndio em áreas florestadas. 120

Figura 5.5 - Arquitetura de um sistema para aplicação de modelos hidrológicos baseada em soluções open source e serviços WPS. 121

Figura 5.6 - Arquitetura de ontologias para anotações semânticas (Fonte: Klien e Probst, 2005). 123

Figura 5.7 - Arquitetura de sistema com suporte para anotações semânticas proposto por Macário e Medeiros (2009). .124

Figura 5.8 - Anotações semânticas de serviços de geoprocessamento (Maué et al., 2009) 125

Figura 5.9 - Classificação das operações espaciais proposta por Albrecht. 126

Figura 5.10 - Representação de geo-campos no modelo OMT-G (Borges et al. 2005) 129

Figura 5.11 - Representação de geo-objetos no modelo OMT-G (Borges et al. 2005). 129

Figura 5.12 - Relacionamentos no OMT-G (Borges et al. 2005). 130

Figura 5.13 - Exemplos de generalização espacial (Borges et al. 2005). 131

Figura 5.14 - Agregação espacial (Borges et al. 2005). 131

Figura 5.15 - Generalização espacial (Borges et al. 2005) 132 
Figura 5.16 - Arquitetura de ontologias para anotação semântica de serviços de geoprocessamento (adaptado de Lemmens, 2006). 135

Figura 5.17 - Proposta de mapeamento entre OMT-G e ontologias para anotação semântica de serviços de informações geográficas.

Figura 5.18 - A generalização conceitual no mapeamento entre OMT-G e ontologias.

Figura 5.19 - Detalhamento do Meta-Nível da Ontologia de Símbolos (adaptado de Lemmens, 2006). 139

Figura 5.20 - Classe Operações Espaciais. 140

Figura 5.21 - Descrição de um serviço de roteirização.

Figura 6.1 - Anotação do serviço com conceitos da ontologia desenvolvida na Tese. 143

Figura 6.2 - llustração do Protótipo do Sistema de Apoio aos Bancos de Alimentos: entrada de dados. 145

Figura 6.3 - llustração do Protótipo do Sistema de Apoio aos Bancos de Alimentos: mapa com a seqüência de pontos de parada. 145

Figura A.1 - Gráficos representando as quantidades distribuídas de alimentos por DD.RR. e suas variações entre os anos de 2005, 2006 e 2007. 176

Figura A.2 - Gráfico representando a quantidade de alimentos distribuídos e os recursos destinados para cada regional, para os anos de 2006 e 2007 176

Figura A.3 - Gráfico representando as taxas de variação nas quantidades de alimentos distribuídos entre os anos 2005-2006 e 2006-2007 e a variação de recursos destinados entre 2005-2006 para cada regional 177

Figura A.4 - Gráfico representando cessões e doações analisadas. 179

Figura A.5 - Gráficos representando número de viagens e capacidade, necessárias. 


\section{LISTA DE TABELAS}

Tabela 2.1- Iniciativas recentes relacionadas ao domínio do Geoprocessamento....37

Tabela 3.1 - Áreas e níveis de decisão: estratégica, tática e operacional.

Tabela 3.2 - Categorização dos problemas de logística humanitária.

Tabela 3.3 - Artigos relacionados à logística humanitária classificados pelo tipo de operação.

Tabela 3.4 - Comparação entre cadeia de suprimentos empresarial e humanitária. 51

Tabela 3.5 - Especificidades das operações de bancos de alimentos. 65

Tabela 4.1 - Relação das bibliotecas de ontologias disponíveis na Web. 80

Tabela 4.2 - Relação de ontologias da área de geoprocessamento (Minard et al., 2009)

Tabela 4.3 - Processos e eventos logísticos (Peng et al., 2007) 89

Tabela 4.4 - Descrição dos processos e atividades logísticas proposta por Martins et al. (2006)

Tabela 5.1 - Descrição de alguns serviços de informações geográficas segundo padrões OGC. Fonte: Adaptado de Schut, 2007.

Tabela 6.1 - Requisitos para desenvolvimento de um Sistema de Apoio aos Bancos de Alimentos.

Tabela 6.1 - Requisitos para desenvolvimento de um Sistema de Apoio aos Bancos de Alimentos (Continuação).

Tabela A.1 - Classificação das divisões regionais (DD.RR). 
Tabela A.2 - Avaliação da evolução histórica dos programas por DD.RR.

Tabela A.3 - Número de bancos de alimentos que fazem parte da Federação Européia de Bancos de Alimentos. 190

Tabela A.4 - Quantidade de alimentos coletada por bancos de alimentos que fazem parte da Federação Européia de Bancos de Alimentos

Tabela A.5 - Origem das doações de bancos de alimentos que fazem parte da Federação Européia de Bancos de Alimentos. 192

Tabela A.6 - Destino das doações de bancos de alimentos que fazem parte da Federação Européia de Bancos de Alimentos. 192

Tabela A.7 - Infraestrutura dos bancos de alimentos que fazem parte da Federação Européia de Bancos de Alimentos. 193

Tabela A.8 - Recursos humanos dos bancos de alimentos que fazem parte da Federação Européia de Bancos de Alimentos. 193

Tabela A.9 - Tipo de alimentos doados aos bancos de alimentos que fazem parte da Federação Européia de Bancos de Alimentos. 194 


\section{SUMÁRIO}

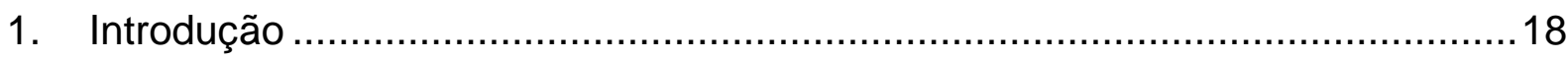

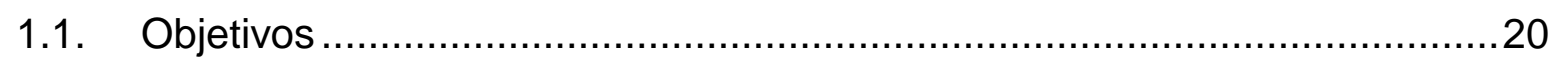

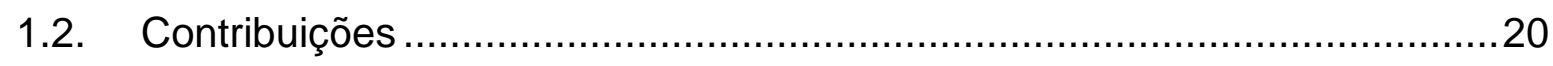

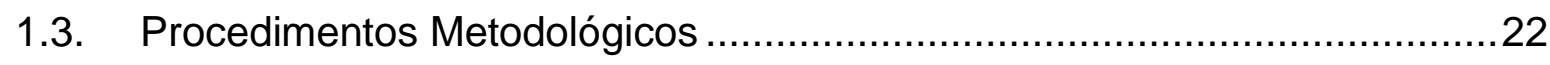

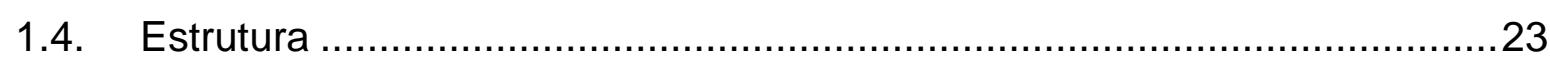

2. Geoprocessamento para Sistemas de Apoio a Logística Humanitária ...............25

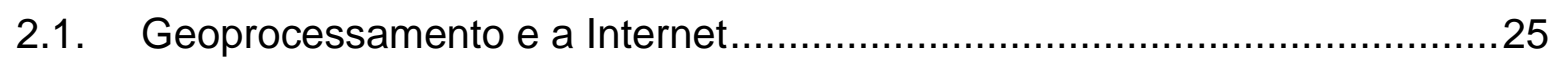

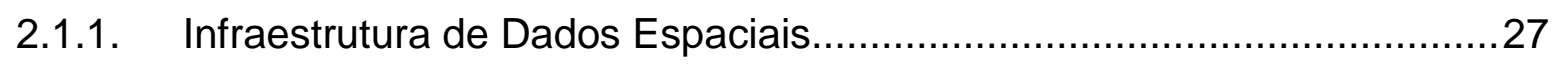

2.1.2. Volunteered Geographic Information (VGI) ...................................... 32

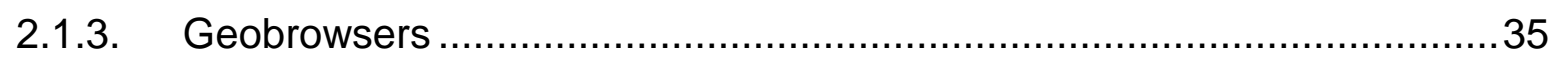

2.2. Arquitetura para Sistemas de Apoio a Logística Humanitária. .....................39

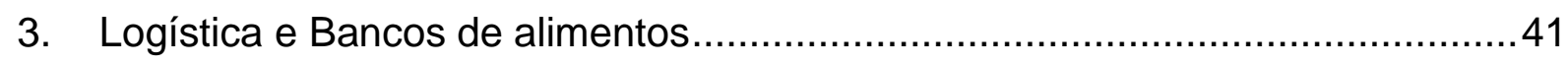

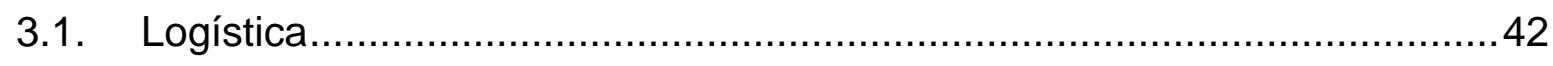

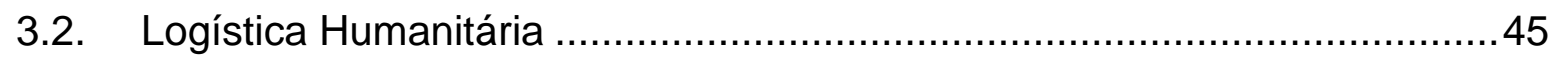

3.2.1. Logística Humanitária: Classificação................................................. 46

3.2.2. Logística Humanitária: Comparação com Outras Cadeias de

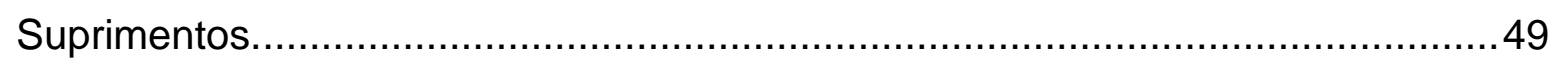

3.3. Logística de Bancos de Alimentos …………........................................53

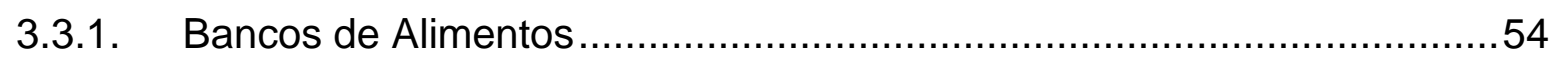


4.1. Interoperabilidade .70

4.2. Semântica .71

4.3. Ontologias 73

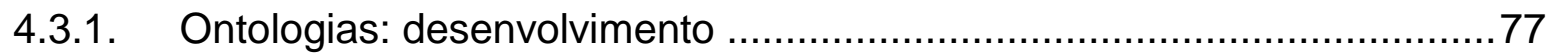

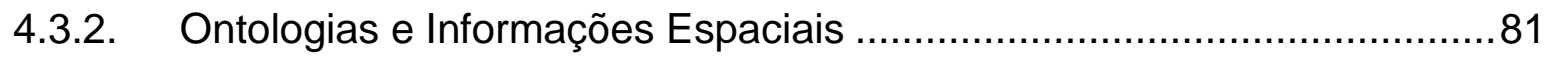

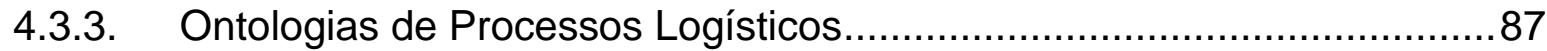

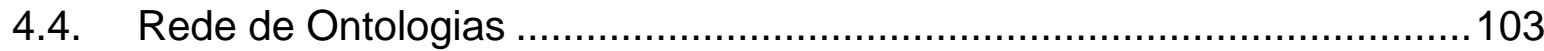

4.4.1. Ontologia da Cadeia de Suprimentos Humanitária.............................105

4.4.2. Ontologia de Processos Logísticos ...............................................107

4.4.3. Ontologia de Bancos de Alimentos....................................................109

4.4.4. Ontologia de Processos Logísticos de Bancos de Alimentos ................110

4.4.5. Consultas Lógicas às Ontologias Desenvolvidas ...............................110

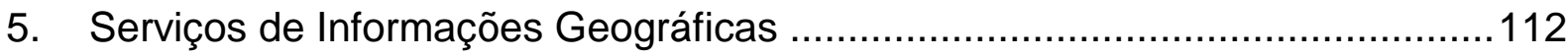

5.1. Classificações de Serviços de Informações Geográficas..........................112

5.2. Cadeias de Serviços de Informações Geográficas ................................116

5.3. Semântica para Composição de Serviços de Informações Geográficas...122

5.4. Mapeamento entre Modelagem Conceitual e Ontologias .......................127

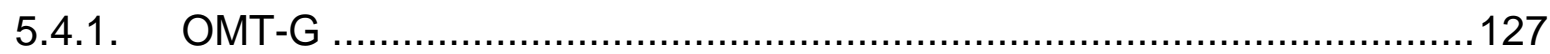


5.4.2. Arquitetura de ontologias para anotações semânticas de serviços de geoprocessamento.

5.4.3. Mapeamento entre OMT-G e Arquitetura de Ontologias.

6. Aplicação: Sistema de Apoio aos Bancos de Alimentos

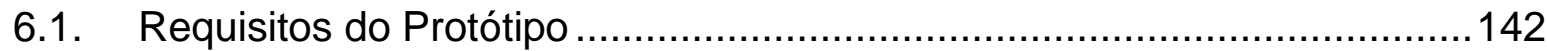

6.2. Etapas de Desenvolvimento do Protótipo …........................................142

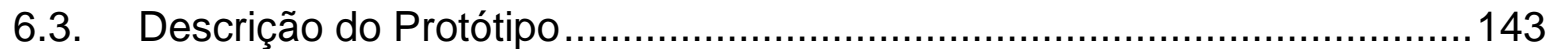

6.4. Requisitos para Sistema de Apoio aos Bancos de Alimentos ..................146

7. Conclusões e Recomendações para trabalhos futuros ..................................149

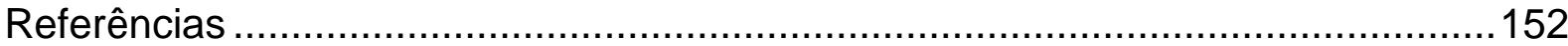

Apêndice A - Entrevistas e Trabalho de Campo ................................................171

A.1 - Entrevistas com Bancos de Alimentos no Brasil .....................................171

A.1.1 - Entrevista com uma rede nacional de bancos de alimentos no Brasil: O

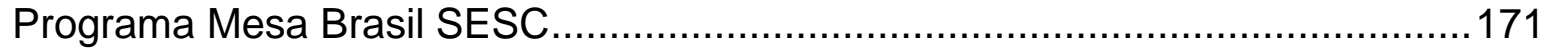

A.1.2 - Entrevista com doador de bancos de alimentos Wal-Mart ......................187

A.2 - Entrevistas com Bancos de Alimentos na Europa..................................189

Apêndice B - Códigos das Ontologias em Mídia Digital. .....................................196 


\section{INTRODUÇÃO}

Com o advento da Internet, novas tecnologias têm sido criadas para tratar, trocar, disponibilizar e acessar informações e dados espaciais. O número de aplicações que lida com atributos espaciais não somente cresceu como também se diversificou.

A diversificação e expansão dos meios pelos quais transitam a informação geográfica exacerbaram os problemas de integração diante da heterogeneidade estrutural e semântica dos dados. À capacidade relacionada ao compartilhamento de informações atribui-se o termo interoperabilidade.

Nesse contexto de popularização e disseminação da utilização de informações geográficas, as formas de modelar o conhecimento assumem notável importância, não somente para traduzir as necessidades dos usuários, como também para aprimorar a interoperabilidade semântica, neste vasto campo de aplicações.

O presente trabalho apresenta uma proposta para modelar o conhecimento relacionado aos processos logísticos, mais especificamente relativos às operações realizadas por bancos de alimentos. Para essa modelagem foram desenvolvidas ontologias.

Ontologias formalizam o conhecimento necessário para organizar e permitir o uso de dados de diferentes fontes. Ontologias são modelos de referência robustos devido à sua expressividade e capacidade de serem compartilhados pela internet. Podem ser usadas em diferentes contextos, por diferentes usuários, com diferentes propósitos. Nesta tese, as ontologias foram desenvolvidas com vistas a dar suporte para sistemas que se utilizam da internet para acessar dados e operações através de serviços de informações geográficas.

Serviços de informações geográficas surgiram a partir da migração do uso de Sistemas de Informações Geográficas de ambientes locais para ambientes distribuídos, com o uso da Internet. O número de serviços de informações 
geográficas disponíveis ainda é pequeno e a composição desses em cadeias de serviços, ainda é pouco automatizada. A composição de serviços de informações geográficas em cadeias, formando novos serviços, abre uma perspectiva para que operações espaciais, não fiquem mais restritas às soluções proprietárias e possam ser exploradas. Os serviços de informações geográficas podem ser acoplados a sistemas de apoio aos processos logísticos, na medida em que forem sendo disponibilizados, mas para isso é preciso que questões de interoperabilidade semântica sejam superadas.

Bancos de alimentos proporcionam a arrecadação de alimentos que não foram vendidos, e a sua distribuição para instituições filantrópicas, como asilos, orfanatos, instituições que atendem pessoas com necessidades especiais, entre outros. A logística de bancos de alimentos envolve decisões de localização com relação aos pontos de distribuição, decisões de alocação e roteirização dos alimentos a serem coletados e distribuídos, verificação da acessibilidade a esses pontos de distribuição, entre outros.

Os processos logísticos referentes aos bancos de alimentos possuem várias especificidades e não se enquadram na lógica clássica da logística empresarial. A começar com o objetivo principal a ser alcançado, por se tratar de uma operação humanitária. A comunidade científica nomeou esse conjunto de processos logísticos que lida com operações humanitárias de logística humanitária.

A adequação do tema logística humanitária para a exploração do potencial dessas novas tecnologias deve-se não somente às suas características técnicas, como também, à sua abrangência mundial, permitindo investigações mais profundas com relação às questões de interoperabilidade semântica.

A motivação para o desenvolvimento do trabalho reside, deste modo, não apenas no desafio de desenvolvimento tecnológico, como também na própria natureza do problema e propósito do serviço a ser prestado. 
O estudo teve como ponto de partida a experiência e as informações sobre a operação de bancos de alimentos fornecidas pelo Programa Mesa Brasil SESC, no Brasil e pela Federação Européia de Bancos de Alimentos, na Europa.

\subsection{Objetivos}

O objetivo deste trabalho foi desenvolver ontologias visando sistematizar o conhecimento sobre logística humanitária de bancos de alimentos para dar suporte à criação de sistemas baseados em serviço de informações geográficas.

Para atingir este objetivo foram considerados os seguintes objetivos específicos:

1. Caracterizar problemas de logística humanitária de bancos de alimentos.

2. Identificar operações espaciais pertinentes e úteis para solução desses problemas e investigar as questões semânticas relacionadas.

3. Desenvolver ontologias para o suporte de sistemas de apoio a logística humanitária de bancos de alimentos.

4. Desenvolver uma arquitetura para sistemas de apoio a logística humanitária, em ambiente Web, que explore as ferramentas de geoprocessamento e que considere aspectos de interoperabilidade semântica relativos a serviços de informações geográficas.

\subsection{Contribuições}

O desafio do presente projeto consistiu em desenvolver ontologias para sistemas de apoio à logística humanitária de bancos de alimentos, que tenham como 
característica: (1) poderem ser utilizadas pela comunidade de bancos de alimentos, independentemente de onde estiverem fisicamente localizados; (2) reunir conceitos gerais do modo de operação de bancos de alimentos; (3) considerar aspectos espaciais envolvidos no processo de arrecadação e distribuição de alimentos doados, identificando objetos, atributos, relações e operações espaciais relacionadas; (4) facilitar o desenvolvimento de sistemas que integrem dados e operações espaciais pela Internet.

A possibilidade de fornecer elementos para um instrumento que auxilie a tomada de decisão, visando aprimorar a atuação de bancos de alimentos fornecendo bases para a implementação de sistemas de apoio à logística humanitária, inspirou o desenvolvimento das ontologias. A busca por maximizar a utilidade de informações espaciais e corroborar com as operações humanitárias de bancos de alimentos motivou o desenvolvimento do trabalho.

Nesse contexto, a possibilidade de contribuir com (1) a sistematização do conhecimento em logística humanitária de bancos de alimentos e a formalização desse conhecimento através de ontologias que possibilitam que este modelo referencial seja compartilhado e utilizado em sistemas que utilizem serviços de informações geográficas; e (2) a discussão sobre metodologias que visam à interoperabilidade semântica de serviços de informações geográficas em busca de aumentar a disponibilização de dados e operações espaciais em ambiente distribuído através da internet, orientaram o desenvolvimento deste trabalho. 


\subsection{Procedimentos Metodológicos}

Para atingir os objetivos as seguintes atividades compuseram os procedimentos metodológicos desta tese (Figura 1.1).

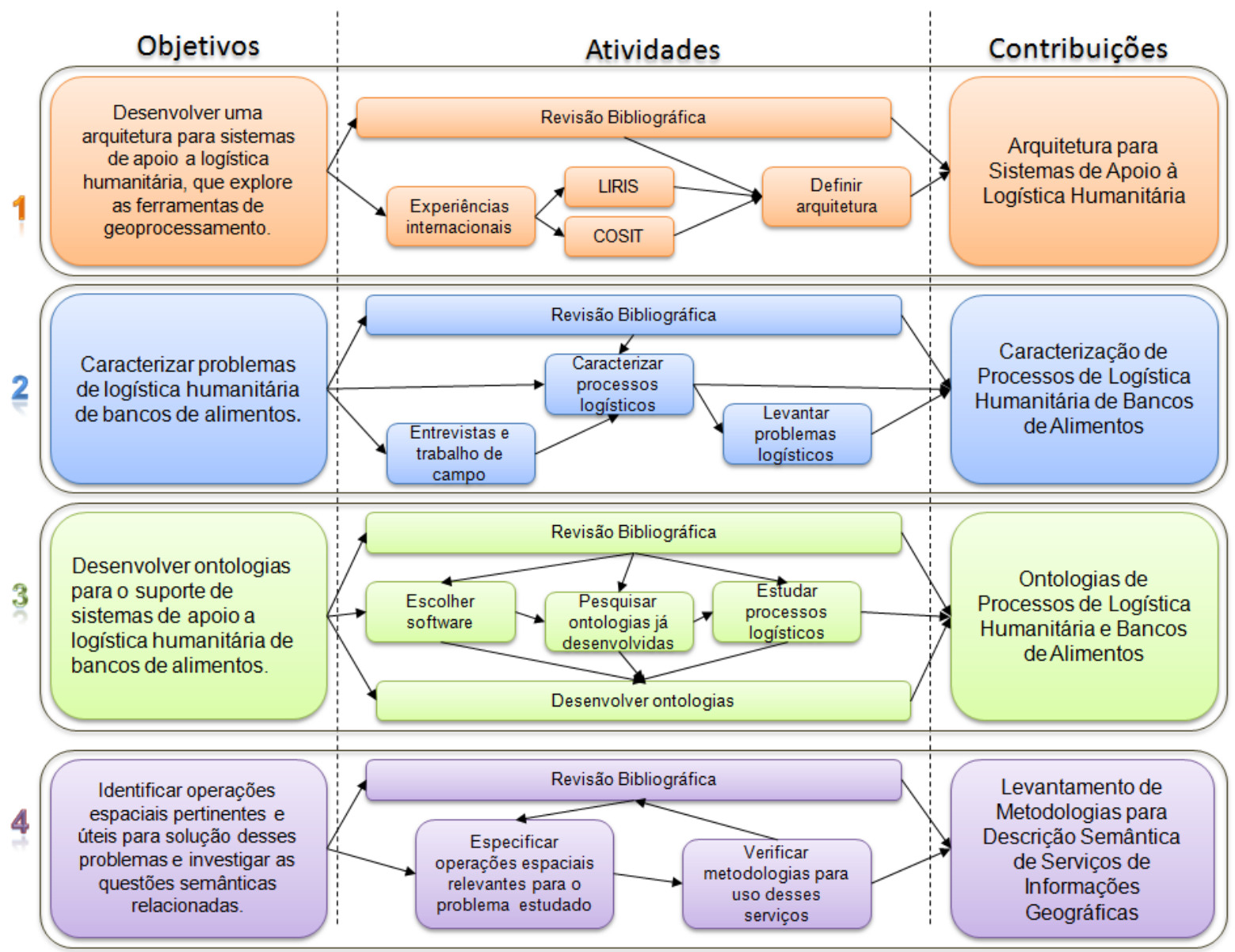

Figura 1.1 - Fluxograma.

1. Para desenvolver uma arquitetura para sistemas de suporte à logística humanitária foi feita uma revisão bibliográfica em busca de explorar o "estado da arte" das ferramentas de geoprocessamento. Somado a isso, atividades realizadas em experiências internacionais, contribuíram para mapear esse "estado da arte". 
2. Entrevistas e trabalhos de campo foram feitos para a caracterização de problemas de logística humanitária de bancos de alimentos, além de revisão bibliográfica.

3. O desenvolvimento das ontologias envolveu a escolha do software mais adequado, a pesquisa de ontologias já desenvolvidas para entender melhor os conceitos levantados em revisão bibliográfica, e o estudo mais detalhado sobre os processos logísticos para que esse conhecimento pudesse ser formalizado.

4. A identificação de operações espaciais pertinentes à aplicação e investigação de questões semânticas relacionadas envolveu o levantamento a partir de revisão bibliográfica sobre como as operações espaciais têm sido disponibilizadas em serviços de informações geográficas, a especificação das operações relevantes para a aplicação e a análise de metodologias relacionadas à interoperabilidade semântica de serviços de informações geográficas.

\subsection{Estrutura}

Esta tese está organizada em 6 capítulos: introdução, quatro capítulos de desenvolvimento do trabalho e as conclusões e perspectivas levantadas.

Os quatro capítulos intermediários foram divididos a partir de temas gerais que estruturam o trabalho. Cada capítulo apresenta referências teóricas e metodológicas sobre cada tema, seguidas de discussões sobre os resultados.

O segundo capítulo discorre sobre as possibilidades, no atual estágio tecnológico, de desenvolvimento de sistemas que se apóiem em dados e informações espaciais, introduz as motivações para abordar o problema de interoperabilidade semântica e, ao final, apresenta uma proposta de arquitetura para sistemas que utilizem as tecnologias comentadas. 
O terceiro capítulo trata dos conceitos de logística, discute as questões relativas à logística em operações humanitárias e caracteriza a operação logística de bancos de alimentos.

O quarto capítulo formaliza esse conhecimento sobre logística humanitária de bancos de alimentos em ontologias e discute a metodologia utilizada.

O quinto capítulo trata sobre serviços de informações geográficas e a importância da questão semântica. Inclui, ao final, uma discussão sobre metodologias de como anotar semanticamente esses serviços em busca de interoperabilidade.

O sexto capítulo discute o desenvolvimento de um protótipo para um Sistema de Apoio aos Bancos de Alimentos, como prova de conceito dos temas abordados nos capítulos anteriores.

Por fim, o sétimo capítulo apresenta as conclusões e perspectivas. Referências Bibliográficas e Apêndices completam este trabalho. 


\section{Geoprocessamento para Sistemas de Apoio a Logística HUMANITÁRIA}

Neste capítulo serão tratadas as questões conceituais sobre os sistemas que utilizam serviços e dados espaciais em ambiente de Internet. $O$ intuito dessa revisão conceitual é fornecer apontamentos sobre o estado de desenvolvimento tecnológico atual dessas ferramentas, indicando o universo de possibilidades a serem consideradas quando do desenvolvimento de sistemas. Em particular, sistemas para suporte à decisão em logística de bancos de alimentos e operações humanitárias correlatas.

Essa revisão introduz as motivações que levaram às investigações sobre as metodologias para lidar com as questões de interoperabilidade semântica. Com base nas discussões, ao final, é apresentada a arquitetura sugerida para sistemas de apoio à decisão em logística humanitária.

\subsection{Geoprocessamento e a Internet}

Um novo paradigma na área de geoprocessamento está sendo construído diante das recentes tecnologias viabilizadas a partir da Internet. $O$ uso e acesso às informações espaciais mudaram consideravelmente na última década. Anteriormente, dados e métodos eram locais. Agora, tanto dados como métodos podem ser recuperados e combinados em qualquer parte do mundo (Kuhn, 2005). As inúmeras opções para disseminar dados geográficos pela Internet tornam clara a elevada demanda por informação espacial simples de acessar, obter e usar (Davis e Alves, 2005). 
Enquanto a primeira geração da Web era majoritariamente unidirecional, permitindo que um grande número de usuários visualizasse o conteúdo de um número relativamente restrito de sites, a nova Web 2.0 caracteriza-se por ser colaborativa e bi-direcional, permitindo que seus usuários possam interagir e prover informações para sites, visualizar essa informação coletada e disponibilizá-la para outros usuários (Goodchild, 2007).

Essa perspectiva abriu espaço para a materialização de uma visão antiga (Fuller, 1969), mas amplamente divulgada somente a partir de um discurso de Al Gore, em 1998. Ela postulava a possibilidade de se construir representações tridimensionais do planeta, com múltiplas resoluções, em que pudéssemos incorporar grande quantidade de dados georreferenciados, navegando tanto pelo espaço quanto pelo tempo, para visualizar informações naturais, culturais e políticas sobre o planeta (Gore, 1998). Essa concepção de um modelo computacional que pudesse proporcionar cenários sobre a Terra (Fuller, 1969) recebeu a denominação de digital earth.

Atualmente, iniciativas que remontam a esta visão tem sido concebidas para irem além da representação, uma vez que buscam o potencial de maximização da utilidade das informações espaciais. Para Ehlers (2008) a visão de digital earth engloba o princípio de que qualquer cidadão do planeta, ligado pela internet, poderá acessar livremente um mundo virtual de recursos de informação e conhecimento. Foresman (2008) descreve as ferramentas proporcionadas pela digital earth como sendo ubíquas, úteis a todos os cidadãos para que possam lidar com os desafios cotidianos de suas vidas.

Dentro desta perspectiva novas formas de organizar, coletar, trocar e disponibilizar, informações espaciais tem sido propostas a exemplo de Infraestruturas de Dados Espaciais (IDE), Geobrowsers (ex: Google Earth) e Voluntered Geographic Information (VGI), valendo-se de tecnologias emergentes como os diversos Geosensores, Mash-ups e Application Programing Interfaces (APIs) (Craglia et al., 2008). 
Serviços da Web usados para acesso, integração e reutilização de informações geográficas a partir de múltiplas fontes têm, também, aumentado rapidamente (Klien, 2008). Embora estes serviços ainda sejam, em geral, aplicações isoladas, a sua modularidade é percebida como seu maior valor (Lutz, 2007).

Diante desta perspectiva discute-se a seguir os conceitos relacionados a essas tecnologias para embasar a modelagem do sistema para aplicações de logística de bancos de alimentos, levando em conta as diversas tecnologias na área de geoprocessamento que se baseiam em serviços distribuídos através do ambiente de internet.

\subsubsection{Infraestrutura de Dados Espaciais}

Os aspectos que iremos explorar ao investigar conceitos relacionados às Infraestruturas de Dados Espaciais (IDE) são guiados pelas seguintes perguntas:

É possível oferecer serviços via Web, para suporte à decisão logística de bancos de alimentos (BA), se não possuirmos concretamente os dados relativos às redes de transporte das localidades onde os BAs atuam? Quais seriam as limitações atuais?

Segundo Rajabifard (2004), uma Infraestrutura de Dados Espaciais (IDE) é uma iniciativa necessária para a efetiva coleção, gerenciamento, acesso, distribuição e utilização de dados espaciais. Na visão de Câmara et al. (2006), uma IDE deve atuar como um facilitador para a disseminação de dados espaciais associados a um controle de qualidade, informações sobre metadados e descrições semânticas, operando como um veículo para o entendimento do espaço.

Ocultar e suavizar detalhes de integração de dados, facilitando o acesso, reduzindo problemas de manutenção de bases de dados e possibilitando o aumento do número de aplicações em Sistemas de Informações Geográficas são alguns dos objetivos a 
serem atingidos a partir da constituição de Infraestruturas de Dados Espaciais (Davis e Alves, 2005).

Rajabifard et al. (2002) identifica os componentes da IDE como: dados, recursos humanos, padrões, tecnologias de acesso e políticas necessárias para a coleção, gerência, acesso e utilização eficaz de dados espaciais em diversos níveis políticoadministrativos (Figura 2.1).

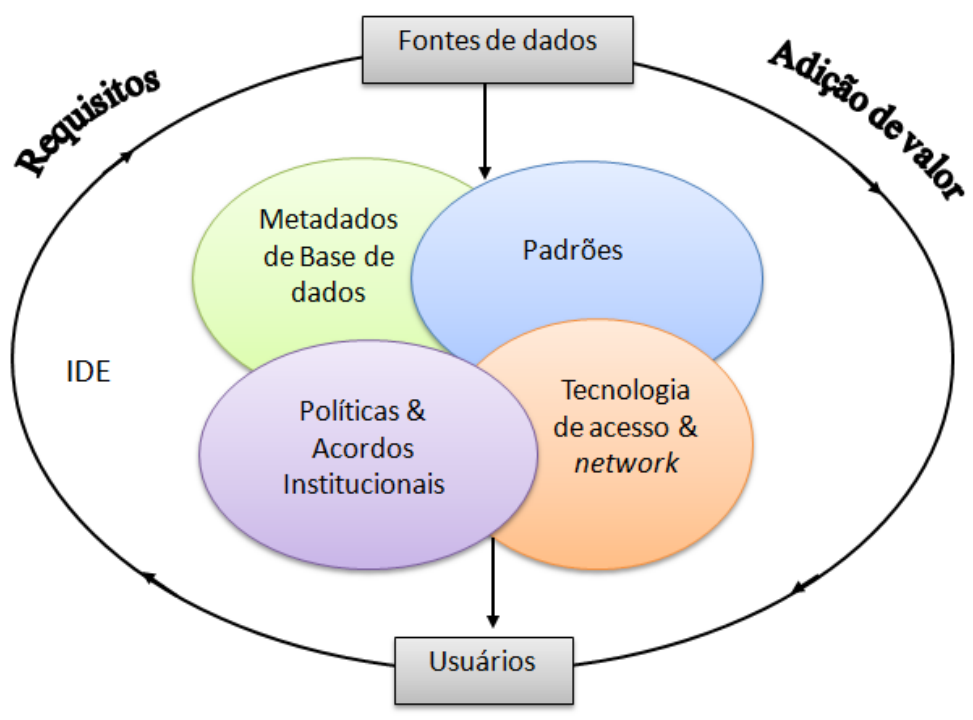

Figura 2.1 - Componentes do IDE. Fonte: Rajabifard et al. (2002).

A partir dos componentes, os autores analisam várias experiências internacionais e em diversas escalas de implementação, locais, regionais e nacionais. De forma geral, esses componentes podem ser resumidos em:

$\checkmark$ Dados e Metadados: dados gerais básicos para aplicação (temáticos, cadastrais, etc); e informações sobre os dados, como por exemplo, qualidade do dado, nível de atualização, projeções cartográficas utilizadas, origem do dado (responsável, data e local de geração), entre outros;

$\checkmark$ Recursos humanos: são os produtores, provedores, administradores, mantenedores e usuários; pessoas jurídicas ou físicas pertencentes a instituições 
governamentais, setor privado, terceiro setor (instituições sem fins lucrativos ONGs), comunidade acadêmica ou cidadãos em geral;

Tecnologias de acesso: constituem as tecnologias que possibilitam que os dados circulem, respeitando as políticas de acesso previamente estabelecidas e especificadas em cada estrutura institucional. São exemplos: as clearinghouses, os bancos de dados geográficos, as arquiteturas orientadas aos serviços, os geoportais, etc.;

Padrões: são necessários para a conexão entre todos os componentes da IDE, abrangendo os modelos de dados, os padrões de metadados, os padrões para interoperabilidade, os padrões de acesso e privilégio, entre outros;

$\checkmark$ Políticas: tratam das definições de restrição e acesso de uso, valoração ou não dos dados, garantias para coordenação, efetivação de parcerias, fomento, disseminação e legislação.

A escala de implementação nacional remonta à origem dos modelos de Infraestruturas de Dados Espaciais. Inicialmente, as Infraestruturas de Dados Espaciais contavam com uma metodologia de modelagem orientada aos produtos que visava um escopo temático amplo, em uma estratégia de concepção baseada na estrutura top-down. A partir das experiências dessa primeira geração, percebeuse que esse modelo não mais satisfazia às necessidades preconizadas para uma Infraestrutura de Dados Espaciais. Com a evolução para a segunda geração de IDE, a modelagem passou a ser orientada a processos e sua constituição contava com uma visão bottom-up, partindo de estruturas locais para a posterior formação de uma estrutura nacional (Rajabifard, 2006). Crompvoets et al. (2004) analisam experiências em vários países, descrevendo cada componente do IDE sob a perspectiva de cada iniciativa estudada, e reforçam a idéia dessa mudança de estratégia da primeira geração de IDEs, orientada aos produtos e dados, para a segunda geração, mais orientadas às aplicações e seus usuários.

Iniciativas que privilegiam os conhecimentos locais são valorizadas pela riqueza de aplicações e diversidade de interesses impondo novos requisitos às IDEs. 
Diferentemente das questões relativas às propostas de IDE nacionais, as propostas locais requerem um maior detalhamento e, com isso, um maior acesso a diferentes fontes de dados, mantidas por diversos provedores (Davis e Alves, 2005).

Rajabifard (2006) relaciona a primeira e segunda gerações a uma necessidade de padronização e uniformidade, e a uma idéia de diversidade e heterogeneidade, respectivamente. Conclui destacando a importância do desafio proeminente de assegurar a padronização e uniformidade ao reconhecer a diversidade e heterogeneidade.

A tendência de popularização da utilização de dados geográficos, decorrente das facilidades promovidas pelos serviços disponibilizados pela Web, tem feito com que, recentemente, haja uma convergente demanda por modelos de Infraestruturas de Dados Espaciais locais orientadas a serviços (Davis e Alves, 2005; Vaccari, 2008). Chan et al. (2001) ao analisarem as diversas definições de IDE, já mencionavam a falta de uma perspectiva de serviços nessas definições.

Segundo Davis e Alves (2005), uma das grandes vantagens de arquiteturas orientadas a serviços é a promoção da interoperabilidade. Isso se deve ao fato dos detalhes sobre formatos de armazenamento, estruturas de dados e métodos de acesso ficarem distantes dos usuários, ou seja, os detalhes sobre o sistema que mantém os dados de interesse não precisam ser conhecidos pelo usuário.

Elwood (2008) alerta sobre o desafio da interoperabilidade indicando o uso de ontologias como uma forma de captar, dentro desse universo cognitivo, as diferentes percepções de usuários com relação ao mundo físico.

Alguns pesquisadores apresentam o uso de ontologias como meio para melhorar a recuperação, a descoberta, a interpretação e a integração de dados em uma IDE (Lutz e Klien, 2006).

Masser et al. (2008) mencionam que o desenvolvimento de Infraestruturas de Dados Espaciais efetivas deve servir de forma transparente como suporte para a vasta maioria da sociedade que é não familiarizada com conceitos sobre consultas espaciais. Essas estruturas devem ser aprimoradas de tal forma que seja possível 
compartilhar, adicionalmente aos dados, estratégias, processos, operações, produtos de valor agregado, dentre outros. Os autores sugerem, ainda, que sejam elaborados modelos mais inclusivos de IDEs, cujos envolvidos possam desenvolver uma visão compartilhada e uma sensação comum de pertencimento.

Nesse sentido, a investigação de questões relacionadas à interoperabilidade direcionadas ao compartilhamento das diferentes visões de mundo, convergindo para um entendimento comum sobre aquilo que se está modelando, passa a ser extremamente valorizado. A estruturação semântica e a criação de ontologias assumem cada vez mais destaque nas discussões técnicas e proporcionam uma ampla variedade de demandas a serem pesquisadas.

A ligação entre conjuntos de dados de origens diversas, a partir do estabelecimento da localização geográfica como ponto de referência, é uma das principais promessas dos Sistemas de Informações Geográficas (Davis e Alves, 2005). As IDEs caminham nesse sentido, mas para que tal preceito seja realmente alcançado será necessário ultrapassar as barreiras impostas pelos problemas de interoperabilidade.

As IDEs indicam uma perspectiva positiva para a pergunta inicialmente postulada sobre a possibilidade de desenvolver sistemas baseados em dados gratuitos, ou seja, dados para aplicação podem não ser mais um entrave. Somado a isso, os requisitos exigidos para a modelagem de processos de logística humanitária de banco de alimentos, tais como (1) a necessidade de transparência do sistema para o estabelecimento de um ambiente confiável para impulsionar doações, (2) grande diversidade de usuários, (3) a necessidade de informações em múltiplas escalas, compatíveis com os níveis de planejamento estratégico e operacional, (4) a abrangência em diversas localidades e (5) os desafios de modelagem espacial de problemas logísticos fazem do problema um desafio condizente com questões exploradas em modelagens de Infraestruturas de Dados Espaciais. 


\subsubsection{Volunteered Geographic Information (VGI)}

Com o advento da Internet, iniciativas que tentavam aproximar o público geral, não técnico, ao uso de SIGs tomaram outra dimensão. As perspectivas para tal integração mudaram significativamente quando comparadas às possibilidades disponíveis anteriormente. Esforços que até então vinham sendo materializados pelas iniciativas de PPGIS (Public Participation GIS) hoje exploram novas possibilidades como aquelas originadas a partir do fenômeno que vem sendo chamado de VGI (Volunteered Geographic Information). Nesta seção, o histórico da preocupação com a participação do usuário não técnico no âmbito das tecnologias relacionadas aos SIGs será brevemente comentado para, posteriormente, serem discutidas questões sobre este último fenômeno, o VGl, que teve como um de seus marcos a intensiva participação de usuários nos esforços de recuperação e ajuda após o furacão Katrina, nos Estados Unidos, em 2005.

É de longa data a preocupação com a popularização do uso de SIGs. A despeito de ser um poderoso mediador do conhecimento espacial, a complexidade do desafio de promover ambientes participativos, com usuários não especializados, através de SIGs faz com que perguntas relativas a essa questão sejam postuladas a mais de 10 anos (Elwood, 2006). Tanga e Waters (2005) comentam que em 1995 houve uma discussão a respeito do uso colaborativo de SIG promovida pelo NCGIA (National Center for Geographic Information and Analysis), centro de referência em SIG. Este evento foi uma das primeiras iniciativas que deu início à aproximação do público não técnico aos SIGs. A partir deste evento, as iniciativas de uso colaborativo de SIG passaram a ser chamadas de PPGIS (Public Participation GIS).

O PPGIS foi concebido como um amplo e inclusivo processo baseado em um conjunto de métodos e tecnologias propícias para a participação do público. Ela explora as questões teóricas relacionadas com a aplicação de SIG, cuja meta consiste em envolver membros da comunidade no processo de ordenamento, coleta 
de dados, análise e mapeamento (Harris e Weiner, 2002). Como um dos objetivos do PPGIS é prover um acesso igualitário a dados e informações para todos os setores da comunidade (Kingston et al, 2000).

Essa preocupação de incorporar nos sistemas computacionais os aspectos relevantes para seus usuários, os tornando ambientes úteis, seguros e funcionais e valorizando o desenvolvimento desses sistemas centrados aos usuários, pode trazer contribuições não apenas ao PPGIS como também às outras iniciativas como VGI e a IDE.

Diferentemente do PPGIS, que tem uma missão rigorosa de garantir a inclusão e acesso envolvendo todos os membros de uma comunidade, por ser muitas vezes utilizado como técnica para planejamento participativo, o VGI se caracteriza por ser uma iniciativa menos rígida e menos formalizada.

De acordo com Goodchild (2007), a forma de mapeamento do VGI é desordenada, com pouca estrutura formal, pois a informação é constantemente criada e referida, fluindo em todas as direções. Produtores e consumidores voluntários de informação não são distinguíveis. Segundo o autor, assim como qualquer atividade de grande escala, o VGI está ocasionando seu efeito próprio em padrões geoespaciais.

Elwood (2007) discute as dificuldades relacionadas à integração entre SIG e o público em geral. Para a pesquisadora, que tem como foco o entendimento das interdependências entre tecnologias de análise espacial e o relacionamento entre cidadãos, governo e instituições da sociedade civil, a grande questão é como devemos sistematizar as práticas tecnológicas e sócio-políticas para desenvolvimento de VGI de forma a captar o tremendo potencial deste recurso para melhorar o acesso do público em geral aos dados espaciais. Tulloch (2007) questiona quais motivações levam as pessoas a participarem de iniciativas como 0 VGI e quais as implicações diante dessas motivações.

Craglia (2007) faz um paralelo entre VGI e IDEs. Uma de suas considerações diz respeito à crescente constatação de que para atingir um público amplo é necessário disponibilizar informações ao invés de dados. Segundo o autor, isso requer o 
desenvolvimento de serviços de informações espaciais e cadeias de serviços capazes de processar dados para gerar informações, ou responder questões. Outra convergência entre ambos seria incorporar às IDEs este aspecto mais dinâmico do VGI, com a inclusão de dados de redes de sensores que monitoram em tempo real (ou quase real) o estado do ambiente (ex: qualidade do ar, intensidade de tráfego, etc.). Nesse sentido, o autor adverte quanto aos inúmeros desafios de pesquisa, como por exemplo as questões relativas à modelagem espaço-temporal, arquiteturas de sistemas, além de questões de privacidade e confidencialidade no caso de sensores humanos.

Para Gould (2007), tanto o VGI quanto a IDE têm como uma de suas principais características facilitar o acesso à informação espacial, com a diferença que o primeiro usa um caminho informal enquanto o segundo segue um caminho formal. Segundo o autor, eles diferem em sua estrutura, modelo de liderança, modelo financeiro e, mais importante, em sua agilidade e adaptabilidade. Para o autor, IDEs tendem a cobrir necessidades de governo para governo (g2g). Em contrapartida, as iniciativas como o VGI contam com cidadãos comuns atualizando constantemente informações. Segundo Craglia (2007), a maior diferença entre os dois é o processo de validação, o uso dos dados por outras pessoas versus a certificação e segurança de qualidade, regulamentada por padrões.

Um dos exemplos atualmente bastante ilustrativo de VGI é o OpenStreetMap. Esta iniciativa consiste na construção de um mapa urbano de domínio público, do mundo inteiro, através de um esforço voluntário, em que cada contribuinte desenvolve um mapa de sua rua digitalizando sobre imagens de alta resolução, que posteriormente são fundidas em um único mosaico (Goodchild, 2007). Segundo Gould (2007), a vantagem de indivíduos digitalizando suas próprias ruas é que são as pessoas que mais conhecem a rua e suas características freqüentemente mutáveis. Para o autor, faz sentido colher a contribuição individual de pessoas para então produzir uma base de dados agregada. Neste contexto, uma das contribuições que a experiência do VGI traz ao IDE é a transição de uma estrutura mais lenta e estável para uma infraestrutura mais dinâmica e baseada no usuário. 
Em um nível mais sofisticado, as iniciativas promovidas pela Google, o Google Earth e o Google Maps, que através de suas interfaces para programação de aplicações ( $A P I s)$, permitem que usuários possam criar e publicar novos conteúdos na forma de planos de informações geográficas que podem ser visualizados sobre sua base de imagens e dados (Goodchild, 2007). Este meio sobre o qual dados de diversos formatos tem sido publicados, consultados e acessados, vem sendo chamado de Geobrowser.

\subsubsection{Geobrowsers}

Segundo Craglia et al. (2008), os Geobrowsers utilizam o globo como mecanismo para dar zoom ou voar sobre a superfície da Terra para áreas de interesse, se aproximando da idéia original de Digital Earth. Associado a essas representações 3D da Terra, existem ainda as aplicações $2 \mathrm{D}$ que também permitem que usuários adicionem e compartilhem informações através de APIs. São exemplos de representações 3D o Google Earth, o Microsoft Virtual Earth, o NASA Worldwind e, de 2D, o Google Maps e o Microsoft Live Search Maps.

Goodchild, citado por Butler (2006b), afirma que sistemas como o Google Earth têm um poder de democratização dos SIG, assim como os PCs democratizaram a computação. Para Butler (2006b), ao ter como uma de suas missões organizar a informação georreferenciada do mundo e torná-la universalmente acessível e útil, o Google vem persuadindo seus milhões de usuários a partilharem voluntariamente seus dados.

Estes fatos atuam como agentes multiplicadores da utilidade de dados espaciais, tornando inúmeras pesquisas relativas a serviços e aplicações baseadas em informações espaciais viáveis, em campos até então impensáveis (Butler, 2006b).

Na visão de Craglia et al. (2008), os Geobrowsers não atingem, por si só, o que seria esperado de uma digital earth. Isso acontece devido ao fato de serem orientados ao 
mercado e, conseqüentemente, não suportarem um entendimento do estado atual da Terra, pois não conseguem representar as mudanças no tempo, as causas dessas mudanças e os relacionamentos entre fenômenos físicos e atividades humanas.

Em contrapartida, o GEOSS (Global Earth Observation System of Systems, uma organização internacional que compreende 73 nações, a Comissão Européia, e 52 organizações internacionais) tem como principal objetivo promover a conexão científica entre sistemas de observação constituindo um sistema de sistemas. Cabe ao GEOSS promover aplicações em benefício de diferentes áreas, sendo elas: clima, energia, saúde, desastres, biodiversidade, agricultura, ecossistemas, água e meteorologia (Craglia et al., 2008).

Um grande passo já havia sido dado nesse sentido, com o aparecimento dos mashups. Segundo Butler (2006a), originalmente o termo mash-up referia-se à mistura de trilhas musicais e foi apropriado para fazer referência a websites que integram dados de diferentes fontes para proporcionar um novo serviço. De maneira similar a alguns softwares que permitem que especialistas façam consultas, de qualquer parte do mundo, a uma seqüência genética em um banco de genes, ou possam acessar automaticamente as informações disponíveis sobre objetos captados por diferentes telescópios, os mash-ups permitem que pessoas que não são pesquisadores com avançadas habilidades de programação, ou trabalhando em áreas suficientemente organizadas para terem seus dados apropriadamente referenciados e disponíveis on-line, possam utilizar esse tipo de serviço, através de linguagens simplificadas, fazendo com que o reuso das informações se torne o grande potencializador de pesquisas, criando os meios para uma sistemática colaboração mundial em tempo real.

Segundo Craglia et al. (2008), a visão de uma nova geração de digital earth deve abarcar a possibilidade de serem constituídas várias digital earths, cada qual relacionada a seus propósitos, mas que possam formar, quando reunidas, diferentes visões complementares. Os autores fazem um resumo das iniciativas recentes relacionadas conforme descrito na Tabela 2.1 . 
Tabela 2.1- Iniciativas recentes relacionadas ao domínio do Geoprocessamento.

\begin{tabular}{|l|l|l|l|l|}
\hline & $\begin{array}{l}\text { Principais } \\
\text { atores }\end{array}$ & Motivação & Público-alvo & $\begin{array}{l}\text { Mecanismo de } \\
\text { implementação }\end{array}$ \\
\hline IDE & Setor público & Apoio a políticas & $\begin{array}{l}\text { Analistas no no } \\
\text { setor público }\end{array}$ & $\begin{array}{l}\text { Mecanismos } \\
\text { legais (nem } \\
\text { sempre) }\end{array}$ \\
\hline Geobrowsers & Setor privado & Publicidade & Mercado & $\begin{array}{l}\text { Mercado e } \\
\text { voluntário }\end{array}$ \\
\hline GEOSS & Setor público & Apoio a políticas & Cientistas & $\begin{array}{l}\text { Voluntário e } \\
\text { político }\end{array}$ \\
\hline VGI & Indivíduos/grupos & Redes sociais & Sociedade & Voluntário \\
\hline
\end{tabular}

Fonte: adaptado de Craglia et al. (2008).

Esse vasto número de aplicações reflete o reconhecimento de que a demanda por dados e serviços geográficos é de fato significativa e crescente. Mais do que isso, trata-se da constatação de que a informação, estando disponível no tempo certo, com qualidade adequada, de maneira livre e a baixo custo, pode fomentar uma vasta gama de iniciativas, públicas, privadas, individuais ou do terceiro setor (Davis e Alves, 2005).

No contexto do presente trabalho, busca-se considerar as potencialidades e limitações em termos de iniciativas relacionadas ao provimento de serviços de informações geográficas.

Fica claro, diante da literatura, que um dos grandes desafios em se utilizar diversas dessas tecnologias apresentadas refere-se à interoperabilidade semântica. De forma geral, compondo as atuais iniciativas para formação daquilo que se aproximaria a visão de digital earth, IDEs e iniciativas como o GEOSS ainda parecem ser bastante orientadas a organizações e técnicos que fornecem e acessam dados espaciais. Para transformar esses dados em informações, ambas enfrentam questões de interoperabilidade semântica, que podem ser tratadas através de ontologias (Figura 2.2). 


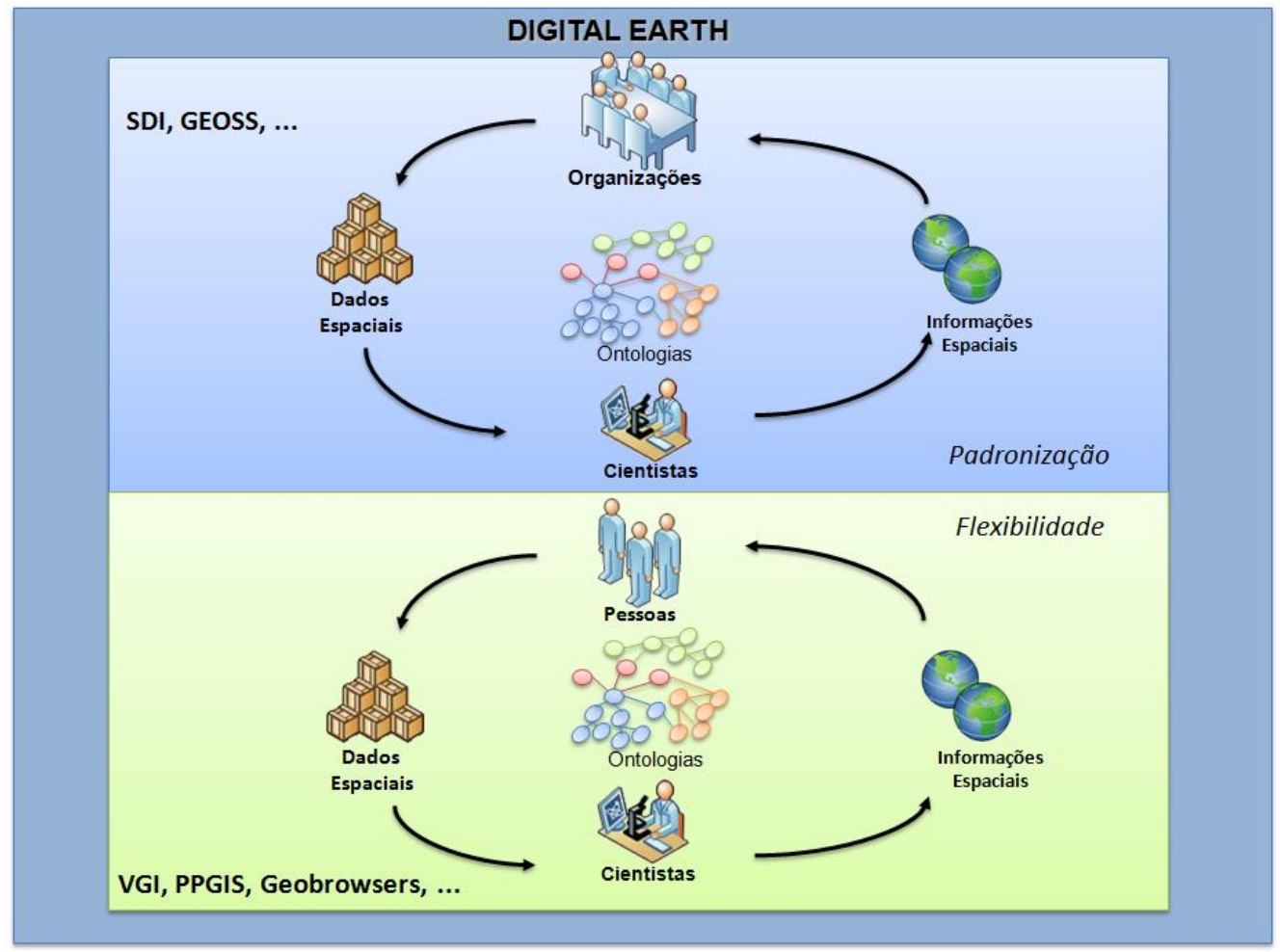

Figura 2.2 - Semântica e iniciativas recentes relacionadas ao geoprocessamento.

Por outro lado, iniciativas orientadas ao público em geral não necessariamente especializado, como VGI, PPGIS e os Geobrowsers, apesar de apresentarem uma maior flexibilidade, também enfrentam o mesmo tipo de problema de interoperabilidade.

Davis et al. (2009) ilustram a formação da digital earth considerando aspectos sobre essas novas tecnologias mencionadas (Figura 2.3). 


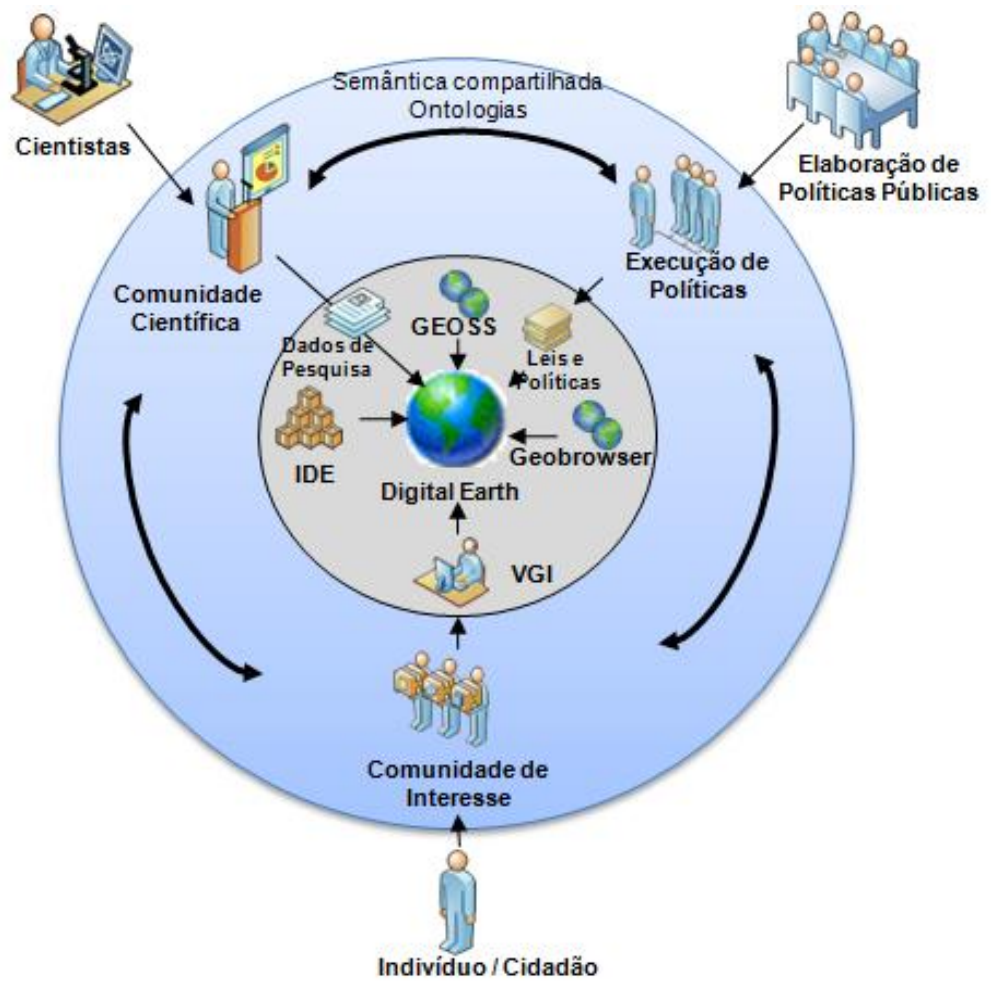

Figura 2.3 - Configuração da digital earth (Davis et al., 2009).

\subsection{Arquitetura para Sistemas de Apoio a Logística Humanitária.}

A partir das tecnologias referenciadas propõe-se uma arquitetura para sistemas de apoio a logística humanitária (Figura 2.4). 


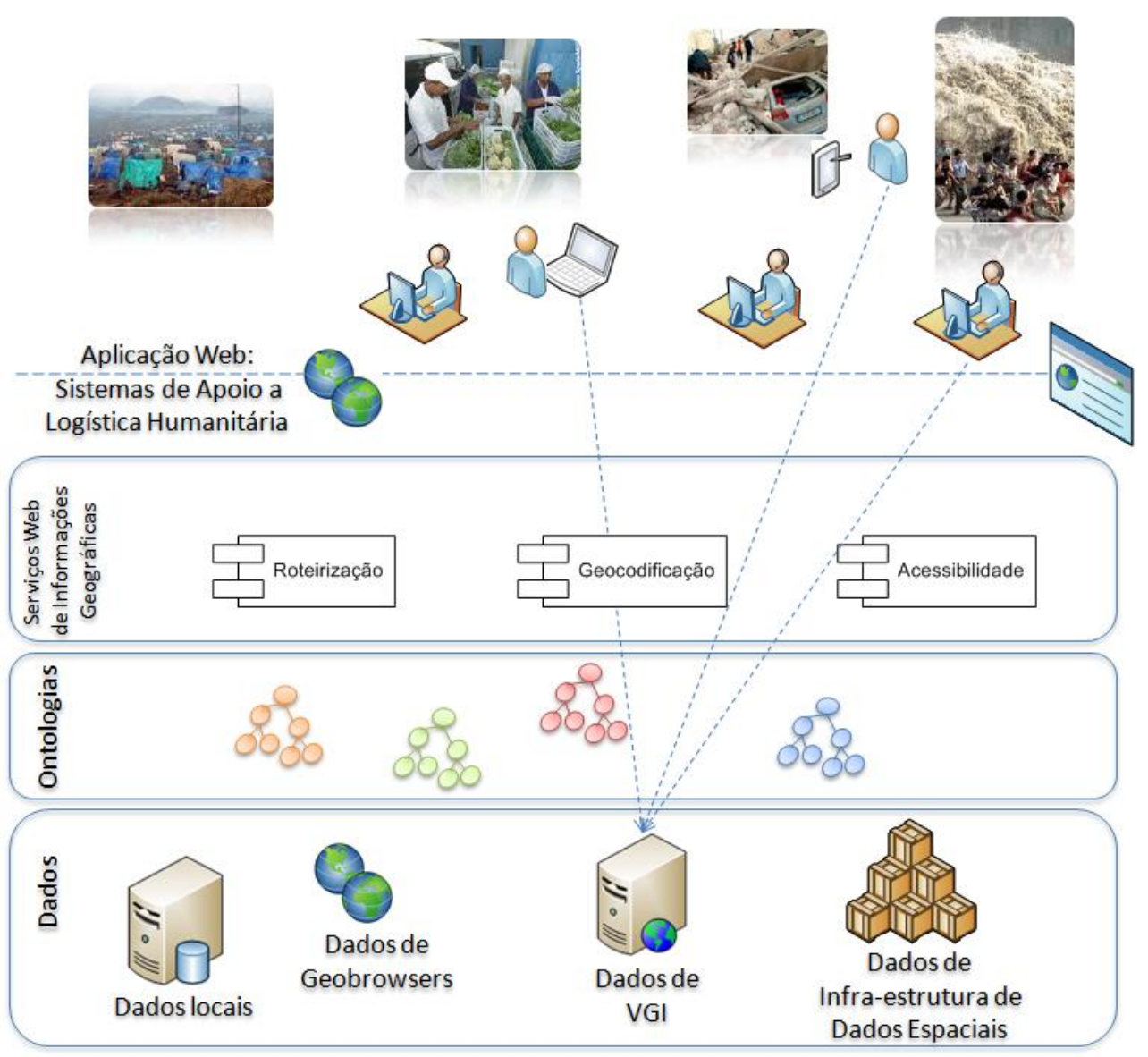

Figura 2.4 - Arquitetura para sistemas de apoio a logística humanitária.

A arquitetura considera a utilização de dados provenientes de Infraestruturas de Dados Espaciais, VGI, Geobrowsers além de dados locais. A interoperabilidade semântica dos dados é assegurada pelas ontologias que também servem de base para a anotação semântica que auxilia no processo de composição de serviços de informações geográficas em Sistemas de Apoio a Logística Humanitária.

O papel das ontologias para interoperabilidade semântica de dados e serviços é discutido com maior profundidade nos capítulos quatro e cinco. O capítulo três, a seguir, trata de referências conceituais relacionadas à logística humanitária. 


\section{Logística e BANCOS DE ALIMENTOS}

Os processos logísticos dos bancos de alimentos não se enquadram na lógica capitalista, base da logística empresarial clássica. O propósito dos bancos de alimentos não é a obtenção de lucro, mas sim o atendimento de pessoas vulneráveis da melhor forma possível.

Assim como no caso dos bancos de alimentos, uma série de outros exemplos nos quais os processos logísticos não têm como objetivo a maximização do lucro podem ser encontrados. Na literatura, problemas logísticos relacionados a essas operações humanitárias são chamados de logística humanitária.

Há, no entanto, uma diversidade enorme de processos referentes à logística humanitária. Tratar de uma operação logística após um terremoto, por exemplo, é bem diferente de tratar o problema logístico em um campo de refugiados. Nesse sentido a discussão que se segue procura explorar essas questões e posicionar as operações de bancos de alimentos nesse contexto. Além disso, comparações entre a logística humanitária e a logística praticada em outras cadeias de suprimentos, como a empresarial e a militar, são apresentadas.

Com relação à logística dos bancos de alimentos não foi encontrada bibliografia específica. Considerou-se, portanto, como referência teórica os artigos relacionados às aplicações de logística em operações humanitárias.

Já a produção científica relacionada especificamente aos bancos de alimentos refere-se principalmente à área nutricional, com algumas contribuições sobre o aspecto de saúde pública, relacionado ao ponto de vista sócio-econômico e demográfico. Apesar desse tipo de pesquisa não estar diretamente relacionada ao problema central deste trabalho, uma breve revisão foi apresentada com o intuito de caracterizar melhor os bancos de alimentos. 


\subsection{Logística}

A Logística tem seus primórdios associados às operações militares durante a Segunda Guerra Mundial. Desde então apresenta uma evolução continuada (Novaes, 2001). Há dez anos, a Logística era definida como:

"O processo de planejar, implementar e controlar o fluxo e a armazenagem eficientes e eficazes de matérias-primas, estoque em processo, produtos acabados e informação relacionada desde o ponto de origem até o ponto de consumo, com o propósito de atender os requisitos dos clientes." (Definição do Council of Logistics Management Norte-americano citada por Novaes, 2001 e Ballou, 2001)

Atualmente o Conselho de Profissionais de Gerenciamento Logístico (Council of Logistics Management Professionals, 2010), define logística como:

"A parte do gerenciamento da cadeia de suprimentos que planeja, implementa e controla fluxos bidirecionais e armazenagem eficientes e eficazes de produtos, serviços e informações relacionadas desde o ponto de origem até o ponto de consumo, com o propósito de atender os requisitos de clientes."

A inclusão de termos na definição de logística, como cadeia de suprimentos, fluxos bidirecionais (fluxos para frente e reversos, "forward and reverse flows") e serviços, reflete as mudanças decorrentes do avanço tecnológico e de novas formas de organização do mercado e da sociedade ocorridas nesses últimos anos.

Ao considerar os fluxos para frente e reversos, bidirecionais, abre-se espaço para a discussão sobre logística reversa. Os fluxos reversos se fazem cada vez mais presentes, principalmente quando se trata do setor de serviços. E a inclusão do próprio termo serviços, aponta para a preocupação com um setor com grande participação no PIB de muitos países, que demanda operações logísticas sofisticadas, que até então vinham sendo tratadas da mesma forma que são tratados os produtos manufaturados (Lima Jr, 2008). 
Dentre os termos inclusos na definição de logística, o termo cadeia de suprimentos parece apresentar divergências na comunidade científica quanto ao seu significado. Segundo Yoshizaki (2002), alguns autores consideram o termo apenas um novo nome para a disciplina logística empresarial. Yoshizaki (2002) reconhece a diferença entre os termos e associa cadeia de suprimentos a um ramo da área de administração de empresas, com foco na integração de processos, entre empresas, e não internos da empresa. Segundo a visão do Conselho de Profissionais de Gerenciamento Logístico, o termo cadeia de suprimentos apresenta uma definição mais ampla do que a logística, uma vez que inclui aspectos como a coordenação e colaboração com parceiros da cadeia, que podem ser fornecedores, intermediários, prestadores de serviços terceirizados e clientes. Em essência, o gerenciamento da cadeia de suprimentos, segundo esta visão, integra a oferta e a gestão da demanda dentro e entre empresas (Council of Logistics Management Professionals, 2010).

Esta discussão epistemológica, no entanto, ultrapassa o foco do presente trabalho que, neste ponto, pretende apenas enfatizar que os termos logística e cadeia de suprimentos, muitas vezes são tratados na comunidade científica e empresarial como sinônimos e serão referenciados conforme tratados nas fontes, sem prejuízo do entendimento do que se pretende discutir.

De acordo com Ballou (2001) existem três grandes áreas de atuação no planejamento logístico, quais sejam: decisões de localização de instalações, decisões de estoque e decisões de transporte, conforme ilustrado na Figura 3.1, a seguir.

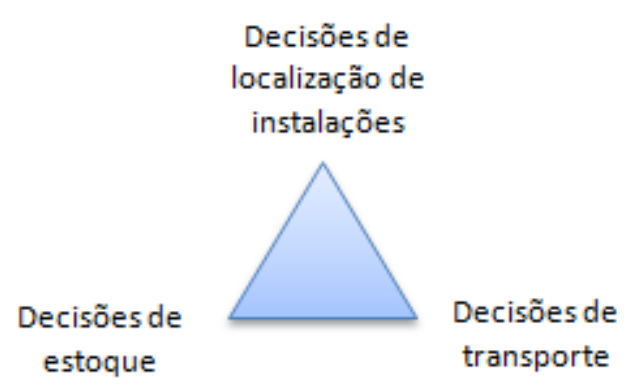

Figura 3.1 - Triângulo do planejamento logístico. Fonte: Ballou, 2001. 
O planejamento logístico dessas três grandes áreas se desenvolve em três níveis: operacional, tático e estratégico (Ballou, 2006). A Tabela 3.1 relaciona os processos de decisão estratégica, tática e operacional às áreas de decisão dentro do planejamento logístico, que são mais relevantes para este trabalho. Temos então:

Tabela 3.1 - Áreas e níveis de decisão: estratégica, tática e operacional.

\begin{tabular}{|c|c|c|c|}
\hline Nível de decisão & Localização & Transportes & Estoques \\
\hline $\begin{array}{c}\text { Estratégico } \\
\text { (longo prazo) }\end{array}$ & $\begin{array}{c}\text { Quantidade, área e } \\
\text { localização de armazéns, } \\
\text { plantas e terminais }\end{array}$ & $\begin{array}{c}\text { Seleção do modal; } \\
\text { seleção da frota }\end{array}$ & $\begin{array}{c}\text { Políticas de } \\
\text { estoque }\end{array}$ \\
\hline $\begin{array}{c}\text { Tático } \\
\text { (médio prazo) }\end{array}$ & $\begin{array}{c}\text { Indicadores de } \\
\text { installações às } \\
\text { Posicionamento do } \\
\text { estoque na rede }\end{array}$ & $\begin{array}{c}\text { Uso sazonal de } \\
\text { veículos; definição de } \\
\text { rotas; zoneamento } \\
\text { para alocação de } \\
\text { cargas às frotas }\end{array}$ & $\begin{array}{c}\text { Estoque de } \\
\text { segurança, regras } \\
\text { de controle }\end{array}$ \\
\hline \hline $\begin{array}{c}\text { Operacional } \\
\text { (curto prazo) }\end{array}$ & $\begin{array}{c}\text { Designação de carga a } \\
\text { fábricas e depósitos }\end{array}$ & $\begin{array}{c}\text { Roteirização, } \\
\text { agendamento e } \\
\text { despacho }\end{array}$ & $\begin{array}{c}\text { Reposição } \\
\text { (quantidades e } \\
\text { prazos) }\end{array}$ \\
\hline
\end{tabular}

Fonte: Adaptado de Ballou (2006) e Yoshizaki (2002).

A diferenciação entre esses níveis de planejamento se dá não apenas com relação à questão da periodicidade de planejamento, escala de tempo. Também possui uma associação aos fatores relacionados ao SIG, como a escalabilidade de espaço e a necessidade de precisão dos dados. Davis et al. (1997), ao descreverem alguns modelos de utilização de SIGs, quando da sua implementação em prefeituras, organizam as funções do SIG segundo esses níveis de planejamento.

Há que se atentar, no entanto, que conceitos de logística empresarial, ou cadeia de suprimentos empresarial, que se baseiam na lógica capitalista clássica dificultam o tratamento de relações que não estejam baseadas em aspectos financeiros e poder (Lima Jr, 2008), como é o caso dos bancos de alimentos. A logística em operações humanitárias até pouco tempo atrás não recebia muita atenção da comunidade científica. No entanto, o número crescente de desastres (Davidson, 2006) trouxe para discussão os problemas de logística humanitária. 


\subsection{Logística Humanitária}

Essencialmente, a logística humanitária envolve processos e sistemas relacionados à mobilização de pessoas, recursos, habilidades e conhecimento com o propósito de ajudar pessoas vulneráveis (van Wassenhove, 2006).

Logística ou cadeia de suprimentos humanitária são as formas como a logística e a cadeia de suprimentos tem sido referenciadas na literatura quando tratam de operações humanitárias. Nessas operações o objetivo clássico relacionado à obtenção de lucro, das cadeias de suprimento empresariais, é deixado de lado para dar lugar a uma causa mais nobre, aliviar o sofrimento de pessoas vulneráveis.

Em termos de modelagem, isso significa que a função objetivo não necessariamente envolverá os custos, que podem mudar de posição e aparecer como restrições no modelo. O ambiente em logística humanitária lida com uma série de incertezas (Beamon, 2004), somando complexidade e desafios aos problemas modelados.

Em 2003, Thomas apresentou a seguinte definição de logística humanitária:

Logística humanitária é definida como o processo de planejar, implementar e controlar de forma eficiente e eficaz o fluxo e armazenamento de bens e materiais, assim como das informações relacionadas, do ponto de origem até o ponto de consumo com o propósito de aliviar o sofrimento de pessoas vulneráveis (Thomas, 2003).

Esta definição, no entanto, foi revisada por um grupo de profissionais de logística e reapresentada da seguinte forma:

Logística humanitária é o processo de planejar, implementar e controlar eficientemente o fluxo e armazenamento de bens e materiais, assim como informações relacionadas, do ponto de origem ao ponto de consumo com o propósito de atender as necessidades dos beneficiários (Thomas e Mizushima, 2005). 
Os conceitos clássicos de logística balizam fortemente as definições de logística humanitária, mas alguns autores discutem o que faz a logística humanitária ser especial e diferente das outras cadeias de suprimentos, a ponto que mereça ser considerada a parte.

\subsubsection{Logística Humanitária: Classificação.}

Logística humanitária está relacionada a operações em diversas situações como: terremotos, tsunamis, furacões, epidemias, ataques terroristas, entre outros (Kovács e Spens, 2009).

Kovács e Spens (2007) identificam a expressão logística humanitária como um termo guarda-chuva que engloba um grupo misto de operações, mas atentam para o fato que cada tipo de operação pode envolver questões diferentes. Os autores exemplificam comentando que fatores envolvidos na assistência a um campo de refugiados, por exemplo, diferem bastante daqueles relacionados à assistência prestada após um desastre natural.

Ou seja, a despeito do fato que problemas de logística humanitária compartilham o mesmo propósito geral, qual seja ajudar pessoas em sua sobrevivência, lidar com diferentes tipos de operações geram conseqüências importantes em termos de planejamento logístico e modelagem (Kovács and Spens, 2007).

Com o intuito de esclarecer melhor essas conseqüências, alguns pesquisadores propõem diferentes classificações para os problemas de logística humanitária. Van Wassenhove (2006) propõe uma classificação baseada em dois critérios: um relativo ao tempo de abrangência do processo, rápido ou lento, e outro referente às causas possíveis, naturais ou ocasionadas pelo homem (Tabela 3.2). 
Tabela 3.2 - Categorização dos problemas de logística humanitária.

\begin{tabular}{|l|l|l|}
\hline & Natural & Ocasionados pelo homem \\
\hline Rápido & Terremoto & Ataque terrorista \\
& Furacão & Golpe de estado \\
& Tornado & Vazamento químico \\
\hline Lento & Seca & Crise política \\
& & Refugiados \\
\hline
\end{tabular}

Fonte: Adaptado de van Wassenhove (2006).

Thomas (2003) distingue dois grupos principais de operações humanitárias relacionadas às questões de curto e de longo prazos. $\mathrm{O}$ autor as nomeia como sendo ações de assistência e ações de desenvolvimento, respectivamente. Kóvacs e Spens (2007) tratam a mesma distinção com diferentes nomes: "atendimento a desastres" (disaster relief) e "trabalho contínuo de ajuda" (continuous aid work). Em busca de uma classificação que seja adequada aos propósitos do presente trabalho, optou-se por agrupar e resumir as principais características das classificações mencionadas, conforme detalhado a seguir:

1. Operação de logística humanitária de curto prazo: atividades de ajuda relacionadas ao atendimento aos desastres, naturais (terremotos, furacões, tsunamis, etc.) ou ocasionados pelo homem (ataques terroristas, vazamento químico, entre outros), envolvendo o provimento emergencial de comida, abrigo e serviços para vítimas dessas emergências.

2. Operações de logística humanitária de longo prazo: relacionadas ao desenvolvimento de atividades ou trabalho de ajuda contínua, focando na autosuficiência da comunidade e sustentabilidade, na qual podemos situar o caso da operação de bancos de alimentos. 
A Tabela 3.3 foi organizada com o intuito de dar uma visão geral de como diferentes tipos de operações de logística humanitária vêm sendo apresentados no meio científico até o momento.

Tabela 3.3 - Artigos relacionados à logística humanitária classificados pelo tipo de operação.

\begin{tabular}{|c|c|c|c|c|}
\hline \multirow[t]{2}{*}{ Artigo } & \multicolumn{2}{|c|}{ Tipo de operação logística } & \multirow{2}{*}{$\begin{array}{l}\text { Dados e } \\
\text { Operações em } \\
\text { SIG }\end{array}$} & \multirow{2}{*}{$\begin{array}{l}\text { Principais questões } \\
\text { levantadas }\end{array}$} \\
\hline & $\begin{array}{l}\text { Curto/Longo- } \\
\text { prazo }\end{array}$ & Tipo & & \\
\hline $\begin{array}{l}\text { Balcik and } \\
\text { Beamon } \\
(2008)\end{array}$ & Curto prazo & $\begin{array}{l}\text { Desastre } \\
\text { natural }\end{array}$ & $\begin{array}{l}\text { Calculo de } \\
\text { matrizes de } \\
\text { distância }\end{array}$ & Localização de facilidades \\
\hline $\begin{array}{l}\text { Balcik et al. } \\
\text { (2008) }\end{array}$ & Curto prazo & $\begin{array}{l}\text { Desastre } \\
\text { natural }\end{array}$ & Não & $\begin{array}{l}\text { Problema de distribuição (last } \\
\text { mile) }\end{array}$ \\
\hline Akkihal (2006) & Curto prazo & $\begin{array}{l}\text { Desastre } \\
\text { natural }\end{array}$ & $\begin{array}{l}\text { Regionalização da } \\
\text { demanda, } \\
\text { Calculo de } \\
\text { matrizes de } \\
\text { distância }\end{array}$ & Localização de facilidades \\
\hline $\begin{array}{l}\text { Beamon and } \\
\text { Kotleba (2006) }\end{array}$ & Curto prazo & $\begin{array}{l}\text { Desastre } \\
\text { natural }\end{array}$ & Não & Gerenciamento de estoques \\
\hline $\begin{array}{l}\text { Whybark } \\
(2007)\end{array}$ & $\begin{array}{l}\text { Curto/ Longo } \\
\text { prazo }\end{array}$ & $\begin{array}{l}\text { Político, } \\
\text { Desastre } \\
\text { natural }\end{array}$ & Não & Gerenciamento de estoques \\
\hline $\begin{array}{l}\text { Karlaftis et al. } \\
(2007)\end{array}$ & Curto prazo & $\begin{array}{l}\text { Desastre } \\
\text { natural }\end{array}$ & Não & $\begin{array}{l}\text { Alocação de fundos para } \\
\text { recuperação de infraestrutura }\end{array}$ \\
\hline $\begin{array}{l}\text { Angelis et al. } \\
(2007)\end{array}$ & Longo prazo & Guerra civil & Não & Problema de roteirização \\
\hline $\begin{array}{l}\text { Saadatseresht } \\
\text { et al. (2009) }\end{array}$ & Curto prazo & $\begin{array}{l}\text { Desastre } \\
\text { natural }\end{array}$ & Redes & Evacuação \\
\hline
\end{tabular}


Conforme ilustrado na amostra da Tabela 2.2 percebe-se que os problemas de logística humanitária de longo prazo não são tão comuns em pesquisas científicas quanto os problemas de curto prazo. Em especial, nota-se uma maior freqüência dos problemas relacionados ao atendimento às vítimas de desastres naturais.

Observa-se, então, que a operação logística de banco de alimentos está inserida em um conjunto de operações humanitárias que apresentam peculiaridades quando comparadas às operações tratadas pela logística clássica e, somado a isso, ainda refere-se a um tipo de operação humanitária de longo prazo que é menos freqüentemente tratado na literatura.

$\mathrm{Na}$ próxima seção serão comparados aspectos referentes às operações humanitárias e às operações em outras cadeias de suprimentos, com o intuito de analisar diferenças e possíveis contribuições para a pesquisa em logística humanitária.

\subsubsection{Logística Humanitária: Comparação com Outras Cadeias de Suprimentos.}

Em logística, problemas humanitários têm recebido atenção na pesquisa científica apenas mais recentemente (Kovács e Spens, 2009). Geralmente o foco na prática e na pesquisa em logística referia-se ao setor empresarial. Para Thomas (2005) alguns desafios presentes em operações de logística humanitária são similares aos que o setor empresarial enfrentou há 20 anos.

A capacidade de transferir soluções da logística empresarial para a logística humanitária é restrita às especificidades do ambiente humanitário (Petit e Beresford, 2009). De forma geral, dois aspectos importantes distinguem a logística humanitária: a motivação (ou propósito) e as incertezas do ambiente onde essas operações ocorrem. 
As incertezas associadas à logística humanitária (Tomassini e van Wassenhove, 2009) devem-se às mudanças dinâmicas a que seu ambiente está sujeito (Beamon, 2004; van Wassenhove, 2006; Kovács e Spens, 2007).

A pressão do tempo, em virtude da urgência em situações de emergência, é outra característica usualmente relacionada às operações de logística humanitária. Beamon (2004) aponta que a restrição de tempo afeta a questão de armazenamento, disponibilidade, aquisição e distribuição de produtos e serviços. Tomassini e van Wassenhove (2009), comentam que a urgência proporciona um alto nível de intensidade nessas operações.

A falta de conhecimento técnico, um contexto de trabalho de contribuições financeiras voluntárias, consumidores finais que não estão envolvidos em nenhuma transação comercial e, muitas vezes, possuem sérias restrições de infraestrutura são alguns dos aspectos apontados por Petit e Beresford (2009) para logística humanitária.

Beamon (2004) lista as características específicas da logística humanitária, distinguindo-a das cadeias de suprimento empresariais:

1. Tempo de resposta ("lead time") zero, ou aproximadamente zero, afetando dramaticamente armazenamento, disponibilidade, aquisição e distribuição de bens e serviços.

2. Falta de confiabilidade, incompletude, ou inexistência de informações.

3. Falta de medidas efetivas de desempenho.

A autora também compara características gerais entre as cadeias de suprimento empresariais e humanitárias conforme resumido na Tabela 3.4. 
Tabela 3.4 - Comparação entre cadeia de suprimentos empresarial e humanitária.

\begin{tabular}{|l|l|l|}
\hline & Empresarial & Humanitária \\
\hline Demanda & $\begin{array}{l}\text { Relativamente estável, } \\
\text { ocorre para locais pré- } \\
\text { determinados e em } \\
\text { quantidades pré-fixadas. }\end{array}$ & $\begin{array}{l}\text { É gerada por eventos aleatórios, na maior } \\
\text { parte imprevisíveis em termos de tempo, } \\
\text { localização, tipo e tamanho. É estimada após } \\
\text { a ocorrência da necessidade. }\end{array}$ \\
\hline Tempo de resposta & $\begin{array}{l}\text { Determinado a partir da } \\
\text { cadeia de suprimentos }\end{array}$ & $\begin{array}{l}\text { Tempo de resposta requerido é praticamente } \\
\text { zero. (zero entre a ocorrência da demanda e } \\
\text { a necessidade da mesma). }\end{array}$ \\
\hline Rede de \\
distribuição & $\begin{array}{l}\text { Bem definidas em termos } \\
\text { do número e localização. }\end{array}$ & $\begin{array}{l}\text { Desafiadoras pela natureza desconhecida } \\
\text { (localização, tipo e tamanho); Considerações } \\
\text { de "Última Milha". }\end{array}$ \\
\hline $\begin{array}{l}\text { Controle de } \\
\text { estoque }\end{array}$ & $\begin{array}{l}\text { Utilização de métodos just } \\
\text { in time, demanda e níveis } \\
\text { de serviço. }\end{array}$ & $\begin{array}{l}\text { Desafiador pela grande variação da } \\
\text { demanda e a localização da mesma. }\end{array}$ \\
\hline $\begin{array}{l}\text { Sistemas de } \\
\text { informação }\end{array}$ & $\begin{array}{l}\text { Geralmente bem definidos; } \\
\text { Uso de tecnologia } \\
\text { avançada. }\end{array}$ & $\begin{array}{l}\text { As informações são pouco confiáveis, } \\
\text { incompletas ou inexistem. }\end{array}$ \\
\hline $\begin{array}{l}\text { Medidas de } \\
\text { desempenho }\end{array}$ & $\begin{array}{l}\text { Tradicionalmente foco em } \\
\text { medidas de recursos }\end{array}$ & $\begin{array}{l}\text { Geralmente relacionadas a medidas } \\
\text { externas, como exemplo tempo de resposta } \\
\text { a vitimas de um desastre }\end{array}$ \\
\hline Objetivos & $\begin{array}{l}\text { Maior qualidade, ao menor } \\
\text { custo, de maneira a } \\
\text { maximizar a satisfação do } \\
\text { cliente. }\end{array}$ & $\begin{array}{l}\text { Minimizar perdas de vidas e aliviar o } \\
\text { sofrimento. }\end{array}$ \\
\hline O que é a demanda & Produtos e serviços. & Pessoas e suprimentos \\
\hline
\end{tabular}

Fonte: Beamon (2004).

$\mathrm{Na}$ cadeia de suprimentos empresarial, oferta e demanda são geralmente mensuráveis ou passíveis de serem estimados (Tabela 3.4). Em logística humanitária, prever a demanda constitui uma tarefa difícil devido a sua imprevisibilidade.

Referente à demanda, Beamon (2004), Kovács e Spens (2007) apontam que enquanto no setor empresarial a demanda é estável, ou ao menos previsível, no setor humanitário, em contraste, a demanda é irregular com restrições pouco usuais. A imprevisibilidade da demanda em operações humanitárias refere-se ao tempo, à localização e ao tamanho (Balcik e Beamon, 2008). Os prazos de entrega para uma demanda, que é geralmente grande, são curtos e questões importantes (algumas 
vezes de vida ou morte) estão relacionadas a este tempo de resposta. Somado a isso, os tipos de suprimentos demandados podem ainda ser variados (Balcik e Beamon, 2008):

O gerenciamento da oferta também está relacionado a incertezas, uma vez que se trata de uma categoria especial de fornecedores, que são em sua maioria doadores. O fato dos produtos serem doados traz algumas especificidades que podem se tornar dificuldades no gerenciamento das operações, como é o caso produtos fornecidos que não foram solicitados, produtos de difícil manipulação devido à forma em que foram embalados ou identificados, ou até mesmo produtos que tiveram sua data de validade vencida (Kovács e Spens, 2007). Na cadeia de suprimentos empresarial um conjunto pré-determinado de fornecedores é conhecido, já na cadeia de suprimentos humanitária, os interesses de alguns atores não são claros, fato que dificulta a integração logística.

Outra questão apontada na literatura que distingue a logística humanitária refere-se à falta de recursos. Beamon (2004), Balcik and Beamon (2008), Kovács e Spens (2007), Tomassini e Wassenhove (2009) comentam sobre a falta de recursos não apenas financeiros, como também humanos, tecnológicos e de infraestrutura.

Tomassini e van Wassenhove (2009) destacam ainda que os envolvidos em operações humanitárias possuem objetivos ambíguos, dificultando 0 estabelecimento de um nível de comprometimento entre os diferentes atores.

Davidson (2006) enfatiza que, em muitos sentidos, as operações humanitárias são mais próximas das operações militares do que das operações empresariais:

1. Flexibilidade: ambos, militar e humanitário, devem ser suficientemente flexíveis para organizar uma cadeia de suprimentos em um prazo curto.

2. Ambientes instáveis: ambos trabalham em um ambiente potencialmente caótico e perigoso.

3. Medidas de desempenho: ambos não possuem lucro como um objetivo, portanto devem medir sucesso de uma forma diferente. 
A estruturação presente no setor de logística militar e o investimento em tecnologia tem sido úteis para o setor humanitário, tanto no aspecto de transferência tecnológica quanto como possibilidade de atendimento de emergências em grande escala (Russel, 2005).

Por outro lado, Davidson (2006) também menciona algumas diferenças nas operações logísticas desses dois setores, humanitário e militar, como por exemplo, o problema de lidar com itens não solicitados, muito comuns no setor humanitário, mas inexistente no setor militar.

Logística humanitária traz desafios metodológicos e científicos interessantes, no entanto, ainda há uma demanda por estudos conceituais e empíricos visando aprimoramentos nesta área (Kovács e Spens, 2009).

\subsection{Logística de Bancos de Alimentos}

Após apresentar alguns aspectos conceituais gerais e relevantes para logística humanitária, serão agora especificados alguns aspectos diretamente relacionados à operação de bancos de alimentos.

Primeiramente será feita uma caracterização geral sobre os bancos de alimentos com a intenção de explanar melhor o contexto em que estão inseridos. No final da seção, as características específicas dos bancos de alimentos e as gerais de logística humanitária e logística empresarial são comparadas com o intuito de resumir as idéias previamente apresentadas. 


\subsubsection{Bancos de Alimentos}

Enquanto milhões de brasileiros não conseguem se alimentar adequadamente, aproximadamente 70 mil toneladas de alimentos vão para o lixo por mês no Brasil (Akatu, 2003). Mais especificamente na cidade de São Paulo, estima-se que das 10 mil toneladas de produtos que entram diariamente na Companhia de Entrepostos e Armazéns Gerais de São Paulo (CEAGESP), 1\% (100 toneladas) vai para o lixo, sendo que entre $30 \%$ e $50 \%$ do lixo é composto de alimento próprio para o consumo (CEAGESP, 2006).

Para contornar situações similares de desperdício e contribuir para o combate à desigualdade de distribuição alimentar, experiências de Programas de Bancos de Alimentos vêm sendo desenvolvidas com sucesso pelo mundo e, recentemente, no Brasil.

Os bancos de alimentos (BAs) propiciam a arrecadação de alimentos que não foram comercializados e a distribuição destes para instituições filantrópicas como creches, asilos, orfanatos, instituições que atendem a portadores de necessidades especiais, entre outras.

O desperdício alimentar está relacionado às disparidades entre oferta e demanda de alimentos, que acabam por ocupar os estoques dos centros de distribuição (CD), centros de compra (CC) e centrais de abastecimento (CEASAs), bem como as redes de supermercados, padarias e outros serviços. Alimentos que estão nas prateleiras acabam não sendo vendidos por apresentarem aparência pouco convidativa, prazos de validade prestes a vencer, embalagens danificadas, etc. Cabe aos BAs encaminhar esses alimentos para complementar refeições servidas em associações beneficentes e instituições sociais em geral, como ilustra a Figura 3.2. 


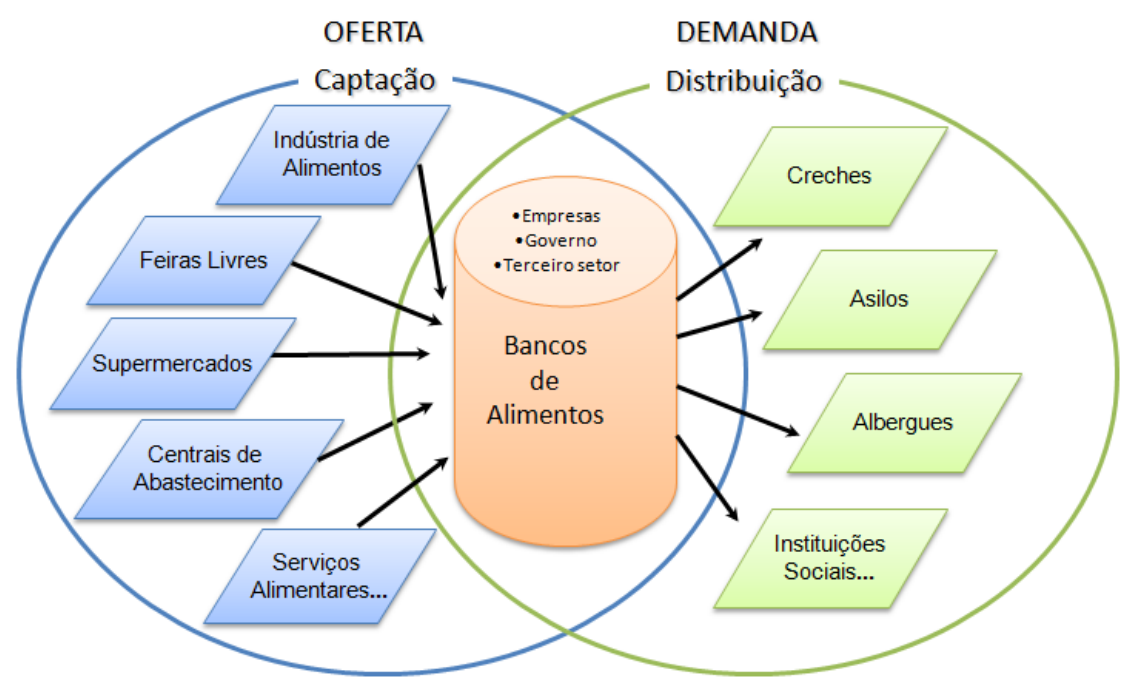

Figura 3.2 - Fluxograma da operação de bancos de alimentos.

Importantes instrumentos de luta contra o desperdício, os bancos de alimentos possibilitam a integração de uma política de combate à fome que ultrapasse o caráter meramente assistencial, na medida em que sua implantação venha acompanhada de ações estruturantes de promoção de segurança alimentar e nutricional, como capacitação e treinamentos para as entidades sociais, seus atendidos e/ou para seus parceiros. A capacitação promovida pelos BA pode abordar temas sobre educação alimentar, nutricional, aproveitamento integral de alimentos, técnicas de redução de desperdício, entre outros.

O primeiro Banco de Alimentos do Mundo surgiu em 1967, nos Estados Unidos, na cidade de Phoenix, Arizona, pela ação de John van Hengel. Em menos de 10 anos, foi criada a organização Second Harvest, dando início à primeira rede nacional de Bancos de alimentos no mundo. Em 1981, surgiu o primeiro Banco de Alimentos no Canadá, em Edmonton. Em 1984, foi criado o primeiro Banco de Alimentos da Europa, na capital francesa, sendo que apenas dois anos depois já foi constituída a Federação Européia de Bancos de Alimentos. Em 1989, foi criada a Associação Canadense de Bancos de Alimentos. 
A rede norte-americana conta hoje com mais de 200 bancos de alimentos, distribuídos por 50 estados, que distribuem anualmente cerca de 4 bilhões de quilos para mais 50.000 entidades locais.

A rede européia, por sua vez, congrega organizações nacionais como a francesa (Fédèration Française des Banques Alimentaires), com 79 bancos de alimentos associados, que atendem a 1901 instituições e distribuem aproximadamente 66,5 milhões de quilos a 4640 associações. Também existe a italiana (Fondazione Banco Alimentare - Onlus), criada em 1999, em Milão, tendo coletado 53,4 milhões de quilos de alimentos em 2004, os quais foram distribuídos para 7234 instituições; a espanhola (Federation Española de Bancos de Alimentos - FESBAL), criada em 1996, com mais de 25.000 m2 de armazéns, 59 veículos, 2650 empresas doadoras e colaboradoras; a portuguesa, com 10 bancos de alimentos apoiando 1048 instituições; além de outros países como Grécia, Irlanda, Holanda, Luxemburgo, Suíça, entre outros.

A Austrália também possui uma organização nacional que ajuda mais de 20.000 pessoas. Recebe doações de mais de 500 empresas e distribuiu mais de 5 milhões de quilos de alimentos no último ano.

Em maio de 2005, foi assinado pelos presidentes das redes nacionais dos Estados Unidos, Canadá e México um acordo com o intuito de reunir esforços para a criação de uma Organização Internacional para dar suporte à distribuição de alimentos através dos bancos de alimentos no mundo.

Atualmente, o Brasil já conta com mais de uma centena de bancos de alimentos espalhados por todo o território. Eles estão presentes nos 27 estados do Brasil, com pelo menos um Banco de Alimentos em cada capital para o atendimento das periferias dessas grandes cidades, além de outros espalhados no interior de alguns estados. Apenas o Programa MESA BRASIL (SESC) abrange 297 cidades com seus 69 bancos de alimentos instalados em suas próprias unidades.

Os bancos de alimentos podem ser implantados por órgãos públicos, pela iniciativa privada e por organizações da sociedade civil, de maneira participativa ou individual. 
No Brasil, desde 2003, o Ministério de Desenvolvimento Social e Combate à Fome (MDS) investe em bancos de alimentos, totalizando mais de $\mathrm{R} \$ 10$ milhões transferidos para o apoio ao setor. Estão em funcionamento 45 unidades de bancos de alimentos públicos atendendo a cerca de 1.130 entidades assistenciais por mês.

Os volumes de alimentos captados e redistribuídos pelos Bancos de alimentos variam de acordo com a região do país, a proximidade das centrais de abastecimento, as instalações físicas, a organização logística, entre outros. Uma estimativa da média de alimentos distribuídos pelos bancos de alimentos no Brasil atinge hoje, aproximadamente, 30 milhões de quilos por ano, atendendo a mais de 6.000 instituições beneficentes.

Bancos de alimentos lutam contra o desperdício de alimentos. Eles coletam excedentes da produção agrícola, do varejo e da indústria de alimentos, fornecidos gratuitamente, cumprindo todos os requisitos de segurança e saúde alimentar (FEBA, 2008). Segundo Shea (1991) bancos de alimentos são organizações sem fins lucrativos que coletam e distribuem comida para instituições cadastradas.

A doação de alimentos pelos bancos de alimentos é investigada por Sabadin (2005), quanto ao tema legislação. Em seu estudo, compara aspectos da legislação internacional e brasileira para, a partir de então, apontar entraves da inexistência de uma regulamentação para este setor. Já Lins e Oliveira (2004), estudam os aspectos normativos de um banco de alimentos em Pernambuco (Sesc). Exploram, em seu estudo, o processo de institucionalização e geração de capital social, em função das redes de relacionamentos surgidas, associadas às contribuições interpessoais e interinstitucionais estabelecidas a partir de sua implementação.

Custódio (2004) testa a aderência do mapa de vulnerabilidade social do município de São Paulo à demanda por alimentos doados por meio do programa de banco de alimentos municipal. Utiliza, para isso, dados como renda, educação e saneamento do município para a elaboração do mapa de vulnerabilidade social. Posteriormente, cruza este último com o mapa das instituições que potencialmente poderiam ser atendidas pelo Banco de Alimentos visando, desta forma, caracterizar o perfil da demanda que se apresenta ao BA. O trabalho conclui que a distribuição geográfica 
da demanda converge com o perfil de exclusão social da cidade de São Paulo. Em contrapartida, Gambardella (2005), estudando o mesmo Banco de Alimentos, detectou um desacerto entre os locais de distribuição de alimentos e a demanda por atendimento, contradizendo o estudo anterior e, por conseguinte, questionando a eficácia de atuação deste BA.

Gambardella (2005) segue a mesma linha de argumentação apresentada por Tarasuk e Eakin (2003, 2005), que avaliaram o papel dos bancos de alimentos dentro de um programa de combate à fome em Toronto, Canadá. A pesquisa foi feita através de um estudo observacional de 15 dos 49 BA de Toronto, durante 18 meses (janeiro de 1999 a julho de 2000). Concluíram que a oferta de doações de comida era insuficiente para suprir totalmente às necessidades daqueles que precisavam de assistência, por ser limitada, variável e incontrolável. Somado a isso, os autores questionaram se tais iniciativas poderiam mascarar a necessidade de encontrar soluções mais efetivas para o problema.

Starkey et al. (1998), fizeram um levantamento das características sóciodemográficas e perfis nutricionais das pessoas que buscam os bancos de alimentos em Montreal, Canadá. Um total de 490 usuários de BA foi selecionado aleatoriamente, de uma amostra de 57 bancos de alimentos. Um questionário e uma avaliação da dieta foram aplicados por entrevistadores para determinar características sócio-econômicas, demográficas, culturais e nutricionais dos entrevistados. Os resultados mostraram que a idade média dos participantes (256 homens e 234 mulheres) foi de 41 anos; 204 (41,6\%) moravam sozinhos e a maioria deles (409 equivalente a 83,5\%) recebia benefícios de programas de assistência social. O nível educacional era relativamente alto, pois muitos completaram a escola técnica (190 - 38,8\%). A amostra incluiu poucos idosos ou pessoas desabilitadas. $O$ índice de massa corporal média era maior do que 24, o que indica um consumo energético diário abaixo do recomendado, mas não considerado como problema crônico. A interpretação desses resultados pelos autores indicou que os BA atendem principalmente desempregados de uma faixa etária de meia idade, e são vistos pela comunidade usuária como um recurso comunitário necessário. 
Riches (2002) examina a ação dos BA pela perspectiva de sua origem e propósito, institucionalização, uso e efetividade de distribuição de alimentos. O artigo indica que a questão educacional pode ser incorporada como meta no trabalho dessas instituições, mas questiona, assim como Tarasuk e Eakin (2003, 2005), a efetividade da ação dos BA.

Ao interpretar os resultados produzidos pelos estudos canadenses, há que se atentar para a diferença importante do modelo e tipo de demanda para bancos de alimentos destes casos canadenses e do modelo brasileiro. Nestes casos, diferentemente do Brasil, a demanda é caracterizada por pessoas físicas de baixa renda, residentes nas proximidades dos $B A$, que se apresentam para o BA em busca de auxílio. No modelo brasileiro de BA, as doações são feitas exclusivamente para instituições carentes, o que muda a perspectiva de como a distribuição de alimentos doados é realizada, fato que não deve ser desprezado. 


\subsubsection{Logística de Bancos de Alimentos: Aspectos Gerais}

As atividades logísticas da operação de Bancos Alimentares envolvem: o transporte de alimentos recolhidos e distribuídos, a triagem e a armazenagem, o controle de qualidade e o gerenciamento do inventário (FEBA, 2008).

Em operações de bancos de alimentos, o produto principal em questão é o alimento que não foi vendido, devido a um excedente de oferta na cadeia agropecuária. A cadeia na qual os bancos de alimentos se inserem é representada na Figura 3.3. $O$ excesso de produtos alimentares começa "antes da porteira", dentro das fazendas, e continua acontecendo no decorrer da cadeia. Os bancos de alimentos buscam apenas os alimentos que podem ser consumidos, cumprindo todas as exigências de saúde e segurança alimentar (Fédération Européene des Banques Alimentaires FEBA, 2008).

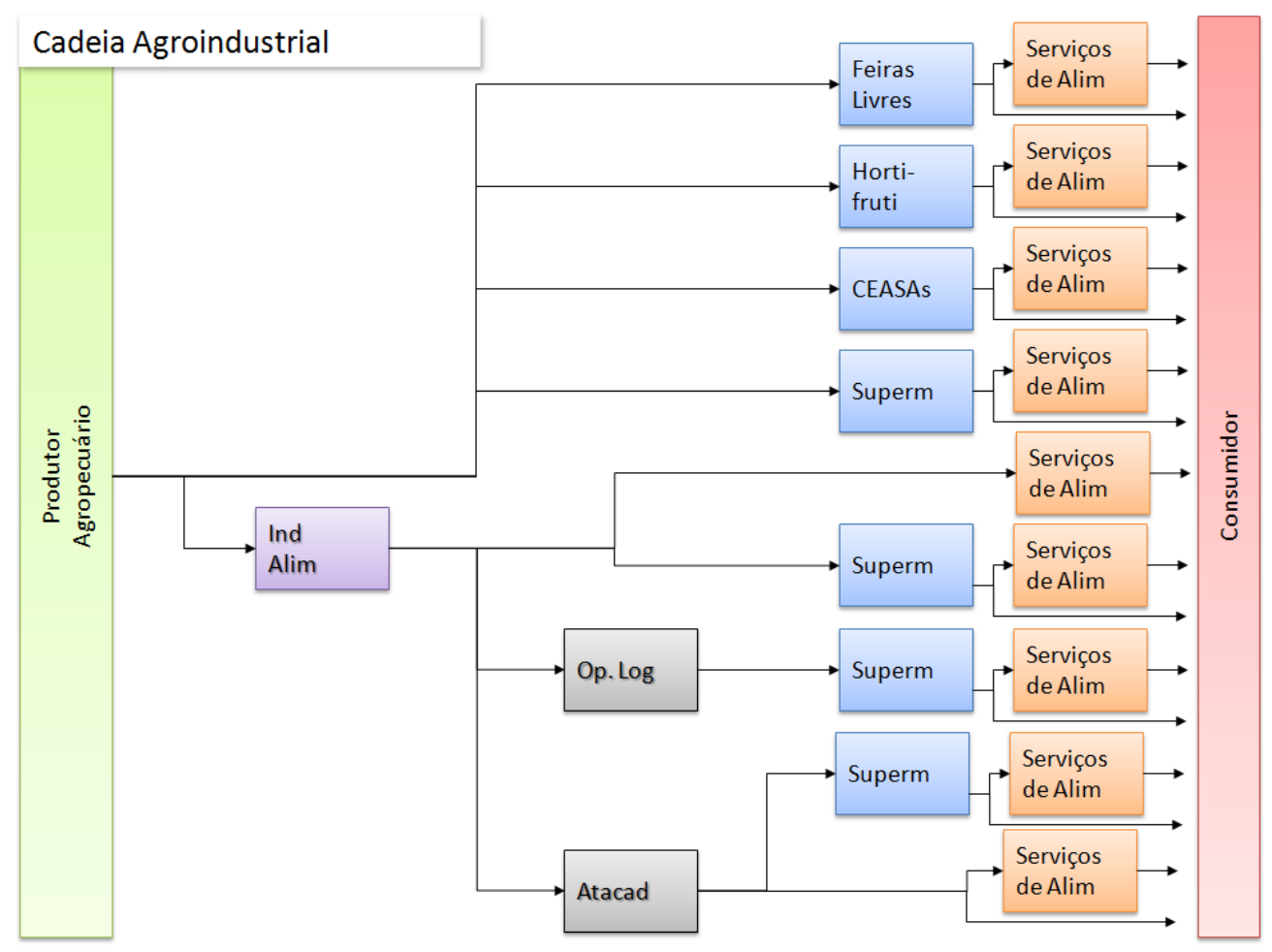

Figura 3.3 - Cadeia de suprimentos onde se insere a ação de bancos de alimentos. 
A logística cria valores de lugar, tempo, qualidade e informação (Novaes, 2007). A logística humanitária envolve tarefas de entrega de suprimentos para as pessoas certas, no lugar certo, no tempo certo e nas quantidades certas (Cottam et al., 2004). Bancos de alimentos procuram agregar valor de lugar, tempo, qualidade e informação trabalhando com um produto de características muito específicas, que são alimentos não comercializados.

Bancos de alimentos podem trazer valor ao produto, o alimento não vendido, transportando-o de locais onde praticamente não possui mais valor comercial, para serem oferecidos a pessoas vulneráveis em instituições filantrópicas e beneficentes.

No entanto, a natureza perecível do produto alimentar torna essa tarefa mais complicada, principalmente porque uma das principais razões para que o produto não tenha sido vendido é a proximidade da data de validade. Há, portanto, um ganho de importância do valor do tempo, para assegurar que a qualidade do produto seja mantida até seu consumidor final.

Alguns bancos de alimentos praticam o processamento mínimo de alimentos agregando valor de qualidade em seus produtos, além de, em alguns casos, aumentarem o tempo de validade para a distribuição dos produtos, depois de reprocessados. O empacotamento e identificação, por exemplo, são processamentos simples e comumente usados por bancos de alimentos (Figura 3.4).
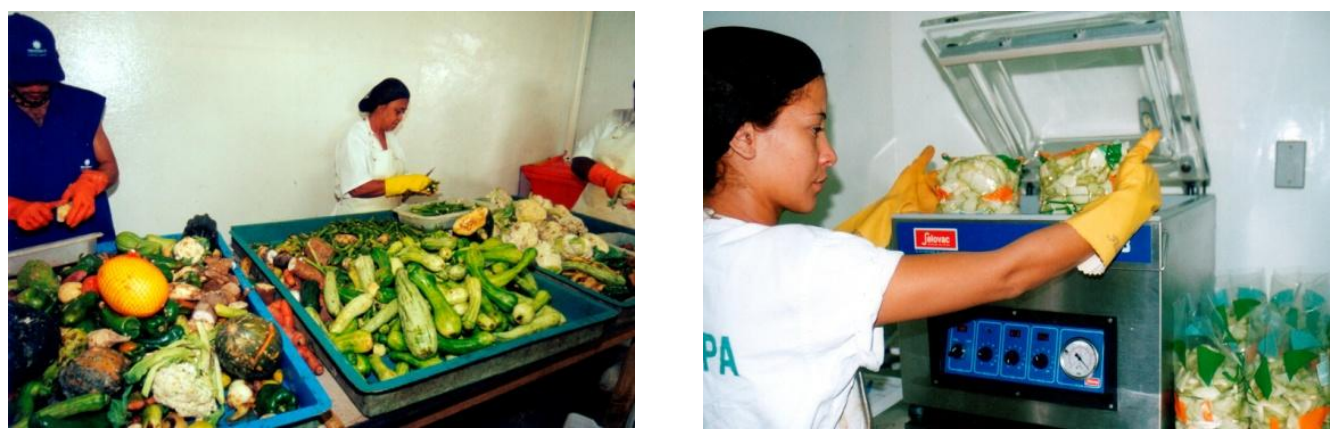

Figura 3.4 - Alimento sendo empacotado e identificado por um banco de alimentos. Fonte: Prefeitura de Belo Horizonte, MG, Brasil. 
Bancos de alimentos podem trabalhar com uma grande variedade de alimentos doados. A variedade refere-se não somente ao nível de processamento, como também ao tipo de alimento. Essa variedade influencia muitos aspectos logísticos como a escolha do veículo de transporte e a infraestrutura de armazenamento.

Em uma das entrevistas realizadas com bancos de alimentos foi mencionado que mais de uma vez a organização recebeu gado como doação. Ou seja, dependendo de onde o banco de alimentos estiver instalado ele deverá se preparar para receber desde gado (vivo) até alimentos processados e congelados. Somado a isso, deve-se lembrar que geralmente o tipo, a quantidade e a origem da doação não são conhecidos com grande antecedência.

Outra dimensão afetada pela variedade de produtos que o banco de alimentos lida é a informação. Muitas questões semânticas, referentes à nomeação dos produtos, agrupamento e classificação podem levar a diferentes formas de armazenar os dados. Este fato, afeta diretamente a utilização de sistemas de informações como suporte às operações logísticas de bancos de alimentos. A Organização das Nações Unidas para Agricultura (FAO - Food and Agriculture Organization) construiu um thesaurus (dicionário de termos) como base para a terminologia relacionada a alimentos e agricultura, que pode ser usado nesses casos.

Decisões logísticas em problemas operacionais são altamente dependentes em informação e muito sensíveis à atualização de informações (Balcik et al., 2008). Se a informação é completa e atualizada, decisões melhores podem ser tomadas, favorecendo doadores, beneficiários e as próprias organizações (Russel, 2005).

Apesar da complexidade envolvida em operações de logística humanitária, processos manuais ainda predominam e os recursos de tecnologia da informação que poderiam melhorar a disponibilidade de informações são raramente utilizados (Thomas, 2005).

Com relação à oferta, as operações de bancos de alimentos apresentam especificidades quando comparadas a outras cadeias de suprimentos. A oferta é instável e imprevisível. Instável porque depende do excedente de produção e 
comercialização de produtos alimentares. Imprevisível porque não é, usualmente, possível prever quando a oferta será feita.

Davidson (2006) faz algumas considerações sobre as dificuldades mencionadas por organizações humanitárias em operações de atendimento às vítimas de desastres naturais com relação à organização de produtos doados não solicitados. Além de haver uma grande variedade de produtos, alguns inesperados, geralmente não há muito tempo para planejar o armazenamento, transporte e distribuição. Somado a isso, em bancos de alimentos, os produtos doados são invariavelmente perecíveis e muitas vezes com a data de validade prestes a expirar.

Por essas razões observa-se que as características relativas aos produtos que os bancos de alimentos lidam, por si só, já conduzem a uma série de desafios. Abaixo são listadas algumas das características que corroboram para tornar a questão de logística de bancos de alimentos uma questão não trivial:

1. Produtos alimentares diferentes podem ser oferecidos ao mesmo tempo.

2. Alguns tipos de alimentos não podem ser transportados juntos devido ao risco de contaminação cruzada.

3. Os requisitos para transporte e armazenamento, como a necessidade de manter um produto a uma certa temperatura, são diversos e dependentes do produto ofertado.

4. O produto alimentar pode ser perecível em diferentes níveis.

Os fluxos financeiro, físico e de informação dos bancos de alimentos também apresentam peculiaridades. A Figura 3.5 adaptada de Blanco e Goentzel (2006) representa os fluxos de informação, financeiro e físico para as cadeias de suprimentos empresarial, dos casos gerais de operações humanitária e especificamente para os bancos de alimentos. 
Fluxos da Cadeia de Suprimentos

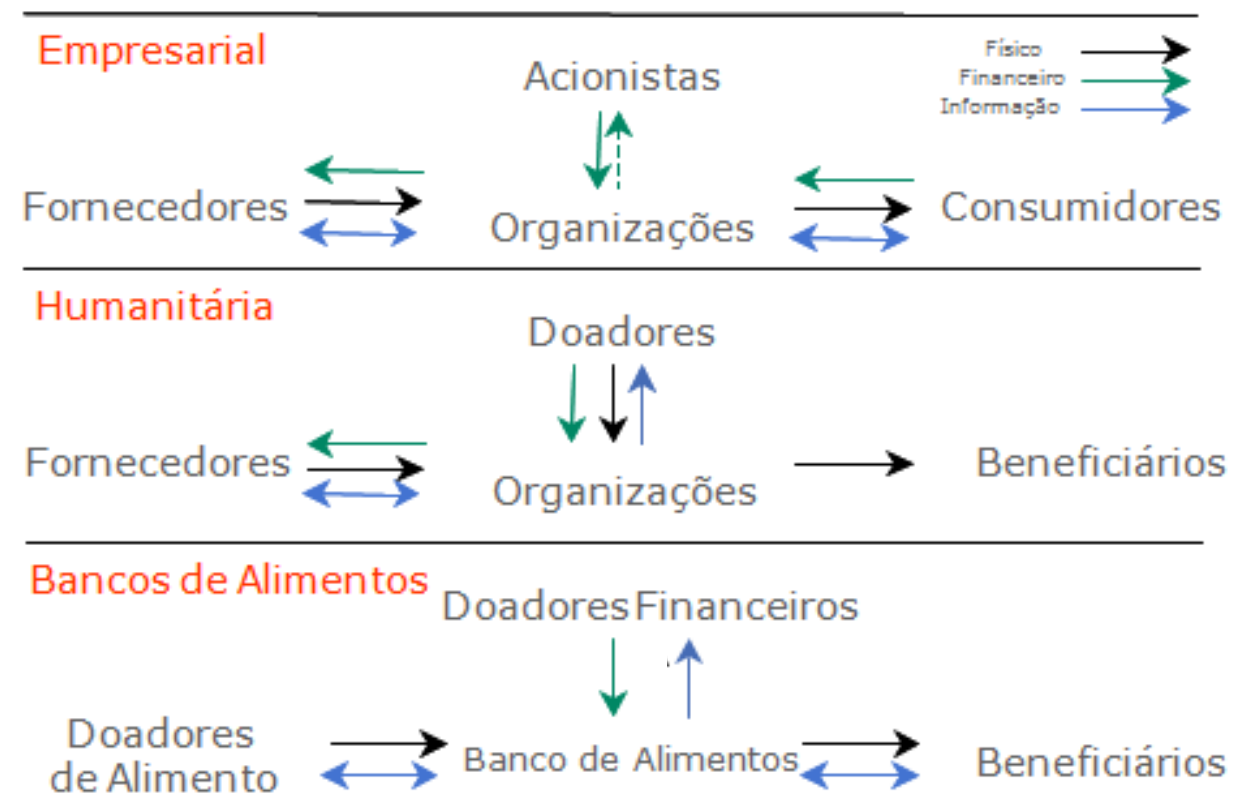

Figura 3.5 - Fluxos das cadeias de suprimentos empresarial, humanitária e dos bancos de alimentos. Fonte: Adaptado de Blanco e Goentzel (2006).

Enquanto a cadeia de suprimentos empresarial tem como atores: consumidores, acionistas e organizações que visam o lucro, a cadeia de suprimentos humanitária lida com beneficiários, doadores e organizações sem fins lucrativos.

$\mathrm{Na}$ operação de bancos de alimentos, as organizações humanitárias sem fins lucrativos são os próprios bancos de alimentos. Os doadores aparecem como doador financeiro e doador de produtos alimentares. Os fornecedores são sempre substituídos pelo doador de produtos alimentares.

Como na cadeia de suprimentos empresarial os atores tem um mesmo objetivo: obter lucro, os fluxos financeiros aparecem em todas as relações entre os atores. $\mathrm{Na}$ cadeia de suprimentos humanitária, diferentemente, os fluxos financeiros não atingem diretamente os beneficiários, que recebem recursos na forma de produtos (alimentos, medicamentos, etc.). De fato, não haveria utilidade, para os beneficiários, em receber dinheiro em uma situação que não pudesse ser trocado pelos produtos desejados (Davidson, 2006). No caso dos bancos de alimentos, os fluxos financeiros 
são ainda mais restritos, limitados pela relação entre os doadores financeiros e os bancos de alimentos.

$\mathrm{Na}$ Tabela 3.5 são resumidas as idéias apresentadas sobre as especificidades de operações de bancos de alimentos em comparação ao contexto de desastres naturais dentro da logística humanitária.

Tabela 3.5 - Especificidades das operações de bancos de alimentos.

\begin{tabular}{|c|c|c|}
\hline & $\begin{array}{l}\text { Operações Humanitárias de } \\
\text { Curto-Prazo em Desastres } \\
\text { Naturais }\end{array}$ & $\begin{array}{l}\text { Operações Humanitárias de Longo-Prazo em } \\
\text { Bancos de Alimentos }\end{array}$ \\
\hline Demanda & $\begin{array}{l}\text { É gerada por eventos } \\
\text { aleatórios, na maior parte } \\
\text { imprevisíveis em termos de } \\
\text { tempo, localização, tipo e } \\
\text { tamanho. É estimada após a } \\
\text { ocorrência da necessidade. }\end{array}$ & $\begin{array}{l}\text { Padrões de demanda relativamente estáveis e } \\
\text { previsíveis: } \\
\text { (1) Instituições fazem requisições antecipadas à } \\
\text { bancos de alimentos. } \\
\text { (2) Bancos de alimentos repassam, mesmo sem a } \\
\text { instituição ter feito alguma solicitação prévia, quando } \\
\text { há uma grande oferta de doação. } \\
\text { (3) Em alguns casos o banco de alimentos } \\
\text { providencia o transporte até as instituições.. }\end{array}$ \\
\hline Oferta & $\begin{array}{l}\text { Nem sempre há produtos } \\
\text { suficientes disponíveis no } \\
\text { mercado. } \\
\text { Algumas doações não são } \\
\text { feitas por requisição e precisam } \\
\text { ser gerenciadas. }\end{array}$ & $\begin{array}{l}\text { Dois tipos de padrão de oferta: } \\
\text { (1) Ocasional, gerado de eventos esporádicos que } \\
\text { são imprevisíveis em termos de localização, tipo e } \\
\text { tamanho. } \\
\text { (2) Regular, quando doadores estabelecem um } \\
\text { acordo com o banco de alimentos que busca } \\
\text { regularmente as doações. Nesse caso é possível } \\
\text { prever local mas tipo e tamanho da doação nem } \\
\text { sempre são previsíveis. } \\
\text { A oferta é feita por doadores que podem ser } \\
\text { supermercados, agro-indústrias e propriedades rurais. }\end{array}$ \\
\hline $\begin{array}{l}\text { Tempo de } \\
\text { resposta }\end{array}$ & $\begin{array}{l}\text { O tempo de resposta requerido } \\
\text { é praticamente zero. (zero } \\
\text { entre a ocorrência da demanda } \\
\text { e a necessidade da mesma). }\end{array}$ & $\begin{array}{l}\text { O tempo de resposta (lead time) é restringido pelo } \\
\text { prazo de validade do alimento doado }\end{array}$ \\
\hline $\begin{array}{l}\text { Rede de } \\
\text { distribuição }\end{array}$ & $\begin{array}{l}\text { Previamente desconhecida } \\
\text { (localização, tipo e tamanho);: }\end{array}$ & $\begin{array}{l}\text { Os pontos de distribuição podem ser bem } \\
\text { conhecidos no caso de doações regulares ou incertos } \\
\text { no caso de doações ocasionais. } \\
\text { Geralmente a distribuição é planejada sem a } \\
\text { utilização de um sistema de informações, baseadas em } \\
\text { um mapa de papel e a sequêencia de paradas muitas } \\
\text { vezes é decidida pelos próprios motoristas no momento } \\
\text { da operação. }\end{array}$ \\
\hline
\end{tabular}




\begin{tabular}{|c|c|c|}
\hline & $\begin{array}{l}\text { Operações Humanitárias de } \\
\text { Curto-Prazo em Desastres } \\
\text { Naturais }\end{array}$ & $\begin{array}{l}\text { Operações Humanitárias de Longo-Prazo em } \\
\text { Bancos de Alimentos }\end{array}$ \\
\hline $\begin{array}{l}\text { Controle de } \\
\text { estoque }\end{array}$ & $\begin{array}{l}\text { Desafiador pela grande } \\
\text { variação da demanda e a } \\
\text { localização da mesma. }\end{array}$ & Variável dependendo do banco de alimentos. \\
\hline $\begin{array}{l}\text { Sistemas de } \\
\text { informação }\end{array}$ & $\begin{array}{l}\text { As informações são pouco } \\
\text { confiáveis, incompletas ou } \\
\text { inexistem. }\end{array}$ & $\begin{array}{l}\text { Informação está disponível para preparar relatórios, } \\
\text { mas não há dados geocodificados. }\end{array}$ \\
\hline Objetivos & $\begin{array}{l}\text { Minimizar perdas de vidas e } \\
\text { aliviar o sofrimento. }\end{array}$ & $\begin{array}{l}\text { Maximizar o número de pessoas atendidas. } \\
\text { Minimizar o desperdício de alimentos }\end{array}$ \\
\hline $\begin{array}{l}\text { Avaliação do } \\
\text { desempenho }\end{array}$ & $\begin{array}{l}\text { Foco em medidas de } \\
\text { desempenho externas }\end{array}$ & Não há medidas de monitoramento estabelecidas \\
\hline
\end{tabular}

\subsubsection{Logística de Bancos de Alimentos: Operação.}

A partir das entrevistas feitas em bancos de alimentos (Apêndice A), pesquisas na internet e revisão de literatura foram estabelecidos os seguintes modelos gerais que representam coleta e entrega em operações de bancos de alimentos ilustrados na Figura 3.6. 


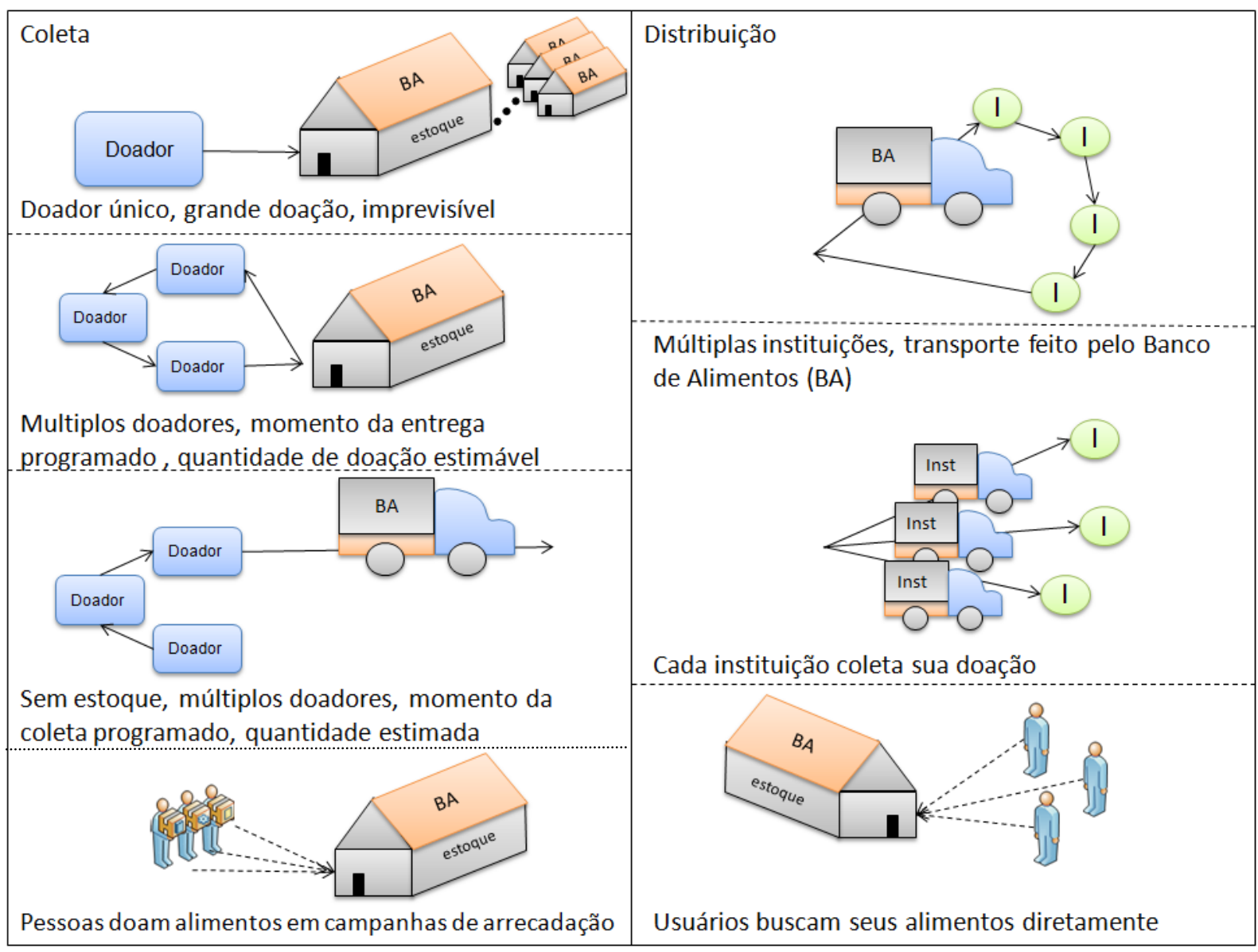

Figura 3.6 - Operação de bancos de alimentos.

Como ilustrado na Figura 3.6, as doações em uma operação podem vir de um ou múltiplos doadores. Os doadores podem ser organizações ou pessoas que doam durante campanhas de arrecadação.

Com relação à armazenagem, é possível haver operações em que o banco de alimentos não possui estoque e as doações não são armazenadas antes de serem distribuídas para as instituições beneficiárias.

A capacidade de planejar com antecedência a operação de coleta pode também variar. Muitas vezes há doadores com grandes quantidades de alimentos a serem doados que entram em contato com o banco de alimentos quando o alimento está quase perdendo sua validade. Por outro lado, há também doadores regulares que sabem estimar aproximadamente quando haverá um excesso de produtos que 
podem ser coletados pelos bancos de alimentos, permitindo que haja um acordo sobre quais dias serão disponibilizados produtos para os bancos de alimentos. Neste último caso o dia da coleta é previamente agendado, mas a quantidade de produtos que estará disponível pode variar bastante. Indústrias de alimentos se enquadram no primeiro perfil de doador esporádico, enquanto supermercados geralmente se enquadram no último caso, do doador regular.

A entrega de doações pode ser feita pelo banco de alimentos, instituições podem buscar essas doações ou pessoas podem retirar as doações diretamente nos bancos de alimentos (esse último caso acontece no Canadá e na Alemanhã, mas não acontece no Brasil). Para que a entrega seja feita pelos bancos de alimentos é preciso que o banco de alimentos tenha infraestrutura para fazê-lo, mas não depende somente disso. Alguns bancos de alimentos não assumem a responsabilidade de transportar a doação até a instituição beneficiária, não apenas porque não possuem condições de fornecer esse serviço. Muitas vezes essa decisão é baseada nos princípios de trabalho do banco de alimentos que, para não interferirem na autonomia da instituição beneficiária, preferem não fornecer o produto no local ou de forma regular.

O conhecimento relativo à logística humanitária e em especial aos bancos de alimentos foi formalizado através de ontologias, discutidas no próximo capítulo. 


\section{Ontologia para Processos de logística de Bancos de ALIMENTOS}

Processos de logística envolvem a participação de diferentes organizações, que apesar de desempenharem fundamentalmente um conjunto de atividades interrelacionadas, pertencentes a um mesmo domínio do conhecimento, muitas vezes não conseguem integrar processos devido às diferenças de contexto de cada ator ou setor. Lidar com essas diferenças entre organizações é um dos grandes desafios para as cadeias de suprimentos, que buscam, através da integração, melhorar o desempenho da cadeia para a partir disso viabilizar que cada um dos atores possa obter melhores resultados.

A integração de processos logísticos não é dependente apenas da integração de dados, mas também de métodos utilizados para gerenciar e modelar esses dados. Por ser uma área relacionada ao domínio empresarial, muitas soluções para processos logísticos são proprietárias e a falta de transparência e interoperabilidade dessas soluções aumenta essa dificuldade de integração. Com o advento da Internet, e particularmente com a evolução da Web, métodos para a solução de integração semântica de informações têm sido pesquisados. No estágio atual, as ontologias parecem ser a grande promessa para lidar com essa questão. A percepção dessa perspectiva pela indústria e comunidade científica na área de logística impulsionou as investigações sobre o potencial dessas ferramentas para a integração de processos na cadeia de suprimentos.

Este capítulo trata fundamentalmente de ontologias para processos logísticos. O capítulo parte de uma breve conceituação sobre os problemas de interoperabilidade, seguida de uma discussão sobre a questão semântica envolvida, que introduzem a discussão sobre as ontologias. Para discutir a utilização de ontologias primeiramente são apresentados os conceitos básicos que constituem referências importantes para o entendimento de como as ontologias têm sido utilizadas, bem como aplicações 
relacionadas a processos logísticos. Ao final é apresentado o conjunto de ontologias propostas, desenvolvidas no presente trabalho.

\subsection{Interoperabilidade}

Interoperabilidade permite que diversas organizações forneçam dados, sem interferir nas suas escolhas tecnológicas, processos de produção, ou cultura interna (Davis et al., 2009). A interoperabilidade pode ser definida como a capacidade de um sistema ou seus componentes para compartilhar informações e aplicações (Bishr, 1998), independentemente da sua heterogeneidade.

Em busca de interoperabilidade a comunidade internacional se organiza em consórcios para discussão e desenvolvimento de padrões. Dentre essas iniciativas não podemos deixar de citar:

- A Organização para Padronização Internacional (International Organizational for Standards -ISO), maior colaborador do mundo para edição de padrões e normas internacionais. Foi estabelecida em 1947 e conta com uma rede de institutos nacionais de normalização de 163 países (ISO, 2010).

- O W3C (World Wide Web Consortium), consórcio internacional fundado por Tim Berners Lee, em 1994, que desenvolve padrões para tecnologias para garantir o crescimento a longo prazo da Web (W3C, 2010).

- O OGC (Open Geospatial Consortium), uma organização sem fins lucrativos formado por membros da comunidade internacional e voluntários, que organizam o desenvolvimento de padrões para dados e serviços baseados em localização espacial. Foi fundada em 1994 e atualmente é formada por quatrocentas e duas companhias, agências governamentais e universidades (OGC, 2010).

- O FGDC (Federal Geographic Data Committee) é um comitê inter-agências que promove o desenvolvimento coordenado, utilização, compartilhamento e 
disseminação de dados de geoespaciais em nível nacional, nos Estados Unidos (FGDC, 2010).

O FGDC, em conjunto com o OGC, desenvolve as especificações ISO/TC 211, que estabelecem normas e padrões em busca de diminuir a heterogeneidade e promover a interoperabilidade de dados espaciais.

A heterogeneidade dos dados inclui dois aspectos: o estrutural e o semântico (Vaccari, 2008). Geralmente, dois níveis de interoperabilidade, são definidos: o nível baixo, chamado sintático e de nível superior, chamada semântico (Lima, 2002; Laurini, 2007).

\subsection{Semântica}

Segundo Kuhn (2005), o conceito de semântica refere-se ao significado de expressões. Expressões essas que podem ser símbolos únicos (palavras) ou combinação de símbolos. Como o próprio termo diz, têm como função expressar, ou comunicar um significado. Em princípio, considera-se que conceitos, entidades, propriedades e processos não possuem semântica, apenas as expressões de linguagem que os descrevem.

A Web Semântica não é uma nova Web, mas sim uma extensão da Web, sobre a qual a informação recebe um significado bem definido, permitindo que pessoas $e$ computadores trabalhem em cooperação (Berners-Lee et al., 2001). A Web Semântica depende da possibilidade de uso compartilhado de vocabulários, cuja semântica seja descrita de uma forma (razoavelmente) inequívoca e processável por máquina (Masolo et al., 2003). Interoperabilidade semântica pode ser alcançada se os dois agentes (tanto os seres humanos quanto máquinas) concordem sobre a forma de entender os dados. O nível de compreensão pode ser diferente e depende principalmente da complexidade do conhecimento formalizado (Maué et al., 2009). 
Para atribuir significado às expressões de linguagem e possibilitar o uso compartilhado de vocabulários, é preciso passar por um processo de conceitualização. A expressão banco, por exemplo, pode referir-se a um estabelecimento que guarda determinado material (dinheiro, alimento, sangue) para um uso futuro; o mesmo termo banco pode também referir-se a um móvel (mobília), que serve para assento. Ou seja, apesar de expressões de linguagem (símbolos) serem utilizadas para expressar idéias que se referem a entidades do mundo real, conceitos são influenciados pelo contexto, moldados pela experiência humana com essas entidades. Esse trio fundamental, relacionando símbolos, conceitos e entidades, é traduzido pelo triângulo semântico, representado na Figura 3.1. (Kuhn, 2005).

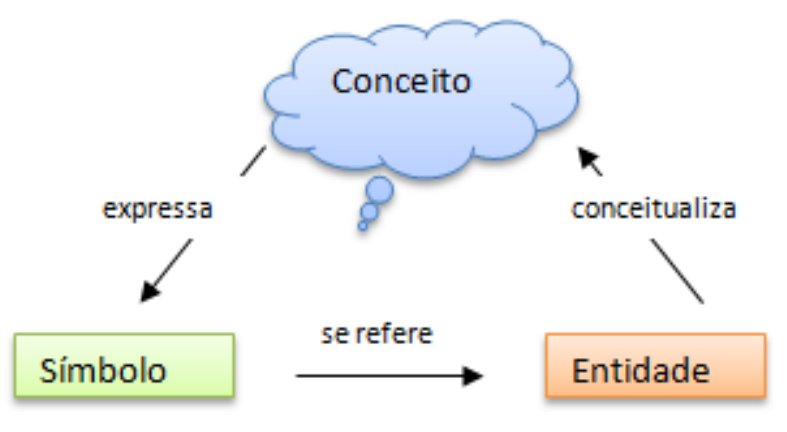

Figura 4.1 - Triângulo semântico (Fonte: Kuhn, 2005).

Maué et al. (2009) sugerem que a heterogeneidade semântica seja abordada quanto à sinonímia, homonímia e polissemia. Sinonímia trata de sinônimos. Um termo é um sinônimo de outra palavra diferente, se ambos denotam o mesmo objeto. Homonímia refere-se a uma palavra que tenha vários significados, e só o contexto torna compreensível para o leitor qual significado pretendido. Polissemia acontece quando uma palavra pode ser entendida de forma diferente dependendo da informação contextual. A diferença entre a polissemia e homonímia é que na polissemia objetos similares recebem nomes iguais enquanto na homonímia objetos diferentes recebem o mesmo nome. Ruas diferentes com o mesmo nome são um exemplo de polissemia. 
Uma das formas de lidar com a conceitualização de expressões de linguagem são as ontologias. Ontologias têm sido utilizadas para abordar questões relacionadas com a semântica na Web (Berners-Lee et al., 2001). O emprego de ontologias para Web Semântica trata exatamente do processo de descrever o significado pretendido de termos de um vocabulário (Masolo et al., 2003).

\subsection{Ontologias}

Atribuem-se à Grécia antiga, berço de grandes filósofos, as primeiras manifestações relacionadas às questões abordadas pelo conceito ontologia. Diversos autores associam como marco deste conceito as idéias expressas pela obra Metafísica, de Aristóteles (Gómez-Pérez et al., 2005).

A palavra ontologia tem sua origem no Grego (Onto - ser) e (logia - discurso) significando o discurso sobre as coisas que existem (Laurini, 2007).

Sob a perspectiva da filosofia, ontologia trata sobre o conceito de existir. O termo, no entanto, foi apropriado por diversas áreas, como a Inteligência Artificial e a Ciência da Computação, com vistas a aplicações como comércio eletrônico, recuperação de informações (information retrieval), banco de dados, Web semântica, entre outros (Goméz-Perez et al., 2003) e, por conseguinte, recebeu diferentes definições, muitas vezes, complementares. Cabe, neste ponto, ressaltar a limitação deste trabalho que não pretende discutir as raízes filosóficas do conceito, partindo do arcabouço conceitual criado a partir da sua incorporação no universo de Sistemas de Informações e Inteligência Artificial.

No escopo do universo de Sistemas de Informação e Inteligência Artificial, uma definição muito citada é a apresentada por Gruber (1993):

"Ontologias são definidas como especificações formais de uma conceitualização compartilhada" 
Esta definição trata basicamente de três aspectos: a definição de conceitos (especificações), a indicação que tal especificação será feita em linguagem computacional (formais) e, por fim, a consideração de que esta conceitualização deva ocorrer de forma consensual, que vários agentes estejam de acordo (Fensel et al., 2003).

Guarino et al. (1995) definem ontologia como uma teoria lógica que fornece uma conceitualização explícita. Ontologias captam o conhecimento consensual de um domínio, descrevem seus conceitos e restrições em seu uso, de forma explicita (Devaraju e Kuhn, 2010). Ontologias são formas estruturadas de descrever características e relacionamentos entre objetos que encontramos em nosso entorno (Hornsby e King, 2008). Uma ontologia especifica quais conceitos representar e como eles estão inter-relacionados (Fensel et al., 2003).

A formalização da conceitualização, ou seja, especificação da ontologia em linguagem computacional, agrega pelo menos dois valores muito importantes para o potencial dessa ferramenta em sistemas de informação: (1) permite a inclusão de axiomas, que agregam expressividade à conceitualização, e viabiliza a validação da consistência das relações estabelecidas através desses axiomas (Frank, 2007); e (2) viabiliza o compartilhamento dessa conceitualização via sistemas facilitando o re-uso e constante aprimoramento.

São diversas linguagens disponíveis para esse processo de formalização. O grau de expressividade das linguagens computacionais para representar as ontologias varia, e está relacionado à capacidade da linguagem de representar axiomas que fornecem maior ou menor expressividade ao processo de conceitualização. Ontologias em linguagem RDF, por exemplo, permitem apenas que seja feita uma estrutura hierárquica dos conceitos enquanto ontologias em linguagem OWL já permitem a inclusão de axiomas que definem melhor a relação entre os conceitos e, por conseguinte, agregam maior expressividade ao processo de conceitualização (Maué et al., 2009).

Masolo et al. (2003) referem-se a ontologias menos ou mais axiomatizadas como ontologias de "peso-leve" (lightweight ontologies) e ontologias "peso-pesado" 
(heavyweight ontologies), respectivamente. Basicamente, a diferença entre ambas está no grau de definição dos termos e nos acordos mais ou menos precisos quanto aos seus significados. Ontologias "peso-leve" referem-se às ontologias mais simples, ou seja, estruturas taxonômicas com definições associadas, enquanto as ontologias "peso-pesado" procuram explicitar acordos mais precisos na definição e explicação do significado pretendido dos termos, o que geralmente leva a ontologias mais axiomatizadas.

A segunda vantagem da formalização de ontologias, qual seja, o compartilhamento dessa conceitualização facilitando o reuso, mapeamento, fusão e integração de ontologias acontece devido ao fato dos conceitos, representados por classes, poderem ser acessados via internet, conforme ilustrado na Figura 4.2.

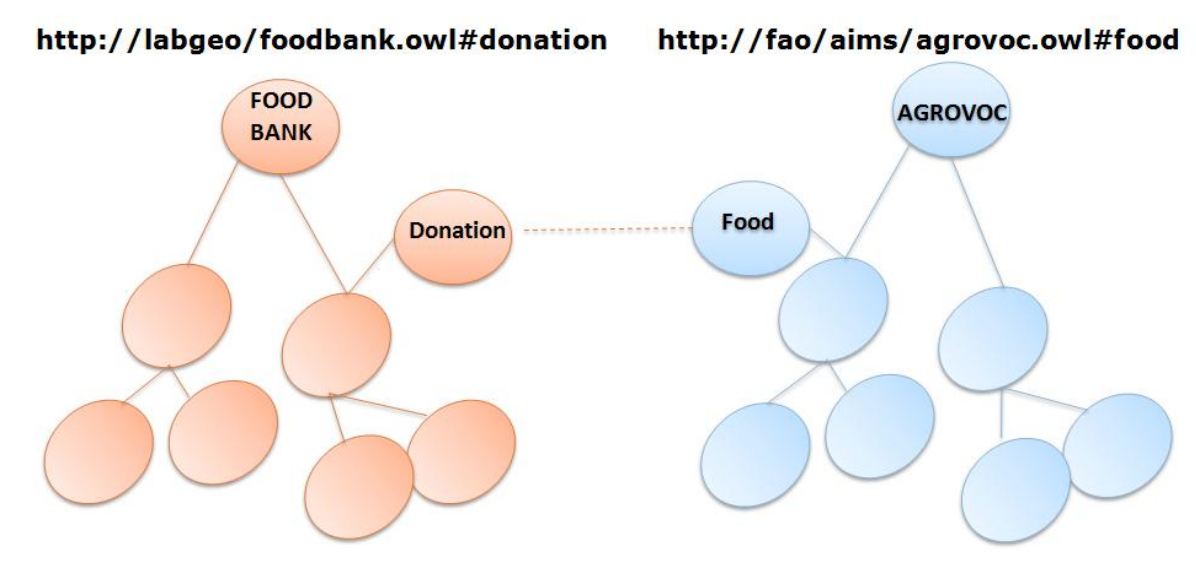

Figura 4.2 - llustração sobre a integração entre ontologias pelo estabelecimento de relacionamentos entre classes.

Ontologias são classificadas de diversas formas na literatura. Alguns autores sistematizaram essas classificações (Gómez-Pérez et al., 2005; Agarwal, 2005). Neste trabalho, adotaremos a divisão sugerida por Guarino (1998), (Figura 4.3): 


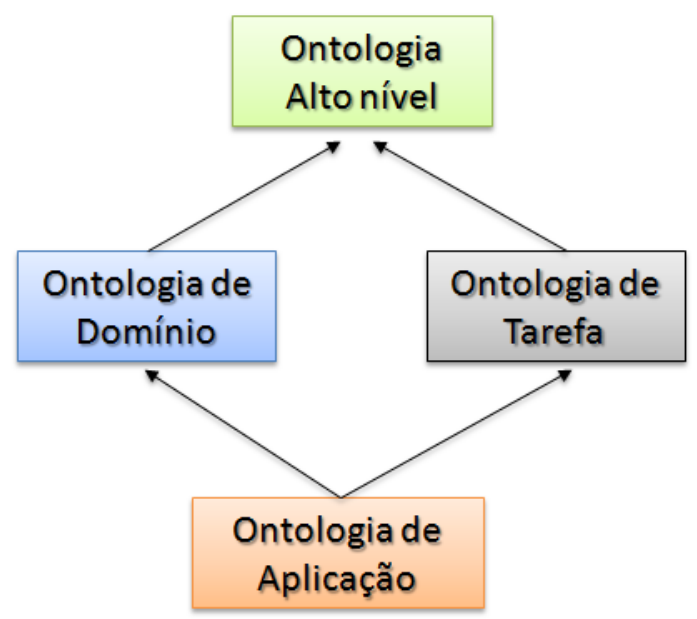

Figura 4.3 - Classificação de ontologias (Guarino, 1998).

$\checkmark \quad$ Ontologias de Alto Nível (Top-level): definem conceitos bem gerais como espaço, tempo, matéria, objeto, evento, ação, etc. que são independentes de um domínio específico.

$\checkmark \quad$ Ontologias ao nível do Domínio (Domain level): descrevem a terminologia de um dado domínio, como por exemplo, o domínio da Logística.

$\checkmark \quad$ Ontologias de Tarefas (Task ontologies): descrevem uma tarefa específica.

$\checkmark \quad$ Ontologias de Aplicação (Application ontologies): apresentam termos que são dependentes de um domínio, mas que descrevem uma tarefa específica.

Maué et al. (2009) faz referência a ontologias locais e ontologias globais. Ontologias locais podem ser associadas a ontologias de tarefas e de aplicação e ontologias globais à ontologias de domínio e de alto nível.

Gruber (1993) identificou cinco componentes de uma ontologia: classes, relações, funções, axiomas e instâncias. 
$\checkmark \quad$ Classes representam conceitos, tomados em um senso geral. São geralmente organizadas em taxonomias através das quais mecanismos de hereditariedade são aplicados. Classes podem representar conceitos abstratos ou concretos.

Relações representam o tipo de associação entre conceitos de um domínio. Ontologias geralmente contêm relações binárias onde o primeiro argumento é conhecido como o domínio da relação, enquanto o segundo argumento determina a extensão deste domínio.

$\checkmark \quad$ Funções são casos especiais de relações em que o enésimo elemento da relação é único para os $\mathrm{n}$-1 elementos precedentes.

$\checkmark \quad$ Axiomas servem para modelar sentenças que são sempre verdadeiras. São geralmente utilizados para representar um tipo de conhecimento que não pode ser formalmente definido pelos outros componentes. Somado a isso, são também utilizados para verificar a consistência da ontologia.

$\checkmark \quad$ Instâncias são usadas para representar elementos ou indivíduos em uma ontologia.

De um ponto de vista computacional, uma ontologia pode ser vista como uma rede semântica (Laurini, 2007). Uma linguagem ontológica impõe uma estrutura na representação do conhecimento e indica que tipo de conclusões lógicas podem ser desenhadas dos dados coletados (Frank, 2007).

\subsubsection{Ontologias: desenvolvimento}

Não existem metodologias consagradas para a construção de ontologias que estejam disponíveis para a comunidade que lida com dados espaciais (Agarwal, 2005). A autora aponta para o fato de que a natureza específica dos dados espaciais, formada por associações cognitivas e referências espaço-temporais, faz com que seja crucial o desenvolvimento de métodos para atender tais 
especificidades. Acrescenta ainda que a criação de um arcabouço comum dentro da comunidade que lida com informações espaciais seria muito importante para que todas as iniciativas de pesquisa possam trabalhar em conjunto e contribuir para o desenvolvimento de um bem comum.

Gruber (1993) levantou 5 princípios para o desenho de ontologias, quais sejam:

$\checkmark \quad$ Clareza: uma ontologia deve comunicar efetivamente o significado de destino dos termos definidos. Definições devem ser objetivas. Definições podem ser feitas em axiomas e uma definição completa é preferível ao invés de uma definição parcial.

$\checkmark \quad$ Coerência: para ser coerente uma ontologia deve permitir que inferências sejam consistentes com definições; se uma sentença que pode ser inferida de um axioma contradiz uma definição ou um exemplo dado informalmente, então a ontologia não possui coerência;

$\checkmark \quad$ Extensibilidade: novos termos para usos específicos devem ser baseados em vocabulário existente, de modo que não seja necessária a revisão das definições existentes;

$\checkmark \quad$ Mínimo de viés para codificação: a conceitualização deve ser especificada no nível do conhecimento sem depender de uma simbologia particular para codificação;

$\checkmark$ Compromisso ontológico: o compromisso ontológico é baseado na consistência de uso do vocabulário.

Guarino (1998) definiu compromissos ontológicos como sendo a conexão entre o vocabulário da ontologia e o significado dos termos deste vocabulário, ou seja, um compromisso ontológico é uma função que liga termos de um vocabulário com sua conceitualização. Compromissos ontológicos garantem consistência, mas não garantem a completude de uma ontologia. Muitas vezes, os termos utilizados em linguagem natural possuem múltiplos significados. Na ontologia, restringimos a interpretação semântica desses termos e provemos definições formais. Portanto, o compromisso ontológico tem como uma das funções determinar qual significado o termo pode assumir. Compromissos ontológicos geralmente envolvem mais do que 
um mapeamento entre termos da linguagem natural e seus significados, envolve também uma escolha geral como a estrutura do tempo, espaço, eventos, etc (Gómez-Pérez et al., 2005).

Linguagens, em ontologia e editores para ontologias, permitem a introdução da noção de compromissos ontológicos de forma que possa se verificar possíveis inconsistências (Frank, 2007).

O livro de Gómez-Pérez et al. (2005) reune uma série de métodos e metodologias para o desenvolvimento de ontologias. Os autores classificam as atividades do processo de desenvolvimento em três tipos, que não necessariamente ocorreram em seqüência, descritas a seguir: atividades de gerenciamento, atividades orientadas ao desenvolvimento e atividades de suporte (Figura 4.4).

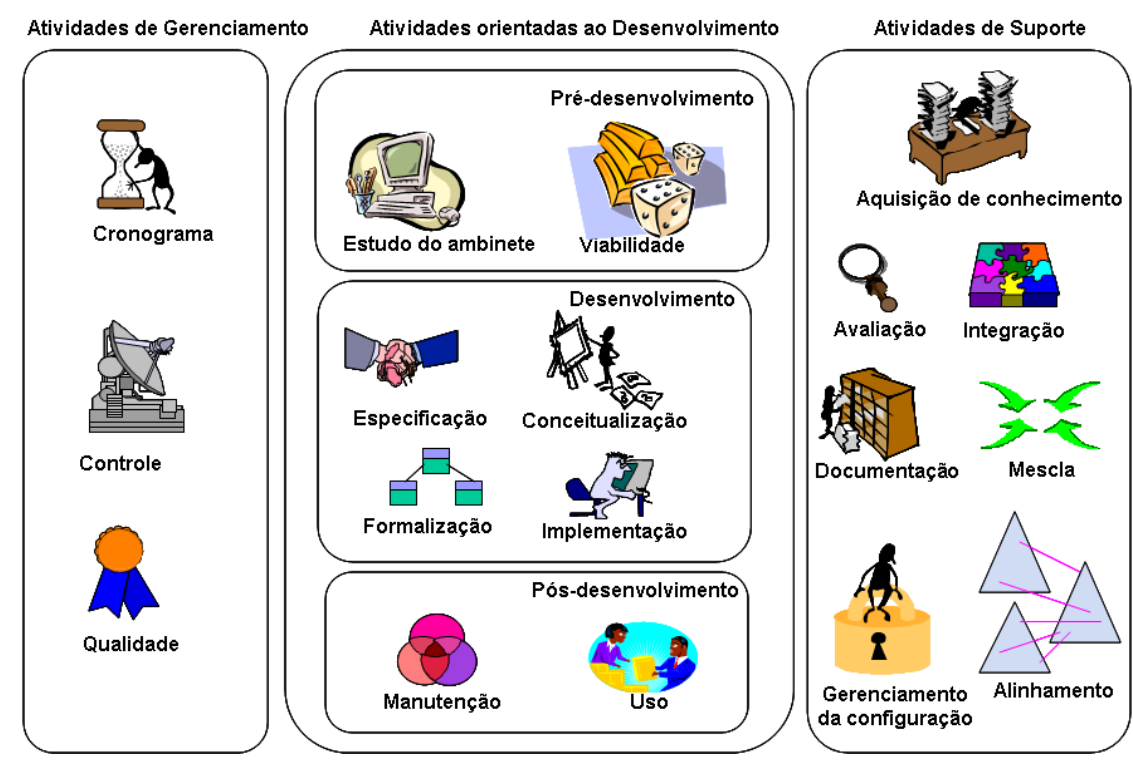

Figura 4.4 - Processo de desenvolvimento de ontologias. Fonte: Goméz-Perez et al. (2003).

Para o reuso de ontologias pré-existentes é possível acessar bibliotecas virtuais (Tabela 4.1) 
Tabela 4.1 - Relação das bibliotecas de ontologias disponíveis na Web.

\begin{tabular}{|c|c|c|}
\hline Nome & Origem & Link \\
\hline Ontoselect & $\begin{array}{c}\text { Competence Center } \\
\text { Semantic Web (dfki) - } \\
\text { Germany }\end{array}$ & http://olp.dfki.de/ontoselect \\
\hline $\begin{array}{l}\text { Schema } \\
\text { web }\end{array}$ & "Privada" & http://www.schemaweb.info/ \\
\hline Protégé & Stanford University - USA & http://protegewiki.stanford.edu \\
\hline Swoogle & $\begin{array}{c}\text { Project - University of } \\
\text { Maryland - USA - 2004- } \\
2006 \\
\end{array}$ & http://swoogle.umbc.edu \\
\hline Watson & $\begin{array}{l}\text { Knowledge Media Institute, } \\
\text { The Open University - UK }\end{array}$ & http://watson.kmi.open.ac.uk/WatsonWUI/ \\
\hline Neon & $\begin{array}{c}\text { Gómez-Pérez group - } \\
\text { Spain }\end{array}$ & http://www.neon-project.org/nw/Ontologies \\
\hline
\end{tabular}

Quando há reuso de ontologias pré-existentes, há basicamente duas possibilidades: apenas alinhar a ontologia a outras ontologias, preservando as ontologias originais, ou mesclar ontologias, com a proposta de gerar uma única ontologia a partir das ontologias originais. Segundo Goméz-Perez et al. (2003), diante do estado atual no contexto da Web Semântica, torna-se mais viável estabelecer alinhamentos, ou mapeamentos, entre ontologias do que criar ontologias unificadas.

A metodologia Methontology sugerida por Goméz-Perez et al. (2003) evoluiu bastante a partir de 2006 em decorrência de um grande projeto Europeu do qual os autores da Methontology participaram. A nova metodologia proposta pelo projeto Neon enfatiza a construção de redes de ontologias. O projeto Neon é um projeto de 14,7 milhões de euros, envolvendo 14 parceiros de 6 países europeus, co-financiado pela Comissão Européia, que durou quatro anos e teve início em março de 2006. 


\subsubsection{Ontologias e Informações Espaciais}

Uma das grandes motivações para a utilização de ontologias em geoprocessamento é a possibilidade de assegurar a interoperabilidade de informações espaciais (Agarwal, 2005; Laurini, 2007; Frank, 2007). Ontologias têm um papel essencial na construção de Sistemas de Informações Geográficas, uma vez que permitem o estabelecimento de correspondências e inter-relações entre diferentes domínios de entidades e relações espaciais (Fonseca et al., 2000). Dados e operações espaciais incluem várias dimensões: espaciais, temporais e temáticas (Maué et al., 2009) que podem ter modelos de referência formalizados através de ontologias.

Dados e serviços geo-espaciais contêm símbolos cujos significados não são apenas uma questão de convenção, pois são baseadas na realidade física. Inversamente, unidades de medida seguem uma convenção. Simultaneamente, informação geoespacial está também baseada em percepções humanas, construções sociais, combinando medidas objetivas com julgamentos subjetivos. Prover o mapeamento entre eles é, provavelmente, um dos maiores desafios para tornar a informação geoespacial mais significativa e compartilhável (Kuhn, 2005).

Laurini (2007) sugere a adoção de dois tipos, ou duas fases no processo de desenvolvimento de ontologias em geoprocessamento: (1) pré-consenso, para iniciar o processo da fase chamada por Gómez-Pérez et al. (2005) de aquisição do conhecimento, e (2) pós-consenso, que estaria relacionada às atividades orientadas ao desenvolvimento, mais especificamente à etapa de conceitualização.

$\mathrm{Na}$ primeira fase, as definições existentes seriam coletadas para a construção de um repositório como um método de aprendizagem para a ontologia. Gómez-Pérez et al. (2005) citam alguns métodos de aprendizagem que têm como objetivo a redução de esforços e o aprimoramento durante o processo de aquisição de conhecimento. Dentre os métodos, a utilização de ferramentas que se baseiam na extração de informações a partir de textos é um dos mais enfatizados. Na proposta de Laurini (2007), para promover um ambiente colaborativo, com contribuições de diversos 
especialistas, a proposta inclui a possibilidade de estes conceitos assumirem diversas formas de representação, para facilitarem seu mapeamento posterior, incluindo ferramentas gráficas, utilização de fotos, além de uma lista alfabética de conceitos.

A partir do momento em que todas as definições estão acumuladas, especialistas podem procurar um consenso à luz das reflexões sobre o conjunto de conceitos previamente formado. Somente depois disso passa-se para a segunda fase, em que são feitas a formalização e tradução para linguagem que possa ser lida computacionalmente.

Há que se atentar, ainda, para a questão multilíngüe enfrentada por esta proposta. Laurini (2007) sugere uma forma primitiva de solução através da escolha do inglês como língua para coleção de termos e, posteriormente, a tradução destes para outras línguas. Outras propostas de como tratar a questão multilíngüe podem ser encontradas no projeto Neon (Neon, 2010).

Fonseca et al. (2000) apresentam o desenvolvimento de ontologias para SIG com base em uma aplicação no contexto urbano. Nesta proposta, a ontologia é vista como um componente que coopera para atingir os requisitos do sistema. O desenho é centrado no objeto suportando múltiplas heranças. A definição de um objeto não restringe a forma de como o mesmo será representado.

llustrando essa questão, os autores citam o exemplo de como um poste de eletricidade é modelado. Considerando-se que um poste pode assumir um papel diferente para distintos usuários (ex: companhia de energia, administrador público, etc.) são criadas classes distintas para referenciar o poste no domínio urbano e o poste como entidade espacial que possui uma forma de representação. Dessa forma, é possível garantir que diversas visões possam ser modeladas dependendo dos propósitos de cada usuário. A Figura 4.5a ilustra este exemplo.

Nela, pode-se observar que a entidade poste provém de classes derivadas de duas ontologias, uma ontologia urbana e outra espacial. Diferentemente da classe 
derivada da ontologia urbana, a classe derivada da ontologia espacial pode herdar distintas formas de representação, como um ponto ou um nó (Figura 4.5b).

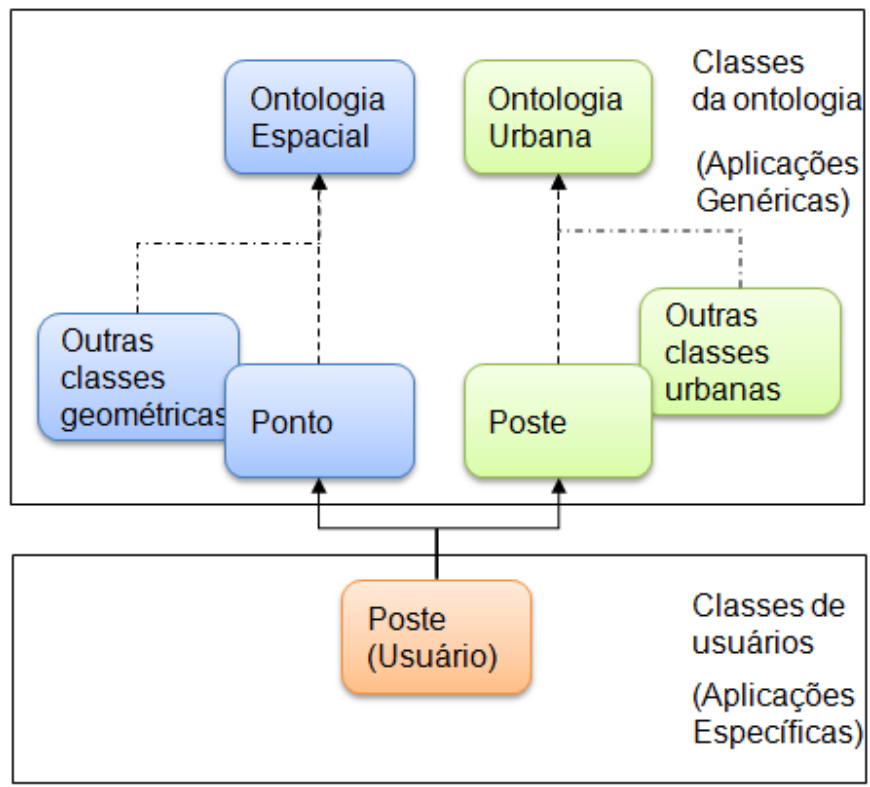

(a)

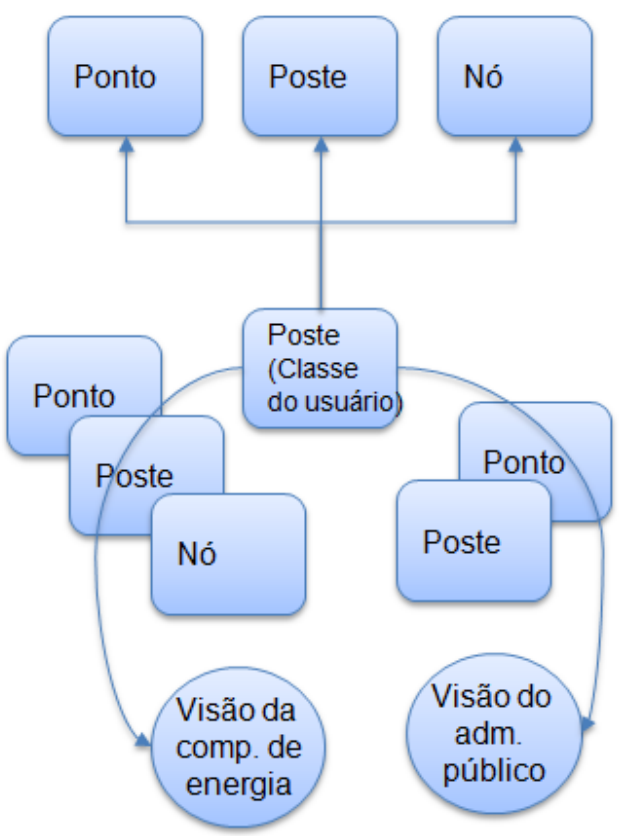

(b)

Figura 4.5 - Ilustração de metodologia para SIG orientados por ontologia. (Adaptado de Fonseca et al., 2000).

Essa proposta permite que diferentes visões possam ser combinadas gerando novas visões. Segue, portanto, o preceito do novo paradigma impulsionado pela Web Semântica em que se privilegia a integração sem, no entanto, depreciar a flexibilidade de adaptação para as diferentes demandas de usuários.

Em busca de manter esse mesmo princípio, Frank (2007) apresenta uma síntese da metodologia por ele proposta que sugere uma ontologia escalonada em vários níveis. O primeiro nível trata da representação de valores que descrevem o objeto. $O$ segundo nível é formado por objetos físicos (ex: pessoas, mesas, etc.) e objetos geográficos (ex: campos, lagos, montanhas, etc.). Objetos geográficos possuem fronteiras não tão definidas como os objetos físicos e estão em sua maioria em duas dimensões. No terceiro nível são representados os objetos socialmente construídos, 
que não possuem uma realidade física, apenas uma convenção social (ex: limites políticos-administrativos).

Câmara et al. (2000) propõem uma ontologia dirigida a ações, que busca capturar as intenções dos usuários e dinâmicas envolvidas na representação computacional. Os autores se baseiam em um conceito de Santos (1997), que define o espaço geográfico como um sistema de entidades e um sistema de ações. A proposta para o desenvolvimento de ontologias considera três componentes:

1. A descrição de um conjunto de entidades, utilizando conceitos do domínio do usuário e relações dessas entidades com representações geométricas no computador.

2. A descrição de um conjunto de ações, incluindo o vocabulário do domínio de conhecimento e suas relações com as operações em SIG e com os dados produzidos.

3. A descrição da intenção de uso desta informação, incluindo os produtos finais e intermediários, proporcionando assim uma perspectiva unificada para modelagem e análise de entidades geográficas que supere a dicotomia campo-objeto.

Agarwal (2005) faz uma série de recomendações para o desenvolvimento de geoontologias:

1. Em qual contexto terminológico a ontologia está inserida e com quais pressuposições?

2. Qual a escala de desenvolvimento da ontologia? Alto-nível ou de domínio?

3. Existem já conceitos e ferramentas não suficientemente exaustivas para a aplicação? Quais são suas limitações?

4. Em qual paradigma a ontologia se insere?

5. Qual o propósito da ontologia, descritivo ou prescritivo?

6. Se teórica, qual o papel prático da ontologia? 
7. Se formalizada, quais são as aplicações finais ou propósitos desta ontologia?

8. Qual é a extensão do domínio? O contexto da aplicação foi delimitado?

9. Quais são as categorias universais do domínio?

10. Quais são os conceitos primários definindo as categorias?

11. Como esses conceitos são identificados e definidos? De onde esses conceitos foram extraídos?

12. De que forma os conceitos estão ligados a entidades, objetos e processos do mundo real?

13. A semântica dos conceitos está explicita? Existem primitivas comuns que podem definir conceitos vagos?

14. Qual o nível de axiomatização?

15. Estes conceitos incluem conceitualizações humanas? Qual o papel do espaço e do tempo, e quais paradigmas espaço temporais e contexto teórico que a ontologia está se baseando?

16. Como as relações entre diferentes entidades podem ser descritas? Estas são definitivas ou vagas?

Minard et al. (2009) investigou ontologias referentes à área de geoprocessamento. As referências das iniciativas investigadas seguem descritas na Tabela 4.2. 
Tabela 4.2 - Relação de ontologias da área de geoprocessamento (Minard et al., 2009).

\begin{tabular}{|c|c|c|}
\hline Domínio & Link & Instituição \\
\hline Gazetteer & http://iridl.Ideo.columbia.edu/ontologies/irigaz.owl & IRI \\
\hline Códigos ISO 19115 & www.geosciml.org/vocabularies/iso-19115-codes.owl & IUGC \\
\hline Localização & http://spypixel.com/2006/tap/tap.xmlns.com/tapplaces.rdf & \\
\hline Hidrologia & http://sim-dl.sourceforge.net/downloads/ & SimCat \\
\hline Geografia & http://www.ncgia.buffalo.edu/i21/i21ontology.html & Universidade de Buffalo \\
\hline Localização & http://www.daml.org/2001/02/geofile/geofile-ont.daml & BBN \\
\hline Geografia & http://ontogeo.ntua.gr/research/goe/geo-ontorequir frame.htm & Geospatial ontology research group \\
\hline Ecologia & http://spire.umbc. edu/ontologies/EthanKeywords.owl & Rocky Mountain Biological Lab \\
\hline Localização fisica & http://frot.org/space/0.1/ & Mudlondon \\
\hline Topografia & http://geoserver.itc.n//lemmens/owl/top10nl dutch v1 test.owl & Lemmens \\
\hline Topografia & http://geoserver.itc.nl/lemmens/owl/top10nl english v2.owl & Lemmens \\
\hline Objetos geográficos & fusionTopoCarto2(ontologies-du-cogit).owl & COGIT-IGN \\
\hline Localização & http://spypixel.com/2006/tap/tap.xmlns.com/tapplaces-schema.rdf & \\
\hline Geografia & http://geoserver.itc.nl/lemmens/owl/ontogeo-v2-47.owl & Lemmens -ITC \\
\hline Urbanismo & http://liris.cnrs.fr/ townto/prototype/Towntology2.zip & Towntology \\
\hline Conceitos espaciais & Geo_swoogle2.owl & MobiLife Space Ontology \\
\hline Geografia & http://ifgi.uni-muenster.de/ janowicz/downloads/FTTV01.owl & Muenster \\
\hline Erosão & http://mida.ucc. ie/ont/20080124/theme.owl & MIDA \\
\hline Geografia & http://reliant.teknowledge.com/DAML/Geography.owl & ASCS \\
\hline Transporte & http://reliant.teknowledge.com/DAML/Transportation.owl & ASCS \\
\hline Agências de viagens & http://homepages.cwi.nl/ troncy/DOE/eon2003/Tourism-DOEExportOWL.owl & EON2003 \\
\hline Ecoregião & http://www.acsu.buffalo.edu/ bittner3/Thomas Bittner files/bailey.owl & Universidade de Buffalo \\
\hline Meio-ambiente & http://geoserver.itc.nl/aster/Ontology/EnvironmentalGeospatialServices.owl & ITC \\
\hline Ciências da Terra & http://www.mindswap.org/2004/multipleOnt/FactoredOntologies/SweetJPL/sweet-full.owl & NASA - SWEET \\
\hline Divisão administrativa & http://www.ordnancesurvey.co.uk/oswebsite/ontology/v1/AdministrativeGeography.owl & Ordnance Survey \\
\hline Geografia & http://rdf.insee.fr/geo/archive-2003.zip & INSEE \\
\hline Géographie & ifgi.unimuenster.de/ $\sim$ klien/tgis/LandscapeClassification.owl & Univ. Muenster \\
\hline Hidrologia & http://www.ordnancesurvey.co.uk/oswebsite/ontology/Hydrology/v2.0/Hydrology.owl & Ordnance Survey \\
\hline eGoverno & Terregov.owl & Terregov \\
\hline Lugar de edificações & http://www.ordnancesurvey.co.uk/oswebsite/ontology/BuildingsAndPlaces/v1.1/BuildingsAndPlaces.owl & Ordnance Survey \\
\hline Agricola & http://www.fao.org/aims/aos/cwr.owl & AGROVOC \\
\hline Ecologia & http://wow.sfsu.edu/ontology/rich/EcologicalConcepts.owl & Rocky Mountain Biological Lab \\
\hline Cenas da Terra & http://iri.columbia.edu/\%7Ebenno/gcmd.owl & NASA EOS \\
\hline Cenas da Terra & geobrain.laits.gmu.edu/ontology/2004/11/gcmdscience.owl & NASA EOS \\
\hline Cenas da Terra & http://iri.columbia.edu/\%7Ebenno/IRISWEET.owl & IRI \\
\hline Top-level & http://www.ontologyportal.org/translations/SUMO.owl & IEEE \\
\hline Recuperação de um mapa & Map-ont.owl & DAML Map \\
\hline Caracteristicas de lugares & Feature-location owl & Lemmens -ITC \\
\hline
\end{tabular}

\section{Estudos sobre ontologias estão apenas começando a considerar aspectos temporais} e mudanças. Ontologias sobre o tempo são um campo vasto, com uma terminologia ainda confusa. Para muitos autores, eventos são mudanças no estado do mundo que são considerados uma unidade sem duração e processos são uma mudança que é afetada por um período entendido de tempo. Dois métodos para formalizar são 
atualmente sugeridos: centrados em processos ou estados. O primeiro usa lógica (temporal) para modelar estados e a transição entre eles. O segundo descreve operações que mudam os estados. A próxima fronteira são ontologias dinâmicas, que descrevam não apenas processos da realidade que mudam de estado, mas também permitam construir uma ontologia da mudança (Frank, 2007).

\subsubsection{Ontologias de Processos Logísticos}

Apesar do uso de ontologias para integração de dados espaciais não ser uma novidade, o estudo de ontologias centradas em processos é um assunto em recente discussão. Ontologias centradas em processos são aquelas em que, em seu desenvolvimento, primeiramente identificam-se os processos, entidades e propriedades, seguidos pelas relações entre eles (Devaraju e Kuhn, 2010).

A discussão sobre processos, eventos e outros fenômenos temporais acontece há algum tempo na comunidade de Geoprocessamento (Hornsby e Egenhofer, 2000; Pequet 2005, Worboys, 2005). Entretanto as pesquisas na área ainda não evoluíram para um arcabouço conceitual estável e consensual formalizado em um vocabulário bem definido que permita uma representação explicita de processos, eventos e seus participantes (Devaraju e Kuhn, 2010).

O uso de ontologias para definição conceitual de processos é um caminho atualmente indicado por diversos autores (Agarwal, 2005; Frank, 2007; Albrecht et al., 2008; Devaraju e Kuhn, 2010). No entanto, a complexidade do tema tem prorrogado muito o estabelecimento de definições consensuais sobre conceitos relativos aos processos. Na visão de Albrecht et al. (2008) um caminho complementar à criação de uma ontologia de alto nível referente à modelagem de processos seria o acúmulo de modelos de processos, mesmo que ainda distantes de um acordo sobre os termos. Através do intenso reuso e discussão sobre esses modelos talvez seja possível alcançar o consenso sobre os conceitos relacionados. 
Modelos relacionados aos processos logísticos descrevem atividades, organizações, meios de transporte, produtos e serviços envolvidos. No entanto, modelos em sistemas de apoio aos processos logísticos precisam de formalização semântica para permitir integração automática de dados entre organizações (Leukel e Kirn, 2008) e a utilização e composição de componentes de sistemas e modelos pela Web (Brock et al., 2005).

Inconsistências semânticas na cadeia de suprimentos devem-se a diferenças culturais e de contexto entre empresas, pessoas que, mesmo dentro da mesma empresa, tendem a ter seu próprio vocabulário para representar domínios de trabalho diferentes, parceiros da cadeia de suprimentos que possuem aplicativos e sistemas proprietários desenvolvidos independentemente (Ye et al., 2008). A integração de tarefas entre empresas é mais do que integração de dados e requer a integração no nível semântico (Smirnov et al., 2007).

Nos últimos anos as ontologias têm atraído tanto indústria quanto a comunidade científica na área de logística (Leukel e Kirn, 2008). A razão de ontologias se tornarem tão populares tem a ver, em grande parte, com o que prometem: uma compreensão comum e partilhada de algum domínio, que possa ser transmitida entre pessoas e sistemas de aplicação (Fensel et al., 2003). Ontologias de logística, no entanto, ainda não atingiram um alto nível de visibilidade e maturidade, e raramente estão disponíveis na Web (Leukel e Kirn, 2008).

Um exemplo desta falta de maturidade nas ontologias de processos logísticos descritas em artigos científicos é a falta de consenso sobre a utilização dos termos, processos, eventos e atividades logísticas.

Peng et al. (2007) utilizam a definição de processos que consta no WordNet (um grande banco de dados léxico - http://wordnet.princeton.edu/) que define processo como sendo um fluxo particular de um conjunto de ações destinados a alcançar um determinado resultado. Os autores propõem uma série de definições de termos relacionados a processos logísticos: (1) processos logísticos são uma composição de ações logísticas e eventos logísticos. (2) ações logísticas são definidas como uma coleção de eventos e (3) eventos ocorrem em um ponto no tempo. O evento 
teria o único papel de terminar uma situação e começar outra nova, marcando uma transição entre situações.

A modelagem de Peng et al. (2007) parte de um conjunto de processos e eventos (Tabela 4.3) base sobre a qual é definida uma ontologia para logística.

Tabela 4.3 - Processos e eventos logísticos (Peng et al., 2007).

\begin{tabular}{|c|c|}
\hline Processo Logístico & Ação Logística \\
\hline \multirow{2}{*}{ Aquisição } & Comprar_Material \\
\hline & Transferir_Material \\
\hline \multirow{2}{*}{ Produção } & Fazer_Partes \\
\hline & Juntar_Partes \\
\hline \multirow{2}{*}{ Armazenamento } & Mover_Produtos \\
\hline & Empilhar_Produtos \\
\hline \multirow{2}{*}{ Inventário } & Selecionar_Produtos \\
\hline & Registrar_Produtos \\
\hline \multirow{3}{*}{ Manutenção } & Estocar \\
\hline & Aquecer \\
\hline & Resfriar \\
\hline Pedido & Aceitar_Pedido \\
\hline \multirow{3}{*}{ Empacotar } & Pegar_Pedido \\
\hline & Mover_Produtos \\
\hline & Empacotar_Produtos \\
\hline \multirow{2}{*}{ Carregamento } & Mover_Produtos_Empacotados \\
\hline & Empilhar_Produtos_Empacotados \\
\hline \multirow{2}{*}{ Transporte } & Transferir_Produtos \\
\hline & Processamento_Durante_Transfer \\
\hline \multirow{2}{*}{ Descarregar } & Movimentar_Produtos \\
\hline & Empilhar_Produtos_Recebidos \\
\hline \multirow{2}{*}{ Distribuição } & Escolher_Produtos \\
\hline & Transferir_Produtos \\
\hline \multirow{2}{*}{ Logística Reversa } & Transferir_Produtos \\
\hline & Devolver_Produtos \\
\hline
\end{tabular}

Já Martins et al. (2006) utilizam o termo atividades para aquilo que Peng et al. (2007) chamam de ações. No entanto, o conjunto de processos e atividades logísticas não 
corresponde exatamente aos processos e ações propostas por Peng et al. (2007) (Tabela 4.4).

Tabela 4.4 - Descrição dos processos e atividades logísticas proposta por Martins et al. (2006).

\begin{tabular}{|c|c|}
\hline Processo Logístico & Atividade \\
\hline Aquisição & $\begin{array}{l}\text { Solicitação de compras (ordem de compras) } \\
\text { Seleção dos fornecedores } \\
\text { Processamento e emissão do pedido }\end{array}$ \\
\hline $\begin{array}{l}\text { Recepção e estocagem de } \\
\text { insumos }\end{array}$ & $\begin{array}{l}\text { Recepção } \\
\text { Controle de qualidade e quantidade } \\
\text { Estocagem de produtos/mercadorias } \\
\text { Distribuição interna de produtos }\end{array}$ \\
\hline Produção & $\begin{array}{l}\text { Planejamento e controle da produção } \\
\text { Produção } \\
\text { Re-trabalho }\end{array}$ \\
\hline Embalagem e expedição & $\begin{array}{l}\text { Controle de pedidos } \\
\text { Controle de qualidade de saída } \\
\text { Embalagem } \\
\text { Documentação } \\
\text { Carga } \\
\text { Expedição }\end{array}$ \\
\hline Distribuição & $\begin{array}{l}\text { Tranporte } \\
\text { Transbordo } \\
\text { Controle intermediários } \\
\text { Manuseio } \\
\text { Entrega }\end{array}$ \\
\hline Informações & $\begin{array}{l}\text { Sistema de informações de pedidos de clientes, ordens de } \\
\text { compra, problemas na qualidade e no transporte, previsão de } \\
\text { vendas e de compras, compartilhamento das informações, etc }\end{array}$ \\
\hline
\end{tabular}

Pawlszcyk et al. (2004) adotam conceitos relativos a processos, planos e atividades baseados na ontologia de empresas proposta por Uschold et al. (1996). Pawlszcyk 
et al. (2004) desenvolvem uma ontologia para processos logísticos referentes à estratégia de customização em massa (mass customization ${ }^{1}$ ).

$\mathrm{Na}$ ontologia de empresas, Uschold et al. (1996) definem plano como sendo uma especificação de uma ou mais atividades, uma caracterização de algo que restringe o leque de possíveis atividades. Atividades são definidas como sendo algo que é feito ao longo de um determinado intervalo de tempo. As atividades podem ser decompostas ou detalhadas em sub-atividades, e realizadas por uma ou mais intervenientes atividades. Processos, por sua vez, são tratados apenas como "especificações de processos" pelo fato do termo processo poder ser associado a muitas interpretações erradas. Um processo-especificado (Processo-Spec) é concebido como uma especialização de um plano que se destina ou pode ser executado mais de uma vez, em seguida.

O termo atividades aparece em dois níveis da hierarquia de conceitos propostos na ontologia de Pawlszcyk et al. (2004). Em um primeiro nível, atividade é relacionada à definição proposta pela ontologia de empresas, como sendo um conjunto de planos, que por sua vez engloba um conjunto de processos. No outro nível atividade é classificada como uma subclasse de processos (Figura 4.6).

\footnotetext{
${ }^{1}$ Customização em massa refere-se ao processo relacionado à individualização do mercado de massa, ou seja, da especificação de produtos e serviços para atender necessidades do cliente, a um preço acessível e razoável (Pawlszcyk et al., 2004).
} 


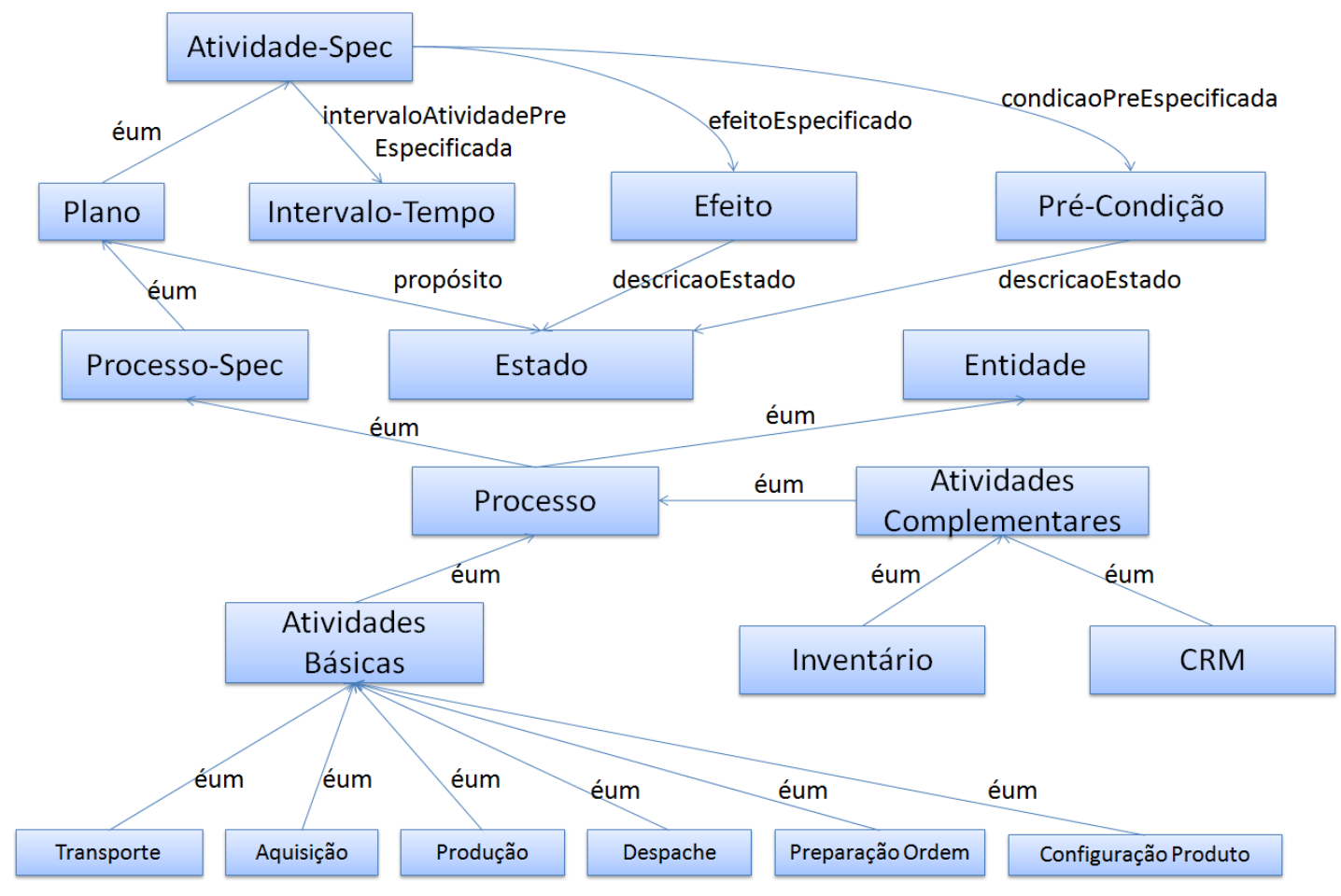

Figura 4.6 - Ontologia proposta por Pawlszcyk et al. (2004)

Observa-se ainda que as atividades (do nível mais baixo) tratadas na ontologia equivalem aos processos propostos por Martins et al. (2006), Peng et al. (2007) e Leukel e Kirn (2008).

Leukel e Kirn (2008) partem do conhecimento consolidado contido no modelo de referência SCOR (Supply Chain Operations Reference) para desenvolver uma ontologia de domínio referente aos processos logísticos. Nessa ontologia, a categoria de processos logísticos fornece não apenas um nível mais detalhado de processos, através de seus elementos de processos, como também enriquece as categorias de processos com métricas e melhores práticas. Infelizmente os autores não apresentam no artigo detalhes da ontologia, no entanto informações adicionais podem ser encontradas no site do projeto Brein (Business objective driven REliable and Intelligent grids for real busiNess). O projeto Brein tem como objetivo levar os conceitos desenvolvidos em projetos de pesquisa Grid, como por exemplo de Organizações Virtuais, para um modelo de negócio mais centrado, utilizando métodos de inteligência artificial, sistemas inteligentes e web semântica. 
Dentre as referências encontradas que tratassem de uma conceitualização geral de processos de logística através de ontologias, o trabalho de Ye et al. (2008) foi o que apresentou maiores detalhes. Ye et al. (2008) apresentam uma ontologia da cadeia de suprimentos escrita de forma modular para viabilizar maior reuso da ontologia e facilitar sua manutenção. A ontologia é decomposta em cinco módulos: Estrutura, Atividade, Recurso, Item e Gerenciamento (Figura 4.7).

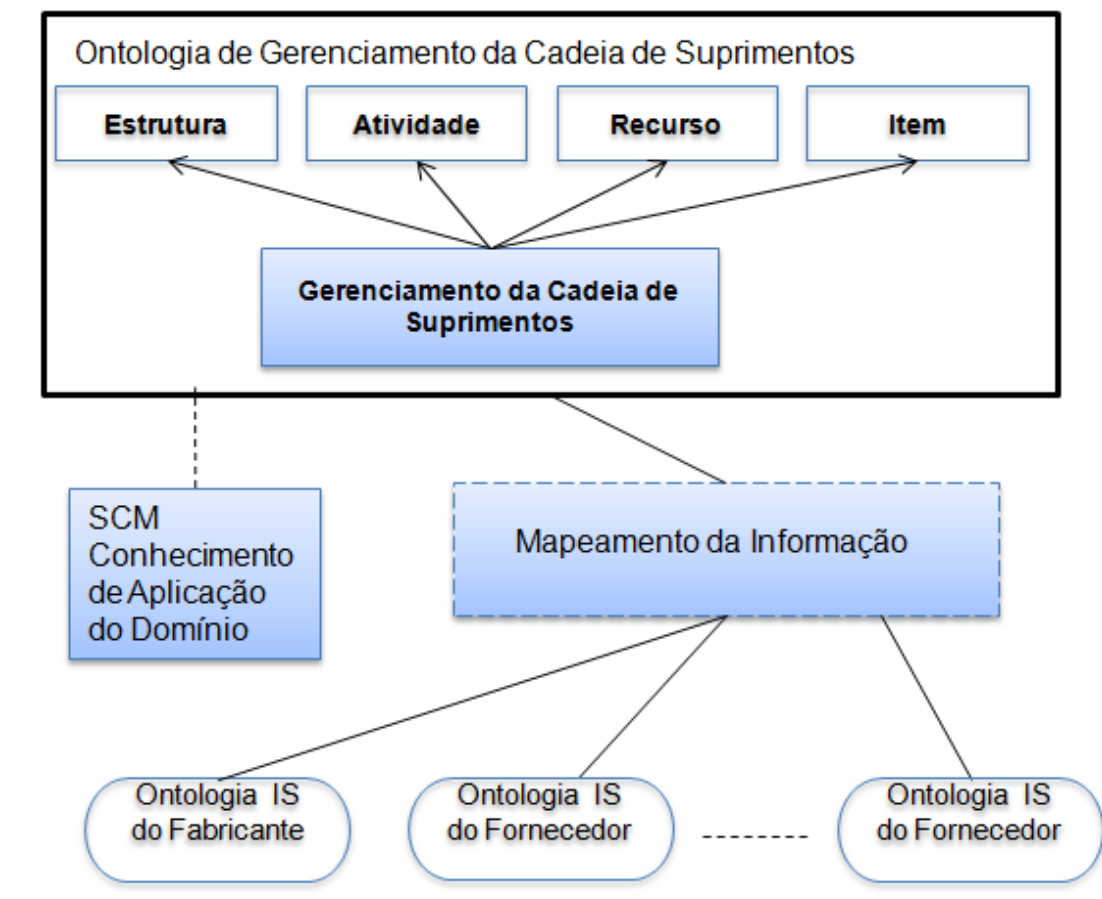

Legenda:

Relação de Dependência

Instanciação e Especialização:

Relação de Mapeamento

Figura 4.7 - Estrutura modular da ontologia proposta por Ye et al. (2008). 
Estes módulos propostos por Ye et al. (2008) constituem uma hierarquia de dependência onde o modulo Gerenciamento depende dos outros quatro módulos e cada um define um conjunto de termos relacionados. O módulo Estrutura define os mecanismos de representação das estruturas da cadeia de suprimentos, estratégias, objetivos e processos. O módulo Atividade proporciona vocabulários para descrever as atividades, sua hierarquia, e relações de dependência nos sistemas de gerenciamento da cadeia de suprimentos. Os módulos Recurso e Item especificam primitivas de linguagem para representar conceitos e relações relacionadas ao recursos e objetos de negócio. Finalmente, o módulo Gerenciamento define as relações de restrição nos processos de gerenciamento e operações da cadeia de suprimento (Figura 4.8).

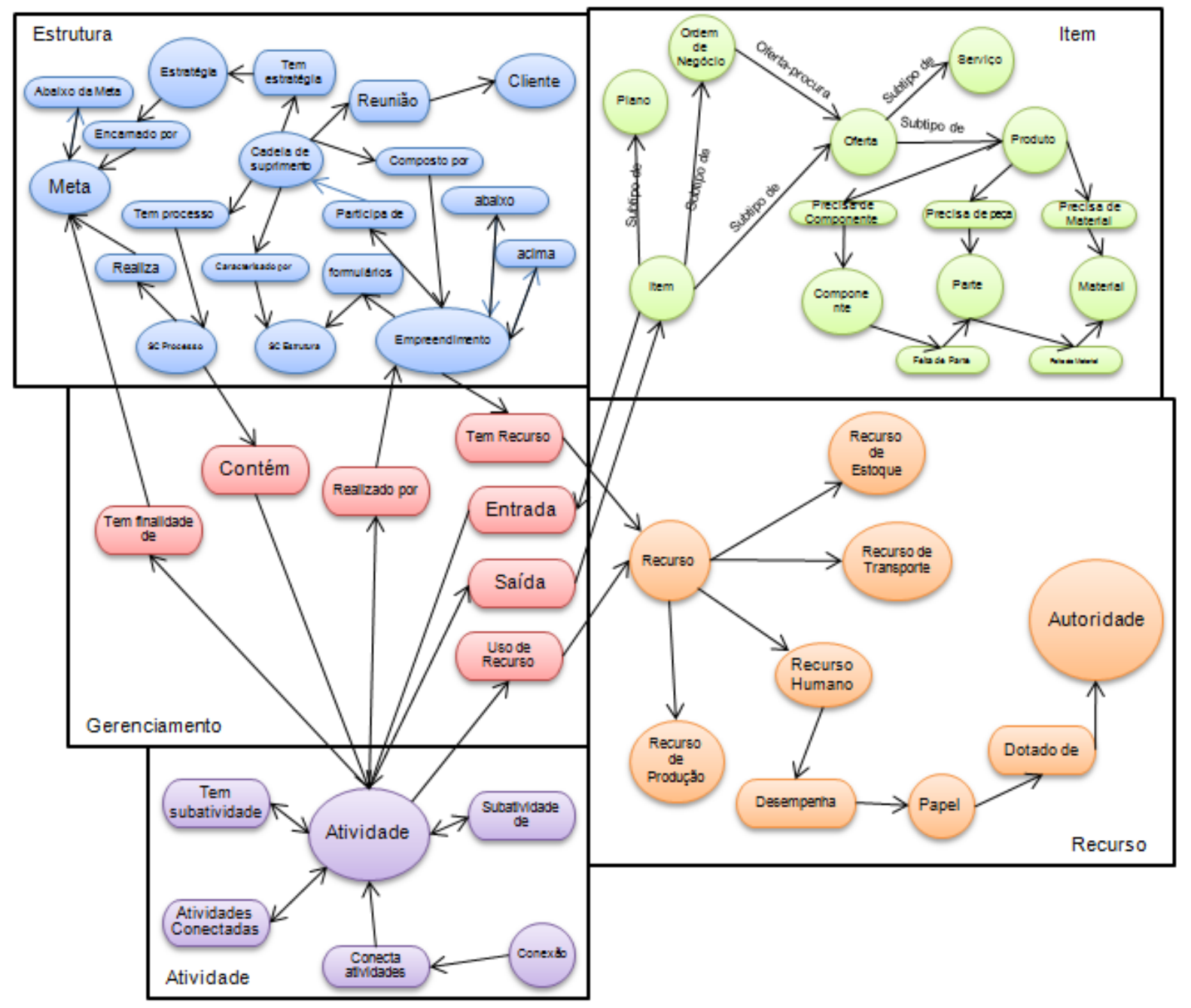

Figura 4.8 - Representação gráfica das classes e relações básicas da ontologia proposta por Ye et al. (2008). 
Alguns autores, no entanto, utilizam ontologias em logística sem descrever os processos de forma geral, focando em questões de interesse específico, como os trabalhos apresentados por Giménez et al. (2008) que tratam sobre um processo de manufatura de balas e, Jinbing et al (2008), que utilizam a ontologia como suporte ao processo de controle de inventário.

Giménez et al. (2008), têm como foco o gerenciamento e a padronização da informação relacionada aos produtos, de tal forma que permita uma consistência semântica e viabilize a integração dos diversos atores das variadas atividades logísticas envolvidas na cadeia de suprimentos. Os autores sugerem uma forma de organizar os dados e informações em diferentes níveis de abstração durante todo o ciclo de vida do produto, através de duas estruturas hierárquicas: uma chamada de estrutural, referente às partes que compõem um produto (ex: papel da bala e bala, Figura 4.9) e outra hierarquia de abstração, referente aos diferentes tipos de especificação e diferenciação do produto (bala de fruta, bala de leite, bala de fruta de morango, bala de leite com café, etc., Figura 4.10).

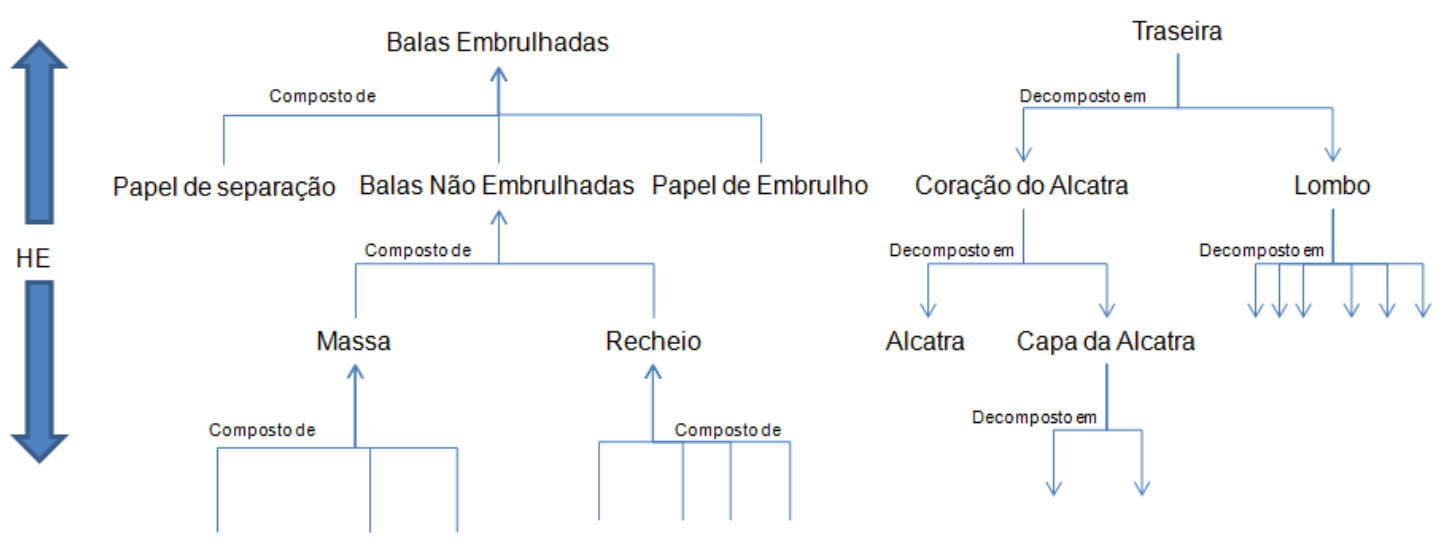

Figura 4.9 - Hierarquias de estrutura formalizada pela ontologia elaborada para produtos manufaturados na cadeia de suprimentos. 


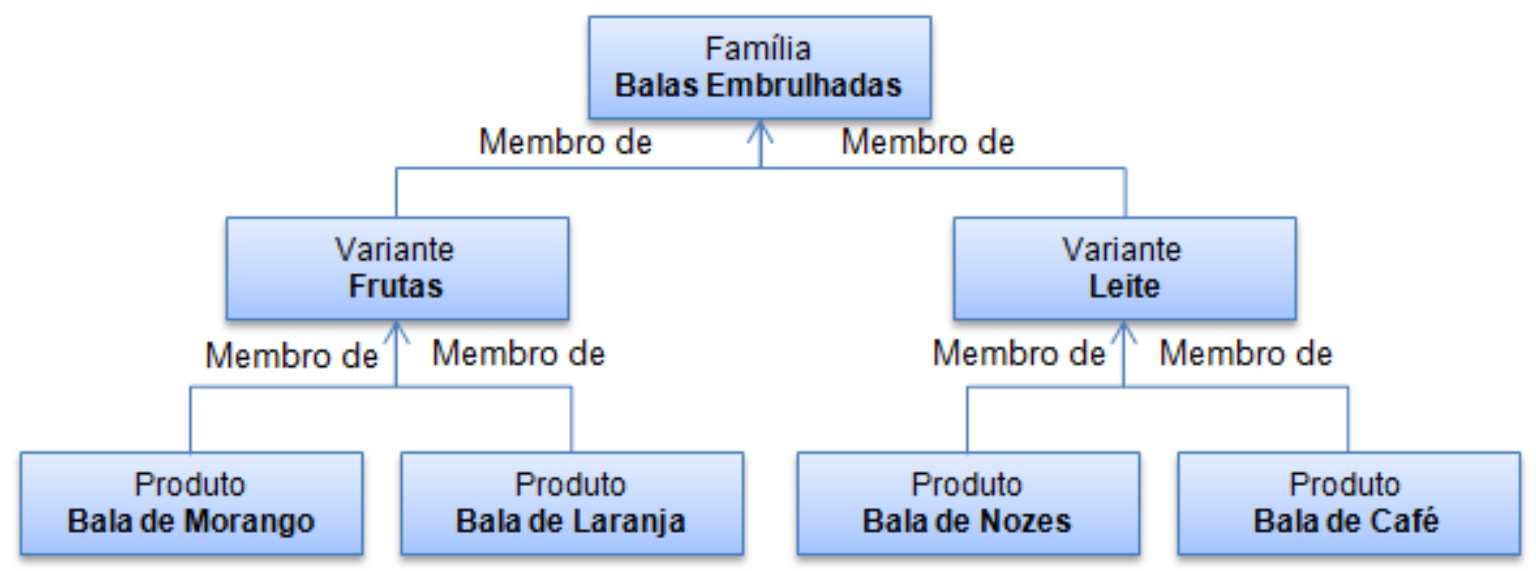

Balas Embrulhadas (Hierarquia Abstrata)

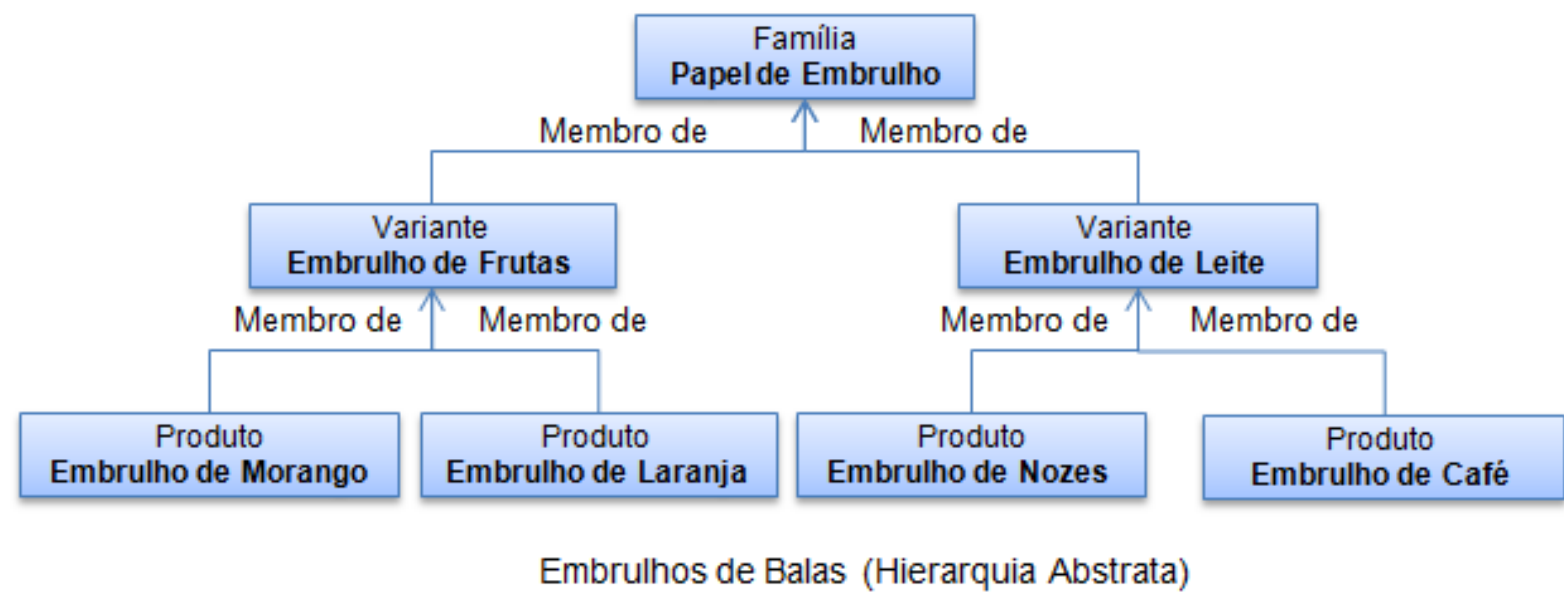

Figura 4.10 - Hierarquias de abstração formalizada pela ontologia elaborada para produtos manufaturados na cadeia de suprimentos.

Jinbing et al (2008), ao implementarem um sistema baseado em ontologias para integrar dados de diferentes sistemas de apoio à decisão em logística para o processo de gerenciamento de inventário (Figura 4.11), se preocuparam com o gerenciamento no nível estratégico. Segundo os autores, os softwares de apoio à decisão no mercado referem-se geralmente ao nível operacional, não priorizando os níveis de gerenciamento estratégico e tático, fazendo com que os tomadores de 
decisão nesses níveis tenham que se basear mais em aspectos subjetivos, como experiência e intuição, do que analíticos.

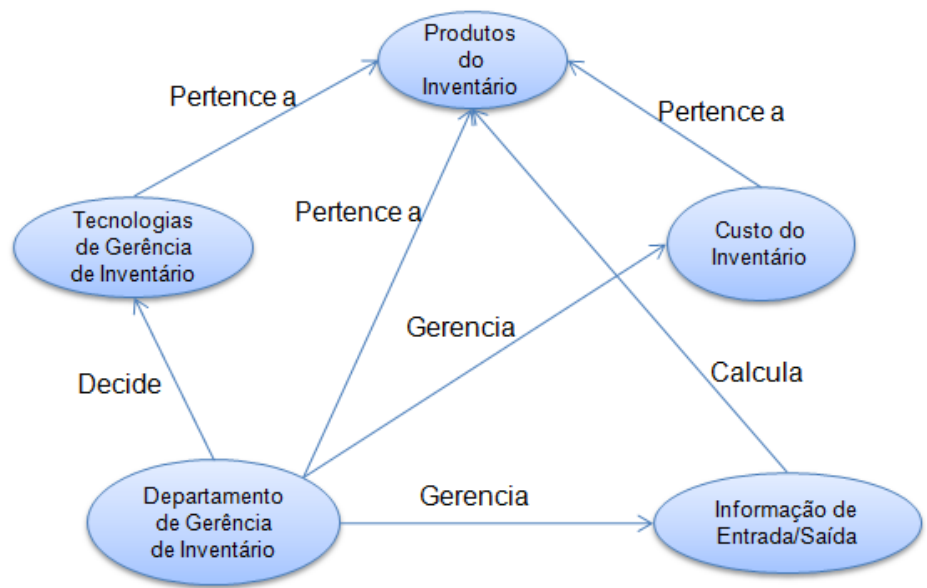

Figura 4.11 - Relacionamento entre classes de uma ontologia de inventário em logística (Jingbing et al., 2008).

São poucos os artigos que apresentam detalhes sobre a implementação das ontologias ou referências para o reuso das mesmas. Martins et al. (2006) e Himoff et al. (2006) são exemplos deste caso.

Martins et al. (2006) desenvolveram um sistema colaborativo, baseado em ontologias, para o controle de custos utilizando a teoria de custeio ABC para relacionar atividades e custos, mas não descrevem detalhadamente classes e relacionamentos da ontologia.

Himoff et al. (2006) propõem o uso de uma arquitetura de ontologias compondo um sistema de apoio à decisão no caso de programação de transporte ("Road Transportation Schedule"). O sistema usa uma ontologia de domínio (proprietária), que descreve formalmente o conhecimento na área de negócios, uma ontologia que descreve formalmente elementos de contexto do problema, que chamam de ontologia da cena, e uma ontologia referente aos objetivos a serem atingidos (por exemplo: aumentar o lucro, maximizar o nível de serviço, diminuir o risco).

Além de aplicações específicas de ontologias em processos logísticos algumas abordagens diferenciadas sobre o que retratar nas ontologias merecem ser destacadas. Peng et al. (2007) se preocupam com a incorporação de informações 
sobre o contexto envolvido nos processos logísticos e Brock et al. (2005) propõem o uso de ontologias para registrar a semântica envolvida em modelagens matemáticas.

Ao modelar o contexto Peng et al. (2007) partem do pressuposto que o entendimento comum sobre uma determinada situação é fundamental em um processo de colaboração dentro de uma cadeia de suprimentos (Figura 4.12). Os elementos básicos considerados pelos autores para modelar a situação foram: um conjunto de informações sobre contexto (tempo, localização, etc., Figuras 4.13) e um conjunto de estados, ou condições (estado do produto, estado do ambiente, etc., Figura 4.14).

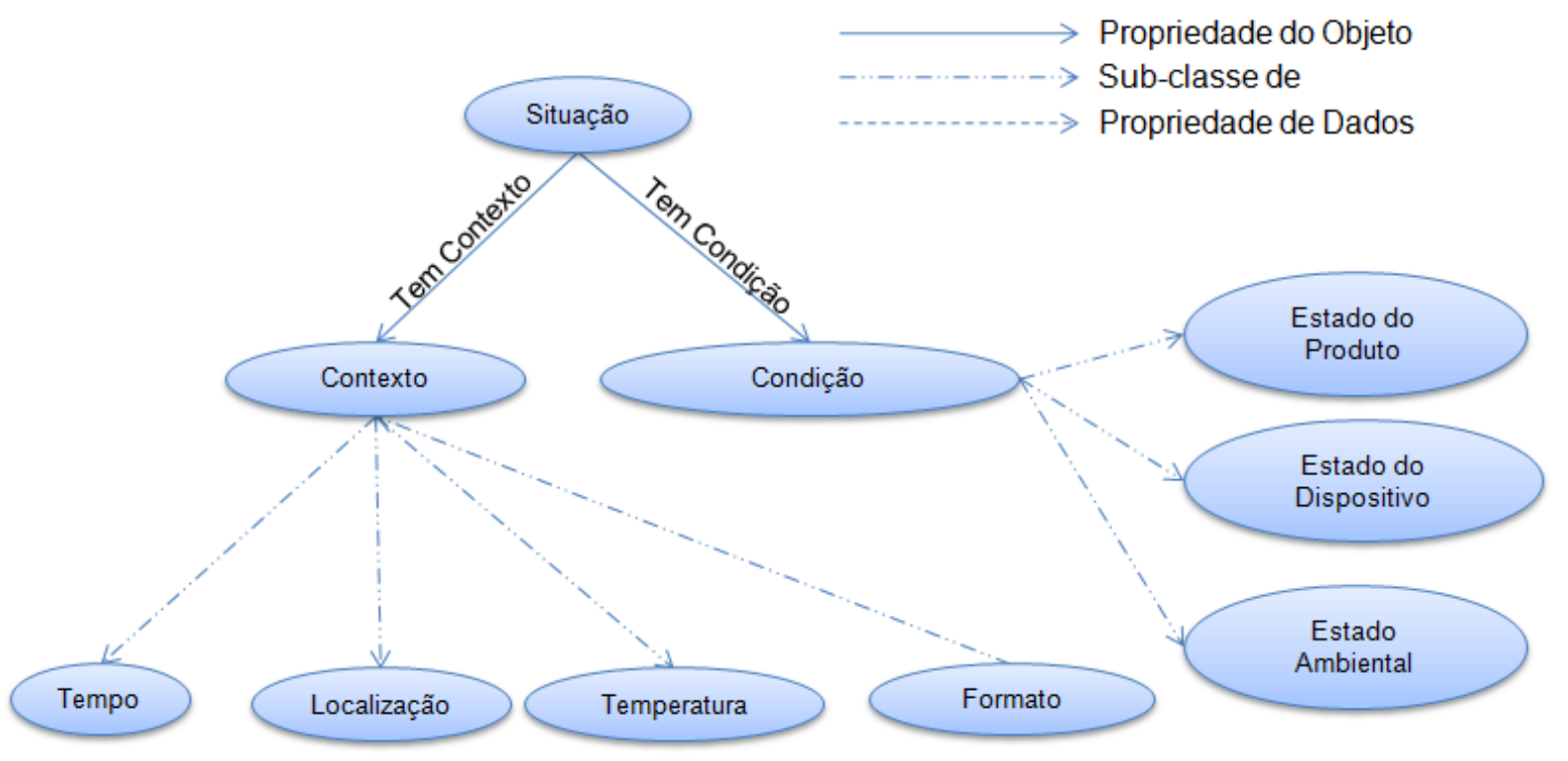

Figura 4.12 - Ontologia logística baseada em contexto e condições (ou estados) proposta por Peng et al. (2007). 


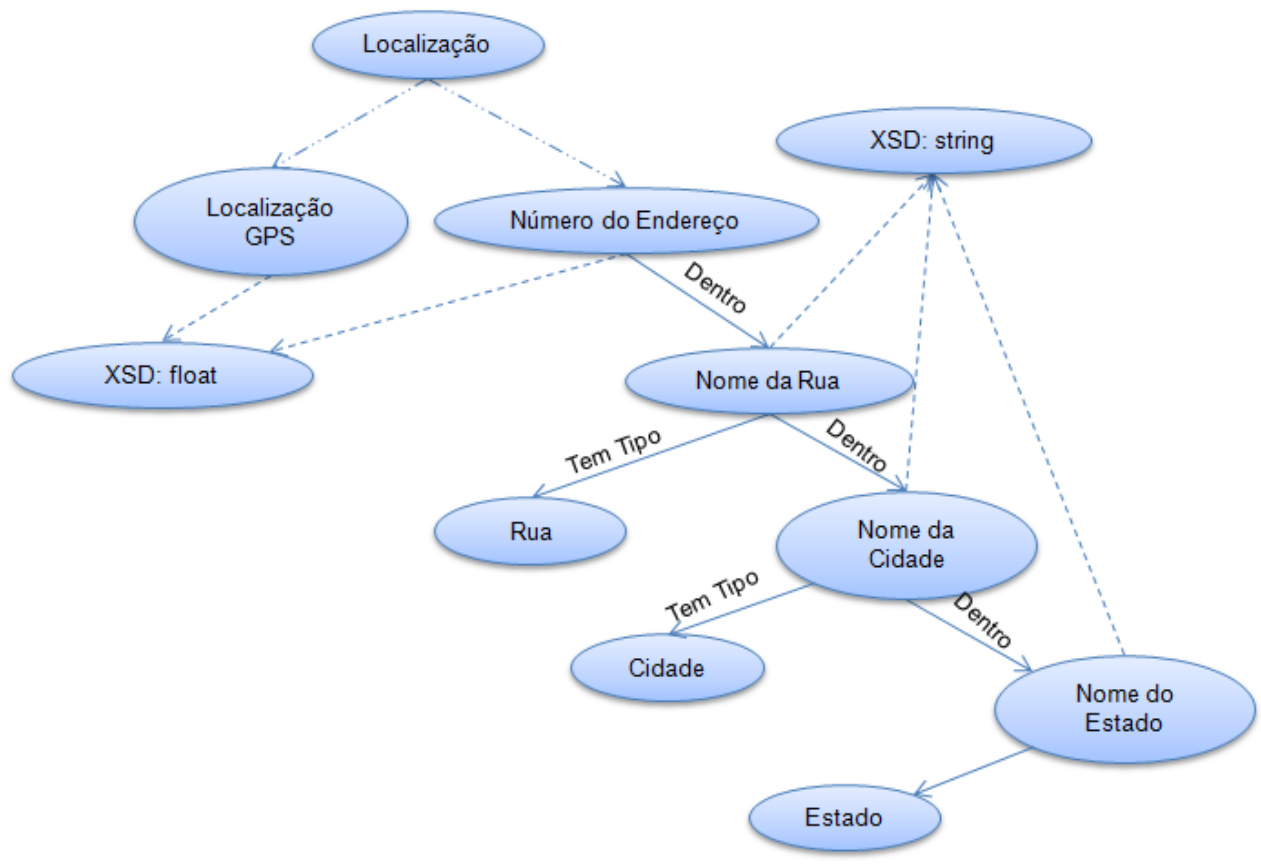

Figura 4:13 - Detalhamento da classe de contexto localização proposta por Peng et al. (2007).

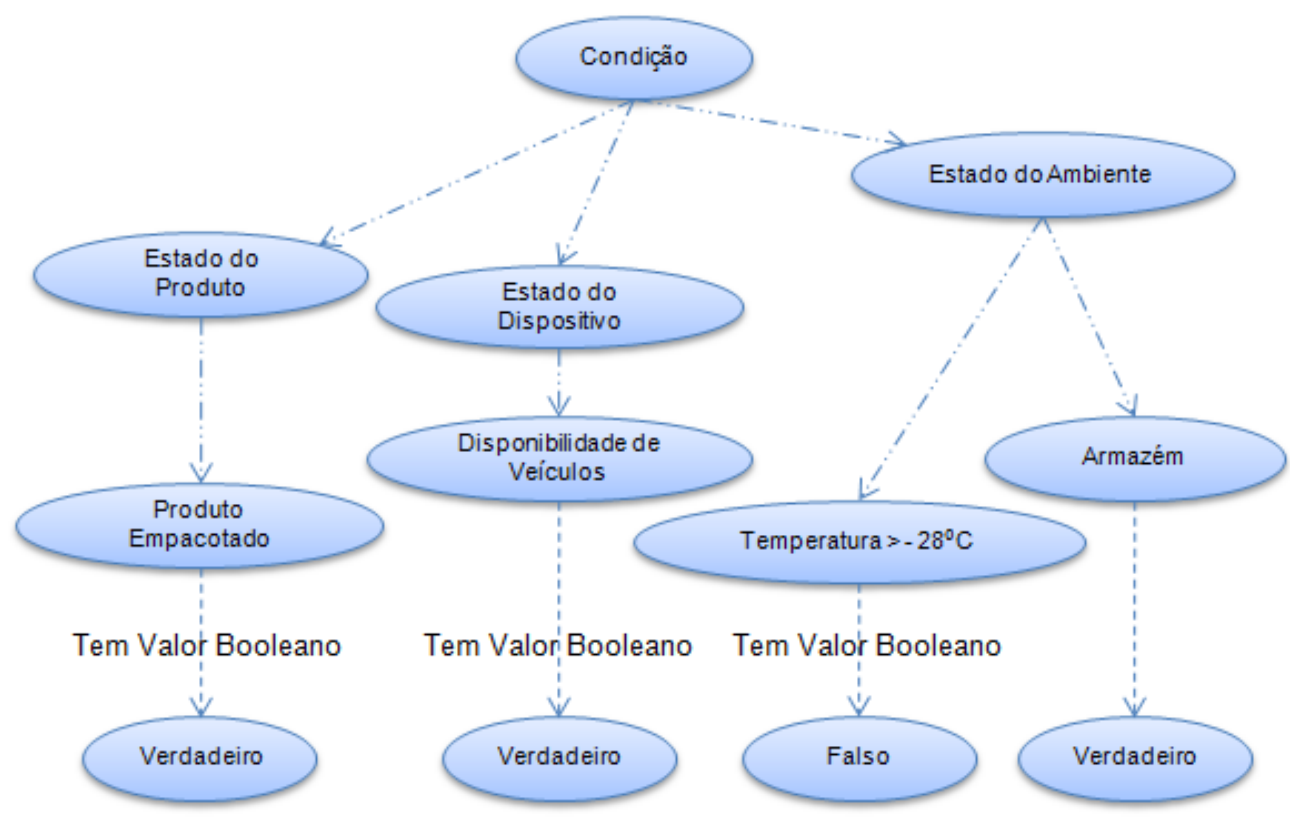

Figura 4.14 - Detalhamento da classe condições (ou estados) proposta por Peng et al. (2007). 
A proposta de Brock et al. (2005) para a criação de um sistema interoperável com foco no uso de modelos matemáticos envolve um conjunto de linguagens e protocolos como base para a modelagem semântica que tem como ponto de partida a classificação de tipos de dados de entrada desses modelos matemáticos. Parte-se do pressuposto que modelos para soluções de problemas em logística que utilizem os mesmos tipos de dados de entrada, tenham o mesmo problema inicial, sejam interoperáveis em termos de dados, e dêem uma indicação indireta sobre o tipo de método (algoritmo) utilizado. O propósito final é obter ganhos de produtividade em termos de tempo de desenvolvimento reduzido e aplicação adequada dos modelos na prática. Os autores defendem o uso de ontologias "peso-leve", abstrações e taxonomias com perspectivas múltiplas que possam ser fundidas pois estruturas rígidas e inflexíveis contradizem a própria natureza da logística.

Wendt et al. (2002), acreditam que o sucesso do uso de ontologias dependerá fortemente da facilitação do processo de fusão, em termos de apoio ao mapeamento explícito de sinônimos, bem como a identificação automática dos núcleos de duas ou mais ontologias, que levarão a uma generalização para uma ontologia comum (uma ontologia de "alto nível"). Os autores pesquisaram esse processo de fusão partindo de duas ontologias, uma referente à logística de produção e outra referente à logística de hospitais, mas não demonstraram detalhes da metodologia para mapeamento e fusão de ontologias utilizado.

Até então o foco dos artigos apresentados tratava mais especificamente sobre detalhes das ontologias, sem, no entanto, contextualizar claramente os sistemas nos quais as ontologias são utilizadas. Para finalizar esta revisão sobre ontologias para processos logísticos serão comentados trabalhos relacionados ao uso de ontologias em aplicações práticas.

Smirnov et al. (2007, 2008, 2009 e 2010) propõem o uso de ontologias como base para sistemas de suporte à decisão em problemas dinâmicos de logística. Os autores têm publicado nos últimos anos uma série de aplicações que tem em comum o uso de ontologias para o gerenciamento de informações referentes (1) ao domínio de logística, (2) aos métodos de solução de problemas logísticos e, em especial, (3) à modelagem do contexto de situações em processos logísticos. 
Processos de tomada de decisão em domínios dinâmicos se caracterizam pela necessidade de processar e integrar dinamicamente informação de fontes heterogêneas e fornecer elementos do contexto ao usuário para auxiliar na análise da situação corrente (Smirnov et al., 2007). As decisões referentes a um problema de roteirização, por exemplo, em uma situação de socorro às vítimas de acidentes, decorrentes de desastres naturais envolvem a necessidade de se obter informações sobre o contexto tais como (1) quais vias estão sem acesso, (2) qual o local das vítimas, (3) qual a localização dos hospitais, (4) qual a disponibilidade de equipes de emergência e onde estão localizadas, e ainda (5) como as condições do tempo podem influenciar o resgate (Figura 4.15).

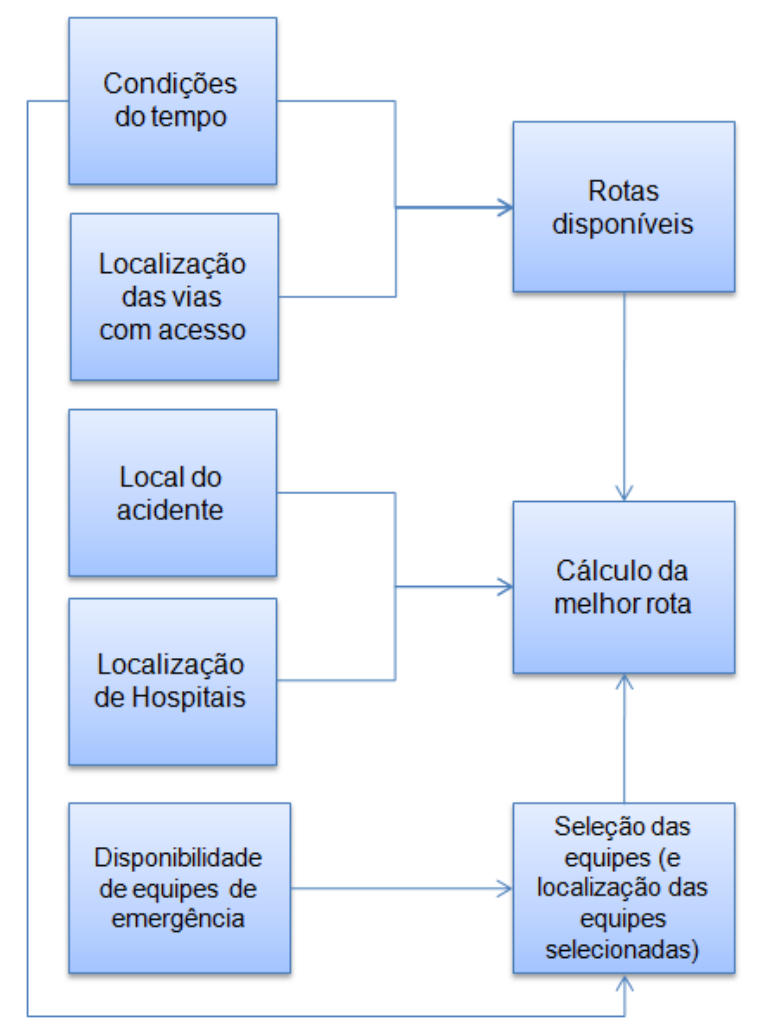

Figura 4.15 - Modelagem do contexto em operações de atendimento à situação de emergência. Smirnov et al. (2009).

A modelagem do contexto é essencial em sistemas de apoio à decisão em processos logísticos que utilizam agentes inteligentes (Smirnov et al., 2010). A modelagem de sistemas multi-agentes na área de desenvolvimento de aplicações 
distribuídas é um tema que tem recebido atenção atualmente na pesquisa científica. Esses sistemas oferecem benefícios como a interoperabilidade (uma vez que as interações entre agentes são baseadas em especificações claras) e escalabilidade (já que sistemas multi-agentes podem ser estendidos com novos tipos de agentes e/ou funções dos agentes já existentes podem ser modificadas).

Nos trabalhos de Smirnov e sua equipe, o contexto é modelado através de: (1) um contexto abstrato que é um modelo para integração de informação e conhecimento relevante para o problema, formalizado através de ontologias; e (2) um contexto operacional que instancia o contexto abstrato com dados provenientes das fontes de informação ou resultados de cálculos baseados nas funções especificadas no contexto abstrato (Smirnov et al. 2007) conforme ilustrado na Figura 4.16.

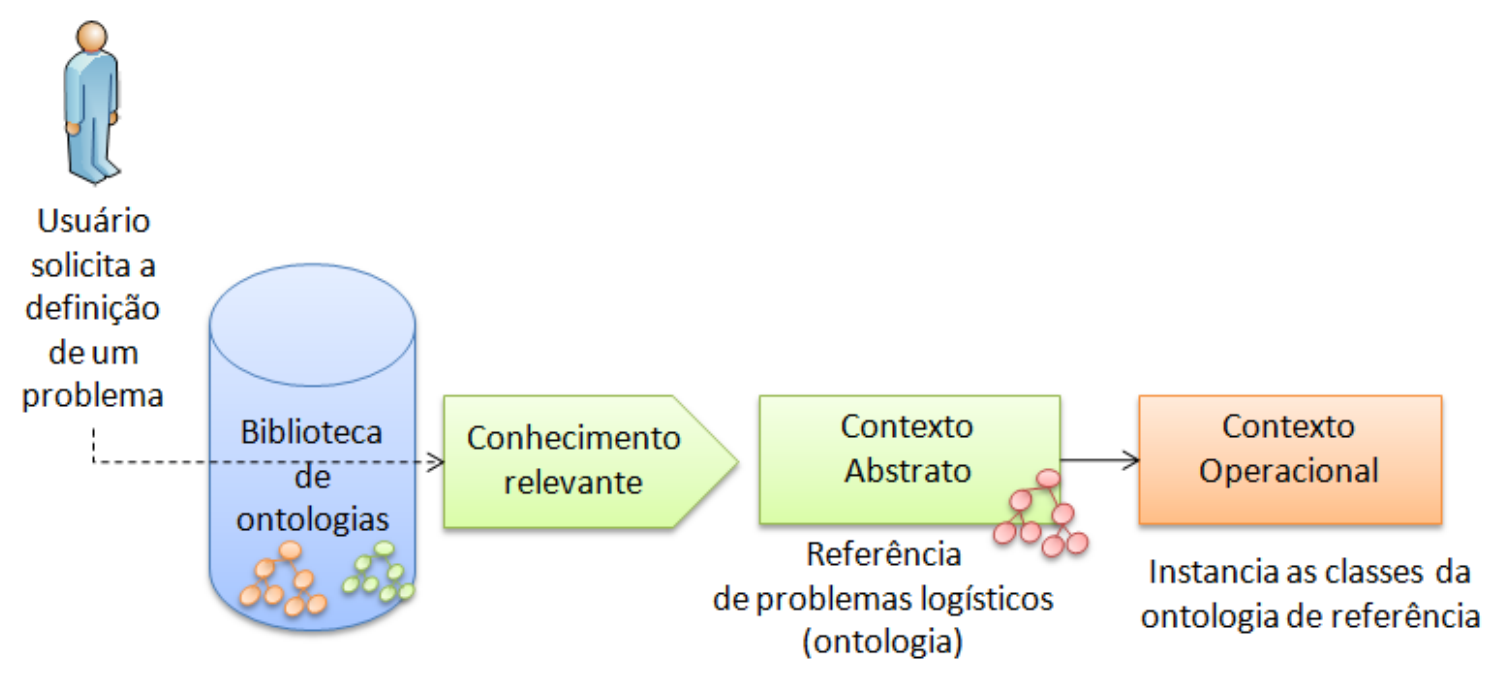

Figura 4.16 - Modelagem do contexto através de ontologias proposto por Smirnov et al. (2007)

Além da ênfase nesses trabalhos para o uso de ontologias para a formalização do contexto operacional e abstrato, Smirnov et al. (2007) utilizam ontologias para que diferentes tipos de decisões sejam analisadas através de uma metodologia de mineração de decisões. As ontologias são usadas para documentar o histórico de decisões tomadas e respectivas situações e contextos referentes ao processo decisório, para que sejam posteriormente recuperadas. O objetivo da mineração de 
decisão é encontrar "regras", explicando em que circunstâncias uma atividade deve ser selecionada (Figura 4.17).

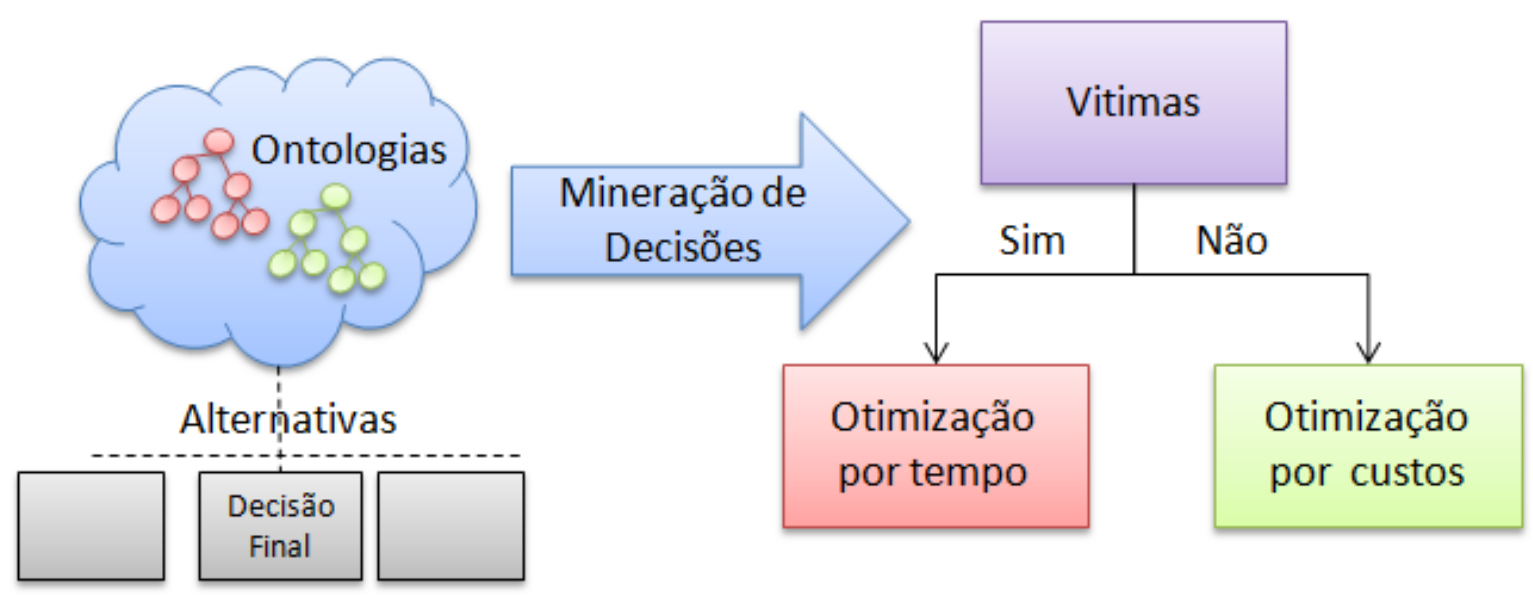

Figura 4.17 - Exemplo de mineração de regras influenciando a decisão do usuário (adaptado de Smirnov et al., 2007).

A partir deste arcabouço conceitual apresentado, foram desenvolvidas ontologias que a seguir serão comentadas.

\subsection{Rede de Ontologias}

Partindo das metodologias propostas por Goméz-Perez et al. (2003) e pelo Projeto Neon (Neon, 2010) foram desenvolvidas ontologias para os domínios: (1) cadeia de suprimentos humanitária, (2) processos logísticos, (3) bancos de alimentos e (4) processos logísticos de bancos de alimentos. Para o desenvolvimento das ontologias foi utilizado o aplicativo Protegé versão 4.0.2.

O passo inicial de desenvolvimento foi à busca de ontologias pré-existentes nos mecanismos de busca citados na Tabela 4.1 (página 71). Alguns mecanismos de 
busca consideram a busca nas classes das ontologias e facilitam o entendimento do contexto que o termo foi utilizado. Esse é o caso do Watson, do Ontoselect e do Schemaweb. As ontologias nos sites do Protegé e do Projeto Neon, por sua vez, encontram-se apenas listadas. No Swoogle não é possível distinguir a linguagem da ontologia no momento da busca e a resposta final é pouco estruturada. Infelizmente as ontologias encontradas que mencionavam alguns dos termos pesquisados eram inadequadas para o propósito do trabalho. Foram então pesquisados termos correlatos cujas poucas ontologias encontradas foram estudadas para averiguar sua adequação ao propósito do trabalho.

A despeito da ausência de ontologias para processos logísticos, algumas ontologias de outras áreas puderam contribuir para a formação da rede de ontologias proposta. Dentre elas destaca-se a ontologia AGROVOC, criada pela Organização das Nações Unidas para Agricultura e Alimentação (FAO), que ainda está em desenvolvimento, mas já apresenta informações uteis para esta pesquisa.

Somado a isso, uma intensa busca bibliográfica foi feita em busca de maiores referências sobre ontologias desenvolvidas nos domínios da logística ou da cadeia de suprimentos, conforme descrito nos itens anteriores deste capítulo. Essas referências acabaram formando a base sobre a qual as ontologias foram criadas. Além disso, foram seguidos os procedimentos metodológicos, como a listagem de conceitos, formação de frases para o levantamento de relacionamentos, descrição de atividades da operação logística para a identificação de conceitos e elaboração de mapas conceituais, além de discussões sobre os resultados.

Vale lembrar que a metodologia proposta pelo Projeto Neon (Neon, 2010) consiste na constituição de uma rede de ontologias, de modo que cada ontologia que compõe esta rede possa ser individualmente alterada, permitindo que a rede de ontologias possa evoluir. Entende-se, portanto, que as ontologias aqui propostas são apenas o primeiro passo para o desenvolvimento de ontologias de domínio mais consensuais relacionadas ao tema estudado, a partir do qual sistemas poderão ser modelados. 


\subsubsection{Ontologia da Cadeia de Suprimentos Humanitária}

O desenvolvimento da ontologia para a Cadeia de Suprimentos Humanitária partiu das referências conceituais discutidas nos capítulos três e quatro, e contou com algumas especificidades:

1. Classes e relacionamentos sugeridos para a cadeia de suprimentos por Ye et al. (2008).

2. Medidas de desempenho sugeridos por Beamon (2004).

3. Controle de custos, mencionados por Martins et al. (2006).

4. Classes que permitam que o processo decisório seja registrado, vislumbrando a perspectiva apontada por Smirnov et al. (2007) para a mineração de decisões.

5. Níveis de decisão e áreas de decisão, descritos por Ballou (2006) e Yoshizaki (2002).

A Figura 4.18 apresenta uma visão geral da ontologia para Cadeia de Suprimentos Humanitária. Algumas classes e relacionamentos não foram representados exatamente como formalizados nos códigos para facilitar a compreensão geral e a representação gráfica. Os códigos encontram-se no Apêndice B. 


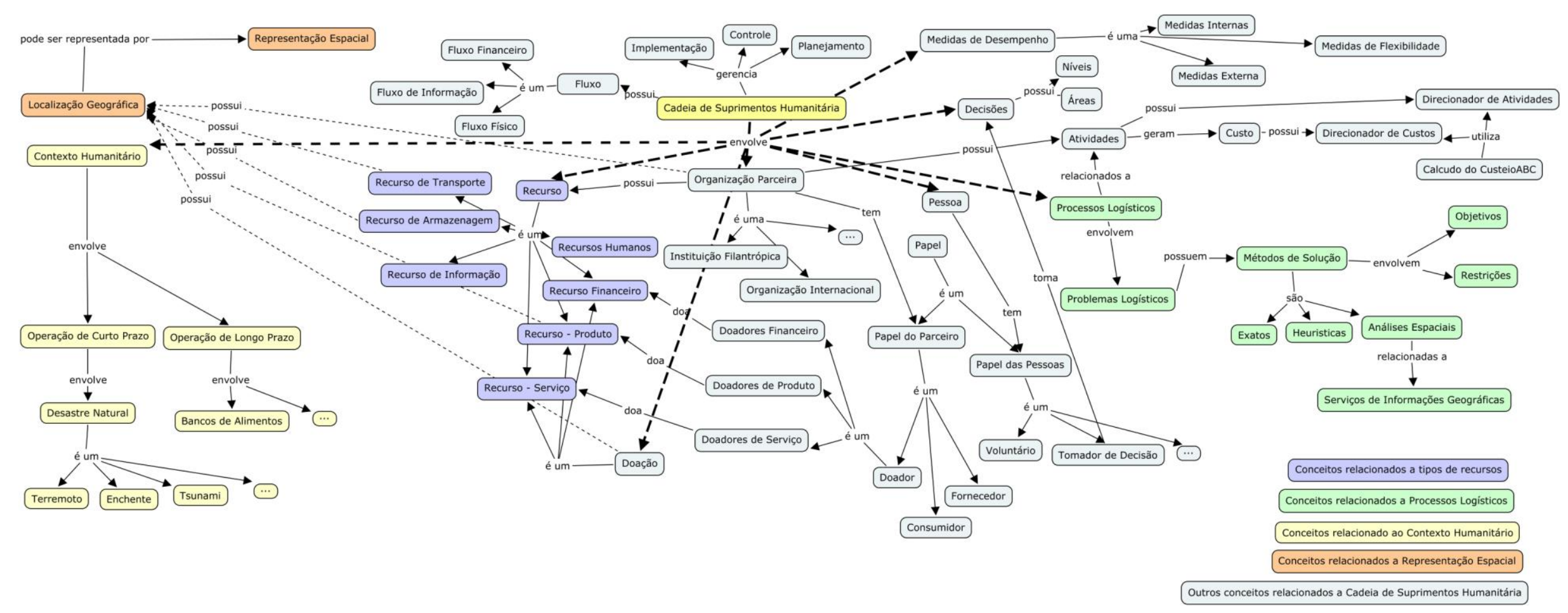

Figura 4.18 - Representação gráfica da ontologia da Cadeia de Suprimentos. 
A partir da ontologia de Cadeias de Suprimentos Humanitária foram desenvolvidas as ontologias referentes aos Processos Logísticos.

\subsubsection{Ontologia de Processos Logísticos}

A ontologia para Processos Logísticos partiu de classes gerais presentes na ontologia da Cadeia de Suprimentos Humanitária, que foram especificadas a partir de conceitos apresentados nas ontologias desenvolvidas pelo projeto Brein (2010), por Peng et al. (2007) e Park et al. (2008) que representam conceitos gerais de processos logísticos (Figura 4.19).

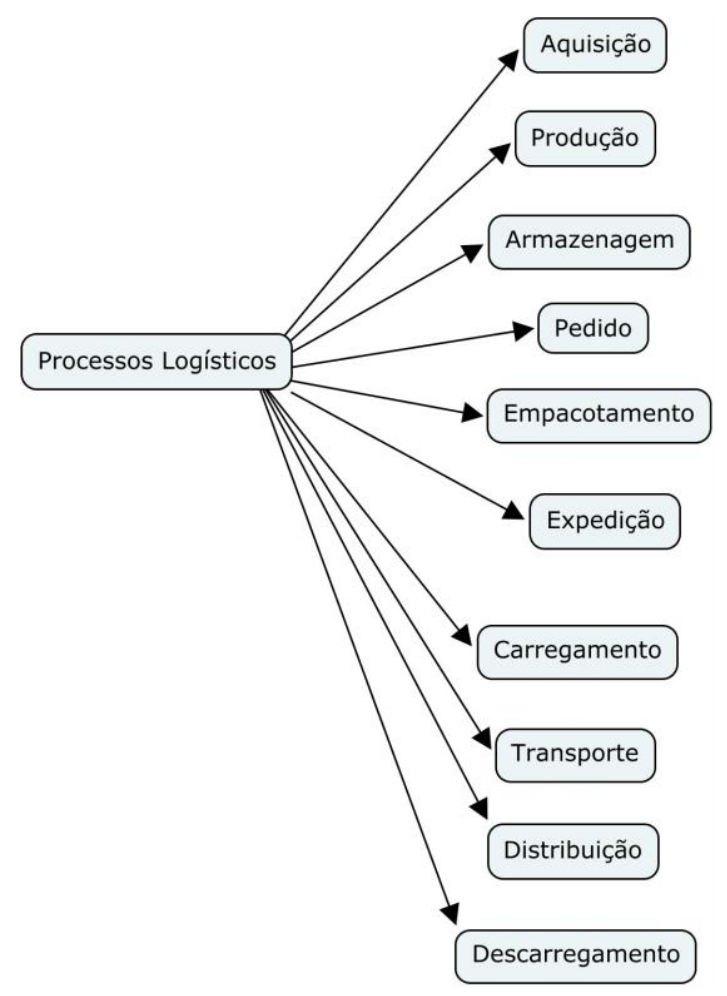

Figura 4.19 - Classes de Processos Logísticos 
Essas classes de Processos Logísticos foram relacionadas às classes de Problemas Logísticos (Figura 4.20).

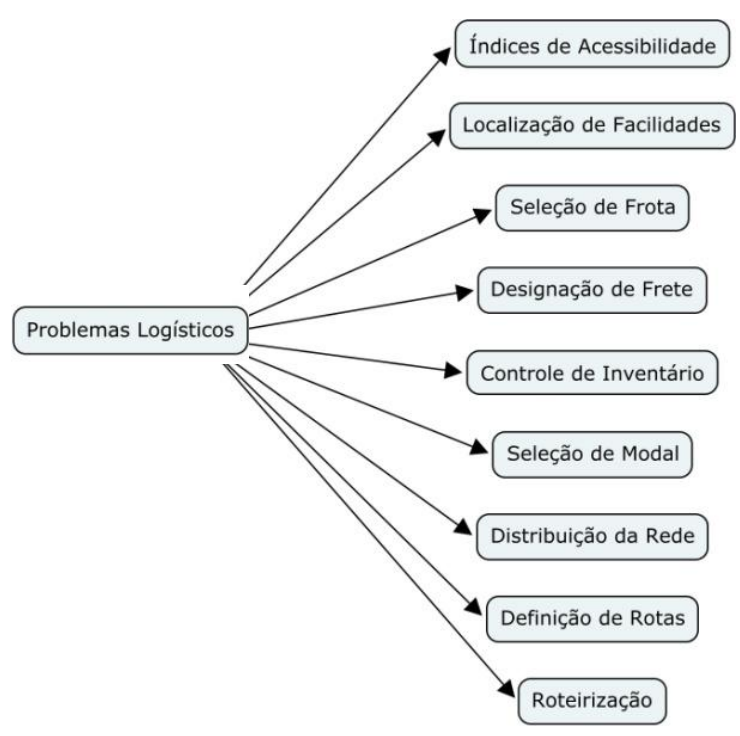

Figura 4.20 - Classes de Problemas Logísticos.

Essas classes de Problemas Logísticos, por sua vez, foram associadas às classes de Análises Espaciais (subclasses de Métodos para Solução de Problemas), referentes aos serviços de geoprocessamento (classificados pela ISO 19019), que serão melhor tratados no capítulo 5.

A classe Métodos para Solução de Problemas considera ainda duas outras classes de Métodos Exatos e Heurísticas a fim de considerar as perspectivas apontadas por Brock et al. (2005). 


\subsubsection{Ontologia de Bancos de Alimentos}

Para a ontologia de Bancos de Alimentos partiu-se de conceitos da ontologia da Cadeia de Suprimentos Humanitária e incluíram-se aspectos específicos dos bancos de alimentos apresentados no capítulo três.

Dentre as alterações importantes, associou-se a classe de Produtos (RecursosProdutos) à classe alimentos, cujas subclasses foram mapeadas a partir da ontologia de alimentos da ontologia AGROVOC da FAO (Food and Agricultural Organization). A essa classe Produtos estão associadas propriedades de dados (data properties) referentes às características dos alimentos como peso, volume, prazo de validade e necessidade de refrigeração.

A classe Organizações da Cadeia Agroindustrial foi acrescentada como subclasse de Organizações Parceiras e foi relacionada ao papel Doador de Produtos. As subclasses Indústrias de Alimentos e Serviços Alimentares foram mapeadas da ontologia AGROVOC (FAO).

A classe Doações recebeu detalhamento de relacionamentos como: (1) entregue por, (2) coletado por, (3) recusada por, (4) aceita por.

A classe Instituições Filantrópicas recebeu subclasses: (1) Creches, (2) Asilos, (3) Atendimento às Pessoas com Necessidades Especiais, (4) Atendimento aos Moradores de Rua, (5) Atendimento aos Dependentes, entre outras. A essa classe relativa às instituições, além de dados de identificação, foram associadas propriedades de dados referentes a (1) Número de Refeições, (2) Número de Pessoas Atendidas por Faixas Etárias.

Por fim as atividades de bancos de alimentos foram inseridas como subclasses da classe Atividades. Essas subclasses envolvem classes gerais como: (1) Atividades Educacionais, (2) Atividades Administrativas, (3) Atividades de Monitoramento de Instituições, (4) Atividades de Gerenciamento de Voluntários, além da classe (5) 
Atividades Logísticas. As Atividades Logísticas foram descritas na ontologia de Processos Logísticos de Bancos de Alimentos.

\subsubsection{Ontologia de Processos Logísticos de Bancos de Alimentos}

Para a determinação dos processos logísticos de bancos de alimentos fez-se o mapeamento entre a ontologia da Cadeia de Suprimentos Humanitária, a ontologia do domínio de Bancos de Alimentos e a ontologia de Processos Logísticos. A classe Atividades Logísticas da ontologia de Bancos de Alimentos foi especificada em subclasses: (1) Coleta de Doações, (2) Entrega de Doações, (3) Recebimento de Doações, (4) Armazenagem de Doações, (5) Alocação de Doações, (6) Processamento de Doações, (7) Seleção de Doações, (8) Empacotamento de Doações e (9) Transporte de Doações, que foram relacionadas a Processos Logísticos e Problemas Logísticos e indiretamente a Métodos para Solução de Problemas Logísticos. Mais detalhes acerca dos métodos referentes às análises espaciais feitas por serviços de informações geográficas serão tratados no próximo capítulo.

\subsubsection{Consultas Lógicas às Ontologias Desenvolvidas}

Como as ontologias propostas nesta tese foram criadas com o objetivo de servirem de base para o desenvolvimento de sistemas foi feita a simulação de valores, instanciando classes com valores fictícios, seguida da execução de consultas para averiguar se as relações estabelecidas estavam consistentes com os propósitos levantados. São exemplos dessas consultas: 
1. Encontre os problemas logísticos relacionados a determinado processo logístico.

2. Encontre os métodos de solução de problemas logísticos para determinado problema logístico (por exemplo, roteirização).

3. Encontre os métodos de solução por análises espaciais para determinado problema logístico.

As consultas foram feitas no próprio aplicativo Protegé (por um aplicativo - plugin - que já vem instalado - DL Query). Versões anteriores do Protegé possuem outras opções para consultas, como o SPARQL, que adota como estrutura básica a linguagem SQL. Mas como as linguagens ontológicas estão em evolução, e mudanças significativas nos softwares têm sido feitas para adaptálos a essas novas linguagens, alguns aplicativos de versões anteriores nem sempre são adaptados às versões mais atuais. Os códigos referentes às consultas seguem registrados no Apêndice $B$. 


\section{SERVIÇOS DE INFORMAÇões GEOGRÁFICAS}

Com o advento da internet, dados e operações espaciais que podiam ser manipuladas apenas em ambientes locais, em Sistemas de Informações Geográficas, passaram a ser disponibilizadas na forma de serviços Web, denominados serviços de informações geográficas. Este capítulo trata da caracterização destes serviços Web que lidam com dados e, em especial, com operações espaciais.

Discute-se sobre o potencial de composição desses serviços formando cadeias de serviços e sobre os problemas semânticos que limitam esse potencial. Ao final discute-se sobre metodologias para anotar semanticamente serviços de geoprocessamento, através de ontologias, como forma de contribuir para superar os problemas semânticos apontados.

\subsection{Classificações de Serviços de Informações Geográficas}

Web services são aplicações modulares (atômicas), auto descritivas (cada serviço fornece sua própria descrição), que permitem a composição de vários serviços. GeoWebServices (serviços de informações geográficas) são WebServices que analisam e manipulam dados espaciais (Schut, 2007).

Padronizações e especificações sobre esses serviços de informações geográficas são feitos pela OGC e pela ISO (Percivall, 2002).

No contexto da OGC, Web services possuem especificações brevemente descritas na Tabela 5.1, abaixo. 
Tabela 5.1 - Descrição de alguns serviços de informações geográficas segundo padrões OGC. Fonte: Adaptado de Schut, 2007.

\begin{tabular}{|c|c|c|}
\hline $\begin{array}{l}\text { Acrônimos de } \\
\text { Padrões OGC }\end{array}$ & Nome & Descrição Geral \\
\hline WMS & Web Map Service & $\begin{array}{l}\text { Fonece um mapa ou imagem, que pode } \\
\text { corresponder à superposição de vários planos } \\
\text { de informação. }\end{array}$ \\
\hline WFS & $\begin{array}{l}\text { Web Feature } \\
\text { Service }\end{array}$ & $\begin{array}{l}\text { Fornece e permite atualizações de objetos } \\
\text { geográficos no formato GML }\end{array}$ \\
\hline WCS & $\begin{array}{l}\text { Web Coverage } \\
\text { Service }\end{array}$ & $\begin{array}{l}\text { Fornece 'campos' , ou seja, representações de } \\
\text { fenômenos que variam no espaço e no tempo } \\
\text { (MNT, imagens de satélite, etc.) }\end{array}$ \\
\hline WPS & $\begin{array}{l}\text { Web Processing } \\
\text { Service }\end{array}$ & Serviços de geoprocessamento \\
\hline CT & $\begin{array}{l}\text { Coordinate } \\
\text { transformation }\end{array}$ & Transformação de coordenadas \\
\hline OpenLS & Location Services & $\begin{array}{l}\text { Serviços para aplicações móveis : } \\
\text { geocodificação, cálculo de itinerário, entre } \\
\text { outros }\end{array}$ \\
\hline CS-W & Catalog Service & $\begin{array}{l}\text { Permite a publicação de catalogos de } \\
\text { metadados (relativos à dados e serviços) e a } \\
\text { pesquisa por esses catálogos }\end{array}$ \\
\hline sos & $\begin{array}{l}\text { Sensor Observation } \\
\text { Services }\end{array}$ & $\begin{array}{l}\text { Gerenciamento de aquisição e coleta de dados } \\
\text { de sensores }\end{array}$ \\
\hline SPS & $\begin{array}{l}\text { Sensor } \quad \text { Planing } \\
\text { Services }\end{array}$ & $\begin{array}{l}\text { Serviços de planejamento da consulta de } \\
\text { sensores e recuperação de dados associados }\end{array}$ \\
\hline
\end{tabular}

Os dados espaciais incluem várias dimensões de busca: espaço, tempo e tema. Padrões como os estabelecidos pela OGC têm abordado a dimensão espacial e até mesmo características temporais dos dados geográficos podem ser consultadas. A dimensão temática, por outro lado, é restrita aos filtros de busca de palavras-chave, que negligenciam os problemas semânticos introduzidos no capítulo anterior e dificultam a descoberta de recursos de localização geográfica (Maué et al., 2009). 
Quando se trata de serviços relativos a processos, e não a dados espaciais, os problemas semânticos são ainda mais complexos, pois um serviço relativo a um processo pode ser caracterizado pela informação com a qual ele lida (de entrada e de saída) além de como processa essa informação (a operação feita para o usuário) Lemmens et al. (2007).

A OGC disponibiliza documentos que tratam especificamente sobre os WPS (Web Processing Services) (Schut, 2007). Segundo Schut (2007), originalmente os WPS eram chamados de Geoprocessing Services. O nome foi mudado para "Web Processing Service" no início de seu desenvolvimento para evitar a sigla GPS, uma vez que teria causado a confusão com o uso convencional da sigla para Global Positioning System. Como WPS é uma especificação da OGC, utilizar o termo geoprocessamento seria redundante.

A ISO 19119 classifica os WPS em:

\section{Serviços de Processamento Espaciais:}

- Serviço de conversão de coordenadas. Serviço que permite modificar as coordenadas de um sistema de coordenadas para outro sistema de coordenadas que está relacionado com o mesmo datum.

- Serviço de ortorretificação. Serviço que permite transformar uma imagem numa projeção paralela perpendicular e, portanto, uma escala constante.

- Serviço de subconjuntos. Serviço que extrai dados de uma entrada em uma região espacial contínua, quer por localização geográfica ou por coordenadas de grade.

- Serviço de determinação de rota. Serviço para determinar o caminho ótimo entre dois pontos especificados. 


\section{Serviços de Processamento Temáticos:}

- Serviço de classificação temática. Serviço para classificar as regiões de dados geográficos com base em atributos temáticos.

- Serviço de generalização de elementos. Serviço que generaliza os tipos de elementos em uma coleção de recursos para aumentar a eficácia da comunicação.

- Serviço de subconjuntos. Serviço que extrai dados de uma fonte baseada em valores de parâmetro.

\section{Serviços de Processamento Temporais:}

- Referência temporal serviço de transformação do sistema. Serviço que permite modificar os valores de instâncias temporais de um sistema de referência temporal para outro.

- Serviço de amostragem. Serviço que extrai dados de uma entrada usando uma amostra consistente, baseado em valores de localização temporal.

\section{Serviços de Processamento de Metadados:}

- Serviço de cálculo estatístico. Serviço para calcular as estatísticas de um conjunto de dados, por exemplo, média, mediana, moda e desvio-padrão.

\section{Serviços de Processamento de Comunicação:}

- Serviço de codificação. Serviço que permite a execução de uma regra de codificação e fornece uma interface para codificação e decodificação

A especificação dos Web Processing Services fornece uma definição que integra operações espaciais e não espaciais e devem ser implementadas em três interfaces: (1) getCapabilities, que descreve o processo (operação) oferecido pelo serviço; (2) describeProcess que mostra detalhes sobre parâmetros de entrada e saída de um processo (operação) específica disponível no getCapabilities, juntamente com a indicação da funcionalidade do processo; (3) execute, que executa de fato o serviço (Schut, 2007). 
Tanto na OGC quanto na ISO os processos geográficos são vistos como cadeias de serviços. Uma cadeia de serviços consiste em vários serviços cada qual contribuindo com uma parte para o total da funcionalidade (Lutz, 2007).

Brauner et al. (2009) propõem uma agenda de pesquisa para serviços de informações geográficas (Figura 5.1).

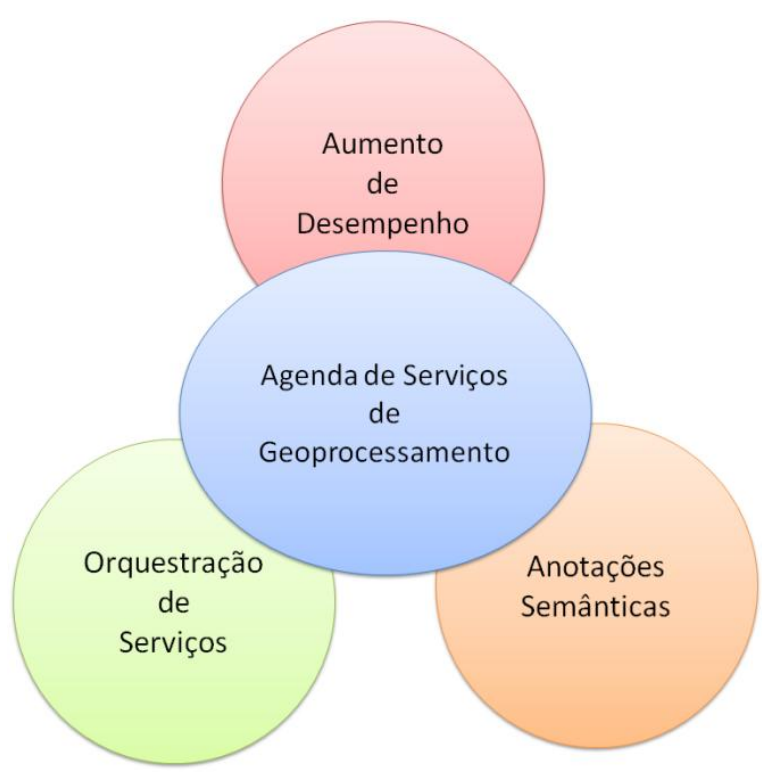

Figura 5.1 - Agenda de pesquisa para serviços de informações geográficas.

Nesse trabalho tratamos sobre a área de pesquisa referente às descrições semânticas de serviços de geoprocessamento, mas antes disso é feita uma breve referência a aspectos gerais da composição de serviços e suas aplicações para embasar as propostas posteriormente apresentadas.

\subsection{Cadeias de Serviços de Informações Geográficas}

Nos últimos anos tem aumentado progressivamente o número de serviços de informações geográficas disponíveis na web. Apesar de geralmente ainda serem 
aplicações isoladas, o seu maior valor é atribuído à possibilidade de composição formando cadeias de serviços de informações geográficas (Lutz, 2007).

Serviços de geoprocessamento podem ser desde cálculos simples de buffer, por exemplo, até cálculos mais complexos integrando modelos de mudanças climáticas (Foerster et al., 2009).

Um dos desafios para composição de serviços de informações geográficas refere-se à integração desses serviços em cadeias, o que envolve o descobrimento do serviço, a composição abstrata (identificar a função da cadeia de serviços), a composição concreta (identificar a mensagem da cadeia de serviços) e execução, tipicamente nesta ordem (Lemmens et al., 2007).

Friis-Christensen et al. (2009) apontam que um dos problemas dos trabalhos existentes no encadeamento de serviços é que a terminologia nem sempre é muito clara. Alguns dos termos definidos pelo autor, com base na ISO, são (1) encadeamento de serviço é um termo genérico que usamos para fazer referência a "combinar serviços em uma série de tarefas dependentes para alcançar uma tarefa maior; (2) um fluxo de trabalho (workflow) é uma "automação de um processo de negócio, no todo ou em parte, durante o qual documentos, informações ou tarefas são passadas de um serviço para outro, de acordo com um conjunto de regras processuais (3) orquestração é o processo de composição de um fluxo de trabalho das atividades de serviços.

De forma geral existem duas formas de utilizar uma cadeia de serviços: (1) o usuário encontra uma composição que satisfaz a requisição, (2) o usuário não encontra uma cadeia que satisfaça e os serviços tem que ser compostos. Para este último caso abrem-se três possibilidades: (1) o usuário decompõe aquilo que deseja manualmente e realiza repetidas consultas para cada parte do serviço decomposto, (2) o aplicativo de descobrimento de serviços faz a decomposição automaticamente, (3) o processo de decomposição do serviço é interativo, semi-automático (Lemmens et al., 2007). 
O ponto inicial para compor uma cadeia de serviços de informação geográfica é encontrar o serviço adequado para o propósito pretendido. O processo de busca e descobrimento de serviços de informações geográficas trata, essencialmente, sobre encontrar uma correspondência entre duas partes: de um lado os requisitos levantados pelo usuário, de outro a descrição do serviço disponibilizado. Essa correspondência deve acontecer em dois aspectos: (1) na semântica da operação (funcionalidade), (2) na semântica dos serviços adjacentes. O primeiro aspecto garante que o serviço faça realmente a operação desejada, enquanto o segundo garante que o serviço interprete corretamente os dados de entrada de um serviço predecessor (Lutz, 2007).

No caso de mais de uma correspondência entre serviço requisitado e serviço publicado, o usuário deve escolher o que melhor se adapta, baseado em inferências humanas ou por máquinas, a partir das propriedades de cada serviço (Lemmens et al., 2007) (Figura 5.2).

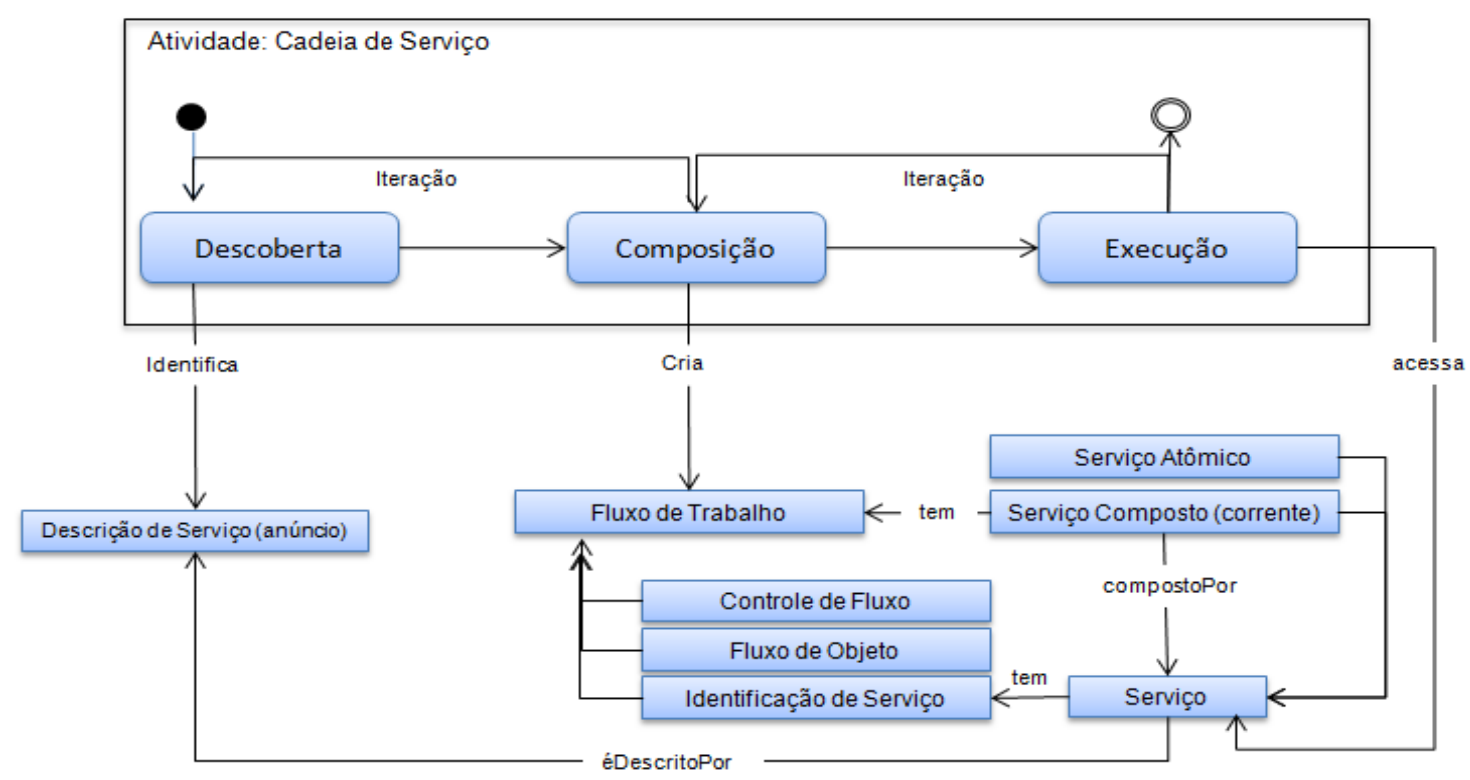

Figura 5.2 - Elementos relacionados à composição de serviços (Lemmens et al., 2007). 
Para avaliar a adequação para o uso de um serviço e criar composições entre serviços significativos, é necessário modelar as propriedades essenciais de serviços para facilitar seu descobrimento, composição e execução (Lemmens et al., 2007).

O número de aplicações que utilizam cadeias de serviços de informações geográficas apresentados na literatura ainda é incipiente, mas a expectativa é que cada vez mais a composição de serviços seja mencionada.

Stollberg e Zipf (2008) e Walenciak e Zipf (2010), apresentaram um sistema para análise de mercado imobiliário utilizando serviços de informações geográficas a partir do padrão WPS. A especificação dos serviços necessários bem como a composição dos mesmos não foi feita de forma automática. A Figura 5.3 detalha a cadeia de serviços utilizada.

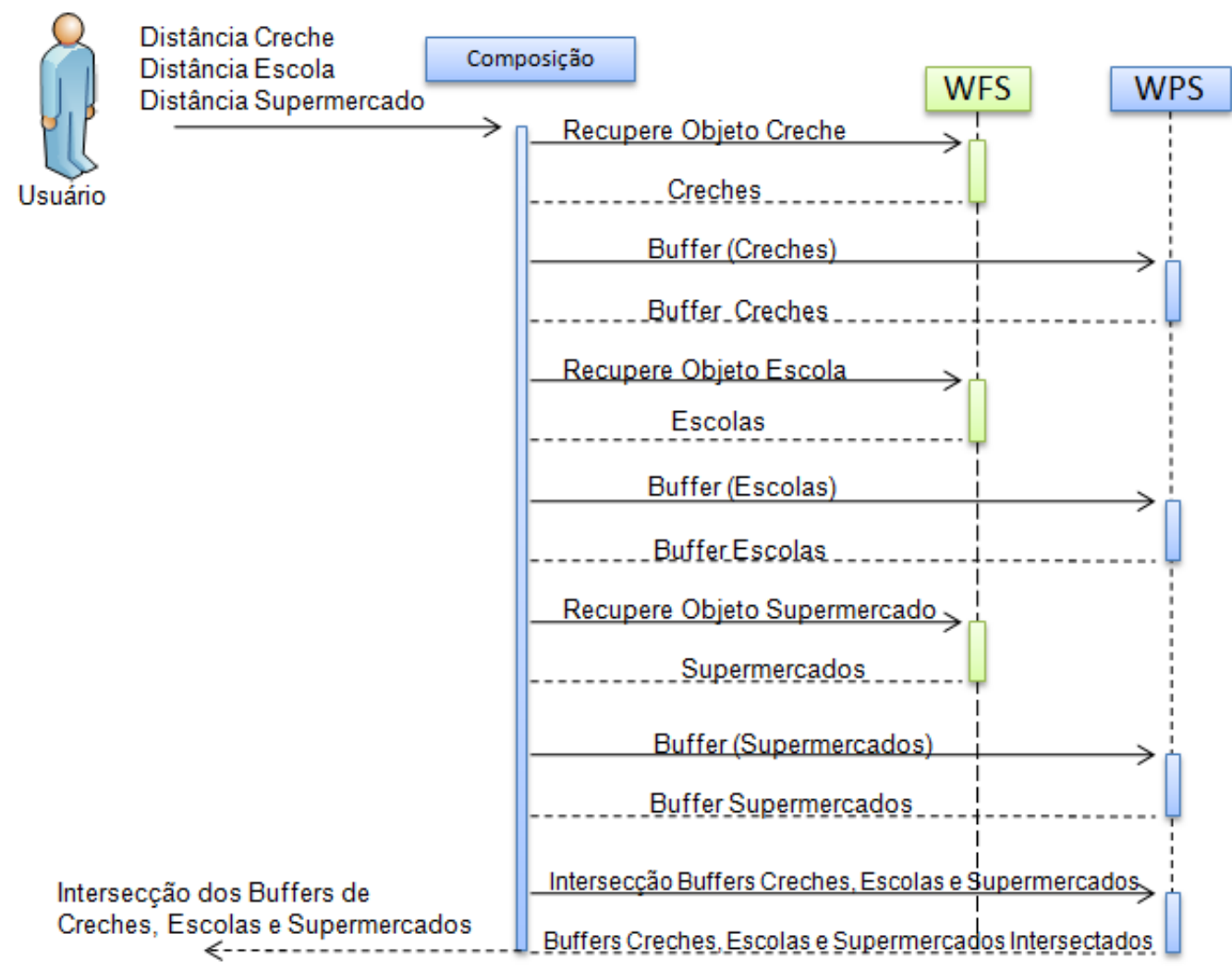

Figura 5.3 - Cadeia de serviços WPS para aplicação de análise de mercado imobiliário (Stollberg e Zipf, 2008). 
Friis-Christensen et al. (2009) apresentam uma arquitetura básica para construção de aplicativos baseados em cadeias de serviço, de processamento distribuído de informação geográfica, para o cálculo de risco de incêndio em áreas florestadas (Figura 5.4).

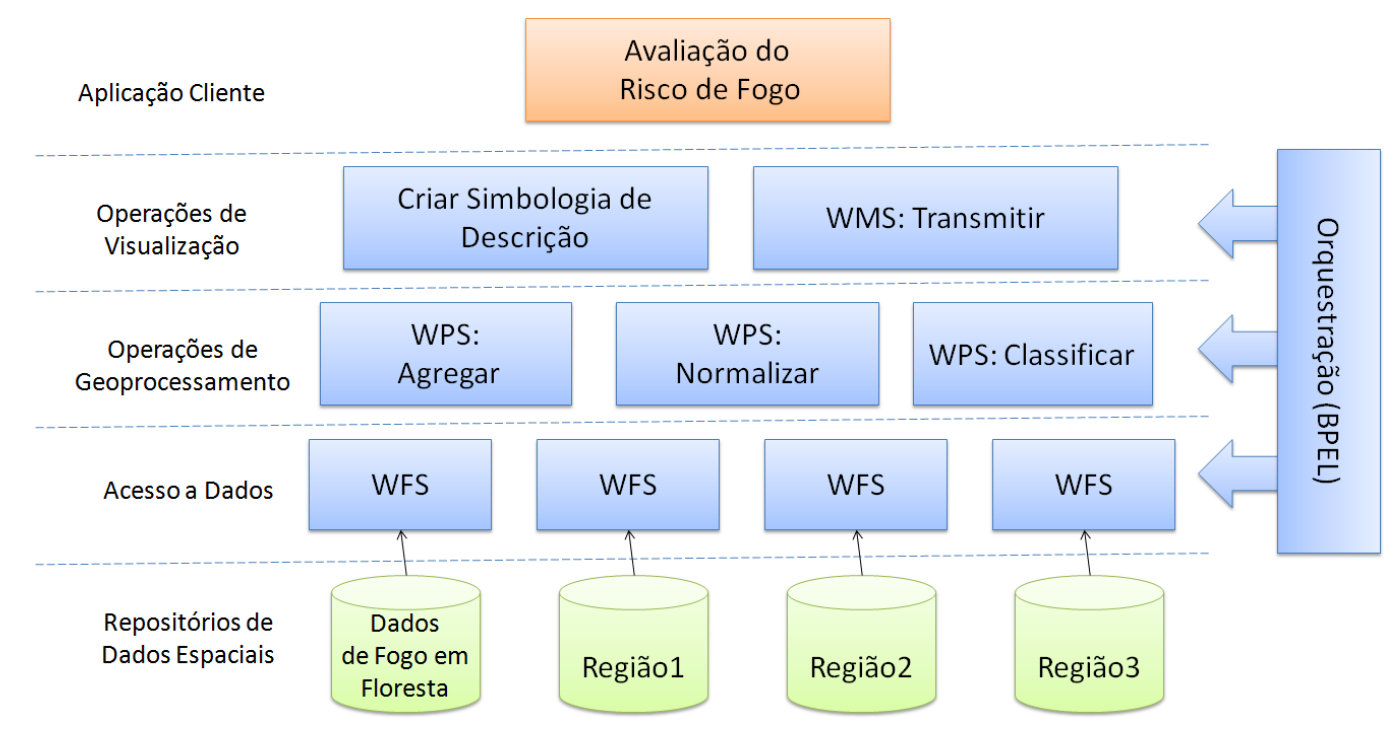

Figura 5.4 - Arquitetura baseada em composição de serviços para aplicação de cálculo de risco de incêndio em áreas florestadas.

Como mencionado anteriormente, a possibilidade de compor serviços de informações geográficas com outros serviços Web permite que dados e operações espaciais possam integrar processos de modelagens mais complexas. Esse potencial começou a ser explorado na prática. Os trabalhos apresentados por Fook et al. (2009), Diaz et al. (2008) e Granell et al., (2010) são alguns dos exemplos.

Diaz et al. (2008) e Granell et al. (2010) propõem um sistema baseado em uma arquitetura que considera a utilização de serviços de informações geográficas e utiliza apenas soluções não proprietárias. O sistema proposto envolve o uso de modelos hidrológicos para um sistema de suporte à decisão para o gerenciamento de recursos hídricos (Figura 5.5). 


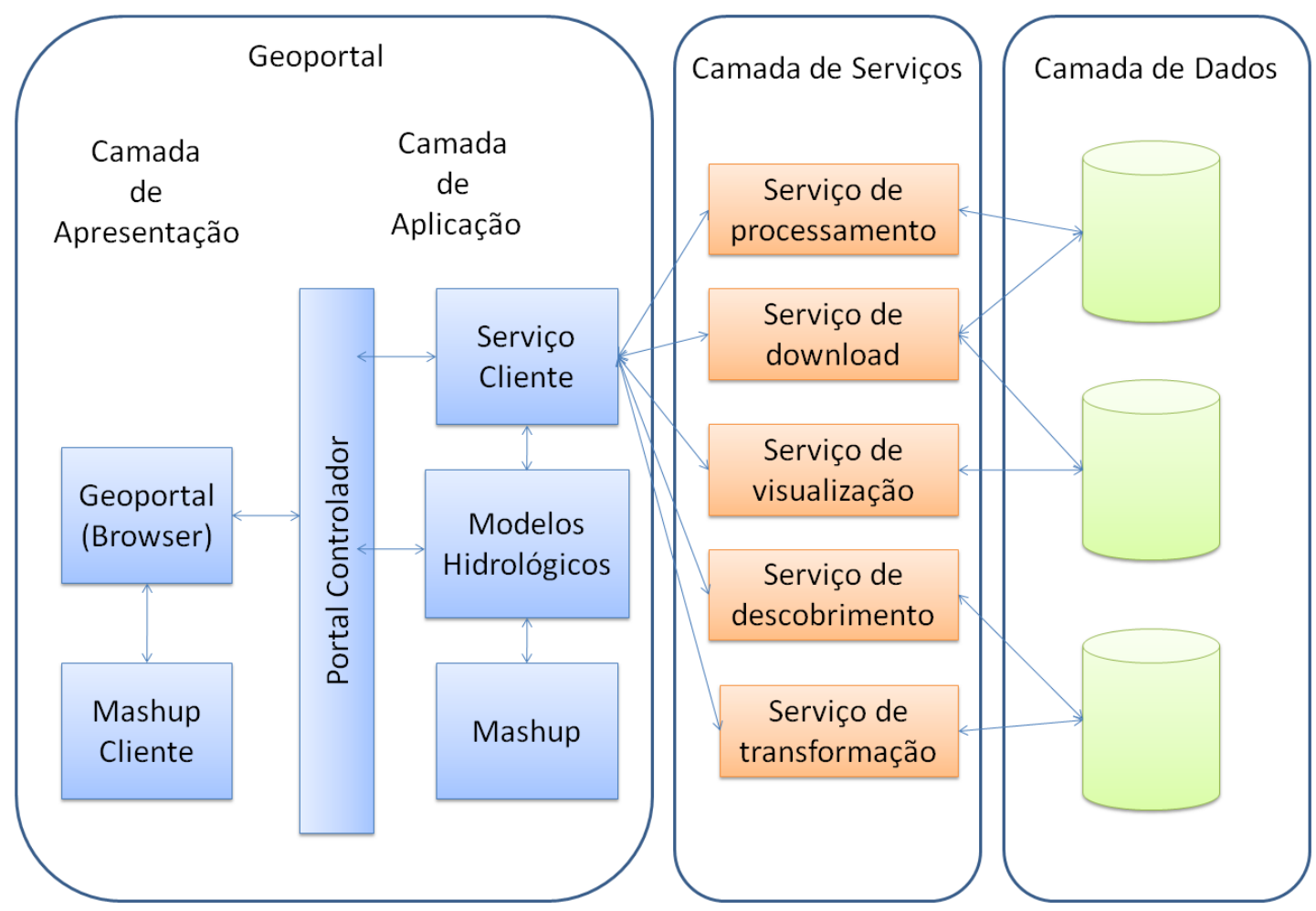

Figura 5.5 - Arquitetura de um sistema para aplicação de modelos hidrológicos baseada em soluções open source e serviços WPS.

Para a implementação do sistema, Diaz et al. (2008) desenvolveram uma coleção de WPS que são reutilizáveis. Os autores comentam sobre a importância do registro desses serviços, bem documentados, em catálogos abertos visando à evolução de sistemas de serviços distribuídos de geoprocessamento.

Fook et al. (2009) apresentam uma arquitetura para serviços de informações geográficas que oferece serviços para modelagem colaborativa da biodiversidade em ambiente Web. O propósito da aplicação é permitir o compartilhamento de modelagens de espécies. Os autores utilizaram serviços do padrão OGC mas acoplaram outros serviços para dar conta da complexidade dos modelos utilizados.

Em busca de métodos para melhor descobrir e recuperar os serviços da Web, importantes tarefas no processo de composição de serviços, as ontologias estão sendo utilizadas (Lutz, 2007) e ligadas aos recursos geoespaciais e seus metadados através de anotações semânticas (Maué et al., 2009). 


\subsection{Semântica para Composição de Serviços de Informações Geográficas}

Anotações semânticas (Klien, 2008) e sistemas de referência semântica (Kuhn, 2005) são práticas de expressiva descrição formal de dados e serviços, com base em ontologias, propostas em busca de melhorar o potencial de interoperabilidade semântica no campo de geoprocessamento.

Atualmente, a comunidade científica está discutindo sobre métodos para automatizar essas anotações semânticas. Klien (2008) sugere métodos para anotações semânticas de serviços de informações geográficas referentes à representação de dados espaciais (campos e objetos), Lutz (2007), Lemmens (2006) e Maué et al. (2009) discutem metodologias de anotações semânticas em serviços de informações geográficas relativos a operações de geoprocessamento. Lefort (2009) propõe anotações semânticas em aplicações com mashups.

As descrições semânticas de serviços de informações geográficas consistem na caracterização dos seguintes elementos referentes à operação espacial (Lemmens et al., 2007):

1. Descrição da contribuição de cada operação e tipos de parâmetro de saída;

2. Descrição das informações espaciais que são acopladas a cada operação;

3. A classificação da funcionalidade de cada operação espacial;

4. A descrição do fluxo de controle em que ocorrem operações de composição;

5. Pré e pós-condições do serviço.

Anotações semânticas podem ser feitas em metadados (dados sobre os dados) que podem ser incorporados como um cabeçalho, como parte de um arquivo XML, ou armazenados separadamente em repositórios diferentes, o que pode facilitar sua gestão (Macário e Medeiros, 2009). 
As ontologias são usadas como modelos de referência para essas anotações semânticas, e uma de suas grandes vantagens é que qualquer conceito especificado em uma ontologia formalizada em uma linguagem computacional (OWL, por exemplo) pode ser unicamente referenciado por um URI (Maué et al., 2009). As anotações especificam formalmente os dados através do uso de conceitos e as relações entre eles, de forma que possam ser processados por máquina (Macário e Medeiros, 2009).

Kien e Probst (2005) propõem a seguinte arquitetura de ontologias para anotar semanticamente serviços de informações geográficas (Figura 5.6).

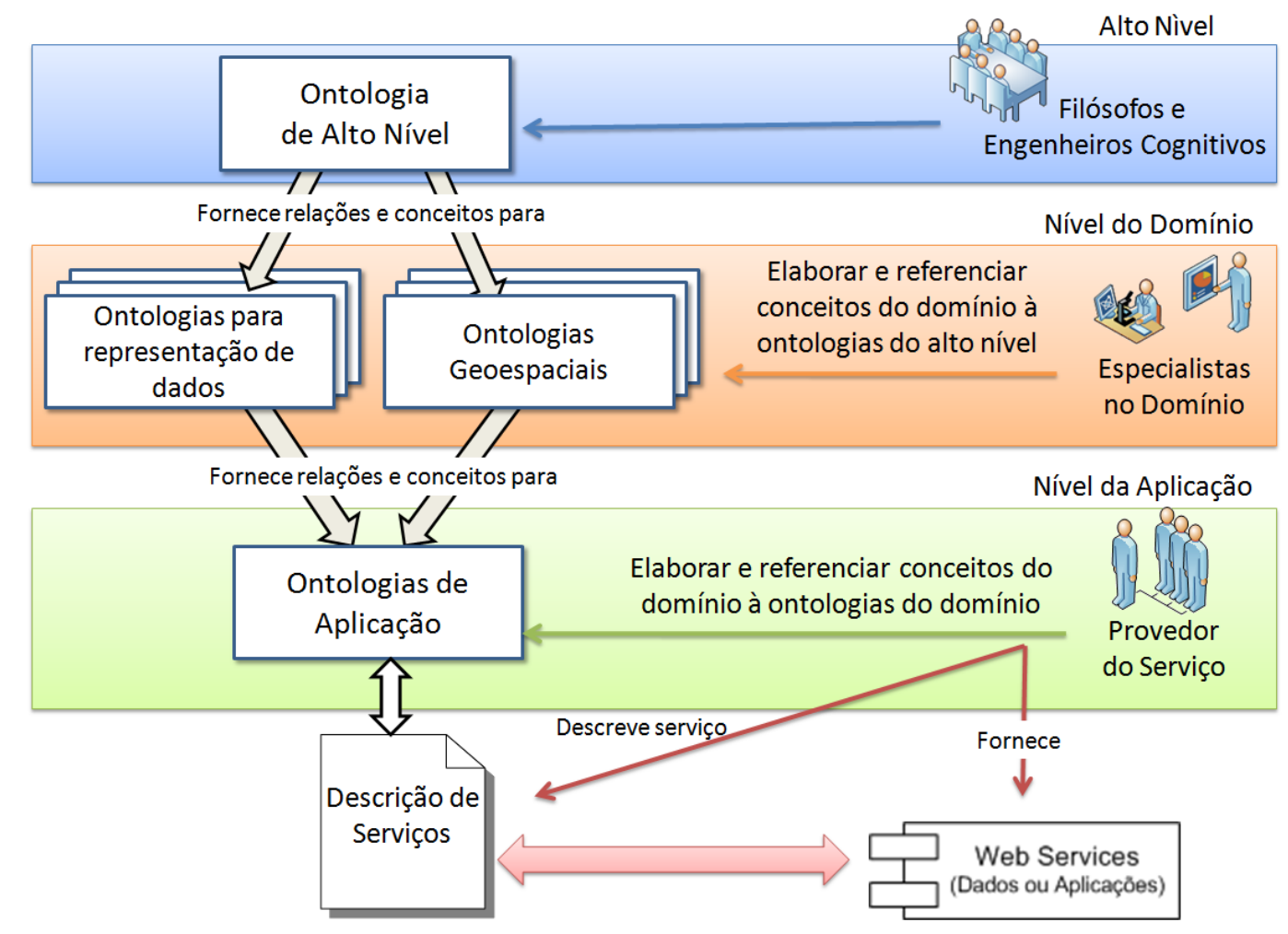

Figura 5.6 - Arquitetura de ontologias para anotações semânticas (Fonte: Klien e Probst, 2005).

2 Uniform Resource Identifier(URI) 
Macário e Medeiros (2009) propõem uma arquitetura de sistema que possibilita que anotações semânticas baseadas em ontologias sejam feitas (Figura 5.7).

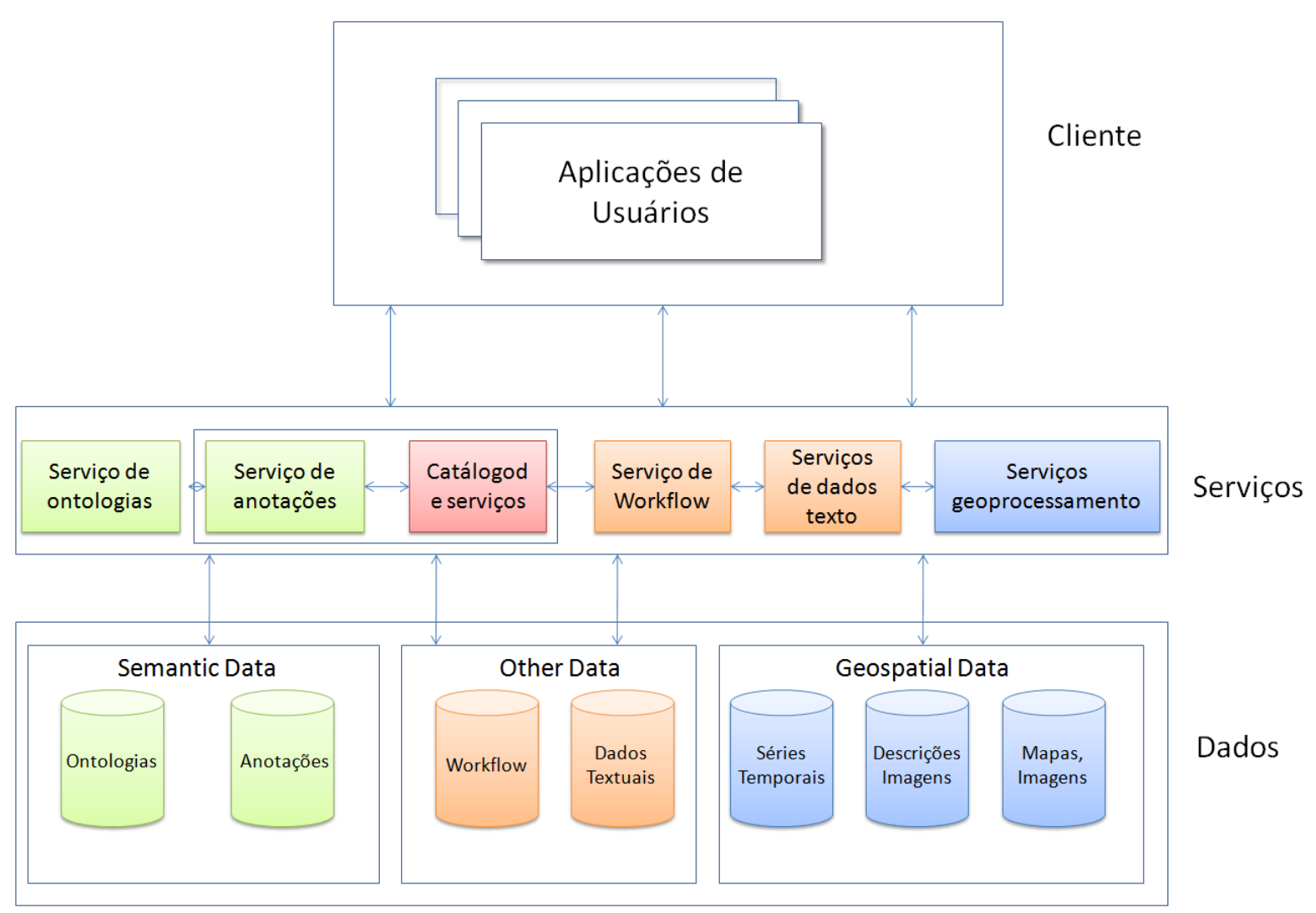

Figura 5.7 - Arquitetura de sistema com suporte para anotações semânticas proposto por Macário e Medeiros (2009).

Lemmens et al. (2007) propõem descrições semânticas de serviços de geoprocessamento baseados em ontologias.

$\mathrm{Na}$ ausência de informações semânticas sobre um determinado serviço de geoprocessamento, pode acontecer que uma operação, um buffer, por exemplo, referente a um serviço disponibilizado por determinada fonte, forneça resultados diferentes de outra operação buffer, de outro serviço, apesar de tratarem da mesma 
operação (Lemmens et al., 2007). A Figura 5.8 representa o processo de anotações semânticas de serviços de geoprocessamento (Maué et al., 2009).

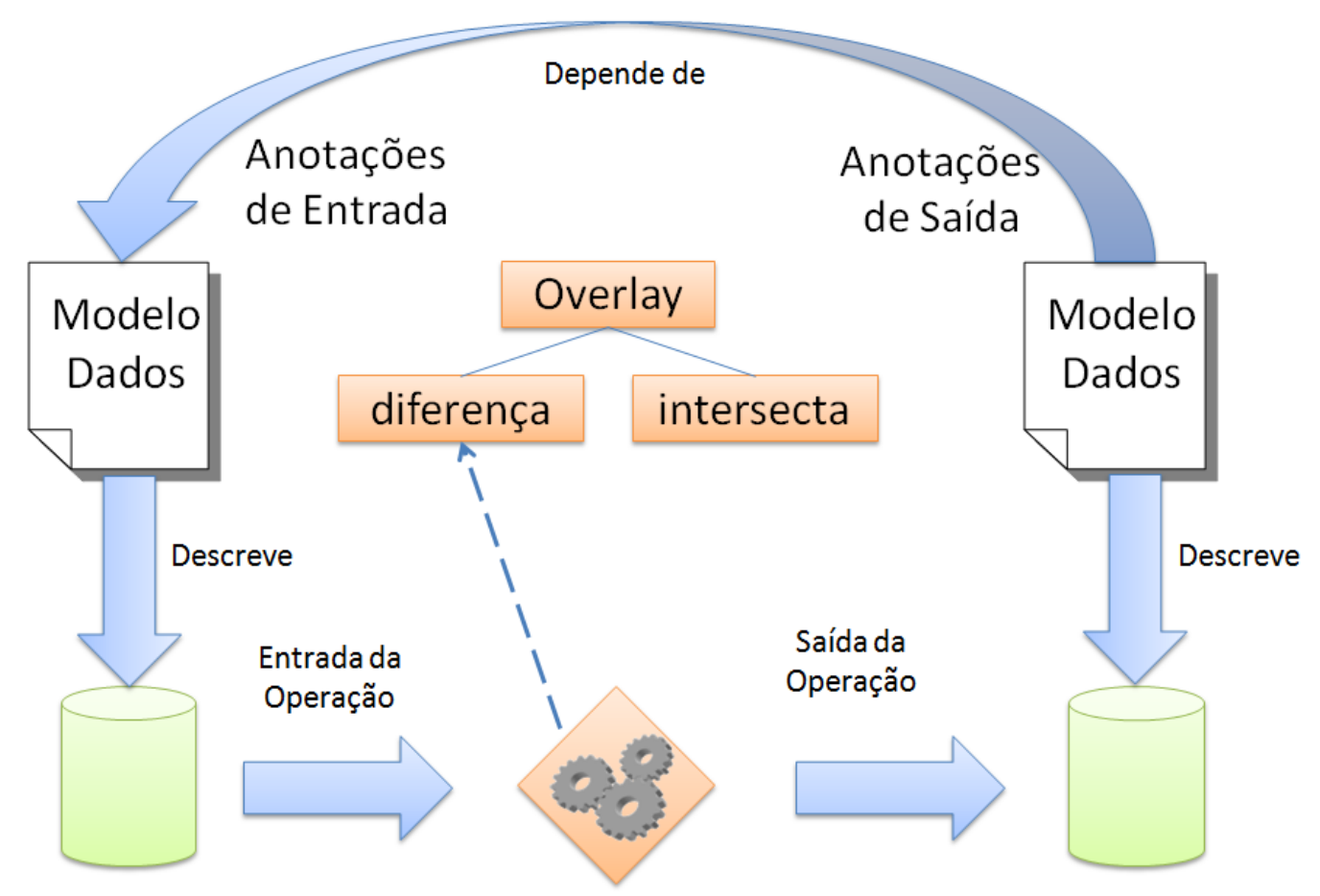

Figura 5.8 - Anotações semânticas de serviços de geoprocessamento (Maué et al., 2009).

Gobel e Zipf (2008) propõem definições para operações de geoprocessamento relacionadas a operações 3D. Os autores fazem uma revisão sobre como as operações são classificadas na literatura e, em consonância com Lemmens et al. (2007), argumentam que propostas genéricas sobre modelagem de processos e uma análise mais específica das tarefas e operações no domínio geográfico são necessárias.

Para descrever os serviços de geoprocessamento, Lemmens (2006) desenvolve uma arquitetura de ontologias com vistas a incorporar informações de entrada e saída dos serviços e sua funcionalidade. As ontologias são usadas como modelos de referência que fornecem informações para anotações semânticas que entram como parâmetros no código executável. Esses modelos de referência são utilizados 
no processo de anotação dos parâmetros de entrada e saída de dados de cada operação, que também deve ter suas características discriminadas. Essa arquitetura será tratada em maiores detalhes na próxima seção.

As operações espaciais inclusas no trabalho de Lemmens (2006) partem das descrições de operações propostas por Albrecht (1995 e 1998), Chrisman (1999 e 2002), Goodchild (2001).

Em especial, o trabalho de Albrecht, publicado há quinze anos, tem sido referenciado (Lemmens, 2006 e Ruschel et al., 2008) por fornecer bases conceituais para estudos sobre a semântica de operações espaciais. O trabalho de Albrecht analisa várias propostas de classificação de operações espaciais Goodchild (1992), Burrough (1992), Man (1988), Rhind e Green (1988) e Unwin (1990), e lista cada uma dessas operações, classificando-as e relacionando-as (Figura 5.9).

Fazendo-se um paralelo entre a classificação proposta por Albrecht (1995) e as idéias propostas por Lemmens (2006), funções e tarefas são operações espaciais atômicas e complexas, respectivamente.

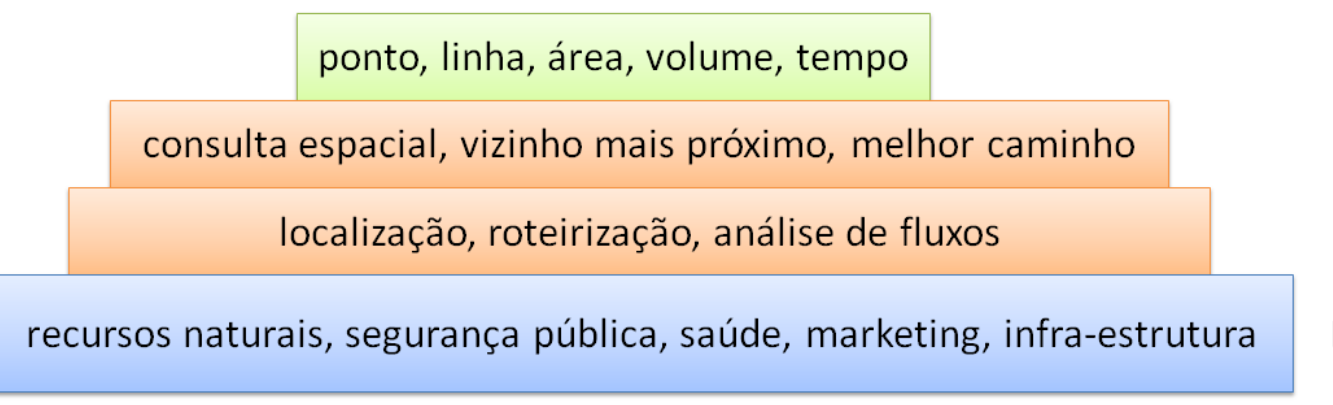

Dados

Funções

Tarefas

Propósitos

Figura 5.9 - Classificação das operações espaciais proposta por Albrecht.

Fica claro que contribuições metodológicas para anotação semântica de serviços de informações geográficas vêm sendo feitas a exemplo das propostas que tratam sobre anotações semânticas de serviços que disponibilizam dados espaciais (Klien, 2008) e propostas que tratam sobre serviços que disponibilizam operações espaciais (Lemmens, 2006; Maué et al., 2009). 
No entanto, para que essas metodologias sejam aplicadas é necessário um grande nível de conhecimento em aspectos relacionados à programação computacional, principalmente para o processo de desenvolvimento de ontologias. Alguns pesquisadores vêm desenvolvendo metodologias para transformar automaticamente modelos conceituais em Unified Modeling Language (UML), que possuem uma representação gráfica, em linguagens ontológicas como o OWL (Gasevit et al., 2004; Gronmo et al., 2005). Analogamente, o desenvolvimento de uma ferramenta para transformar automaticamente modelos conceituais de bancos de dados geográficos poderia facilitar o desenvolvimento de ontologias na área de geoprocessamento. $\mathrm{Na}$ próxima seção sugere-se conceitualmente uma forma de se mapear um modelo conceitual de dados geográficos para uma arquitetura de ontologias para anotações semânticas de serviços de geoprocessamento.

\subsection{Mapeamento entre Modelagem Conceitual e Ontologias}

Para o mapeamento entre Modelagem Conceitual e Ontologias foram escolhidas a metodologia de modelagem OMT-G, de Borges et al. (2005), e a arquitetura de ontologias proposta por Lemmens (2006). A próxima seção será descritiva e explicará elementos básicos das duas metodologias necessários para o entendimento da proposta de mapeamento. Maiores detalhes sobre as metodologias podem ser encontrados nas referências originais.

\subsubsection{OMT-G}

O modelo OMT-G baseia-se em primitivas definidas para o diagrama de classes da UML e insere primitivas geográficas para aprimorar a representação semântica em aplicações geográficas.

Geometria e topologia dos dados geográficos podem ser representadas pelo modelo OMT-G. Há suporte para a representação de estruturas topológicas "todo-parte", estruturas de rede, múltiplas representações de objetos e relacionamentos 
espaciais. Três diagramas são propostos pelo OMT-G: (1) diagrama de classes, que especifica classes, suas representações (com suporte para múltiplas representações) e seus relacionamentos; (2) diagrama de transformação, que especifica métodos de transformação no caso de classes com múltiplas representações ou classes derivadas, e (3) diagrama de apresentação, que especifica as alternativas de visualização que cada representação pode assumir. Para o mapeamento utilizaremos apenas o diagrama de classes.

O diagrama de classes do OMT-G descreve a estrutura e o conteúdo de um banco de dados geográfico

Três conceitos principais baseiam o OMT-G: (1) classes, (2) relacionamentos e (3) restrições de integridade espaciais (como por exemplo, uma regra que impede que edifícios sejam interceptados por trechos de logradouro). As classes podem ser georreferenciadas ou convencionais e representam três grupos de dados: (1) contínuos, (2) discretos e (3) não-espaciais. A classe georreferenciada representa objetos que possuem representação espacial enquanto a classe convencional descreve objetos que não possuem propriedades geométricas, mas estão relacionados a objetos espaciais.

As classes georreferenciadas são especializadas em classes do tipo geo-campo e geo-objeto. A simbologia das classes é baseada na UML, sendo que classes convencionais seguem exatamente a UML enquanto classes georreferenciadas se assemelham a UML mas indicam a forma geométrica de representação no canto superior esquerdo. O OMT-G apresenta um conjunto fixo de tipos de representação geométrica que distingue geo-campos (Figura 5.10) de geo-objetos (com ou sem topologia) (Figura 5.11). Métodos ou operações são especificados na seção inferior. 
Rede triangular irregular

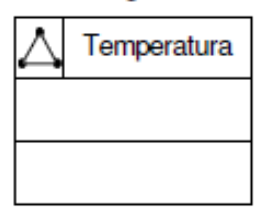

Isolinhas

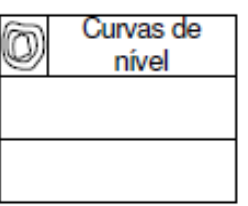

Subdivisāo planar

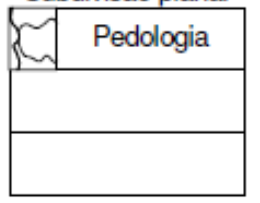

Tesselaçāo

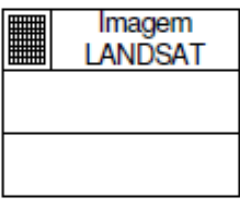

Amostras

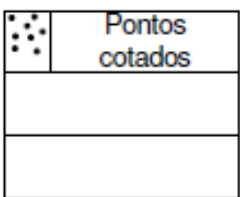

Figura 5.10 - Representação de geo-campos no modelo OMT-G (Borges et al. 2005).

Geo-objetos com geometria

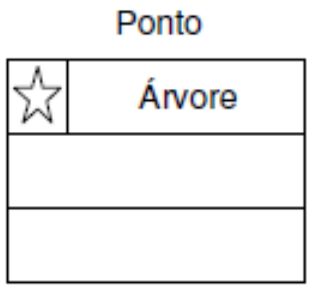

Linha

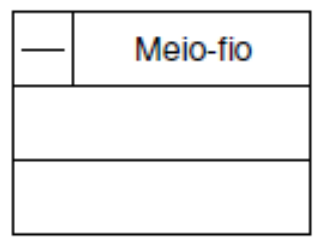

Poligono

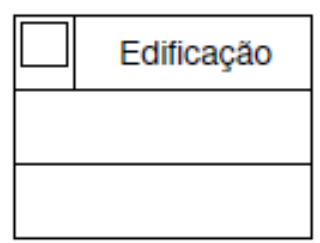

Geo-objetos com geometria e topologia

Linha unidirecional

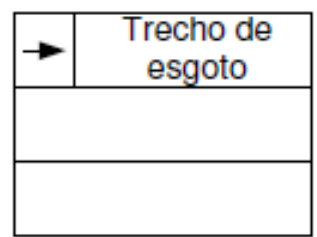

Linha bidirecional

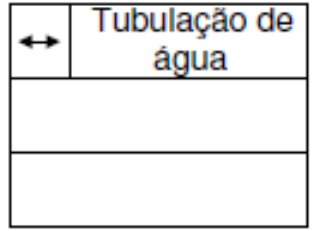

Nó de rede

- Cruzamento

Figura 5.11 - Representação de geo-objetos no modelo OMT-G (Borges et al. 2005).

Três tipos de relacionamentos são representados no OMT-G: (1) associações simples (2) relacionamentos topológicos em rede e, (3) relacionamentos espaciais (relações topológicas, métricas, de ordem e fuzzy). Sendo o primeiro indicado por linhas contínuas e os dois últimos indicados por linhas pontilhadas (Figura 5.12). 


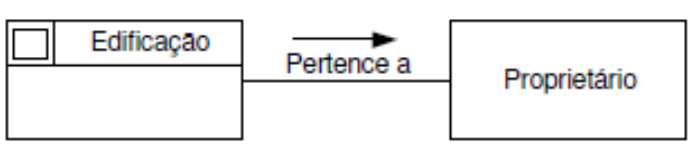

(a) Associação simples

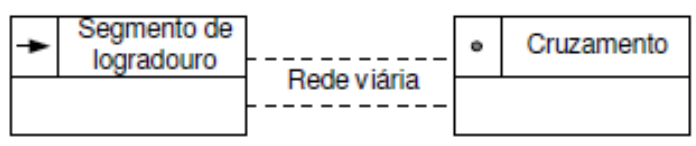

(c) Relacionamento de rede arco-nó

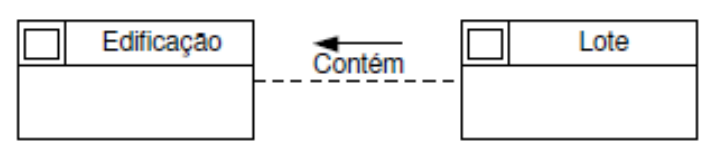

(b) Relacionamento espacial

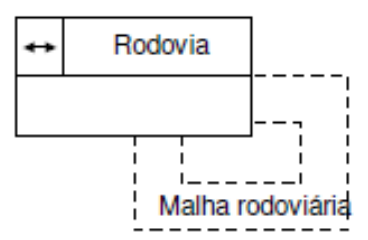

(d) Relacionamento de rede arco-arco

Figura 5.12 - Relacionamentos no OMT-G (Borges et al. 2005).

Quanto à cardinalidade (número de instâncias de uma classe que podem estar associadas à outra classe) o OMT-G adota a mesma representação da UML.

Para representar generalização/especialização o modelo OMT-G parte da notação da UML, mas inclui contribuições de outros métodos para a representação de total (ponto no ápice do triângulo) e parcial (sem ponto no ápice do triângulo) e para a representação de disjunto (triângulo em branco) e sobreposto (triângulo preenchido) (Figura 5.13). 


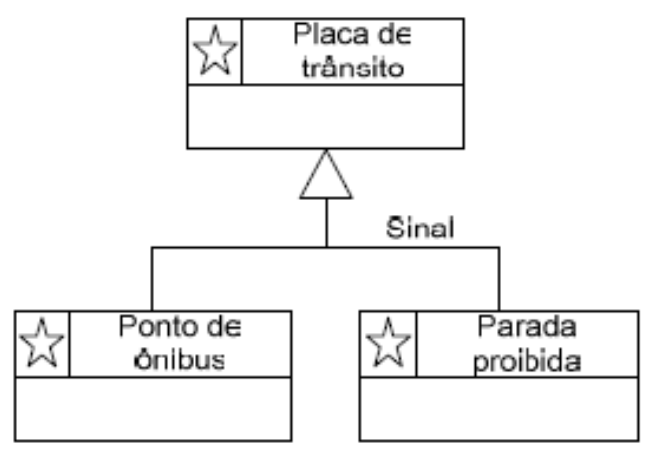

(a) Disjunto/parcial

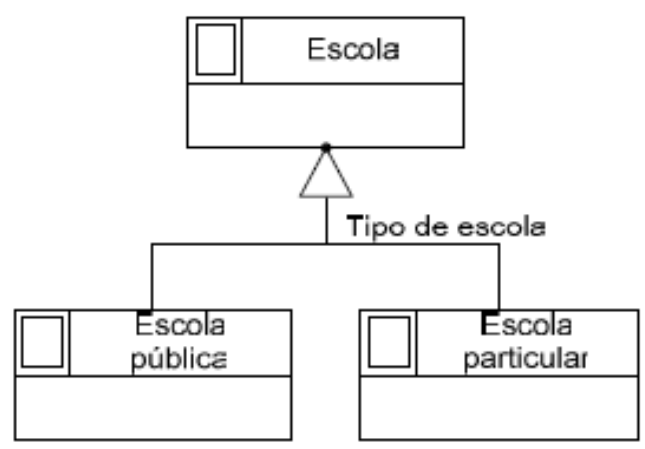

(c) Disjunto/total

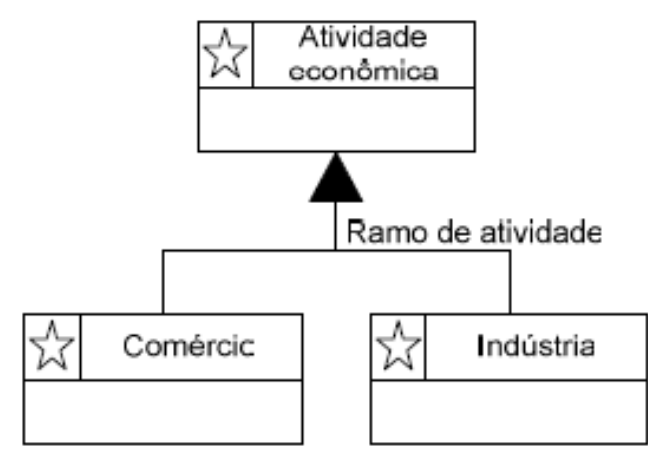

(b) Sobreposto/parcial

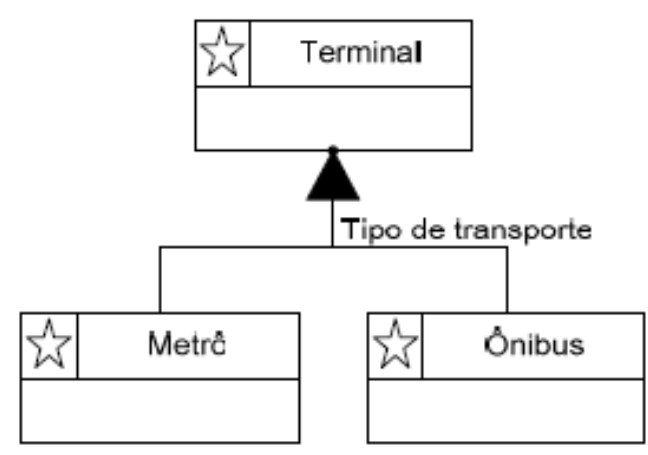

(d) Sobreposto/total

Figura 5.13 - Exemplos de generalização espacial (Borges et al. 2005).

A notação da agregação segue a UML, mas quando trata-se de agregação espacial, que explicita relacionamentos topológicos "todo-parte", parte-se do pressuposto no modelo que as restrições de integridade espacial serão respeitadas indicando que a geometria de cada parte estará contida na geometria do todo (Figura 5.14).

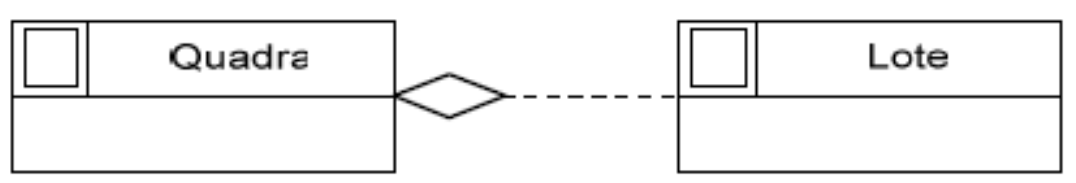

Figura 5.14 - Agregação espacial (Borges et al. 2005). 
O modelo OMT-G inclui ainda uma primitiva de generalização conceitual, que permite que a superclasse não tenha uma representação específica e que possa assumir representações distintas de acordo com a forma geométrica ou com a escala especificada nas subclasses (Figura 5.15).

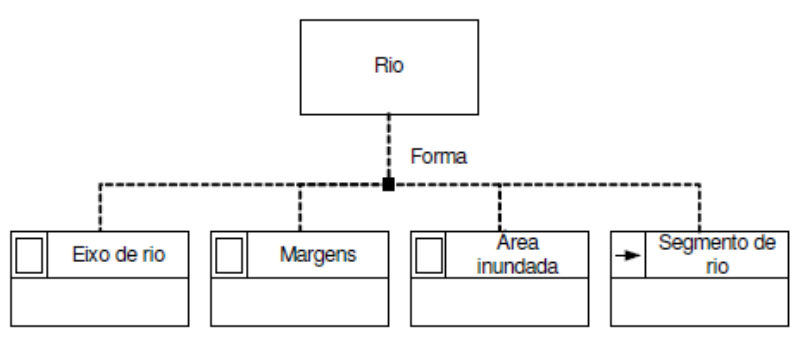

(a) Variação de acordo com a forma (sobreposto)

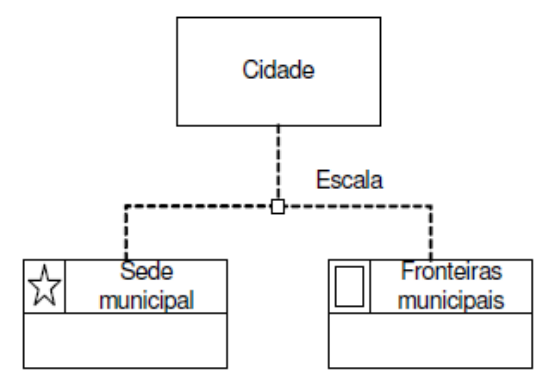

(b) Variação de acordo com a escala (disjunto)

Figura 5.15 - Generalização espacial (Borges et al. 2005). 


\subsubsection{Arquitetura de ontologias para anotações semânticas de serviços de geoprocessamento.}

A arquitetura de ontologias proposta por Lemmens (2006) conta com uma estrutura que abrange tanto geo-informações quanto geo-serviços. Esta arquitetura é utilizada para integrar um sistema de descoberta e encadeamento de serviços de informações geográficas através de consultas às ontologias. Exemplos de consultas feitas a essas ontologias são:

1. Encontre todas as operações que se referem a um conjunto de tipos de parâmetros de entrada e saída.

2. Encontre todas as operações que se encaixam em uma determinada cadeia de serviços observando-se seus parâmetros de entrada e saída.

3. Encontre todas as operações que são compostas por operações que instanciam certo tipo de operação.

4. Encontre todos os conceitos de informações e serviços que são sub ou super classes de um determinado conceito.

5. Encontre todos os conjuntos de dados que contêm um determinado objeto.

A arquitetura de ontologias conta com três tipos de ontologias formais: (1) uma ontologia de conceito do objeto, (2) uma ontologia referente a representação espacial do objeto (que o autor chama de símbolo) e (3) uma ontologia referente à operação.

A ontologia conceitual de objetos define formalmente as conceitualizações de fenômenos do mundo real e os relacionamentos entre eles. Exemplos de classes são BancosdeAlimentos e Doadores. Um elemento na ontologia conceitual de objetos é definido pelos relacionamentos com outros elementos na ontologia conceitual e pelos relacionamentos contidos na ontologia de símbolos dos objetos (por exemplo, Doador é representado em uma aplicação particular por um Ponto). Esta última relação é indicada na Figura 5.11 por temGeometria para o exemplo 
específico de Doador, ou seja, uma classe da ontologia conceitual de objetos usa uma classe da ontologia de geometria de símbolo de objetos para sua definição.

A ontologia de símbolos de objetos define formalmente os objetos no nível de representação. $O$ termo símbolos utilizado pelo autor não necessariamente refere-se a um símbolo visual, mas a um símbolo semântico (por exemplo, um TipoObjeto, no meta-nível, e um Ponto no nível de aplicação). Uma instância da classe Ponto é concretamente o Ponto com suas coordenadas.

A ontologia de geo-operação define formalmente tipos de operações em termos de seu comportamento. Cada tipo é caracterizado por um comportamento de um conjunto de operações de SIG atômicas e seus parâmetros típicos de entrada e saída. Os tipos de parâmetros de entrada e saída são descritos por elementos referenciados na ontologia de símbolos. Por exemplo, esses elementos podem indicar que um serviço precisa atributos temáticos para funcionar adequadamente. Somado a isso, para composições de operações, a ontologia contém elementos para o controle de fluxo, como seqüência e escolha.

Cada uma das ontologias descritas da arquitetura deve ser materializada por uma ontologia específica ou uma combinação de ontologias.

A Figura 5.16 representa a arquitetura de ontologias proposta por Lemmens (2006). 


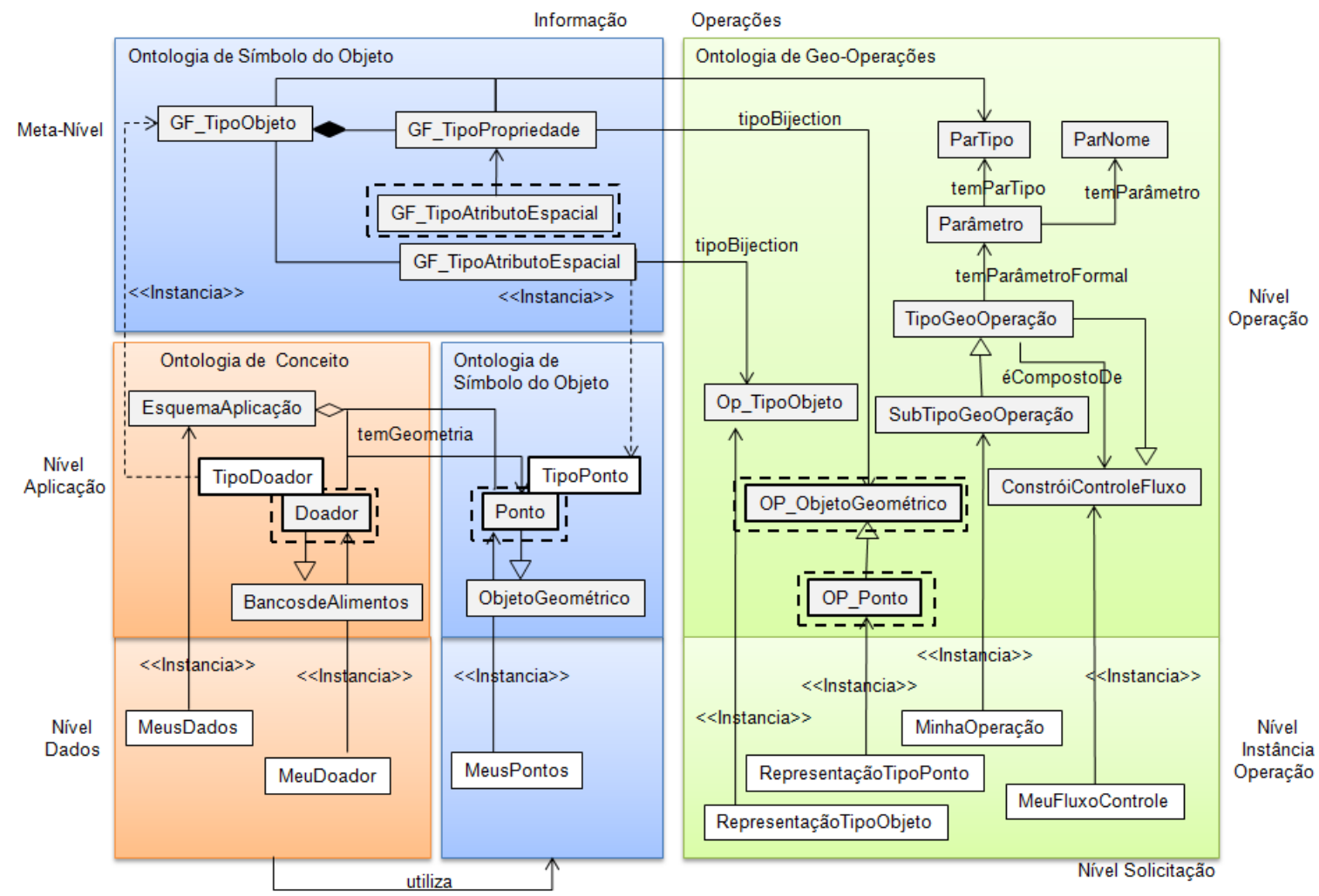

Figura 5.16 - Arquitetura de ontologias para anotação semântica de serviços de geoprocessamento (adaptado de Lemmens, 2006).

A Figura 5.16 é dividida em duas partes, uma que contém elementos relacionados à informação e outra que contém elementos de operações. A figura contém classes, indicadas por caixas cinzas, e instâncias, indicadas por caixas brancas.

A parte relativa à informação é dividida em três níveis horizontais, que representam (1) um "meta-nível", (2) um nível de aplicação e (3) um nível de dados. De acordo com o autor, essa arquitetura em três níveis está de acordo com as camadas propostas pela ISO 19101.

O meta-nível contém classes do Modelo Geral de Objetos (General Feature Model GFM - ISO 19109) que são usadas para classificar os objetos e especificar suas relações. O meta-nível contém duas classes, uma relativa ao tipo de objeto e outra 
relativa às propriedades desse objeto (atributos, comportamento e associação entre objetos).

No nível de aplicação, uma instância da classe TipodeObjeto é um tipo específico de objeto que representa uma classe de um fenômeno do mundo real, por exemplo, Doador. Nesse nível, o objeto recebe a especificação de atributos, como por exemplo, Ponto, que é uma instância de um tipo de atributo espacial.

No nível de dados estão as instâncias dos objetos como, por exemplo DoadorA, DoadorB, etc.

Em um sistema com meta-classes, como o proposto pelo autor, uma classe pode também ser vista como um objeto, no entanto, no estágio atual da linguagem computacional de ontologias não é possível tratar essa classe como objeto e, com isso, criou-se uma alternativa que foi a classe meta-indivíduo. Na Figura 5.11, para representar a associação do meta-indivíduo TipoDoador à classe Doador foram utilizadas duas caixas, uma encostada na outra.

A parte relativa à operação é dividida em três níveis: (1) um nível do tipo de operação, (2) um nível de instância da operação e (3) um nível de solicitação da operação. Os tipos de operação são parte de uma hierarquia de tipos de operação. Os parâmetros de entrada e saída dessas operações são meta-classes definidas no meta-nível de informação. Definições mais específicas de operações requerem a definição de parâmetros também em termos de classes, como Ponto por exemplo. No entanto, não seria apropriado associar os tipos de parâmetros e classes no nível de aplicação da informação, pois isso implicaria, por exemplo, que MeuPonto (que é realmente um ponto com coordenadas) seria uma instância de ParTipo. Por essa razão as classes estruturadas no nível de informação são copiadas para a parte da operação. Os elementos são identificados com um prefixo OP. O tipo de relacionamento tipoBijection é inserido como uma ponte entre as classes de informação no meta-nível e essas classes OP. Essa ponte pode ser vista como uma ponte entre uma classe (por ex. OP_Ponto) e uma meta-classe (Tipo de Atributo Espacial) em que a classe tem apenas uma instância (TipoRepresentacaoPonto). 
Neste sentido uma instância específica de uma operação (minhaOperacao) pode ser associada a um indivíduo que representa um tipo de parâmetro.

\subsubsection{Mapeamento entre OMT-G e Arquitetura de Ontologias.}

O mapeamento entre o OMT-G e a arquitetura de ontologias propostas por Lemmens (2006) pode ser dividido em três etapas. A Figura 5.17 resume as idéias da proposta de mapeamento.

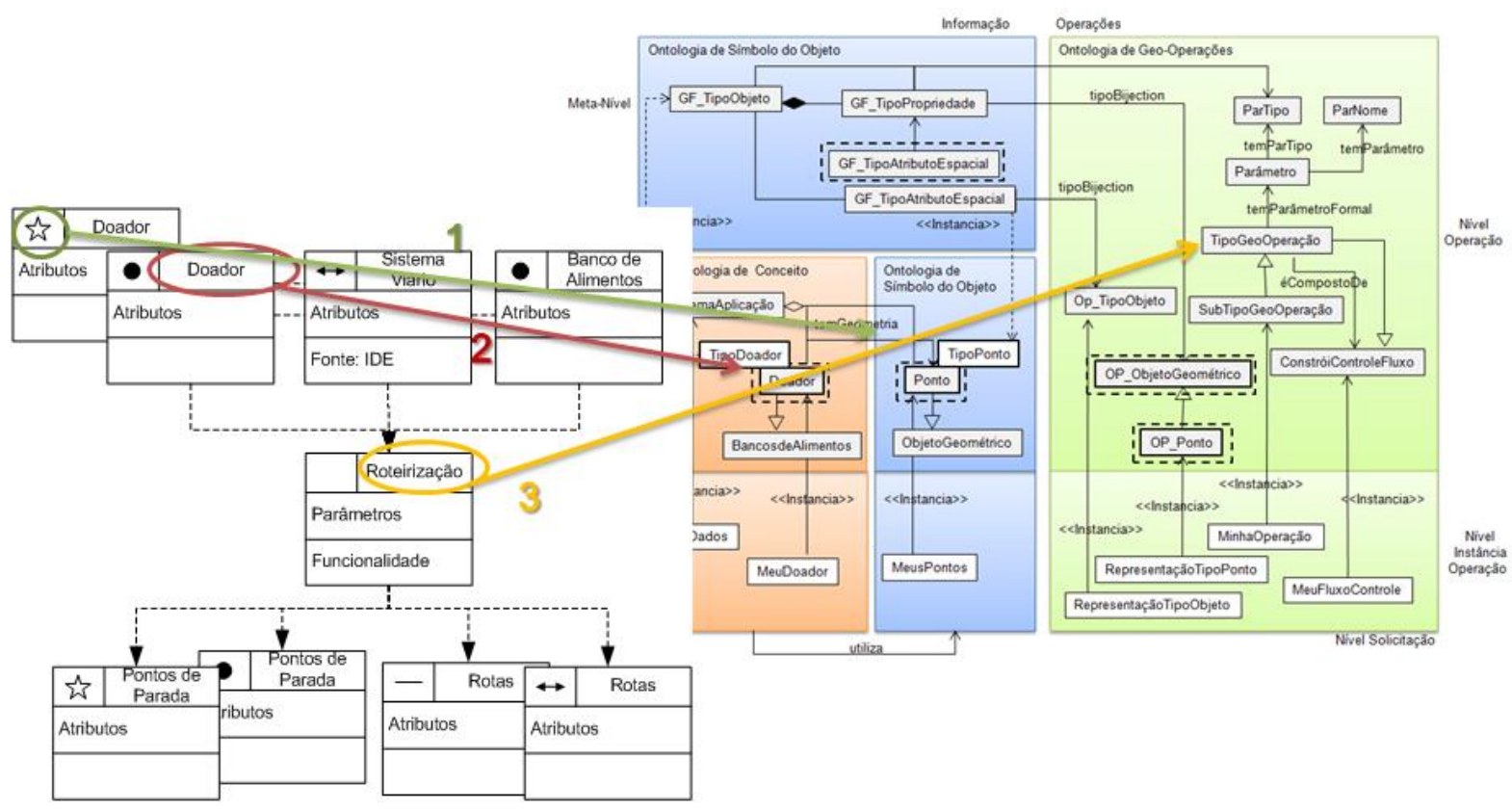

Figura 5.17 - Proposta de mapeamento entre OMT-G e ontologias para anotação semântica de serviços de informações geográficas.

Primeira etapa: desenvolvimento da ontologia de conceitos.

A partir dos nomes atribuídos às classes OMT-G criar classes correspondentes na ontologia seguindo a hierarquia de heranças pré-estabelecida. Em seguida incorporar relacionamentos entre classes e reavaliar a consistência das hierarquias. 
Segunda etapa: desenvolvimento da ontologia de símbolos.

A partir dos tipos de representação, instanciar as classes referentes às representações geométricas na ontologia de símbolos.

Terceira etapa: desenvolvimento da ontologia de operações.

Para esta etapa seria necessário incluir no modelo OMT-G classes que representassem operações, a exemplo do proposto por Ruschel et al. (2008) para o framework GeoFrame.

Cada classe de operação no OMT-G seria mapeada para uma classe de operação da ontologia de operações.

Dentro dessas três etapas de mapeamento, alguns detalhes devem ser observados.

A generalização conceitual proposta no modelo OMT-G pode ser representada nas ontologias através da criação de uma classe na ontologia conceitual referente à superclasse e suas subclasses seriam mapeadas para ontologia de símbolos (Figura 5.18). Ou então através da determinação de uma relação de herança no meta-nível (Figura 5.19).

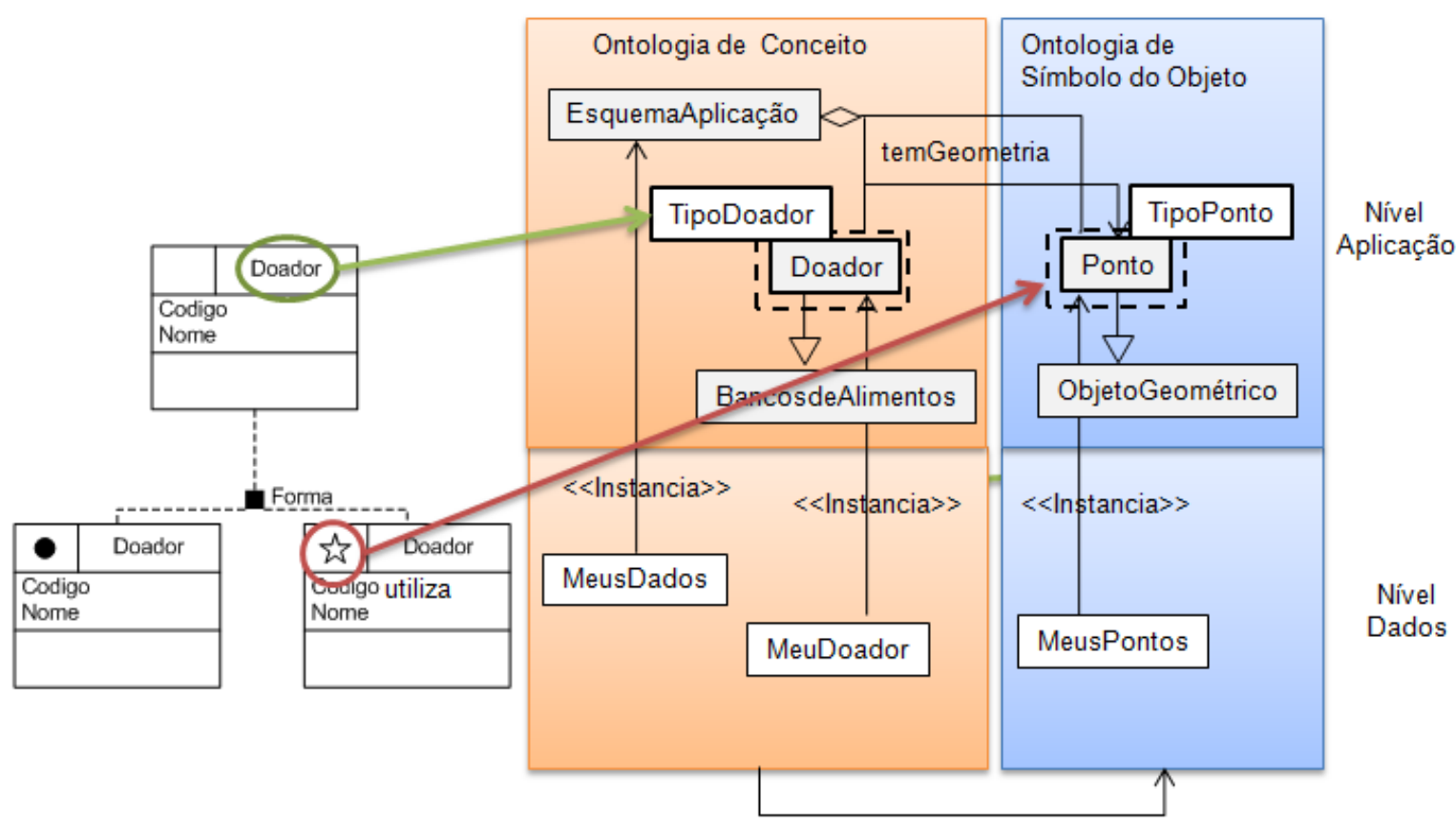

Figura 5.18 - A generalização conceitual no mapeamento entre OMT-G e ontologias. 


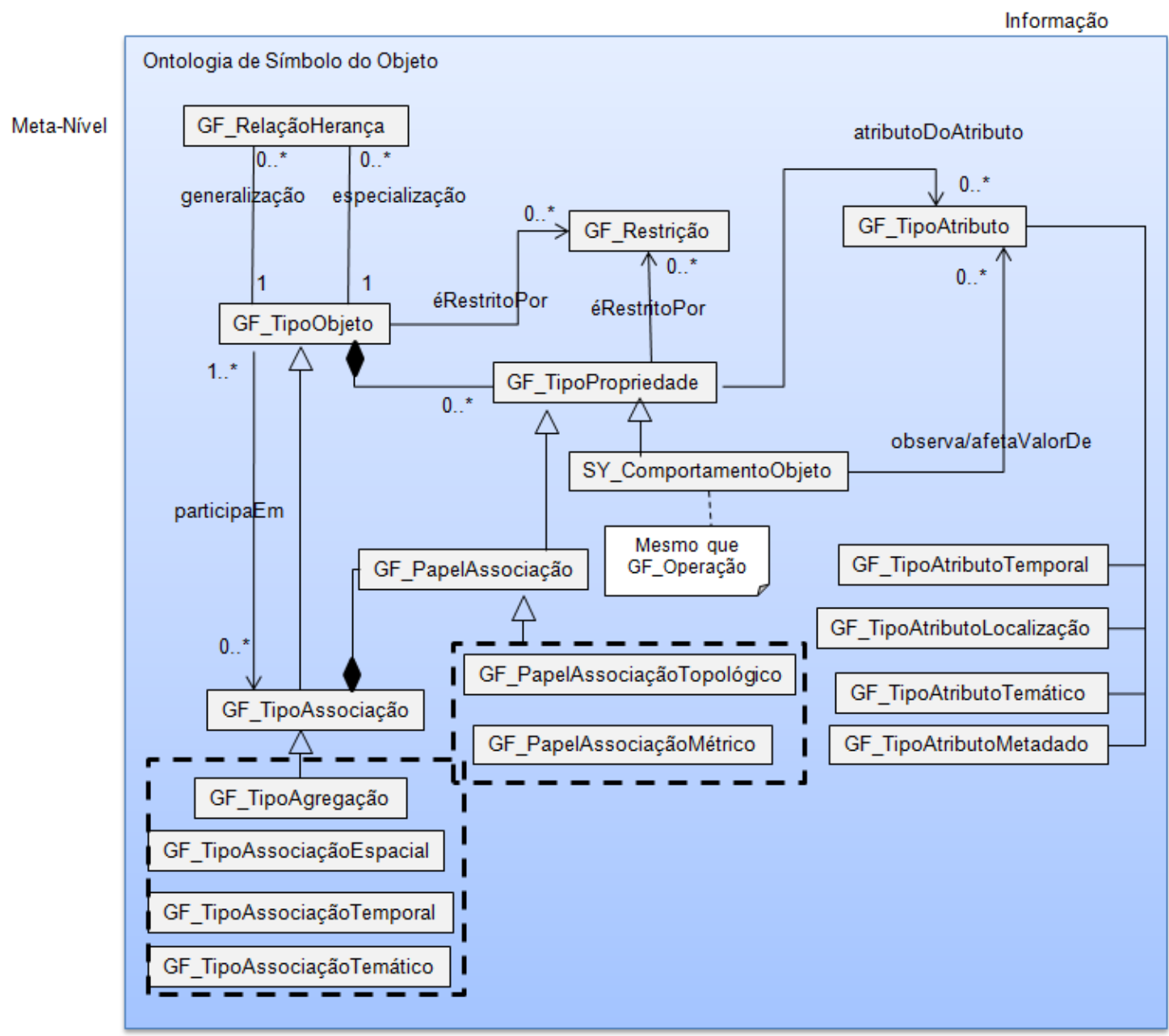

Figura 5.19 - Detalhamento do Meta-Nível da Ontologia de Símbolos (adaptado de Lemmens, 2006).

É também no meta-nível da ontologia de Símbolos que relações espaciais e topológicas podem ser representadas, mais especificamente na classe GF_TipoAssociaçãoEspacial que é uma subclasse GF_TipoAssociação (Figura 5.19).

Especialmente com relação às operações espaciais, Ruschel et al. (2008) propõem que para cada operação seja feito um gráfico de atividades descrevendo as suboperações ou operações atômicas. Se o modelo OMT-G incorporasse uma classe de operações talvez fosse interessante diferenciar operações atômicas ou compostas. Isso porque no caso do encadeamento de serviços essa diferenciação será importante. Somado a isso, algo também teria que ser pensado em termos de como descrever o serviço, quanto à funcionalidade, tipos de dados de entrada e saída. 
Esses últimos, os dados de entrada e saída, poderiam ser representados no próprio modelo, conforme ilustrado na Figura 5.20 (um serviço de roteirização pode ter como dados de entrada pontos ou nós e como dados de saída pontos, linhas ou arcos, etc). Para a aplicação estudada outros tipos de operações espaciais poderiam ser exploradas em sistemas de suporte à decisão, como (1) cálculos de acessibilidade aos bancos de alimentos, doadores ou instituições beneficiadas, (2) buffers para medidas de desempenho relacionadas à abrangência de atuação dos bancos de alimentos, (3) agregação de pontos para agrupar pontos de coleta e distribuição de doações, (4) consultas espaciais para determinar quais bancos de alimentos estão mais próximos a uma determinada instituição, ou quais instituições com uma determinada demanda estão mais próximas de um banco de alimentos ou doador, ou ainda qual banco de alimentos com capacidade de armazenagem está mais próximo a um determinado doador, entre outras possibilidades.

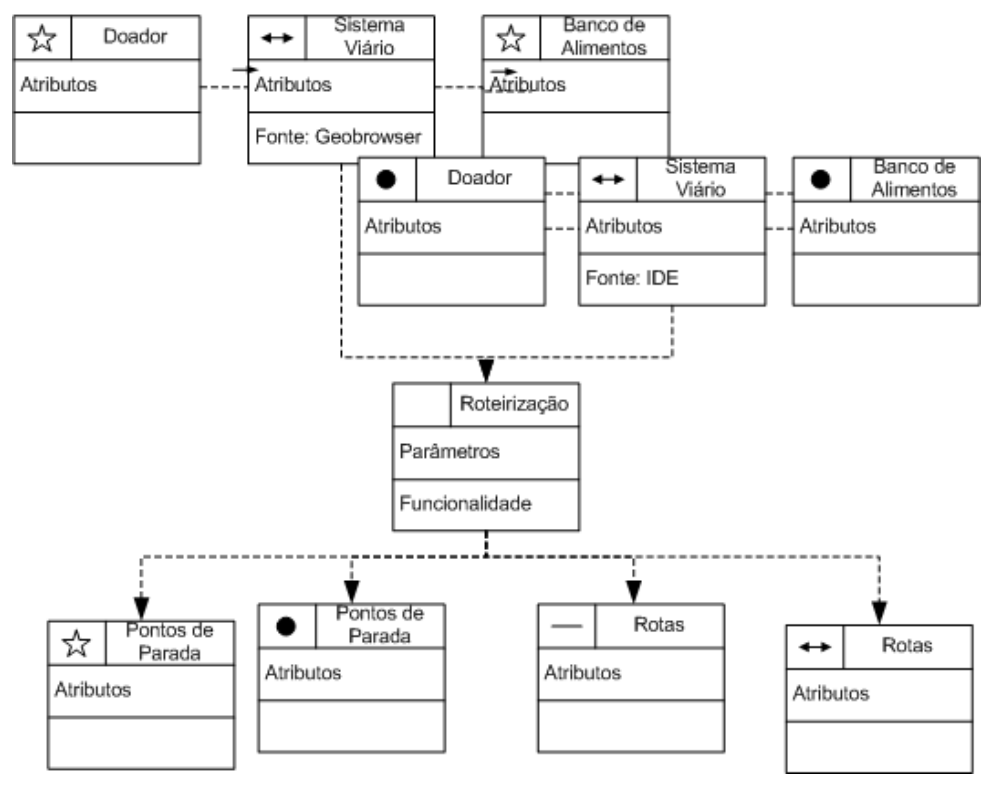

Figura 5.20 - Classe Operações Espaciais.

A Figura 5.21 exemplifica aspectos que podem ser considerados em uma operação complexa como uma roteirização. Pelo número de especificidades apresentado na tabela, constata-se que anotações semânticas de operações complexas precisam ser melhor estudadas. 


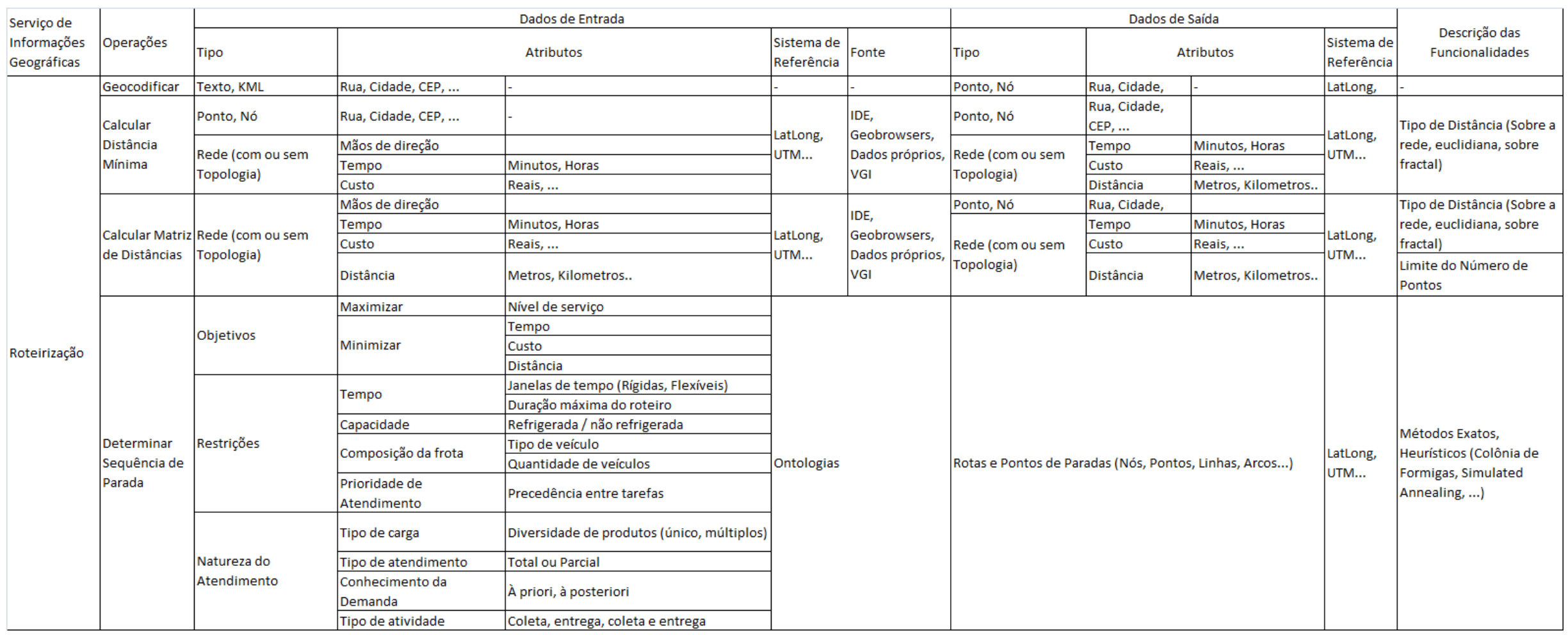

\section{Figura 5.21 - Descrição de um serviço de roteirização.}




\section{Aplicação: Sistema de Apoio aos Bancos de Alimentos}

Este capítulo aborda o protótipo de um Sistema de Apoio aos Bancos de Alimentos (SISBA), desenvolvido como prova de conceito dos aspectos discutidos nos capítulos anteriores desta tese. Para apresentar o protótipo são descritos os requisitos levantados, as etapas de trabalho para seu desenvolvimento, e as funcionalidades implementadas. Ao final do capítulo é discutida uma lista de requisitos mais ampla, como suporte ao desenvolvimento de sistemas de apoio aos bancos de alimentos que possam vir a ser desenvolvidos futuramente.

\subsection{Requisitos do Protótipo}

Foram requisitos para o desenvolvimento do protótipo:

1. Disponibilizar um algoritmo para roteirização como um serviço web;

2. Utilizar dados gratuitos disponíveis em geobrowsers;

3. Disponibilizar o serviço no padrão OGC (WPS);

4. Anotar semanticamente o serviço com as ontologias desenvolvidas na Tese.

5. Contar com um módulo (Middleware) para descobrir e invocar este serviço.

\subsection{Etapas de Desenvolvimento do Protótipo}

Para o desenvolvimento do protótipo, a fim de atingir os requisitos levantados, os desenvolvedores realizaram as seguintes etapas de trabalho. 
1. Disponibilizaram um algoritmo do caixeiro viajante que utiliza dados do Google Maps como um serviço web;

2. Desenvolveram uma versão inicial de uma aplicação que acessa o serviço web e exibe os resultados do planejamento de roteirização;

3. Encapsularam o serviço web desenvolvido como um serviço WPS do OGC;

4. Anotaram o serviço WPS com conceitos da ontologia desenvolvida nesta tese (Figura 6.1);

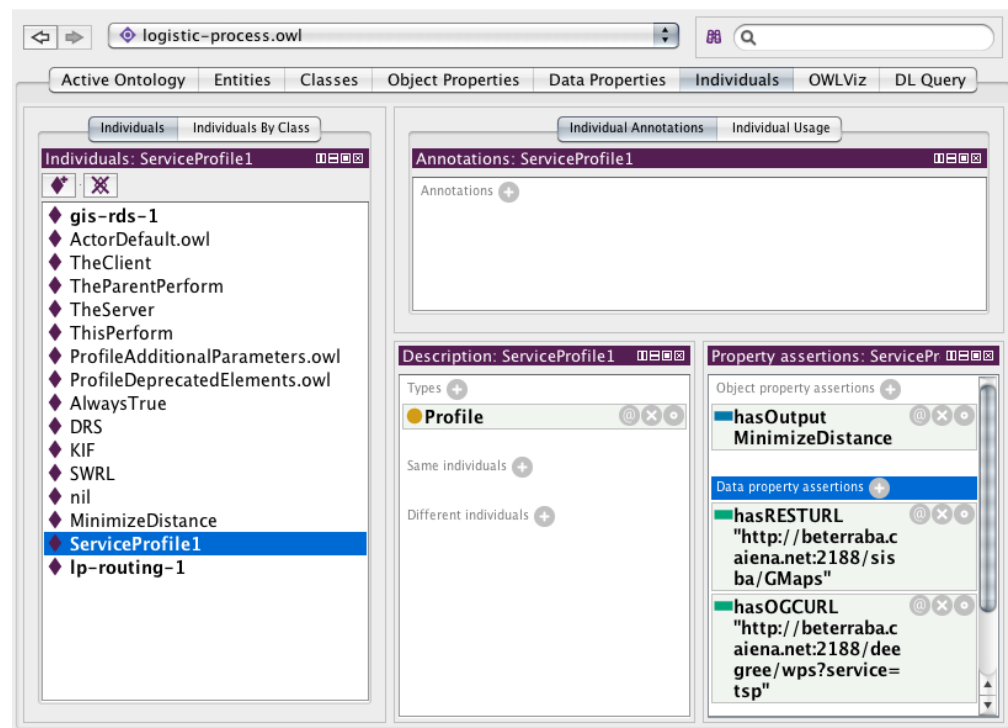

Figura 6.1 - Anotação do serviço com conceitos da ontologia desenvolvida na Tese.

5. Utilizaram um módulo (ex. Middleware) desenvolvido por Marques (2010), que permite descobrir o serviço e invocá-lo.

\subsection{Descrição do Protótipo}

A implementação do protótipo, bem como seus requisitos, foram limitados pelas restrições de tempo e financiamento para seu desenvolvimento. Como o intuito maior era utilizá-lo como uma prova de conceito, priorizou-se a escolha de um 
serviço cujo algoritmo pudesse utilizar dados provenientes de geobrowser, e que conceitos das ontologias desenvolvidas pudessem ser utilizados para anotá-lo.

Nesse sentido, o protótipo implementado possui apenas a funcionalidade de roteirização baseada em um algoritmo do caixeiro viajante. $O$ algoritmo é capaz de encontrar a solução ótima para uma rota multipontos, com até nove pontos, e o objetivo principal do protótipo é fornecer a seqüência dos pontos de parada.

No protótipo optou-se por ter como resultado a seqüência de pontos de parada ao invés de especificar roteiros detalhados com nomes de ruas. Isso se deve, ao pressuposto que o transporte das doações é feito por um motorista experiente em uma ambiente urbanizado. Nessas condições, acredita-se que a maior contribuição do algoritmo seja otimizar a rota entre vários pontos ao invés de detalhar um caminho entre dois pontos, uma vez que entre dois pontos a experiência do motorista e a flexibilidade para tomar decisões diante de possíveis fatores intervenientes na rota, podem ser mais eficazes que seguir o detalhamento prévio fornecido por um algoritmo.

Para utilizar o protótipo o usuário deve digitar os endereços de pontos de coleta ou entrega de doações, a serem visitados, e acionar o algoritmo que calculará a rota (Figura 6.2), que em seguida será disponibilizada em forma de pontos no mapa numerados seqüencialmente, de acordo com o resultado do algoritmo (Figura 6.3), além de uma lista com esta seqüência de pontos de parada. 


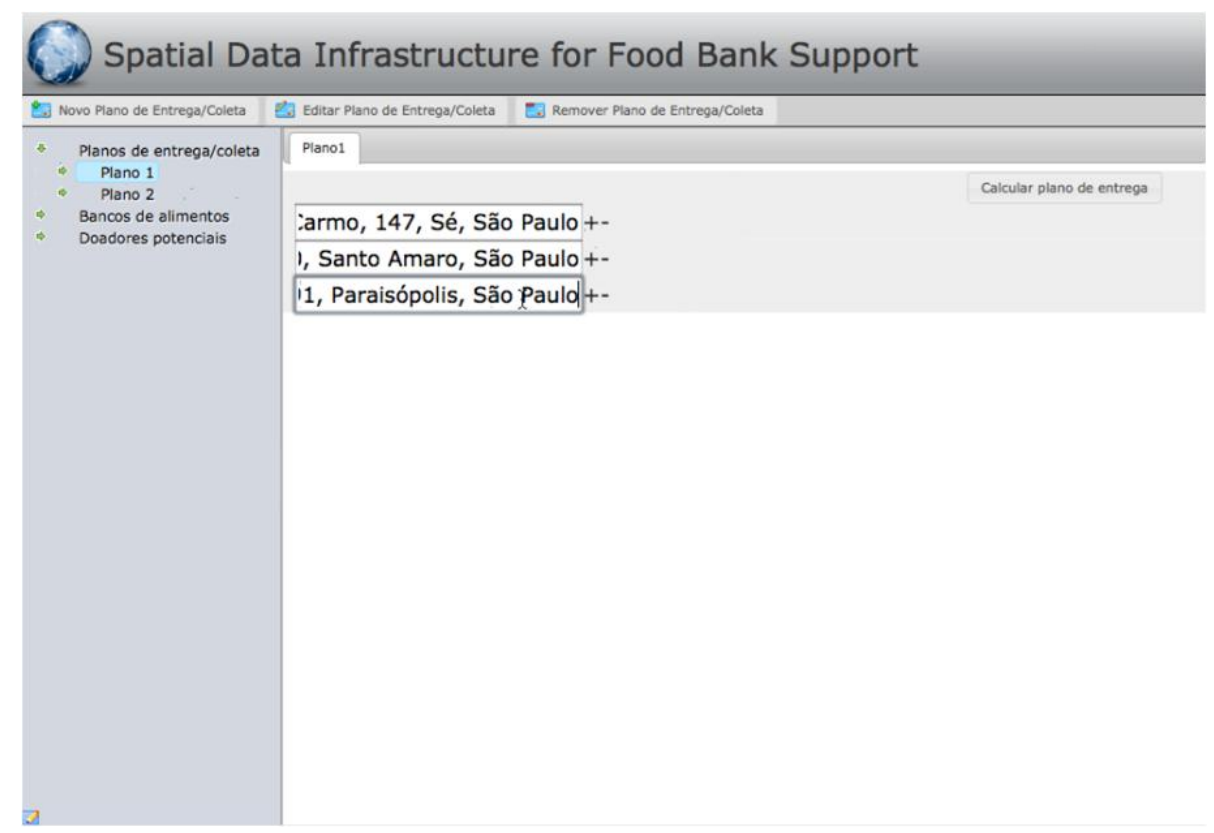

Figura 6.2 - Ilustração do Protótipo do Sistema de Apoio aos Bancos de Alimentos: entrada de dados.

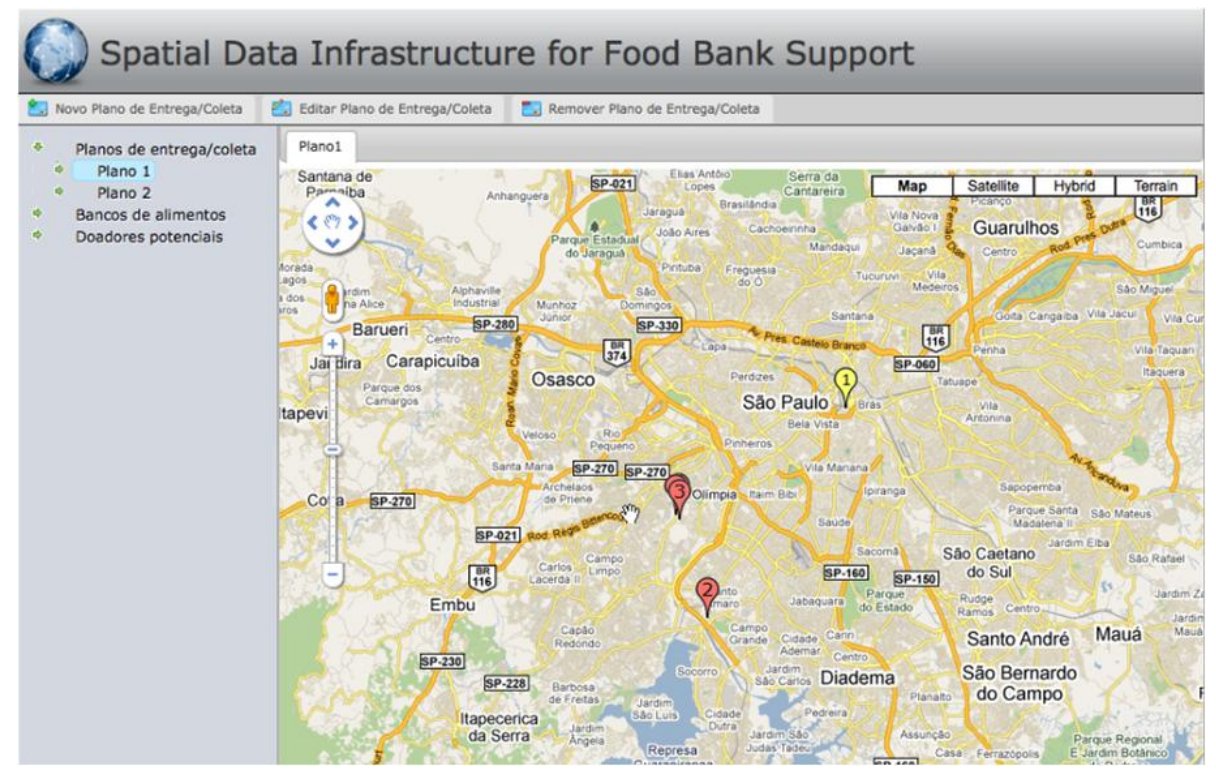

Figura 6.3 - llustração do Protótipo do Sistema de Apoio aos Bancos de Alimentos: mapa com a seqüência de pontos de parada.

Além de calcular as rotas é possível visualizar pontos de bancos de alimentos, doadores potenciais e instituições filantrópicas no mapa. 
6.4. Requisitos para Sistema de Apoio aos Bancos de Alimentos

Por fim, a Tabela 6.1 resume requisitos para concepção de um Sistema de Apoio aos Bancos de Alimentos, baseados nas experiências discutidas nesta tese, a partir da qual o protótipo apresentado foi concebido. 
Tabela 6.1 - Requisitos para desenvolvimento de um Sistema de Apoio aos Bancos de Alimentos.

\begin{tabular}{|c|c|c|c|c|c|}
\hline SubSistema & Funcionalidade & Descrição & GeoWebServices & Dados Necessários & Fontes de Dados \\
\hline \multirow[t]{5}{*}{$\begin{array}{l}\text { Suporte a } \\
\text { Operação de } \\
\text { Transportes }\end{array}$} & \multirow[t]{2}{*}{$\begin{array}{l}\text { Busca por } \\
\text { prestadores de } \\
\text { serviço de } \\
\text { transporte } \\
\text { colaborativo } \\
\text { (aproveitamento do } \\
\text { frete de retorno) }\end{array}$} & $\begin{array}{l}\text { Enviar alerta para } \\
\text { potenciais } \\
\text { prestadores de } \\
\text { serviço }\end{array}$ & $\begin{array}{l}\text { 1.WFS:Extrair } \\
\text { endereços } \\
\text { estruturados } \\
\text { 2.Enviar } \\
\text { mensagens (MSN) }\end{array}$ & $\begin{array}{l}\text { Pontos de origem e } \\
\text { destino das } \\
\text { doações } \\
\text { (Doadores, Bancos } \\
\text { de Alimentos, } \\
\text { Instituições) }\end{array}$ & \multirow{5}{*}{$\begin{array}{l}\text { 1.Nova entrada de } \\
\text { dados } \\
\text { 2. Bancos de dados } \\
\text { 3.Geobrowsers } \\
\text { 4. Infraestruturas de } \\
\text { Dados Espaciais }\end{array}$} \\
\hline & & $\begin{array}{l}\text { Registrar } \\
\text { candidatos }\end{array}$ & $\begin{array}{l}\text { 1.WFS:Geocodificar } \\
\text { 2.WFS:Inserir } \\
\text { pontos } \\
\text { 3.WMS:Visualizar } \\
\text { pontos }\end{array}$ & $\begin{array}{l}\text { Localização do } \\
\text { veículo de } \\
\text { transporte }\end{array}$ & \\
\hline & \multirow[t]{2}{*}{$\begin{array}{l}\text { Suporte à } \\
\text { contratação de } \\
\text { serviços de } \\
\text { transporte }\end{array}$} & \multirow[t]{2}{*}{$\begin{array}{l}\text { Estimar custo do } \\
\text { serviço de } \\
\text { transporte }\end{array}$} & \multirow[t]{2}{*}{ WPS:Roteirizar } & $\begin{array}{l}\text { Pontos de origem e } \\
\text { destino das } \\
\text { doações } \\
\text { (Doadores, Bancos } \\
\text { de Alimentos, } \\
\text { Instituições) }\end{array}$ & \\
\hline & & & & Rede viária & \\
\hline & $\begin{array}{l}\text { Suporte a decisões } \\
\text { de roteirização }\end{array}$ & $\begin{array}{l}\text { 1.Visualizar pontos } \\
\text { de Origem Destino } \\
\text { (OD) } \\
\text { 2. Agregar pontos } \\
\text { OD } \\
\text { 3. Calcular rotas }\end{array}$ & $\begin{array}{l}\text { 1.WMS, 2.WFS } \\
\text { 3.WPS: } \\
\text { 3.1.Agregar } \\
\text { pontos } \\
\text { 3.2.Calcular } \\
\text { buffers } \\
\text { 3.3. Calcular rotas }\end{array}$ & Rede viária & \\
\hline
\end{tabular}


Tabela 6.1 - Requisitos para desenvolvimento de um Sistema de Apoio aos Bancos de Alimentos (Continuação).

\begin{tabular}{|c|c|c|c|c|c|}
\hline SubSistema & Funcionalidade & Descrição & GeoWebServices & Dados Necessários & Fontes de Dados \\
\hline \multirow[t]{2}{*}{$\begin{array}{l}\text { Suporte ao } \\
\text { Gerenciamento de } \\
\text { Estoques }\end{array}$} & $\begin{array}{l}\text { Visualizar estoques } \\
\text { de Bancos de } \\
\text { Alimentos }\end{array}$ & $\begin{array}{l}\text { Visualizar } \\
\text { capacidade (livre) } \\
\text { dos estoques }\end{array}$ & 1.WMS:Map service & $\begin{array}{l}\text { Localização dos } \\
\text { estoques }\end{array}$ & \multirow{4}{*}{$\begin{array}{l}\text { 1. Nova entrada de } \\
\text { dados } \\
\text { 2. Bancos de dados } \\
\text { 3.Geobrowsers } \\
\text { 4. Infraestruturas de } \\
\text { Dados Espaciais }\end{array}$} \\
\hline & $\begin{array}{l}\text { Fazer consultas } \\
\text { espaciais sobre } \\
\text { estoques de bancos } \\
\text { de alimentos e } \\
\text { visualizar respostas }\end{array}$ & $\begin{array}{l}\text { Ex de consultas: } \\
\text { 1.Qual é o BA mais } \\
\text { próximo que possui } \\
\text { leite (x litros) para } \\
\text { ser doado? } \\
\text { 2.Com é o BA com } \\
\text { capacidade livre no } \\
\text { estoque para } \\
\text { receber } \\
\text { determinada } \\
\text { doação? }\end{array}$ & $\begin{array}{l}\text { 1.WMS } \\
\text { 2.WPS }\end{array}$ & $\begin{array}{l}\text { Pontos de origem e } \\
\text { destino das } \\
\text { doações } \\
\text { (Doadores, Bancos } \\
\text { de Alimentos, } \\
\text { Instituições) }\end{array}$ & \\
\hline $\begin{array}{l}\text { Medidas de } \\
\text { desempenho } \\
\text { logístico }\end{array}$ & $\begin{array}{l}\text { Calcular } \\
\text { indicadores } \\
\text { espaciais e } \\
\text { visualizá-los }\end{array}$ & $\begin{array}{l}\text { Ex de indicadores: } \\
\text { 1.Distribuição } \\
\text { espacial das } \\
\text { instituições } \\
\text { atendidas } \\
\text { 2.Calculo da } \\
\text { acessibilidade dos } \\
\text { BAs }\end{array}$ & $\begin{array}{l}\text { 1.WMS } \\
\text { 2.WPS }\end{array}$ & $\begin{array}{l}\text { Pontos de origem e } \\
\text { destino das } \\
\text { doações } \\
\text { (Doadores, Bancos } \\
\text { de Alimentos, } \\
\text { Instituições) }\end{array}$ & \\
\hline $\begin{array}{l}\text { Suporte a decisão } \\
\text { de localização de } \\
\text { estoque de BA }\end{array}$ & $\begin{array}{l}\text { Visualizar atributos } \\
\text { relacionados aos } \\
\text { critérios de tomada } \\
\text { de decisão }\end{array}$ & & $\begin{array}{l}\text { 1.WMS } \\
\text { 2.WFS } \\
\text { 3.WPS }\end{array}$ & $\begin{array}{l}\text { Dados sócio- } \\
\text { econômicos e } \\
\text { Pontos OD das } \\
\text { doações }\end{array}$ & \\
\hline
\end{tabular}




\section{Conclusões e ReCOMENDAÇões PARA tRABalHos FUtUROS}

Esta tese abordou as áreas do conhecimento referentes à logística, logística humanitária, serviços de informações geográficas e ontologias. Foram desenvolvidas ontologias para aumentar a interoperabilidade semântica em sistemas de apoio à logística humanitária que utilizam serviços de informações geográficas. A aplicação de logística humanitária estudada foi a operação de bancos de alimentos. O conhecimento relativo aos processos logísticos, problemas logísticos de bancos de alimentos e serviços de informações geográficas úteis para os métodos de solução desses problemas foram formalizados em uma rede de ontologias.

A associação de processos logísticos de bancos de alimentos ao domínio de logística humanitária permitiu que as referências conceituais relacionadas à logística humanitária pudessem nortear o desenvolvimento de metodologias de apoio à logística de bancos de alimentos. A formalização desses conceitos através de ontologias possibilita que estes modelos referenciais sejam compartilhados e aprimorados.

A partir da discussão feita no capítulo dois foi possível concluir que a logística humanitária refere-se aos princípios distintos da logística empresarial. A despeito disso os modelos ainda se baseiam, majoritariamente, no arcabouço conceitual criado para a logística empresarial, que tem raízes na lógica capitalista clássica. Será necessário, dentro dessa área de conhecimento, não apenas discutir melhor os conceitos relacionados, como também aplicar nos modelos métodos de soluções de problemas logísticos que se baseiem nesses conceitos levantados.

Notou-se também que o termo logística humanitária abriga uma série de problemas com contextos diferentes, cujas especificidades precisam ser melhor investigadas. Nesse sentido, lidar com processos logísticos relativos aos bancos de alimentos favoreceu à identificação de aspectos relacionados a operações humanitárias de longo prazo, diferentemente do que usualmente é discutido nas pesquisas relativas a logística humanitária, que se referem às operações de curto prazo decorrentes de situações emergenciais provocadas por desastres naturais. 
Ao desenvolver as ontologias de processos logísticos percebeu-se que a complexidade para o desenvolvimento de ontologias relativas aos processos devese, em grande parte, à falta de referências consensuais na comunidade científica sobre processos, eventos, estados e ações de fenômenos geográficos.

Somado a isso, existem poucas iniciativas de formalizar os conceitos de processos em ontologias, o que dificulta ainda mais esta tarefa por falta de exemplos que possam ser comparados. Nesse sentido, sugere-se que mais aplicações sejam modeladas através de ontologias, mesmo que seu mapeamento com ontologias de alto nível ainda seja difícil. O mapeamento entre ontologias de domínio pode gerar considerações importantes a serem incorporadas nas ontologias de alto nível. Ou seja, o próprio desenvolvimento de ontologias pode ser o meio através do qual os conceitos são rediscutidos em busca de um consenso pretendido dos termos referentes aos processos de fenômenos geográficos.

Novas metodologias de mapeamento de ontologias, como a proposta por Hornsby e King (2008), ratificam essa idéia. Os autores desenvolvem uma metodologia para fazer o mapeamento das ontologias relativas às informações coletadas por diferentes geosensores, mapeando as classes através da comparação das instâncias nas ontologias. Com o número crescente de geosensores, esse tipo de mapeamento pode trazer novas contribuições para as discussões de conceitos relativos aos processos. Em suma, a discussão de conceitos relativos a processos pode ser feita através da própria linguagem de ontologias, a partir do acúmulo de diferentes visões formalizadas.

Com relação às anotações semânticas de serviços de informações geográficas, a evolução de metodologias abre uma perspectiva interessante para se trabalhar com informações espaciais em ambientes distribuídos. As ontologias, atualmente, são apontadas como a melhor forma para fazer essas anotações semânticas e permitir que o potencial da Web semântica na área de geoprocessamento seja bem explorado. No entanto, o desenvolvimento de ontologias ainda constitui uma tarefa árdua, principalmente para pesquisadores sem embasamento na área de ciência da computação, dado que alguns conceitos ainda não podem ser abstraídos e uma carga considerável de aprendizagem é necessária para o desenvolvimento de 
ontologias. Somado a isso, constatou-se que as linguagens computacionais utilizadas para formalização de ontologias estão em pleno processo de evolução, o que faz com que sejam poucos os programas que suportam esse tipo de atividade.

Especificamente com relação às anotações semânticas de serviços de informações geográficas, alguns passos iniciais foram dados pela comunidade científica, mas para que os inúmeros tipos de operações espaciais já mapeadas possam de fato ser utilizados ainda será necessário um esforço considerável para que a semântica dessas operações seja melhor definida. Uma vez encontradas metodologias eficientes e consolidadas para anotar semanticamente os serviços de geoprocessamento, o universo de cadeias de serviços que poderão ser gerados através de sua composição automática ampliará muito a utilidade de serviços de informações geográficas. É importante também comentar que pesquisar sobre a semântica dessas operações possivelmente permitirá que novas operações sejam criadas, impulsionando os pesquisadores a pensar em operações espaciais que resultem em soluções mais criativas e eficazes do que aquelas possíveis a partir do conjunto de operações espaciais hoje disponíveis nos softwares de SIG do mercado.

A partir dessas idéias ao final do capítulo cinco, é mencionada a possibilidade de mapeamento de modelos conceituais para dados espaciais, no caso o OMTG, para uma arquitetura de ontologias que sirva de suporte para o encadeamento de serviços de informações geográficas. No decorrer do desenvolvimento desse mapeamento foi possível identificar uma série de aspectos que, se fossem considerados durante a modelagem, facilitariam o mapeamento para ontologias que fossem mais expressivas com relação à possibilidade de usá-las em anotações semânticas de serviços de informações geográficas.

E, por fim, sugeriu-se uma arquitetura para sistemas de apoio a logística humanitária, baseada em serviços e dados gratuitos, que conte também com a possibilidade de contribuições voluntárias de informações geográficas, além da possibilidade de considerar essa arquitetura em diferentes contextos de operações humanitárias. 


\section{REFERÊNCIAS}

AALDERS, H.J.G.L. Inter-operability. In: Spatial Data Infrastructure. Wageningen Universiteit. $2001 . \quad$ Disponível em:< http://www.gdmc.nl/publications/2001/Spatial_data_infrasructure.pdf >. Acesso em 05 nov. 2010.

AGARWAL P. Ontological considerations in GIScience. International Journal of Geographic Information Science, v. 19, n. 5, p. 501-536, maio, 2005.

AKATU. A nutrição e o consume consciente. Disponível em: <http:www.akatu.org.br>, 2003. Acesso em: 10 mar. 2010.

AKKIHAL A. R. Inventory Pre-Positioning for Humanitarian Operations. Engineering Systems Division, Massachusetts Institute of Technology, Boston, USA. 2006.

ALBRECHT, J. Semantic net of universal elementary GIS functions. In: Proceedings ACSM/ASPRS Annual Convention and Exposition Technical Papers, v. 4, p. 235244. 1995.

ALBRECHT, J. Universal analytical GIS operations: a task-oriented systematization of data structure-independent GIS functionality. In: Geographic Information Research: transatlantic perspectives, M. Craglia and H. Onsrud, Eds., Taylor \& Francis, p. 577-591. 1998.

ALBRECHT, J. Derman, B., and Ramasubramanian, L.. Geo-ontology tools: The missing link. Transactions on GIS, v. 12, n.4, p.409-424. 2008.

ANGELIS, V.D., MECOLI, M., NIKOI, C. AND STORCHI, G. Multiperiod integrated routing and scheduling of World Food Programme cargo planes in Angola. Comput. Operation Research, v. 34, n. 6, p. 1601-1615. 2007. 
BALCIK, B. BEAMON, B. M. Facility Location in Humanitarian Relief. International Journal of Logistics: Research and Applications, v. 11, n 2, p. 101-121. 2008.

BALCIK, B., BEAMON, B. M., SMILOWITZ, K. Last mile distribution in humanitarian relief. Journal of Intelligent Transportation Systems: Technology, Planning, and Operations v. 12, n. 2, p. 51-63. 2008.

BALLOU, R. H. Gerenciamento da cadeia de suprimentos/logística empresarial. 5 ed. Porto Alegre: Bookman. 2006. 616p.

BALLOU, R. H. Gerenciamento da cadeia de suprimentos: planejamento, organizações e logística empresarial. 4. ed. Porto Alegre: Bookman. 2001. 532p.

BEAMON, B. M. Humanitarian Relief Chains: Issues and Challenges. In: 34th International Conference on Computers and Industrial Engineering. São Francisco, CA, USA. 2004.

BEAMON, B.M.; KOTLEBA, S.K. Inventory management support systems for emergency humanitarian relief operations in South Sudan. The International Journal of Logistics Management, v. 17. 2006.

BERNERS-LEE, T.; HANDLER, J.; LASSILA, O. The semantic web: A new form of web content that is meaningful to computers will unleash a revolution of new possibilities. Scientific American, v. 284, n. 5, p. 34-43. 2001.

BISHR, Y. Overcoming the Semantic and Other Barriers to GIS Interoperability. International Journal of Geographical Information Science, v. 12, n. 4, p. 299314, jan. 1998.

BLANCO, E.; GOENTZEL, J. Humanitarian Supply Chains: A Review. Seventeenth Annual POMS Conference, Boston, abr/mai. 2006. 
BORGES, K. A. V., DAVIS JR., C. A., LAENDER, A. H. F. Modelagem Conceitual de Dados Geográficos. In: Casanova, M. A., Câmara, G., Davis Jr., C. A., Vinhas, L., Queiroz, G. R. (Eds.) Bancos de Dados Geográficos. Curitiba (PR): EspaçoGeo, 2005, p. 93-146. 2005.

BRAUNER, J.; FOERSTER, T.; SCHAEFFER, B.; BARANSKI, B.: Towards a Research Agenda for Geoprocessing Services. In 12th AGILE International Conference on Geographic Information Science. Ed. Jan Haunert, B. Kieler, and J. Milde. Hanover, Germany: IKG, Leibniz University of Hanover, 2009.

BREIN (Business objective driven Reliable and Inteligent grids for real business). Apresenta recursos e atividades de desenvolvidas. Disponível em: <http://www.eubrein.com/>. Acesso em 10 mar. 2010.

BROCK, D.L.; SCHUSTER, E.W.; ALLEN, S.J.; KAR, P. An Introduction to Semantic Modeling for Logistical Systems. Journal of Business Logistics, v. 26, p. 97-118, 2005.

BURROUGH, P. Development of intelligent geographical information systems. In International Journal of Geographical Information Systems, v. 1, p. 1-11. 1992.

BUTLER, D. Mashups mix data into global service. Nature, v. 439, n. 5, p. 6-7, jan, 2006a.

BUTLER, D. Virtual globes: The web-wide world. Nature, v. 439, n. 16, p. 776-778, fev, 2006b.

CÂMARA, G., MONTEIRO, A. M. V., PAIVA, J., AND SOUZA, R. C. M. Action-driven ontologies of the geographical space. In: GIScience 2000, ed. M. J. Egenhofer and D. M. Mark (Savannah, GA: AAG). 2000. 
CÂMARA, G.; FONSECA, F.; MONTEIRO, A.M.V.; ONSRUD, H. Networks of Innovation and the Establishment of a Spatial Data Infrastructure in Brazil. Information Technology for Development, v. 12, n. 4, p.255-272, 2006.

CEAGESP (2006). Relatório mensal do banco CEAGESP de alimentos . Disponível em: http://www.ceagesp.gov.br/social/bca/redebca. Acesso em 05 nov 2010.

CHAN, T. O.; FEENEY, M.; RAJABIFARD, A.; WILLIAMSON, I. The Dynamic Nature of Spatial Data Infrastructures: A Method of Descriptive Classification. Geomatica, v. 55, n. 1, p. 451-462, 2001.

CHRISMAN, N. A transformational approach to GIS operations. International Journal of Geographical Information Science. v. 13, n. 7, p. 671-637. 1999.

CHRISMAN, N. Exploring Geographical Information Systems, second ed. Wiley and Sons, 2002.

CLARAMUNT, C. AND M. THERIAULT. Toward semantics for modelling spatiotemporal processes within GIS, Proc. of International Symposiom on Spatial Data Handling (SDH'96), Netherlands, 1996.

COUNCIL OF LOGISTICS MANAGEMENT PROFESSIONALS. Apresenta recursos e atividades desenvolvidas. Disponível em: < http://cscmp.org >. Acesso em: 10 mar. 2010.

COTTAM, H., ROE, M.; CHALLACOMBE, J. Outsourcing of trucking activities by relief organizations. Journal of Humanitarian Assistance. 2004.

CRAGLIA, M. Volunteered Geographic Information and Spatial Data Infrastructures: when do parallel lines converge? Position paper for the VGI Specialist Meeting, Santa Barbara, dez, 2007. 
CRAGLIA, M.; GOODCHILD, M.; ANNONI, A.; CÂMARA, G.; GOULD, M.; KUHN, W.; MARK, D.; MASSER, I.; MAGUIRE, D.; LIANG, S.; PARSONS, E. NextGeneration Digital Earth. International Journal of Spatial Data Infrastructures Research, v. 3; p. 146-167, 2008.

CROMPVOETS, J., BREGT, A., RAJABIFARD, A. AND WILLIAMSON, I. Assessing the worldwide developments of national spatial data clearinghouses. International Journal of Geographical Information Science, v. 18, n. 7, p. 665-689, 2004.

CUSTODIO, M. B. A caracterização da demanda do banco de alimentos municipal de São Paulo: a exclusão social e a procura por alimentos doados institucionalmente. 2004. 112p. Dissertação (Mestrado). Programa de PósGraduação Interunidades em Nutrição Humana Aplicada - PRONUT. Faculdade de Ciências Farmacêuticas, Faculdade de Saúde Pública e Faculdade de Economia, Administração e Contabilidade da Universidade de São Paulo, São Paulo, 2004.

DAVIDSON, A.L. "Key performance indicators in humanitarian logistics", Master of Engineering in Logistics thesis, Massachusetts Institute of Technology, Cambridge, MA, available at: http://ctl.mid.edu (accessed, march, 2009). 2006.

DAVIS JR. C. A.; FONSECA, F. T.; CÂMARA, G. Beyond SDI: Integrating Science and Communities to Create Environmental Policies for the Sustainability of the Amazon. International Journal of Spatial Data Infrastructures Research, v. 4, p. 156-174, 2009.

DAVIS JR. C. A. AND ALVES, L. L. Local Spatial Data Infrastructures Based on a Service Oriented Architecture. In Proc. of Brazilian Symposium on Geoinformatics, p. 3045. 2005.

DAVIS, C. A.; SIKORSKI, S.; YUAÇA, F. SIG em prefeituras. In Ferrari, R. Viagem ao SIG, 139-156, Editora Sagres, 1997. 
DEVARAJU, A.; KUHN, W. A Process-Centric Ontological Approach for Integrating Geo-Sensor Data. A Process-Centric Ontological Approach for Integrating GeoSensor Data, 6th International Conference on Formal Ontology in Information Systems (FOIS 2010), Toronto, Canada, May 11-14, 2010.

DÍAZ, L., GRANELL, C. AND GOULD, M. Case Study: Geospatial processing services forweb-based hydrological applications. In: J.T. Sample, K. Shaw, S. Tu, M. Abdelguerfi (Eds.): Geospatial Services and Applications for the Internet. Springer, 2008.

EHLERS, M. Geoinformatics and digital earth initiatives: a German perspective. International Journal of Digital Earth, v. 1, n. 1, p. 17-30, 2008.

ELWOOD, S. Critical Issues in Participatory GIS: Deconstructions, Reconstructions, and New Research Directions. Transactions in GIS, v. 10, n. 5, pp. 693-708, 2006.

ELWOOD, S. Grassroots groups as actors in spatial data infrastructures: challenges and opportunities for local data development and sharing. International Journal of Geographical Information Science, v. 22, n. 1, p. 71-90, 2008.

ELWOOD, S. Position paper for the VGI Specialist Meeting, Santa Barbara, dez, 2007.

FEBA. Fédération Européennes de Banques Alimentaires. Apresenta recursos e atividades desenvolvidas. Disponível em: <http://www.eurofoodbank.org/> 2008. Acesso em: 02 set. 2008.

FENSEL, D.; HENDLER, J.; LIEBERMAN, H.; WAHLSTER,W. Spinning the Semantic Web. Cambridge, MA: MIT Press. 2003. 
FGDC (Federal Geographic Data Committee). Apresenta recursos e atividades desenvolvidas. Disponível em: <http://www.fgdc.gov/>. Acesso em: 10 mar. 2010.

FOERSTER, T., BROERING, A., JIRKA, S., \& MUELLER, J. Sensor Web and Geoprocessing Services for Pervasive Advertising. In: Workshop for pervasive advertising, Luebeck, Alemanha. 2009.

FONSECA, F. T.; EGENHOFER, M. J.; DAVIS JR.; C. A.; BORGES, K. A. V. Ontologies and knowledge sharing in urban GIS. Computers. Environment and Urban Systems. v 24, n. 3, p. 251-272, , mai, 2000.

FOOK, K. MONTEIRO, A. M. CÂMARA, G. CASANOVA, M. Amaral, S. Geoweb services for sharing modelling results in biodiversity networks". Transactions in GIS. v.13, n.4, p.379-399. 2009.

FORESMAN, T. W. Evolution and implementation of the Digital Earth vision, technology and society. International Journal of Digital Earth, v.1, n. 1, p. 4-16, 2008.

FRANK, A. U. Ontology. In: Encyclopedia of Geographic Information Science. (K. Kemp ed.) Thousand Oaks, CA, Sage Publications. (in press). 2007. Disponível em: $<\mathrm{ftp}$ ://ftp.geoinfo.tuwien.ac.at/frank/Ontology-2rev-v4.pdf> Acesso em 23/09/2008.

FRIIS-CHRISTENSEN, A.; LUCCHI, R.; LUT, M.; OSTLANDER, N. Service chaining architectures for applications implementing distributed geographic information processing. International Journal of Geographical Information Systems. v. 23, n. 5, p. 561-580, 2009.

FULLER, 1969, Operating Manual for Spaceship Earth. Touchstone. New York. Disponível em: http://classes.design.ucla.edu/Spring07/9-1/_pdf/3-fuller_operatingmanual.pdf. Acesso em: 17/10/2008. 
GAMBARDELLA, A. D. Doação de alimentos: fetiche ou política de segurança alimentar. 2005. Dissertação (Mestrado). Serviço Social. Pontifícia Universidade Católica de São Paulo, São Paulo, 2005.

GASEVIC, D., DJURIC, D., DEVEDZIC, V., AND DAMJANOVIC, V.. Converting UML to OWL ontologies. In Proceedings of the 13th International World Wide Web Conference, New York, p. 488-489. 2004.

GIMÉNEZ D.M., VEGETTI M., LEONE H.P., HENNING G.P. PRoduct ONTOlogy: Defining product-related concepts for logistics planning activities. Computers in Industry. v. 59, p. 231-241. 2008.

GÖBEL, R., ZIPF, A. How to define 3D geoprocessing operations for the OGC web processing service (WPS)? Towards a classification of 3D operations. International Workshop on Computational Geoinformatics, Perugia, Italy. 2008.

GÓMEZ-PÉREZ, A.; FERNANDEZ-LÓPEZ, M.; CORCHO, O. Ontological Engineering: With Examples from the Areas of Knowledge Management, eCommerce and the Semantic Web, Springer-Verlag, nov, 2003.

GOODCHILD M. F. Citizens as sensors: the world of volunteered geography. GeoJournal, v. 69, p. $211-221,2007$.

GOODCHILD, M. Spatial Analysis Using GIS: a seminar workbook $2^{\circ}$ National Center for Geographic Information and Analysis, University of California, Santa Barbara. USA. 1992.

GOODCHILD, M. F. Spatial Analysis and GIS. In Proceedings ESRI UsernConference Pre-Conference Seminar. 2001. 
GORE. The Digital Earth: Understanding our planet in the 21st Century. Disponível em: <. http://www.isde5.org/al_gore_speech.htm>. 1998. Acesso em 24/10/2008.

GOULD, M. Position paper for the VGI Specialist Meeting, Santa Barbara, dez, 2007.

GRANELL, C.; ABARGUES, C.; DIAZ, L.; HUERTA, J. Interlinking Geoprocessing Services. In: International Conference Advanced Geographic Information Systems, Applications, and Services, p. 99-104, 2010.

GRENON, P.; SMITH, B. SNAP and SPAN: towards dynamic spatial ontology. Spatial Cognition and Computation, v. 4, pp. 69-104, 2004.

GRøNMO, R., JAEGER, M. C., HOFF, H. Transformations between UML and OWLS. In Proceedings of the European Conference on Model Driven Architecture Foundations and Applications.(ECMDA-FA), Nuremberg, Germany. Springer. 2005.

GRUBER, T.R. A translation approach to portable ontologies. Knowledge Acquisition, v. 5 , p. $199-220,1993$.

GUARINO, N. Formal ontology and information systems. In N. Guarino (Ed.),Proceedings of the Conference on Formal Ontology in Information Systems, FOIS'98, 6-8 June 1998, Trento, Italy, p. 3-15 (Amsterdam: IOS Press). 1998.

GUARINO, N. Formal ontology, conceptual analysis and knowledge representation. International Journal of Human-Computer Studies, v. 43, p. 625 - 640. 1995.

HAKLAY, M.; TOBÓN, C. Usability evaluation and PPGIS: towards a user-centred design approach. International Journal of Geographical Information Science, v. 17, n. 6, p. 577-592, 2003. 
HARRIS, T; WEINER, D. Implementing a community-integrated GIS: perspectives from South African fieldwork. in W. Craig, T. Harris and D. Weiner (Eds.), 2002, Community Participation and Geographic Information Systems, London: Taylor and Francis, p. 246-258, 2002.

HIMOFF, J.; RZEVSKI, G.; SKOBELEV, P. Magenta technology multi-agent logistics i-Scheduler for road transportation. Proceedings of the fifth international joint conference on Autonomous agents and multiagent systems, Hakodate, Japan, p. 812, may, 2006.

HORNSBY, K., EGENHOFER, M.J. Identity-based change: a foundation for spatiotemporal knowledge representation. International Journal of Geographical Information Science, v.14, n.3, p. 207-224. 2000.

HORNSBY, K., KING, K.: Linking geosensor network data and ontologies to support transportation modeling. In: Nittel, S., Labrinidis, A., Stefanidis, A. (eds.) GSN 2006. LNCS, vol. 4540, pp. 191-209. Springer, Heidelberg. 2008.

ISO (International Organization for Standardization). Apresenta recursos e atividades desenvolvidas. Disponível em: <http://www.iso.org/>. Acesso em: 10 mar. 2010.

JINBING, H. YOUNA, W. YING, J. .Logistics Decision-making Support System Based on Ontology. In: International Symposium on Computational Intelligence and Design. p. 309-312, 2008.

KARLAFTIS, M.G.; KEPAPTSOGLOU, K.L., LAMPROPOULOS, S. Fund allocation for transportation network recovery following natural disasters. ASCE Journal of Urban Planning and Development. v. 133, n. 1, p. 82-89. 2007.

KINGSTON, R.; CARVER, S.; EVANS, A.; TURTON, I. Web-based public participation geographical. information systems: an aid to local environmental 
decision-making. Computers, Environment and Urban Systems, v. 24, p. 109-125, 2000.

KLIEN, E., AND PROBST, F. Requirements for Geospatial Ontology Engineering. In Proceedings of the 8th Conference on Geographic Information Science (AGILE 2005), Estoril, Portugal (2005), F. Toppen and M. Painho, Eds., pp. 251-260. 2005.

KLIEN, E: Semantic Annotation of Geographic Information. Tese de Doutorado, Institute for Geoinformatics, University of Muenster. Muenster, Alemanha. 2008.

KOVÁCS, G. AND SPENS, K.M. "Humanitarian logistics in disaster relief operations", International Journal of Physical Distribution \& Logistics Management, v. 37, n. 2, p. 99-114. 2007.

KOVÁCS, G. AND SPENS, K.M. "Identifying challenges in humanitarian logistics", International Journal of Physical Distribution \& Logistics Management, v. 39, n. 6, p. 506-528. 2009.

KUHN, W. Geospatial Semantics: Why, of What, and How? Journal of Data Semantics. 2005.

LAURINI R. Pre-consensus Ontologies and Urban Databases, In Ontologies for Urban Development, Edited by Jacques Teller, John R. Lee and Catherine Roussey, Springer Verlag, Studies in Computational Intelligence, v. 61, pp. 27-36, 2007.

LEFORT, L.: Review of semantic enablement techniques used in geospatial and semantic standards for legacy and opportunistic mashups. 5th Australian Ontology Workshop (AOW 2009), v. 112, p. 53-62. 2009. 
LEMMENS, R.L.G. Semantic interoperability of distributed geo - services. Delft, Delft University of Technology, 2006. ITC. Tese de Doutorado. 303 p. ISBN: 90-6164-2507. 2006.

LEMMENS, R.L.G., GOULD, R.A., WYTZISK, A. Enhancing geo - service chaining through deep service descriptions. Transactions in GIS, v. 11, n. 6, p. 849-871. 2007.

LEUKEL, J.; KIRN, S. A Supply Chain Management Approach to Logistics Ontologies in Information Systems. In: Proceedings of the 11th International Conference on Business Information Systems (BIS 2008), Innsbruck, Austria, May 5-7, 2008, Springer LNBIP Vol. 7, pp. 95-105. 2008.

LIMA JR. O. F. Novos Caminhos com Velhos Sapatos? Revista Mundo Logística, São Paulo, n.07, nov e dez. 2008.

LIMA, P. (2002) GeoBR Intercâmbio de dados espaciais: modelos, formatos e conversores. São José dos Campos, 1v. Dissertação (Mestrado) - Instituto Nacional de Pesquisas Espaciais. Disponível em < http://www.obt.inpe.br/acervo_mest_dout.htm >. Acesso em 05 nov. 2010.

LINS, S. A. G.; OLIVEIRA, R. R. Banco Sesc de Alimentos: uma experiência de geração de capital social. Anais do XXVIII - Encontro da ANPAD (Associação Nacional de Pós-Graduação e Pesquisa em Administração). Curitiba. Paraná. 2004.

LUTZ, M. AND KLIEN, E. Ontology-based retrieval of geographic information, International Journal of Geographical Information Science, v. 20, n. 3, pp. 233260, 2006.

LUTZ, M. Ontology-based descriptions for semantic discovery and composition of geoprocessing services. Geoinformatica, v. 11, p. 1-36. 2007. 
MACÁRIO, C. G. N. E MEDEIROS, C. B. Specification of a framework for semantic annotation of geospatial data on the web. SIGSPATIAL Special, v. 1, n.1, p. 27-32. 2009.

MAN, E. Establish a Geographic Information System in Relation to its Use. International Journal of Geographical Information Systems, v. 11, n. 3 p. 257. 1988.

MARQUES, C. M. Pangea - Arquitetura semântica para a integração de dados e modelos geoespaciais na Web. 2010. 194 p. Dissertação (Mestrado) - Instituto de Biociências, Letras, e Ciências Exatas da Universidade Estadual Paulista "Júlio de Mesquita Filho", São José do Rio Preto, 2010.

MARTINS, M. C.; GARRAFA, I. M.; BIGOLIN, N. M. Integração da cadeia de suprimentos através de ontologia de processos. Revista de Ciências Empresariais, Políticas e Sociais. n. 16. 2006.

MASOLO, C.; BORGO, S.; GANGEMI, A.; GUARINO, N.; OLTRAMARI A.; SCHNEIDER, L. DOLCE: a Descriptive Ontology for Linguistic and Cognitive Engineering. WonderWeb Project, Deliverable D17 v2.1, 2003.

MASSER, I.; RAJABIFARD, A.; WILLIAMSON, I. Spatially enabling governments through SDI implementation. International Journal of Geographical Information Science, v. 22, n. 1, p. 5-20, 2008.

MAUÉ, P. An extensible semantic catalogue for geospatial web services. International Journal of Spatial Data Infrastructures Research, v. 3, p. 168-191. 2008.

MAUÉ, P., SCHADE, S., DUCHESNE, P.: OGC Discussion Paper 08-167r1: Semantic annotations in OGC standards. Technical report, OGC. 2009. 
NEON (Network Ontologies Project). Apresenta recursos, atividades e metodologias desenvolvidas. Disponível em: <http://www.neon-project.org/>. Acesso em: 10 de mar. 2010.

NOVAES, A G; ROSSETO, C F. Localização de Depósitos Numa Rede Logística com o Auxílio de GIS. Anais do VII Congresso de Pesquisa e Ensino em Transportes, São Paulo, v. 2, p 605-617, 1993.

NOVAES, A. G. Logística e Gerenciamento da Cadeia de Distribuição: Estratégia, Operação e Avaliação. Rio de Janeiro: Campus, 2001.

OGC (Open Geospatial Consortium). Apresenta recursos e atividades desenvolvidas. Disponível em: < http://www.opengeospatial.org/>. Acesso em: 10 mar. 2010.

PARK, D.; LEE, G.; KWON, H. "Ontological Approach to Integration of Event-Centric Logistics Information into EPC Network," iwsca, pp.1-8, 2008 IEEE International Workshop on Semantic Computing and Applications, 2008.

PAWLASZCZYK, D.; DIETRICH, A.J.; TIMM, I.J.; OTTO, S.; KIM, ST.: Ontologies Supporting Cooperations In Mass Customization - A Pragmatic Approach. In: International Conference on Mass Customization and Personalization - Theory and Practice in Central Europe, 2004.

PENG L, DAE-WON P, HYUK-CHUL K. Design of Logistics Ontology for Semantic Representing of Situation in Logistics, Digital Media and its Application in Museum \& Heritage, p. 432-437. 2007.

PEUQUET, DJ. Theme section on advances in spatio-temporal analysis and representation. Isprs Journal Of Photogrammetry And Remote Sensing, v. 60, n.1. 2005. 
PERCIVALL, 2002. The OpenGIS Abstract Specification, Topic 12: OpenGIS Service Architecture (version 4.3). OGC Document no. 02-112, January. Disponível em http://www.opengeospatial.org/standards/as. Acessado em: 10 de maio de 2008.

PETIT, S. AND BERESFORD, A. Critical success factors in the context of humanitarian aid supply chains. International Journal of Physical Distribution \& Logistics Management, v. 39, n. 6, p. 450 - 468. 2009.

RAJABIFARD, A. Developing Spatial Data Infrastructure to Facilite Industrial and Mining Decision-Maker. Geomatics Seminar, Ministry of Industries and Mines, Tehran, Iran, mai, 2004.

RAJABIFARD, A.; BINNS, A.; MASSER, I.; WILLIANSON, I. The role of the subnational government and the private sector in future spatial data infrastructure. International Journal of Geographical Information Science, v. 20, n.7, pp. 727741, ago, 2006.

RAJABIFARD, A.; FEENEY, M. F.; WILLIAMSON, I.P. Future directions for SDI development. International Journal of Applied Earth Observation and Geoinformation, v. 4, n. 1, p 11-22, 2002.

RHIND, D. AND N GREEN. Design of a Geographic Information System for a Heterogeneous Scientific Community. International Journal of Geographical Information Systems, v. 11, n. 2, p. 175. 1988.

RICHES, G. Food bank and food security: welfare reform, human rights and social policy. lessons from Canada. Social Policy \& Administration, v. 36, n. 6, p. 648-669, 2002.

RUCHEL, C. C.; IOCHPE, LISBOA FILHO, J.. Modelagem de Processos de Análise Geográfica Utilizando 0 Framework GeoFrame.Disponível em: 
www.geoinfo.info/geoinfo2003/papers/geoinfo2003-30.pdf. Acesso em: março de 2010.

RUSSEL, T. The Humanitarian Relief Supply Chain: Analysis of the 2004 South East Asia Earthquake and Tsunami. Master thesis, Massachusetts Institute o Technology, Cambridge, MA. 2005.

SAADATSERESHT, M., MANSOURIAN, A., TALEAI, M.: Evacuation Planning Using Multiobjective Evolutionary Optimization Approach. European Journal of Operational Research, v. 198, n. 1, p. 305-314. 2009.

SABADIN, L. M. 2005. A doação institucional de alimentos na grande São Paulo: : incentivos e entraves. 2005. 80p. Dissertação (Mestrado). Programa de PósGraduação Interunidades em Nutrição Humana Aplicada - PRONUT. Faculdade de Ciências Farmacêuticas, Faculdade de Saúde Pública e Faculdade de Economia, Administração e Contabilidade da Universidade de São Paulo, São Paulo, 2005.

SANTOS, M., 1997. A Natureza do Espaço. São Paulo, HUCITEC, 1997.

SCHUT, P. ed, 2007, OpenGIS $\AA$ Web Processing Service, OGC 05-007r7, http://portal.opengeospatial.org/files/?artifact_id=24151 acessado October 2009.

SHEA, L. W. B. An insight into food bank usage in the city of dartmouth. 1991. 186p. Dissertação (Mestrado) - Department of Human Ecology, Mount Saint Vincent University, Nova Scotia, Canada. 1991.

SILVA, A. N. Sistemas de informações geográficas para planejamento de transportes. 1998. 124 p. Tese (Livre Docência) - Escola de Engenharia de São Carlos, Universidade de São Paulo, São Carlos, 1998. 
SMIRNOV, A.; LEVASHOVA, T.; PASHKIN, M.; SHILOV, N.; KOMAROVA, A. Disaster response based on production network management tasks. Management Research News, Emerald Publishing Group. 30(11):829 - 842. 2007.

SMIRNOV, A.; LEVASHOVA, T.; SHILOV, N. Ontology-driven knowledge sharing for networked organisation configuration. Enterprise Information Systems, v. 3, p. 179193, 2008.

SMIRNOV, A.; LEVASHOVA, T.; SHILOV, N.; KASHEVNIK, A. A Hybrid Technology for Operational Decision Support in Pervasive Environments. Conference Information: 5th IFIP Conference on Artificial Intelligence Applications and Innvations, Thessaloniki, Greece, apr 23-25, 2009.

SMIRNOV, A.; LEVASHOVA, T.; SHILOV, N.; KASHEVNIK, A. Hybrid Technology For Self-Organization of Resources of Pervasive Environment for Operational Decision Support. International Journal on Artificial Intelligence Tools, v. 19, n. 2, p.211-229, 2010.

STARKEY, L. J.; KUHNLEIN, H.V.; GRAY-DONALD, K. Food bank users: sociodemographic and nutritional characteristics. Canadian Medical Association Journal, v. 158, n. 9, p. 1143-1149, 1998.

STOLLBERG, B., ZIPF, A. Geoprocessing services for spatial decision support in the domain of housing market analyses - experiences from applying the OGC web processing service interface in practice. 11th AGILE Conference on Geographic Information Science, Girona, Spain. 2008.

TARASUK, V. AND J. M. EAKIN. Food assistance through "surplus" food: Insights from an ethnographic study of food bank work. Agriculture and Human Values, v. 22, p. 177 - 186, 2005. 
TARASUK, V.; EAKIN, J. M. 'Charitable food assistance as symbolic gesture: An ethnographic study of food banks in Ontario. Social Science \& Medicine, v. 56, p. 1505-1515, 2003.

THOMAS, A. Humanitarian logistics: Enabling disaster response, White paper, Fritz Institute, San Francisco, CA. 2003.

THOMAS, A.; MIZUSHIMA, M. Logistics training: necessity or luxury? Forced Migration Review. v. 22, p 60-61. 2005.

TOMASINI, R.; van WASSENHOVE, L. Humanitarian Logistics. Palgrave Macmillan. 175p. 2009.

TULLOCH, D. Position paper for the VGI Specialist Meeting, Santa Barbara, dez, 2007.

UNWIN, D. A Syllabus for Teaching Geographic Information Systems. International Journal of Geographical Information Systems, v. 4, p. 461-462. 1990.

USCHOLD, M.; GRUNINGER, M. Ontologies: principles, methods an applications. Knowledge Engineering Review, v. 11, n. 2. 1996

VACCARI, L.; SHVAIKO P.; MARCHESE, M. An emergent semantics approach to semantic integration of geo-services and geo-metadata in Spatial Data Infrastructures. International Journal of Spatial Data Infrastructures, v. 3, 2008.

WASSENHOVE, L. V. BLACKETT. Memorial lecture humanitarian aid logistics: supply chain management in high gear. Journal of the Operational Research Society, v. 57, n. 5, p. 475-489. 2006. 
W3C (Word Wide Web Consortium). Apresenta recursos e atividades desenvolvidas. Disponível em: <http://www.w3.org/>. Acesso em: 10 mar. 2010.

WALENCIAK GEORG, ZIPF ALEXANDER. Designing a Web Processing Service Application Profile for Spatial Analysis in Business Marketing. In: 13th AGILE International Conference on Geographic Information Science 2010, pp. 1-8. Guimarães, Portugal. 2010.

WENDT, O.; STOCKHEIM, T.; GROLIK, S.; SCHWIND, M. Distributed Ontology Management Prospects and Pitfalls on Our Way Towards a Web of Ontologies. In: Dagstuhl Workshop (Event Nr. 02212) - DFG-SPP 1083, 2002.

WHYBARK, D. Issues in managing disaster relief inventories. International Journal of Production Economics, v. 108, n.1, p. 228-235. 2007.

WINSTON, W.L. Operations Research: Applications and Algorithms. International Thomson Publishing, 1418p, 1994.

WORBOYS, M.F. Event-oriented approaches to geographic phenomena. International Journal of Geographical Information Science, v.19, n.1, p.1-28. 2005.

YE, Y., YANG, D., JIANG, Z., AND TONG, L. Ontology-based semantic models for supply chain management. International Journal of Advanced Manufacture Technology. 2007.

YOSHIZAKI, Hugo. Projeto de redes de distribuição física considerando a influência do imposto de circulação de mercadorias e serviços. 2002. 144 p.. Tese (Livre Docência) - Escola Politécnica, Universidade de São Paulo, São Paulo, 2002. 


\section{APÊnDice A - Entrevistas e Trabalho de CAMPo}

\section{A.1 - Entrevistas com Bancos de Alimentos no Brasil}

Para conhecer melhor as operações de bancos de alimentos no Brasil foram feitas entrevistas e coletadas informações da maior rede de bancos de alimentos brasileira: o Programa Mesa Brasil SESC. Além das entrevistas e informações coletadas junto ao Programa Mesa foi feita entrevista com um dos principais doadores do Programa Mesa Brasil SESC, o Wal-Mart. A partir destas informações e juntamente com outras obtidas a partir da internet, elaborou-se um mapa conceitual como uma primeira aproximação para a sistematização do conhecimento relativo aos bancos de alimentos no Brasil, que serviu de base para as investigações subseqüentes e elaboração das ontologias.

\section{A.1.1 - Entrevista com uma rede nacional de bancos de alimentos no Brasil: O Programa Mesa Brasil SESC}

O Programa conta com 69 sedes, sendo 28 em capitais (2 em São Paulo); frota própria de 106 veículos (sem contar os terceirizados); abrangência de 297 municípios; perspectiva de implantação de 18 novas sedes para o próximo triênio (2008-2010) e meta de crescimento nas arrecadações visando atingir $50.000 .000 \mathrm{Kg}$ de alimentos em 2010.

O SESC disponibilizou acesso a dados e organizou entrevistas concedidas por seus técnicos, alem de viabilizar um trabalho de campo, que também já foi realizado. 
Foram recebidas três baterias de informações prévias à liberação de acesso ao Sistema Mesa Brasil Sesc, contendo, resumidamente:

Quantidade de alimentos distribuídos por ano (2005, 2006, 2007);

$\checkmark$ Quantidade de recursos aprovados para cada divisão regional por ano (2005, 2006, 2007);

$\checkmark$ Metas de distribuição de alimentos e recursos pleiteados, por divisão regional (2007 e 2008);

$\checkmark$ Número de pessoas atendidas, por divisão regional, por ano $(2005,2006$, 2007);

$\checkmark$ Número de entidades contempladas por divisão regional, por ano (2005, 2006, 2007);

$\checkmark$ Número de doadores por divisão regional, por ano $(2005,2006,2007)$;

$\checkmark$ Número de voluntários por divisão regional, por ano (2005, 2006, 2007);

$\checkmark$ Número de ações educativas por divisão regional, por ano $(2005,2006$, 2007);

$\checkmark$ Número de programas para cada divisão regional, por ano $(2005,2006$, 2007);

$\checkmark$ Lista de veículos utilizados pelo programa;

$\checkmark$ Relação de gastos com recursos humanos (média);

$\checkmark$ Critérios para a destinação de recursos;

De acordo com os dados gerais obtidos classificamos as divisões regionais em 6 grupos (Tabela A.1). 
Tabela A.1 - Classificação das divisões regionais (DD.RR).

\begin{tabular}{|c|c|c|c|c|c|c|c|c|c|c|}
\hline \multirow{2}{*}{\multicolumn{2}{|c|}{ DDRR }} & \multicolumn{4}{|c|}{ Alimentos Distribuídos } & \multirow{3}{*}{\begin{tabular}{|c|} 
No \\
Prog. \\
1 \\
\end{tabular}} & \multirow{3}{*}{\begin{tabular}{|c|}
$\begin{array}{c}\text { No } \\
\text { Veic }\end{array}$ \\
2 \\
\end{tabular}} & \multirow{3}{*}{\begin{tabular}{|l|}
$\begin{array}{l}\text { Cap. } \\
\text { Veic }\end{array}$ \\
1,8 \\
\end{tabular}} & \multirow{2}{*}{\multicolumn{2}{|c|}{ Classificação }} \\
\hline & & \multirow{2}{*}{$\begin{array}{l}\mathrm{Kg} / \mathrm{ano} \\
155,980 \\
\end{array}$} & \multirow{2}{*}{\begin{tabular}{|c|}
$\mathrm{Kg}$ \\
$/ \mathrm{mês}$ \\
12,998 \\
\end{tabular}} & \multirow{2}{*}{$\begin{array}{l}\mathrm{Kg} \\
/ \mathrm{dia} \\
650 \\
\end{array}$} & \multirow{2}{*}{\begin{tabular}{|c|}
$\%$ do \\
Total \\
$1 \%$ \\
\end{tabular}} & & & & & \\
\hline 23 & $R R$ & & & & & & & & \multirow{6}{*}{$\begin{array}{l}150 \text { a } 300 \text { ton } \\
1 \text { a } 2 \text { unidades }\end{array}$} & \multirow{6}{*}{ 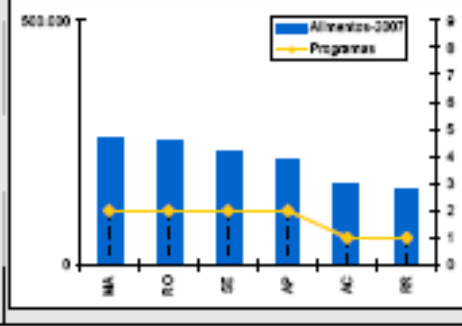 } \\
\hline 1 & $A C$ & 164,905 & 13,742 & 687 & $1 \%$ & 1 & $?$ & $?$ & & \\
\hline 3 & AP & 212,663 & 17,722 & 886 & $1 \%$ & 2 & 2 & 4 & & \\
\hline 26 & SE & 228,545 & 19,045 & 952 & $1 \%$ & 2 & 1 & 0,7 & & \\
\hline 22 & RO & 257,379 & 21,448 & 1,072 & $1 \%$ & 2 & 1 & 0,8 & & \\
\hline 10 & $M A$ & 258,772 & 21,564 & 1,078 & $1 \%$ & 2 & 2 & 1,6 & & \\
\hline 13 & MG & 452,543 & 37,712 & 1,886 & $2 \%$ & 1 & $2 t$ & 1,6 & \multirow{8}{*}{$\begin{array}{l}450 \text { a } 900 \text { ton } \\
1 \text { a } 3 \text { unidades }\end{array}$} & \multirow{8}{*}{${ }^{1000000}$} \\
\hline 18 & PI & 550,135 & 45,845 & 2,292 & $2 \%$ & 3 & 5 & 10,4 & & \\
\hline 7 & DF & 557,098 & 46,425 & 2,321 & $2 \%$ & 1 & 2 & $?$ & & \\
\hline 5 & $B A$ & 656,721 & 54,727 & 2,736 & $2 \%$ & 3 & 3 & 3,6 & & \\
\hline 20 & RN & 716,304 & 59,692 & 2,985 & $3 \%$ & 3 & 5 & 10,4 & & \\
\hline 9 & Go & 740,993 & 61,749 & 3,087 & $3 \%$ & 1 & 1 & 2 & & \\
\hline 11 & MT & 803,612 & 66,968 & 3,348 & $3 \%$ & 2 & 3 & $?$ & & \\
\hline 27 & TO & 836,811 & 69,734 & 3,487 & $3 \%$ & 3 & $?$ & $?$ & & \\
\hline 15 & PB & 986,082 & 82,174 & 4,109 & $4 \%$ & 4 & 4 & $?$ & \multirow{6}{*}{$\begin{array}{c}1.000 \text { a } 1.200 \\
\text { ton }\end{array}$} & \multirow{6}{*}{ 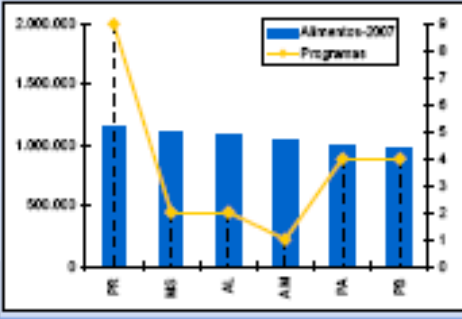 } \\
\hline 14 & PA & $1,000,045$ & 83,337 & 4,167 & $4 \%$ & 4 & 7 & 7,3 & & \\
\hline 4 & AM & $1,040,863$ & 86,739 & 4,337 & $4 \%$ & 1 & 1 & 3 & & \\
\hline 2 & $A L$ & $1,089,600$ & 90,800 & 4,540 & $4 \%$ & 2 & 5 & 7,6 & & \\
\hline 12 & MS & $1,103,502$ & 91,959 & 4,598 & $4 \%$ & 2 & $?$ & $?$ & & \\
\hline 16 & PR & $1,155,983$ & 96,332 & 4,817 & $4 \%$ & 9 & 7 & 11 & & \\
\hline 21 & RS & $1,367,752$ & 113,979 & 5,699 & $5 \%$ & 5 & 6 & 11,8 & \multirow{3}{*}{$\begin{array}{c}1.300 \text { a } 1.500 \\
\text { ton } \\
>=3 \text { unidades }\end{array}$} & \multirow{7}{*}{ 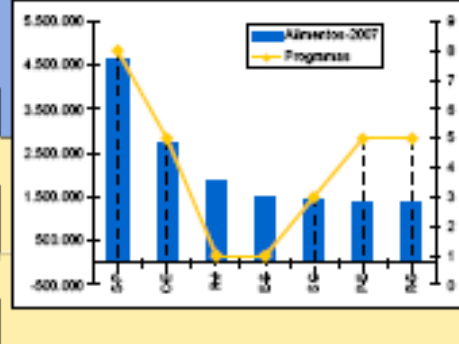 } \\
\hline 17 & PE & $1,386,883$ & 115,574 & 5,779 & $5 \%$ & 5 & 8 & $?$ & & \\
\hline 24 & $S C$ & $1,447,810$ & 120,651 & 6,033 & $5 \%$ & 3 & 4 & & & \\
\hline 8 & ES & $1,500,156$ & 125,013 & 6,251 & $5 \%$ & 1 & $?$ & $?$ & \multirow{2}{*}{$\begin{array}{c}1.500 \text { a } 2.000 \\
\text { ton } \\
1 \text { unidade }\end{array}$} & \\
\hline 19 & RJ & $1,875,439$ & 156,287 & 7,814 & $7 \%$ & 1 & $?$ & $?$ & & \\
\hline 6 & $C E$ & $2,715,083$ & 226,257 & 11,313 & $10 \%$ & 5 & 6 & $?$ & \multirow{2}{*}{$\begin{array}{c}>2500 \text { ton } \\
>=5 \text { unidades }\end{array}$} & \\
\hline 25 & SP & $4,614,748$ & 384,562 & 19,228 & $17 \%$ & 8 & 13 & 35 & & \\
\hline
\end{tabular}

Resumidamente, para esta classificação foram considerados dois critérios, sendo eles: volume de alimentos distribuídos e número de unidades do programa. O critério volume determinou a ordenação da composição dos grupos, ou seja, aqueles com maiores volumes de distribuição foram alocados aos primeiros grupos e assim sucessivamente. São Paulo e Ceará compõem o primeiro grupo, que se sobressai do restante por representar $27 \%$ do total distribuído, e possuir um grande número de 
unidades do programa por regional. O segundo grupo (RJ e ES) se destaca pela particularidade de possuir apenas uma unidade em cada programa, a despeito do grande volume distribuído. Terceiro e quarto grupos apresentam características semelhantes entre si, assim como quinto e sexto grupos. Como particularidade, podemos destacar o caso do Paraná, que, a despeito de fazer parte do quarto grupo, apresenta o maior número de unidades do programa.

Com relação ao histórico de crescimento (Tabela A.2 e Figura A.1), nota-se que primeiro e segundo grupos (SP, CE, RJ e ES) não apresentam uma tendência de crescimento homogênea entre seus integrantes, diferentemente de terceiro e quarto grupos que apresentam altas taxas positivas de variação. Como particularidades nos comportamentos, podemos salientar as taxas de variação negativas, indicando decréscimo nas quantidades distribuídas de 2006 para 2007, para São Paulo e Roraima, primeiro e último colocado, respectivamente. 
Tabela A.2 - Avaliação da evolução histórica dos programas por DD.RR.

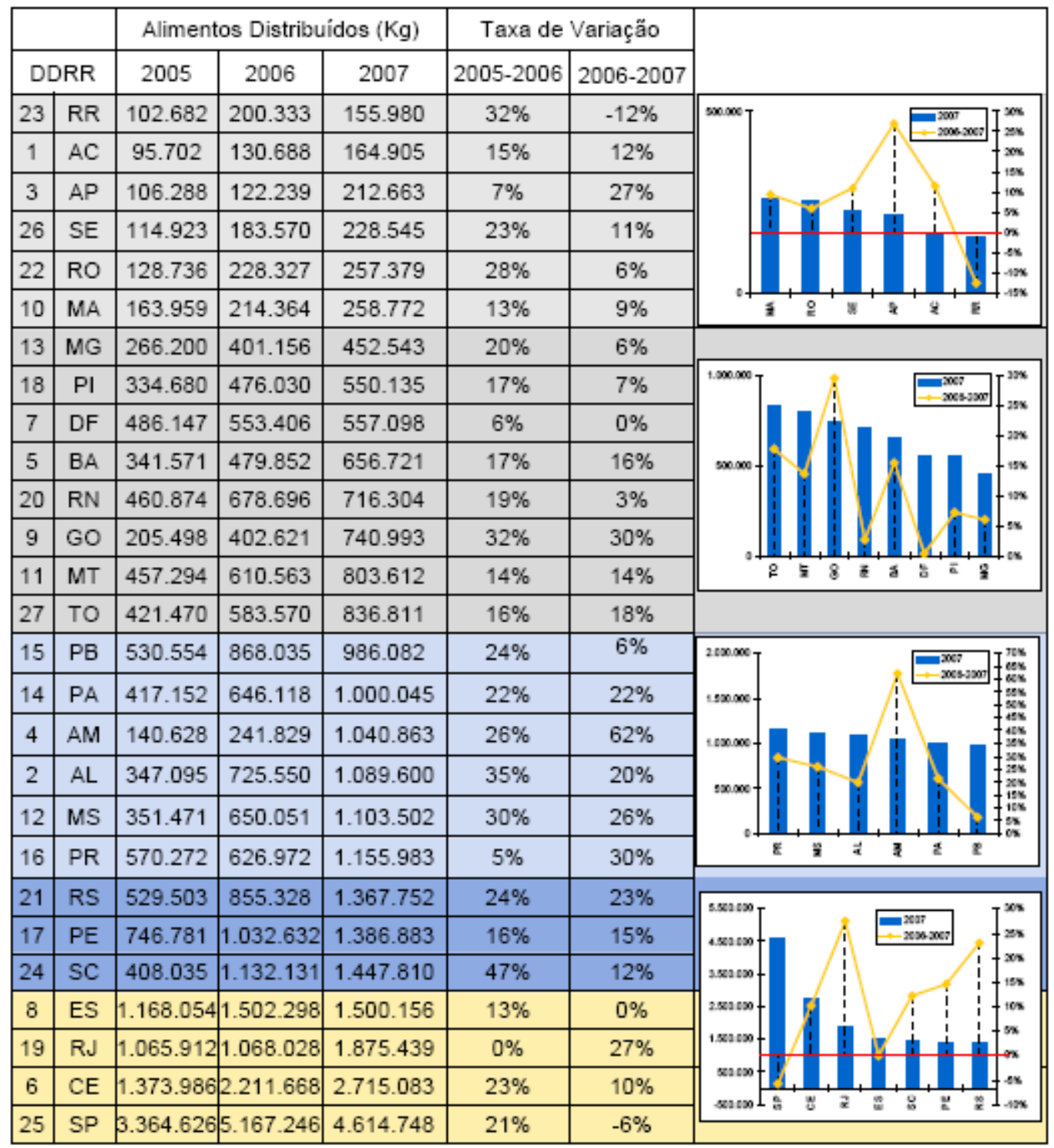

Vale ressaltar ainda o crescimento substancial do quarto grupo mantendo altas taxas positivas de 2005 a 2007 e, em especial, do Amazonas, que apresenta o maior crescimento, atingindo 62\% de 2006 para 2007 (Figura A.1). 

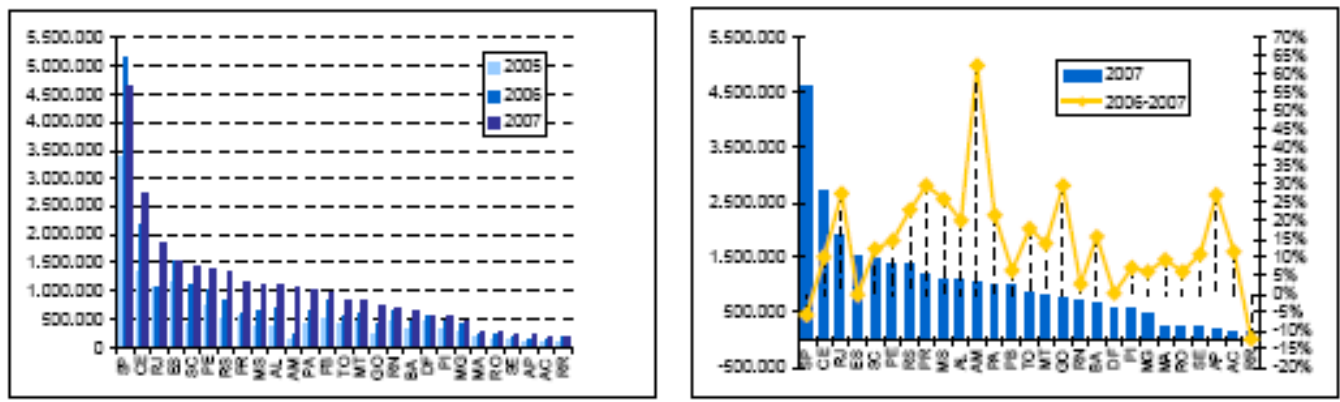

Figura A.1 - Gráficos representando as quantidades distribuídas de alimentos por DD.RR. e suas variações entre os anos de 2005, 2006 e 2007.

Com relação aos recursos destinados para cada regional, considerando que dados do Rio de Janeiro, Mato Grosso e Sergipe estavam incompletos e que São Paulo, possivelmente possui outras fontes de recursos, nota-se que Pernambuco $\left(3^{\circ}\right.$ grupo) e Pará e Paraíba ( $4^{\circ}$ grupo) são as regionais que mais vêm recebendo recursos nesses últimos anos, seguidos pelo Ceará ( $1^{\circ} \mathrm{grupo}$ ).

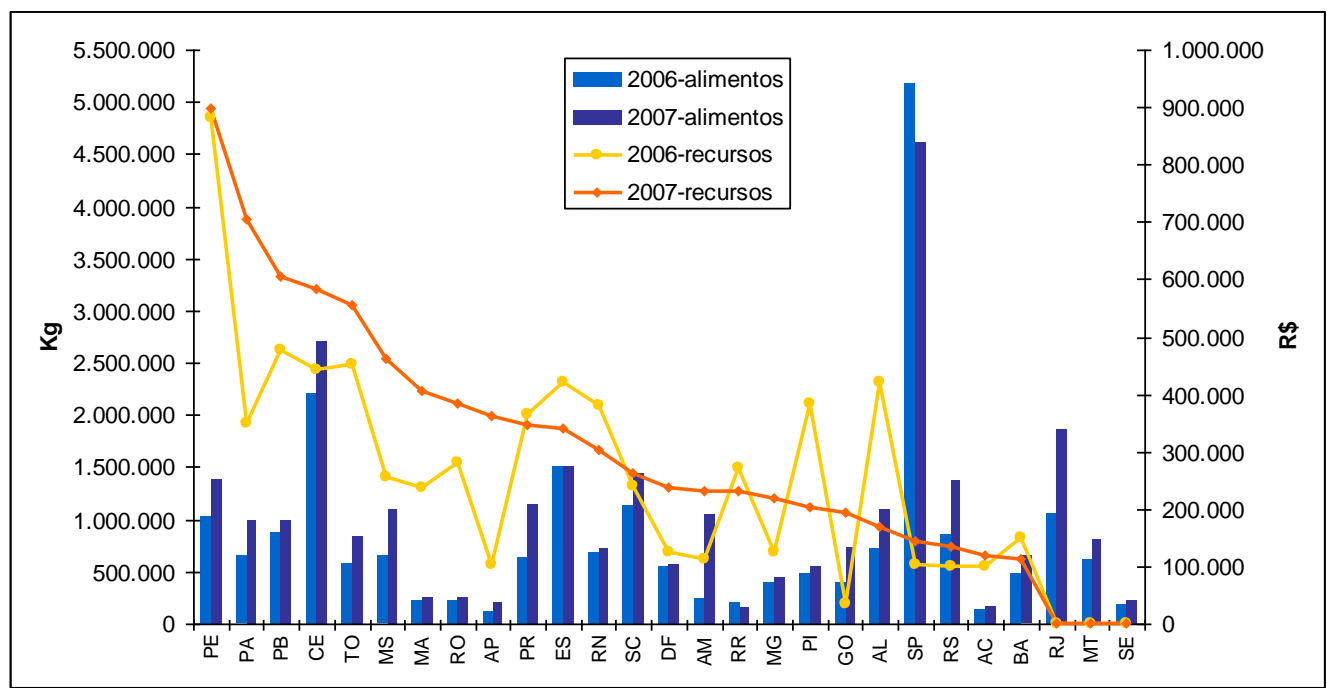

Figura A.2 - Gráfico representando a quantidade de alimentos distribuídos e os recursos destinados para cada regional, para os anos de 2006 e 2007.

Comparando-se as taxas de crescimento do volume de alimentos distribuído, a luz da taxa de variação de recursos destinados aos programas (Figura A.3), pode-se observar que Amazonas e Goiás, que obtiveram altas taxas de crescimento em 
volume de distribuição, também obtiveram um aumento proporcionalmente significativo de recursos alocados, assim como o Amapá.

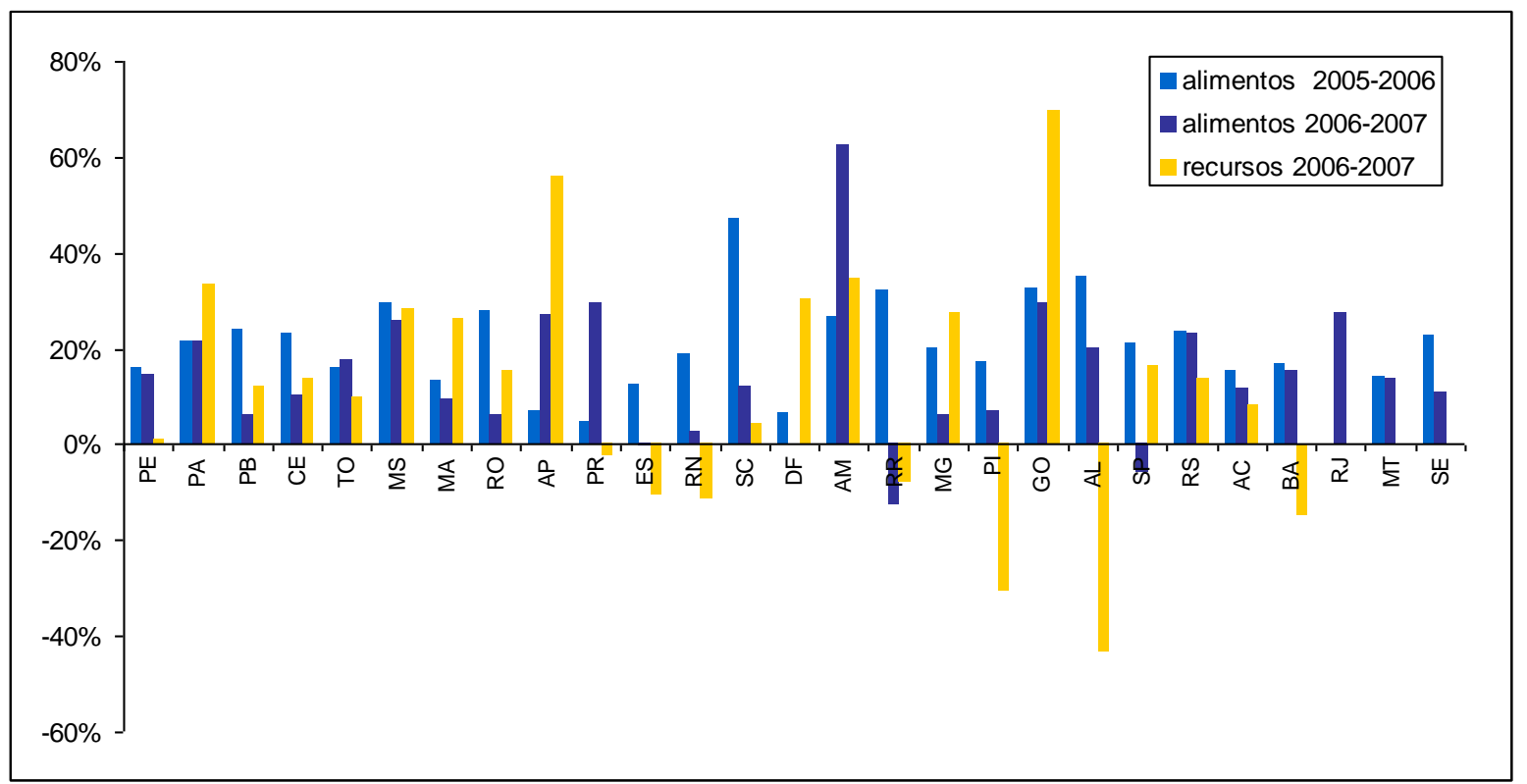

Figura A.3 - Gráfico representando as taxas de variação nas quantidades de alimentos distribuídos entre os anos 2005-2006 e 2006-2007 e a variação de recursos destinados entre 2005-2006 para cada regional.

O acesso ao sistema foi concedido no dia 02/05/2008, mas, efetivamente, apenas no dia 07/05/2008 foi liberado o acesso para os dados dos Programas em São Paulo (Bauru, Santos e Carmo), Espírito Santo (Vitória) e Alagoas (Capital e Arapiraca).

Foi proposto como estudo piloto, diante da disponibilidade de dados espaciais, São Paulo e posteriormente o Rio de Janeiro. Dentre estes foi escolhido São Paulo e sugeridos outros programas como Espírito Santo, por centrar sua operação em armazenagem, diferentemente de São Paulo, que segue o modelo de colheita urbana (coletar e distribuir no mesmo dia); Alagoas (Capital e Arapiraca), para incluir um exemplo do Nordeste, Bauru e Santos, para cobrir alguns programas interiorizados da regional de São Paulo. 
O sistema mostra-se bastante extenso, com múltiplas funcionalidades, incluindo serviços para entrada, consulta e exportação de dados. A exportação se dá em formato Excel para a planilha de cessão e em PDF para os relatórios. Outras consultas podem ser visualizadas em $\mathrm{html}$ e impressas. Algumas funções, no entanto, não vêm sendo utilizadas.

De forma geral, as tabelas administrativas, tanto as centralizadas quanto as regionais, estão completas. Não é possível avaliar o nível de atualização dos cadastros, mas pode-se notar alguns problemas encontrados:

Dados sobre doações e cessões:

$\checkmark$ Bauru: possui dados apenas até junho de 2007.

$\checkmark$ Carmo: até fevereiro de 2007 não apresenta maiores problemas, mas a partir de então cadastrou todas as cessões em um mesmo nome generalizado (instituições gerais).

Cadastro de instituições e doadores:

$\checkmark$ Espírito Santo: não utiliza corretamente o campo Razão Social, que aparece com uma classificação para as instituições (ativa/em espera) e como uma repetição do nome fantasia no caso das doações. Isso implica na inviabilidade de identificação das instituições no relatório de instituições.

$\checkmark$ Cadastro de Roteiros: não é utilizado.

$\checkmark$ Cadastro de Endereços: de forma geral os endereços possuem vários problemas de toponímia (falta de padronização e imprecisão).

Foram analisados os dados de doações e cessões referentes ao ano base 2007, de todos os meses disponíveis. Mais especificamente, foram analisadas, principalmente, as informações referentes aos padrões de distribuição. Nesse sentido, os gráficos apresentados na Figura A.5, a seguir, procuram explorar (1) se existem padrões de distribuição com relação à capacidade necessária para frota $e$ estoque (quando existir) e (2) qual o número de viagens efetuadas, representados por volume e número de doações e cessões, respectivamente. 
Os dados relativos ao número de cessões da unidade Carmo não foram considerados devido ao problema, mencionado anteriormente, no processo de entrada de dados. Também foram desconsiderados os dados de Bauru, por representarem apenas metade do período analisado.

A partir da análise dos dados percebeu-se que a classificação, com propósito de ordenação dos problemas logísticos, deverá ser feita também na escala de unidades do programa, devido às imensas discrepâncias encontradas dentro de uma mesma regional. Ou seja, como se pode observar no gráfico abaixo (Figura A.4) faria mais sentido agrupar Carmo a Maceió, e Santos a Arapiraca do que considerar a divisão regional.

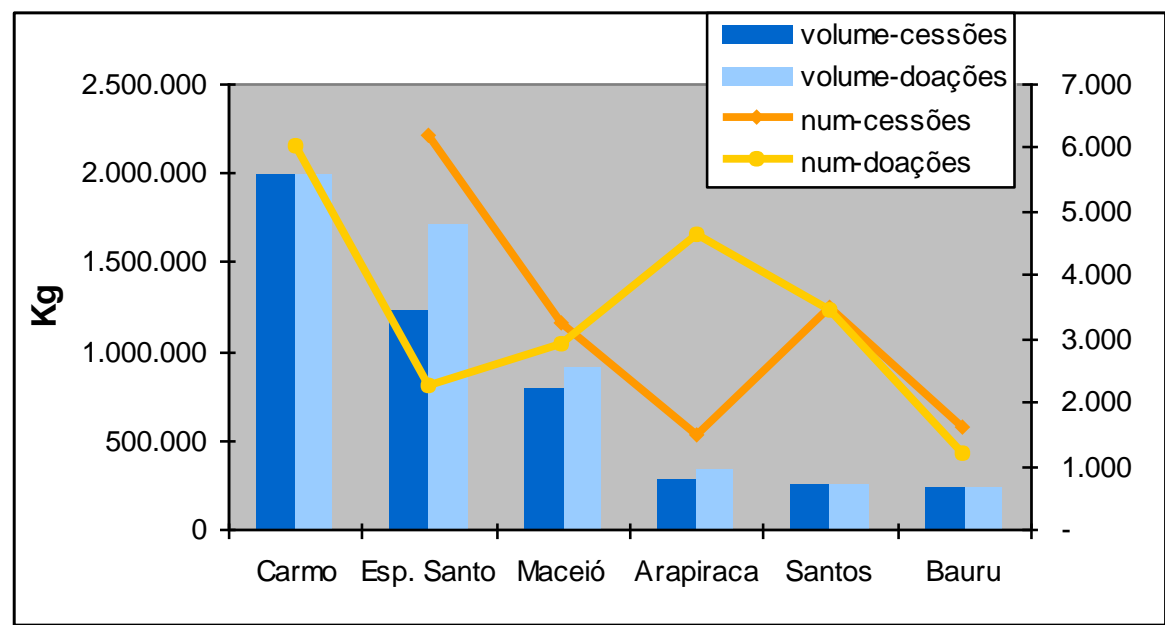

Figura A.4 - Gráfico representando cessões e doações analisadas. 


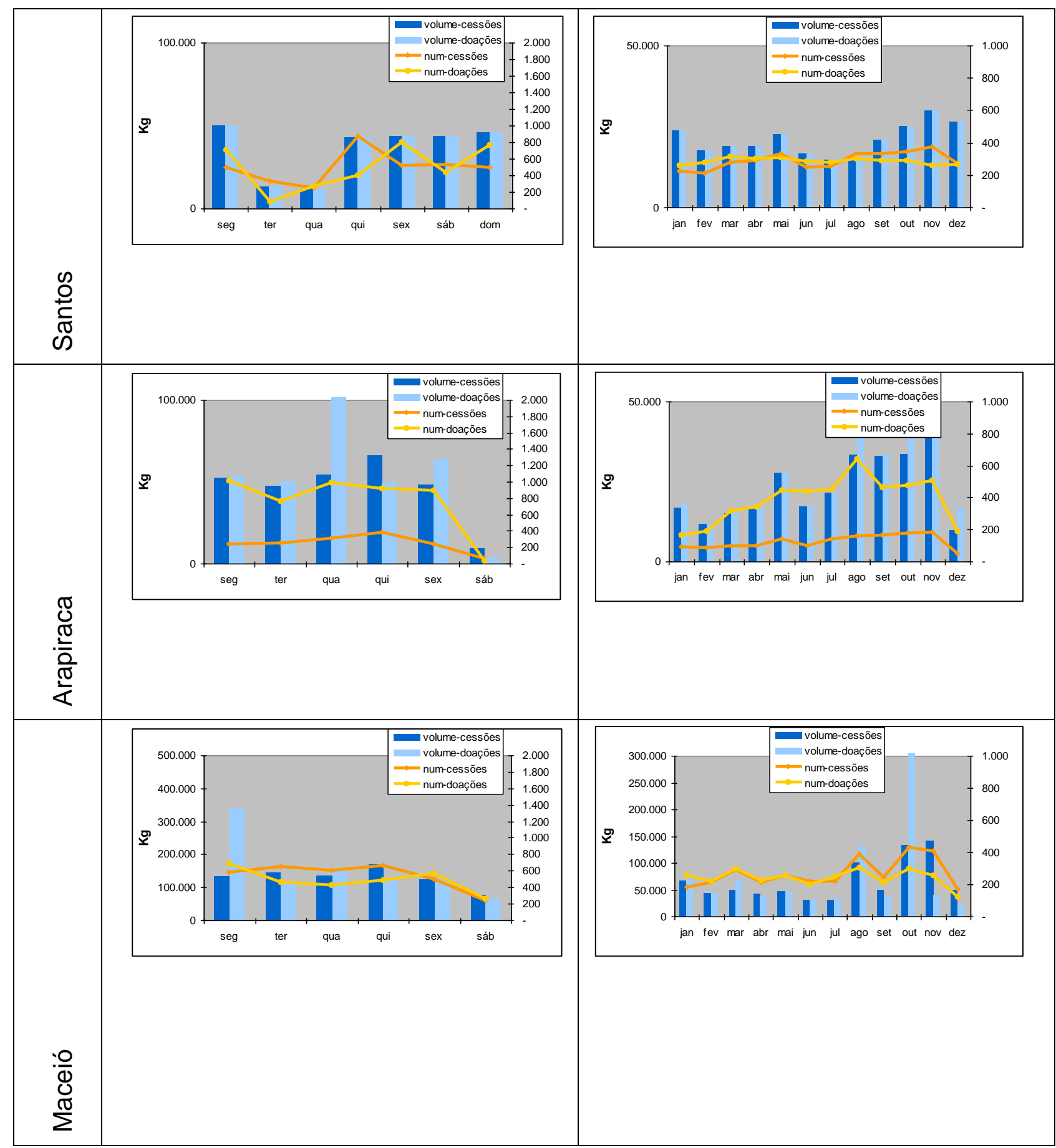




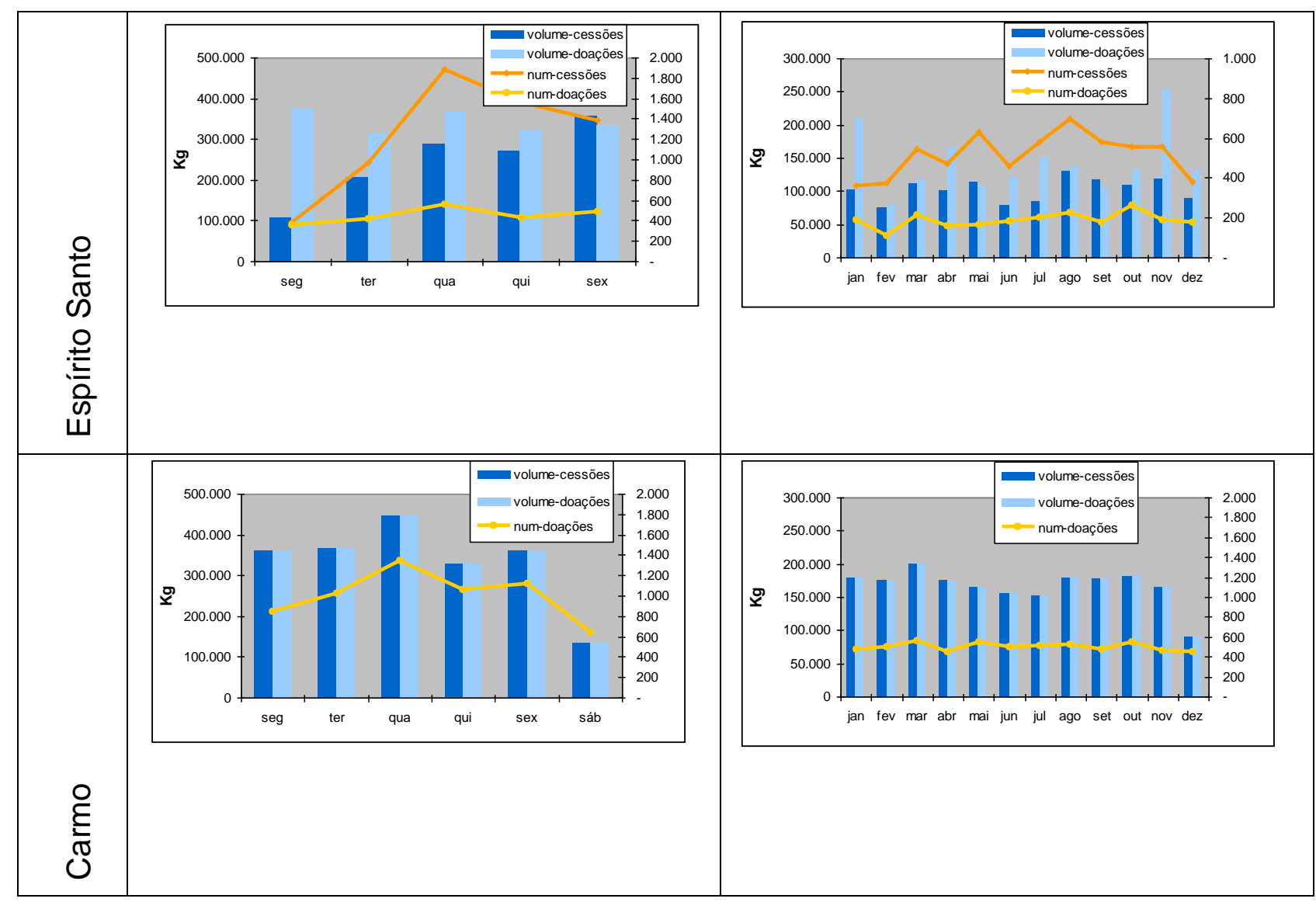

Figura A.5 - Gráficos representando número de viagens e capacidade, necessárias.

Algumas hipóteses poderiam ser formuladas a partir da análise dos dados. É necessário, no entanto, averiguar sua coerência devido às dificuldades de interpretação dos dados. São elas:

Com relação ao número de viagens, aspecto importante para questão de roteirização:

$\checkmark$ Espírito Santo possui um número de cessões, equivalente ao número de viagens feitas para as instituições, muito superior ao número de doações. Isso se deve, provavelmente, ao fato de seguir um modelo centrado em armazenagem. Como conseqüência, nesses casos deve-se concentrar a análise de otimização mais do lado da demanda, viagens a instituições, devido ao seu maior impacto.

$\checkmark$ Arapiraca, em contrapartida, apresenta uma pulverização das doações, com um número de doações (não volume) muito maior que o número de cessões. 
$\checkmark$ Maceió e Santos apresentam um número de viagens, aparentemente, homogêneo entre doações e cessões, mas há que se atentar que boa parte dos doadores de Santos concentram-se espacialmente (barracas de praia), o que pode significar uma menor complexidade na coleta comparativamente à entrega de alimentos doados.

$\checkmark$ Com relação à distribuição das doações semanais e mensais, aspecto relevante para análise de eficiência dos modelos de operação dos bancos de alimentos:

$\checkmark$ Santos apresenta uma distribuição semanal singular devido às doações durante os fins de semana.

$\checkmark$ Não há flutuações significativas entre os meses. Arapiraca e Maceió apresentam uma tendência de aumento de movimentações no segundo semestre, mas pode indicar apenas um crescimento.

O trabalho de campo foi realizado na unidade Carmo (São Paulo) e contou com três etapas para o acompanhamento dos processos administrativos, gerenciais e operacionais, necessários para a constituição deste diagnóstico. A primeira em que foram feitas entrevistas com a equipe, a segunda que consistiu no acompanhamento do processo de doação e uma terceira para tirar dúvidas que surgiram após o acompanhamento da operação em campo. Foram objetivos específicos do trabalho de campo:

$\checkmark$ Acompanhar gerenciamento da operação;

$\checkmark$ Averiguar critérios de decisão para roteirização;

$\checkmark$ Observar tempos de carga e descarga (identificar e caracterizar as janelas de tempo da rota);

$\checkmark$ Averiguar possíveis dificuldades e restrições para embarque e desembarque de doações;

$\checkmark$ Identificar restrições de capacidade dos veículos.

A primeira etapa contou com uma apresentação geral do espaço-físico do SESC Carmo e uma longa entrevista com a coordenadora regional, Luciana Cassiano Machado Curvello Gonçalves, que está há 11 anos no programa e com a gerente da 
unidade Carmo, Denise Meira Dias Gonçalves. De forma geral, foi possível averiguar questões relativas ao gerenciamento e à operação de distribuição.

A determinação do roteiro, segundo relatado nas entrevistas, segue alguns princípios:

$\checkmark$ Compatibilidade do Produto. Não se pode misturar produtos de diferentes naturezas (alimento manipulado $\mathrm{x}$ in natura) para evitar riscos de contaminação cruzada. Foi comentado sobre a possibilidade de dividir o espaço no veículo reservado para a carga em setores que ainda não está sendo empregada.

$\checkmark$ A distribuição é feita segundo o critério de divisão regional.

$\checkmark$ As empresas doadoras são fixas no roteiro e há uma rotação das instituições que recebem.

$\checkmark$ Prioriza-se $o$ atendimento de instituições próximas à empresa doadora, e caso exceda a quantidade necessária encaminha-se para outro núcleo.

$\checkmark$ Desde 2001, eles trabalham com estoque para doações esporádicas, primeiramente em local próprio depois alugado.

$\checkmark$ Atualmente, o depósito se encontra próximo à unidade Carmo, sede do programa, por poder contar com a equipe de gerenciamento para o recebimento e distribuição das grandes doações (majoritariamente Unilever). Dentre as tarefas necessárias para o recebimento estão à própria descarga, a conferência da data de validade e a supervisão com relação às regras de armazenamento. O estoque hoje conta com um guarda 24 horas/dia.

$\checkmark$ Hoje, a infraestrutura do MESA SP conta com veículos terceirizados. No contrato antigo eram 3 veículos (1 caminhão e 3 furgões sendo 1 da $\mathrm{DHL}$ ) que trabalhavam por 12 horas. Já o novo contrato são 8 horas +1 hora para almoço com possibilidade de 2 horas extras.

$\checkmark$ Quando há restrição de capacidade em um dos carros é feita uma redistribuição para outros carros.

$\checkmark$ A segunda etapa consistiu em acompanhar o motorista no processo de coleta e entrega: 
$\checkmark$ Observaram-se dois padrões de tempo de carga: (1) padarias, utilizou um período inferior a 5 minutos para coleta da doação; (2) supermercado, utilizou um período de aproximadamente 3 horas.

$\checkmark$ Para os tempos de descarga, houve um único padrão que resultou em um período de aproximadamente 5 minutos para a entrega das doações.

$\checkmark$ O tempo de carregamento dos alimentos doados é muito superior ao tempo necessário para entrega. Isso se deve, principalmente, a necessidade de triagem de alimentos, que se dá no local. O carro chega ao local, o responsável é avisado, há uma limpeza do local onde seria feita posteriormente a triagem, e depois disso é que se inicia o processo de triagem. A triagem envolvia a separação de alimentos próprios e impróprios para o consumo. $O$ descarte daqueles que eram impróprios para o consumo e a acomodação em caixas dos alimentos a serem doados separados por categorias: frutas, verduras e legumes.

$\checkmark$ Houve alteração na rota inicialmente planejada por ter sido coletada uma quantidade maior de doações que o esperado e pelo fato de uma das instituições receptoras estarem fechada.

$\checkmark$ Não houve problemas com o limite de capacidade do veículo diante do montante doado, porém, foi alocado outro carro para que o alimento fosse melhor distribuído diante do fato que a quantidade de doações superava as necessidades das instituições da região de destino programada.

$\checkmark$ Não houve dificuldade que influenciasse significativamente as operações de embarque ou desembarque das doações. Mas posteriormente, na etapa 3, foram narradas algumas dificuldades, como a existência de ponto de ônibus em frente às instituições. Maiores considerações são descritas na etapa 3.

$\checkmark$ Dificultam a entrega: feiras-livres, chuva, trânsito, entre outros.

$\checkmark$ Itaquera não possui roteiros fixos, motoristas sentem maior dificuldade.

$\checkmark$ Quando a responsável pela logística (Maria) está presente, a alocação da distribuição é feita rapidamente. Quando não, geralmente há demora na alocação da distribuição fazendo com que os veículos fiquem parados a espera da alocação.

$\checkmark$ É programada uma rotatividade mensal do planejamento de distribuição com o objetivo de propiciar às instituições a possibilidade de receberem uma maior variedade de produtos doados. Com isso, busca-se fazer um re-planejamento uma 
vez por mês, em que núcleos de instituições são realocados para outros dias da semana com 0 intuito de modificar a origem dos produtos doados $e$ conseqüentemente a variedade dos mesmos.

$\checkmark$ A DHL recebe um roteiro que exige menos capacitação específica da equipe de coleta e entrega, em outras palavras, um roteiro que exige menos no processo de seleção e triagem das doações. Isso se deve ao fato de haver mudanças freqüentes na equipe da DHL que doa o serviço para o SESC.

$\checkmark$ A terceira etapa referiu-se às questões do sistema e do planejamento de distribuição de doações. Seguem os principais comentários referentes ao sistema:

$\checkmark$ Os dados são conferidos através de algumas formas, quais sejam: 1. a cada nota fiscal soma-se as quantidades e coloca-se em seu verso o resultado para aquela nota; 2. o valor no verso de cada nota e a somatória dos mesmos é comparado ao que foi distribuído para as instituições; 3. o valor da somatória feita manualmente é comparado ao valor informado pelo relatório (Doações por Empresa) emitido pelo Sistema. Além disso, como comentado anteriormente, no próprio processo de entrada de dados há uma conferência entre os valores digitados em uma seção e consolidados em outra.

$\checkmark$ Alguns produtos não estão descritos no sistema. Foi citado o exemplo do extrato e da polpa de tomate que são declarados como sendo o mesmo produto.

$\checkmark$ Se o sistema parecer apresentar qualquer falha no ato da gravação e o usuário repetir a ação, há uma duplicação do dado, que deve então ser cancelado por meio de outra operação (de edição ou exclusão). Este problema muitas vezes só é detectado durante o processo de conferência dos dados.

$\checkmark$ Há duas formas de entrar com os dados de cessão: Planejamento de Distribuição, e Nova Cessão. Se o processo é feito pela primeira via, faz-se necessária uma confirmação na tela de Cessões para a efetiva contabilização. Se o processo é feito pela segunda via, faz-se necessário a inclusão de produtos como passo adicional a entrada de dados.

$\checkmark$ Freqüência de entrada de dados: aproximadamente 2 vezes por semana.

$\checkmark$ Quando há transferências entre carros é feita uma referência no verso da nota fiscal. 
$\checkmark$ Quando o veículo leva doações do estoque juntamente com doações coletadas no dia, pula-se uma linha para declarar os valores na nota.

$\checkmark$ A classificação de produtos adotada pela Unidade Carmo difere daquela agrupada no Sistema.

$\checkmark$ São elaborados vários relatórios, cuja fonte antes do aprimoramento da velocidade da internet, não era o Sistema. Planilhas em Excel eram administradas paralelamente para viabilizar a atualização constante de dados a tempo de produzir as informações necessárias para serem enviadas às respectivas gerências.

$\checkmark$ Pressupostos adotados em um dos relatórios: cada $\mathrm{Kg}$ de doação complementa 10 refeições.

$\checkmark$ Com relação ao processo de planejamento da distribuição das doações:

$\checkmark$ A distribuição baseia-se em uma tabela per capita de doações por instituição onde constam os valores mínimo e máximo que podem ser distribuídos para cada instituição.

$\checkmark$ Há também uma tabela declarando a ordem de prioridade de doação de alimentos.

$\checkmark$ O cálculo para distribuição é feito a partir destas tabelas sendo que quando há "poucas" doações consideram-se os valores mínimos e quando há "muitas doações" consideram-se os valores máximos, sempre respeitando as ordens de prioridade.

$\checkmark$ A ordem de prioridade só não é seguida quando o prazo de validade da doação está próximo do vencimento. Neste caso, a prioridade é enviar tais doações para instituições onde haja garantia que o consumo seja rápido. Por exemplo, foi recebida uma grande doação de yogurte que, pela prioridade, seria destinado às creches, mas com o prazo de validade próximo ao vencimento, o mesmo foi desviado para outras instituições onde o consumo seguramente seria mais rápido. De forma geral, nesses casos, a prioridade é praticamente invertida. Quando a quantidade é muito grande e a perecibilidade muito alta, no caso do leite doado por uma agropecuária, por exemplo, além desta inversão de prioridades o SESC também faz um contato telefônico para assegurar se há demanda ou espaço adequado (refrigerado ou não) para armazenamento. 
$\checkmark$ Algumas particularidades foram apontadas que constituem exceções à regra anterior: instituições que já recebem verduras da prefeitura e, portanto, apesar de se enquadrarem no perfil de prioridade, acabam não recebendo os mesmos alimentos que aquelas que fazem parte da mesma classe. Da mesma forma instituições que declaram receber doações de padarias próximas ou outras instituições e acabam também não correspondendo ao padrão. Outra exceção citada foi uma Instituição Israelita que não recebe alimento processado.

$\checkmark$ Algumas instituições demandam um trabalho extra, de fazer um contato no momento da entrega. Isso acontece, pois a mesma está localizada em local de difícil acesso (por ex: próximo a um ponto de ônibus) o que faz com que o motorista tenha que ligar momentos antes de encostar o carro para a central para que a instituição seja avisada da chegada do carro.

$\checkmark$ Há outro formato de planilha para a distribuição de grandes doações, denominada controle de distribuição de doações. Nesta, grandes quantidades de alimentos são distribuídas para as instituições.

$\checkmark$ Com a restrição de circulação foram feitas algumas mudanças no roteiro.

$\checkmark$ Quando há feriado na semana também há uma preocupação em não enviar alimentos em excesso para que os mesmos não se estraguem na própria instituição.

\section{A.1.2 - Entrevista com doador de bancos de alimentos Wal- Mart}

Foi realizada uma entrevista com Paulo Mindlin, diretor do instituto Wal-Mart. Seguem as principais considerações comentadas:

$\checkmark$ Os produtos alimentícios expostos para venda devem seguir uma padronização de forma, tamanho, cor. O que está fora do padrão é recolhido por funcionário responsável pelo setor. Este funcionário, geralmente, tem como funções: recolher, repor, limpar e controlar o estoque. 
$\checkmark \quad$ Toda mercadoria retirada da loja, que não foi comercializada, vai para um espaço físico, chamado de área de quebra.

A reposição pode ser feita pelo funcionário da loja ou pelo próprio fornecedor e dependerá do acordo comercial firmado.

$\checkmark \quad$ Os perecíveis não possuem acordo de devolução.

$\checkmark \quad$ Bancos de alimentos fazem a triagem e retiram o que Ihes interessa.

$\checkmark \quad$ Tudo o que está na área de quebra que não é recolhido pelo fornecedor ou que não é doado vai para a compactadora de resíduos orgânicos.

As doações são diárias.

Cereais também são doados, mas em menor quantidade.

$\checkmark \quad$ O Wal-Mart possui um sistema de controle de estoque que é comum a todas as lojas no município de São Paulo. Fora de São Paulo há variações devido às fusões ocorridas recentemente.

$\checkmark \quad$ Quando há doação o sistema de controle de estoque registra a saída do produto da gôndola como tal. Essa distinção foi necessária para que pudesse ser gerada uma nota fiscal, importante para que a responsabilidade sobre o alimento doado seja repassada para aquele que vem recolher. Porém, este registro é apenas contábil, ou seja, por valor de produto, o que impede uma discriminação detalhada do volume por categoria de produto doado.

$\checkmark \quad$ Existe uma variação de estoque devido à quebra natural do processo de venda, mas em alguns produtos essa variação é mais significativa, principalmente quando se refere aos alimentos mais perecíveis. Com isso, esses alimentos são os mais doados.

$\checkmark \quad$ Existe um limite de segurança de proximidade do prazo de validade que é de 3 dias. 
$\checkmark$ Possui Centro de Distribuição em Jandira, mas não há doações a partir do CD, devido a questões de segurança, pouca quebra, embalagem do produto imprópria, em pallets.

$\checkmark \quad$ O transporte entre CD e loja é terceirizado.

$\checkmark \quad$ Não é o gerente da loja que decide sobre doar ou não, é uma política da empresa.

$\checkmark$ O Wal-Mart promoveu cursos de aproveitamento integral de alimentos após a parceria com o Programa Mesa Brasil SESC.

$\checkmark \quad$ O entrevistado acredita que a quantidade de alimento doado é limitada pela capacidade de captação do Banco de Alimentos, ou seja, que o Wal-Mart tem um potencial maior para doações do que $o$ atualmente praticado.

\section{A.2 - Entrevistas com Bancos de Alimentos na Europa.}

Foram realizadas entrevistas junto a Federação Européia de Bancos de Alimentos (FEBA) e a Federação Francesa de Bancos de Alimentos.

A gerente geral da Federação de Bancos Européia de Bancos de Alimentos apresentou em linhas gerais o que constitui e como funciona a organização. Forneceu ainda um material contendo a estatísticas (Tabelas A.3, A.4, A.5, A.6, A.7, , A.8, A.9) regulamentos, entre outros.

A história da FEBA é composta por duas fases, uma primeira de 1986 a 1997 e uma segunda, depois disso, quando começaram a participar países do leste europeu.

A Federação Européia é responsável por (1) auxiliar a divulgar e representar os Bancos de Alimentos junto a União Européia, (2) organizar as informações para auxiliar a criação de novos bancos e novas federações nacionais, entre outros. 
Em média $1 / 3$ das doações que vão para os bancos de alimentos tem origem de financiamentos feitos pela União Européia, $1 / 3$ das doações vêm da indústria e 1/3 do varejo/distribuição.

Há isenção de impostos para transporte dos alimentos doados e também quando o alimento é comprado por financiamentos da União Européia e os produtos são vendidos diretamente aos Bancos de Alimentos, os impostos de transporte também não são cobrados.

Grande parte dos funcionários da Federação faz trabalho voluntário (geralmente aposentados).

Tabela A.3 - Número de bancos de alimentos que fazem parte da Federação Européia de Bancos de Alimentos.

\begin{tabular}{|c|c|c|c|c|c|c|}
\hline \multirow{2}{*}{ Países } & \multicolumn{5}{|c|}{ Número de Bancos de Alimentos } & \multirow{2}{*}{$\begin{array}{c}\text { B.A. em } \\
\text { construção }\end{array}$} \\
\hline & 2003 & 2004 & 2005 & 2006 & 2007 & \\
\hline Alemanha & & & 1 & 1 & 1 & 3 \\
\hline Bélgica & 9 & 9 & 9 & 9 & 9 & \\
\hline Espanha & 24 & 40 & 40 & 50 & 52 & \\
\hline França & 79 & 79 & 79 & 79 & 79 & \\
\hline Grécia & 1 & 1 & 1 & 1 & 1 & \\
\hline Hungria & & & 1 & 1 & 1 & \\
\hline Irlanda & 1 & 1 & 1 & 1 & 2 & \\
\hline Itália & 17 & 18 & 19 & 19 & 20 & \\
\hline Letuânia & 1 & 1 & 1 & 1 & & \\
\hline Luxemburgo & 1 & 1 & 1 & 1 & 1 & \\
\hline Holanda & & & 1 & 1 & 1 & 7 \\
\hline Polônia & 14 & 15 & 19 & 22 & 22 & \\
\hline Portugal & 9 & 10 & 10 & 11 & 13 & \\
\hline República Tcheca & & & 1 & 1 & 2 & 1 \\
\hline Reino Unido & & & & & 10 & \\
\hline Eslováquia & & & 1 & 1 & 1 & 1 \\
\hline Suíça & 1 & 1 & 1 & 1 & 1 & \\
\hline Ucrânia & 3 & 3 & 2 & 2 & 2 & 2 \\
\hline Total & 160 & 179 & 188 & 202 & 218 & 14 \\
\hline
\end{tabular}


Tabela A.4 - Quantidade de alimentos coletada por bancos de alimentos que fazem parte da Federação Européia de Bancos de Alimentos.

\begin{tabular}{|c|c|c|c|c|c|c|}
\hline \multirow{2}{*}{ Países } & \multicolumn{5}{|c|}{ Quantidade de alimentos coletada (ton) } & \multirow{2}{*}{\begin{tabular}{|c} 
Evolução em \% \\
$2007 / 2006$ \\
\end{tabular}} \\
\hline & 2003 & 2004 & 2005 & 2006 & 2007 & \\
\hline Alemanha & & & & 145 & 434 & 199,31 \\
\hline Bélgica & 8.582 & 9.128 & 8.400 & 9.433 & 12.000 & 27,21 \\
\hline Espanha & 24.769 & 26.089 & 29.798 & 58.353 & 68.077 & 16,66 \\
\hline França & 66.000 & 71.250 & 72.970 & 74.800 & 72.910 & $-2,53$ \\
\hline Grécia & 648 & 781 & 766 & 1.054 & 865 & $-17,93$ \\
\hline Hungria & & & 32 & 3.605 & 2.790 & $-22,61$ \\
\hline Irlanda & 527 & 617 & 614 & 560 & 621 & 10,89 \\
\hline Itália & 44.673 & 53.411 & 51.307 & 65.997 & 58.675 & $-11,09$ \\
\hline Letuânia & 5 & 5 & ND & ND & & \\
\hline Luxemburgo & 6 & 12 & 14 & 31 & ND & \\
\hline Holanda & & & & 5.000 & ND & \\
\hline Polônia & 8.903 & 9.931 & 38.271 & 44.722 & 48.138 & 7,64 \\
\hline Portugal & 12.702 & 13.479 & 17.642 & 18.014 & 19.919 & 10,58 \\
\hline República Tcheca & & & & 61 & 339 & 455,74 \\
\hline Reino Unido & & & & - & 2.777 & \\
\hline Eslováquia & & & & 4 & 42 & 950 \\
\hline Suíça & 16 & 20 & 44 & 82 & 73 & $-10,98$ \\
\hline Ucrânia & 120 & 125 & 129 & 137 & 162 & 18,25 \\
\hline Total & 166.951 & 184.848 & 219.987 & 281.998 & 287.822 & 2,07 \\
\hline
\end{tabular}


Tabela A.5 - Origem das doações de bancos de alimentos que fazem parte da Federação Européia de Bancos de Alimentos.

\begin{tabular}{|c|c|c|c|c|c|c|c|}
\hline \multirow{2}{*}{ Países } & \multicolumn{7}{|c|}{ Produtos coletados por país e tipo de fornecedor } \\
\hline & Número B.A. & Varejo & Produtos UE & Indústria & Distribuição & Campanhas & Total \\
\hline Alemanha & 1 & 0 & 0 & 434 & 0 & 0 & 434 \\
\hline Bélgica & 9 & 379 & 4951 & 3581 & 2226 & 863 & 12000 \\
\hline Espanha & 52 & 3517 & 41463 & 14575 & 7845 & 677 & 68077 \\
\hline França & 79 & 2710 & 17020 & 20970 & 21140 & 11070 & 72910 \\
\hline Grécia & 1 & 0 & 1 & 775 & 74 & 15 & 865 \\
\hline Hungria & 1 & 0 & 2364 & 283 & 138 & 5 & 2790 \\
\hline Irlanda & 2 & 0 & 1 & 620 & 0 & 0 & 621 \\
\hline Itália & 20 & 2045 & 33841 & 11850 & 1755 & 9184 & 58675 \\
\hline Letuânia & - & - & - & - & - & - & - \\
\hline Luxemburgo & 1 & ND & ND & ND & ND & ND & ND \\
\hline Holanda & 1 & ND & ND & ND & ND & ND & ND \\
\hline Polônia & 22 & 0 & 42073 & 3995 & 1011 & 1059 & 48138 \\
\hline Portugal & 13 & 4573 & 1569 & 8105 & 1063 & 4609 & 19919 \\
\hline República Tcheca & 2 & 0 & 0 & 293 & 46 & 0 & 339 \\
\hline Reino Unido & 10 & 0 & 0 & 2027 & 750 & 0 & 2777 \\
\hline Eslováquia & 1 & 0 & 0 & 42 & 0 & 0 & 42 \\
\hline Suíça & 1 & 0 & 0 & 12 & 46 & 15 & 73 \\
\hline Ucrânia & 2 & 0 & 0 & 0 & 162 & 0 & 162 \\
\hline Total & 218 & 13224 & 143283 & 67562 & 36256 & 27497 & 287822 \\
\hline
\end{tabular}

Tabela A.6 - Destino das doações de bancos de alimentos que fazem parte da Federação Européia de Bancos de Alimentos.

\begin{tabular}{|c|c|c|c|c|c|c|}
\hline Países & \begin{tabular}{|c|} 
Quantidades \\
Distribuídas (1000kg) \\
\end{tabular} & \begin{tabular}{|c|} 
Valor dos produtos \\
(em 1000 euros)
\end{tabular} & \begin{tabular}{|l|} 
Número de \\
Associações
\end{tabular} & \begin{tabular}{|l|} 
Número de \\
Beneficiados
\end{tabular} & $\begin{array}{c}\text { Quantidade acumulada } \\
\text { por pessoa (em kg) }\end{array}$ & \begin{tabular}{|c|} 
Preço acumulado \\
por kilo (em euros)
\end{tabular} \\
\hline Alemanha & 434 & ND & 40 & ND & - & - \\
\hline Bélgica & 11701 & 27900 & 653 & 108100 & 108 & 2,38 \\
\hline Espanha & 66415 & 118469 & 6487 & 888957 & 75 & 1,78 \\
\hline França & 69498 & 202000 & 4890 & 754000 & 92 & 2,91 \\
\hline Grécia & 832 & 2674 & 218 & 24850 & 33 & 3,21 \\
\hline Hungria & 2790 & 2331 & 375 & 50000 & 56 & 0,84 \\
\hline Irlanda & 621 & ND & 78 & 27000 & 23 & ND \\
\hline Itália & 65903 & 202323 & 8248 & 1434853 & 46 & 3,07 \\
\hline Letuânia & - & - & - & - & - & - \\
\hline Luxemburgo & ND & ND & ND & ND & ND & ND \\
\hline Holanda & ND & ND & ND & ND & ND & ND \\
\hline Polônia & 47734 & 27151 & 3094 & 705827 & 68 & 0,57 \\
\hline Portugal & 20359 & 25702 & 1542 & 162194 & 126 & 1,26 \\
\hline República Tcheca & 321 & 687 & 55 & 11250 & 29 & 2,14 \\
\hline Reino Unido & 2570 & ND & 420 & 20000 & 129 & ND \\
\hline Eslováquia & 59 & 169 & 86 & 51343 & 1 & 2,86 \\
\hline Suíça & 60 & 84 & 8 & 566 & 106 & 1,4 \\
\hline Ucrânia & 162 & 85 & 31 & 50000 & 3 & 0,52 \\
\hline Total & 289459 & 609575 & 26225 & 4288940 & 67 & 2,11 \\
\hline
\end{tabular}


Tabela A.7 - Infraestrutura dos bancos de alimentos que fazem parte da Federação Européia de Bancos de Alimentos.

\begin{tabular}{|c|c|c|c|c|c|c|c|c|c|c|}
\hline \multirow{2}{*}{ Países } & \multicolumn{2}{|c|}{ Superfícies } & \multicolumn{2}{|c|}{ Câmaras frias } & \multicolumn{3}{|c|}{ Veículos } & \multicolumn{3}{|c|}{ Material de manutenção } \\
\hline & Depósito $\left(\mathrm{m}^{2}\right)$ & Escritório $\left(\mathrm{m}^{2}\right)$ & Acima de $0^{\circ}$ & Abaixo de $0^{\circ}$ & Refrigerados & Outros & Total & Paleteira & Empilhadeira & Total \\
\hline Alemanha & 2000 & 30 & & & & & & 1 & 0 & - \\
\hline Bélgica & 7494 & 629 & 441 & 2058 & 7 & 6 & 13 & 60 & 18 & 78 \\
\hline Espanha & 19577 & 2448 & 8699 & 1206 & 10 & 63 & 73 & 111 & 39 & 150 \\
\hline França & 67130 & & 6930 & 3817 & 169 & 85 & 254 & 436 & 133 & 569 \\
\hline Grécia & 1035 & 82 & 114 & 72 & 0 & 2 & 2 & 0 & 1 & 1 \\
\hline Hungria & 1000 & 24 & & & 1 & 0 & 1 & 0 & 0 & 0 \\
\hline Irlanda & 80 & 7 & 16 & 36 & 1 & 0 & 1 & 0 & 0 & 0 \\
\hline Itália & 32156 & 2721 & 7678 & 2939 & 33 & 54 & 87 & 148 & 49 & 197 \\
\hline \multicolumn{11}{|l|}{ Letuânia } \\
\hline Luxemburgo & ND & ND & ND & ND & ND & ND & ND & ND & ND & ND \\
\hline Holanda & ND & ND & ND & ND & ND & ND & ND & ND & ND & ND \\
\hline Polônia & 15949 & 1354 & 1552 & 445 & 16 & 9 & 25 & 75 & 20 & 95 \\
\hline Portugal & 9644 & 1016 & 2397 & 262 & 4 & 12 & 16 & 50 & 16 & 66 \\
\hline República Tcheca & 430 & 40 & 44 & 0 & 1 & 0 & 1 & 2 & 2 & 4 \\
\hline Reino Unido & 3650 & 390 & 205 & 120 & 15 & 0 & 15 & 19 & 10 & 29 \\
\hline Eslováquia & 40 & & & & 1 & 0 & 1 & 0 & 0 & 0 \\
\hline Suiça & 170 & 20 & 1 & 1 & 1 & 1 & 2 & 2 & 1 & 3 \\
\hline Ucrânia & 150 & 130 & 0 & 0 & 0 & 0 & 0 & 0 & 0 & 0 \\
\hline Total & 160505 & 8891 & 28077 & 10956 & 259 & 232 & 491 & 904 & 289 & 1193 \\
\hline
\end{tabular}

Tabela A.8 - Recursos humanos dos bancos de alimentos que fazem parte da Federação Européia de Bancos de Alimentos.

\begin{tabular}{|l|r|l|l|l|l|}
\hline Países & Voluntários & $\begin{array}{l}\text { Funcionários } \\
\text { pagos }\end{array}$ & $\begin{array}{l}\text { Contratos } \\
\text { Sociais }\end{array}$ & \multicolumn{2}{l}{ Total } \\
\hline Alemanha & 5 & 0 & 0 & 5 \\
\hline Bélgica & 205 & 4 & 10 & 219 \\
\hline Espanha & 1015 & 39 & 9 & 1063 \\
\hline França & 3194 & 120 & 230 & 3544 \\
\hline Grécia & 36 & 5 & 0 & 41 \\
\hline Hungria & 10 & 3 & 0 & 13 \\
\hline Irlanda & 2 & 4 & 0 & 6 \\
\hline Itália & 1218 & & 77 & 0 & 1295 \\
\hline Letuânia & & & & \\
\hline Luxemburgo & ND & ND & & ND & ND \\
\hline Holanda & ND & ND & & ND & ND \\
\hline Polônia & 76 & 79 & 33 & 188 \\
\hline Portugal & 286 & 32 & 17 & 335 \\
\hline República Tcheca & 5 & & 3 & 2 & 10 \\
\hline Reino Unido & 250 & 13 & 0 & 263 \\
\hline Eslováquia & 9 & & 0 & 0 & 9 \\
\hline Suíça & 17 & 0 & 10 & 27 \\
\hline Ucrânia & 30 & 2 & 0 & 32 \\
\hline Total & 6358 & 381 & 311 & 7050 \\
\hline
\end{tabular}


Tabela A.9 - Tipo de alimentos doados aos bancos de alimentos que fazem parte da Federação Européia de Bancos de Alimentos.

\begin{tabular}{|l|r|r|r|r|r|}
\hline \multicolumn{1}{|c|}{ Grandes familias de produtos em \% } & 2003 & 2004 & 2005 & 2006 & 2007 \\
\hline Derivados de leite & 26 & 29 & 36 & 36 & 27 \\
\hline Biscoitos, cereais e alimentos engomados & 22 & 26 & 25 & 31 & 30 \\
\hline Carne, peixe & 9 & 4 & 5 & 4 & 4 \\
\hline Refeições preparadas & 4 & 5 & 4 & 3 & 4 \\
\hline Gorduras & 2 & 2 & 2 & 2 & 2 \\
\hline Produtos adocicados & 3 & 4 & 4 & 4 & 8 \\
\hline Frutas e vegetais & 24 & 24 & 21 & 15 & 17 \\
\hline Bebidas, temperos, comida de bebê & 10 & 6 & 3 & 5 & 8 \\
\hline TOTAL & 100 & 100 & 100 & 100 & 100 \\
\hline
\end{tabular}

A Federação Francesa de Bancos de Alimentos teve início em 1984 e congrega 79 bancos de alimentos. Em 2007 distribuiu 72.910 toneladas de alimentos, sendo 4\% referente ao varejo, $23 \%$ de produtos fornecidos pela União Européia, 29\% de doações da indústria, 29\% do setor de distribuição, 15\% de campanhas de arrecadação. Em 2007 os bancos de alimentos da Federação Francesa atendiam um total de 4.890 instituições de caridade, o que representa uma média de 754.000 beneficiários. Em termos de infraestrutura os bancos de alimentos franceses possuem $67.130 \mathrm{~m} 2$ de armazéns sendo $10.747 \mathrm{~m} 2$ refrigerados $(6.930 \mathrm{f}>0$ e $3.817<0)$. Em termos de infraestrutura de transporte os bancos de alimentos franceses possuem 254 veículos, sendo 158 frigorificados e 11 isotérmicos. Dos 3.544 funcionários 3.194 são voluntários, 120 contratados por prazo indeterminado e 240 contratados por prazo determinado. Com relação às doações $32 \%$ são produtos lácteos, $28 \%$ féculas, cereais e biscoitos, $18 \%$ frutas e legumes.

A demanda nos bancos de alimentos na França identificada através de requisições das instituições que enviam formulários por fax ou internet para os bancos de alimentos. Os bancos de alimentos verificam se a demanda pode ser atendida e confirmam para as instituições, caso não haja em estoque são dadas alternativas. As Associações retiram os alimentos nos bancos de alimentos. 
Conforme mencionado anteriormente os bancos de alimentos recebem doações de produtos não vendidos mas também recebem doações feitas pela União Européia. Quando a União Européia financia a compra de alimentos os bancos de alimentos vão até produtores, provam os alimentos e escolhem quais são de qualidade aceitável, sem conhecer o preço. A negociação financeira não é feita pelos bancos de alimentos que apenas recebem posteriormente o alimento.

Quando o produto é comprado o produtor ou indústria leva até o banco de alimentos, quando isso não é possível há uma mobilização de bancos de alimentos para cumprir a tarefa.

A administração dos bancos de alimentos na frança é setorizada. São 8 regiões e em cada uma há um comitê regional de prospecção. Este comitê é responsável por conseguir doadores e fazer a intermediação para que os bancos de alimentos recebam a doação, incluindo a organização do transporte. A estrutura da Federação Nacional Francesa atua de baixo para cima, ou seja, os assuntos são resolvidos localmente e repassados para instância superior apenas quando necessário.

Todas as transações são feitas por telefone e quando há uma grande carga estudase a divisão de custos de transporte entre os bancos de alimentos para o deslocamento entre regiões. A freqüência dessas doações em grande quantidade é esporádica de aproximadamente duas vezes ao mês. Os armazéns são alugados e também há alguns casos de armazéns próprios. E quando não há dinheiro para o transporte há recusa de doações, são casos esporádicos, mas acontece.

Comentando sobre possíveis funcionalidades do sistema ele levantou que talvez fosse interessante disponibilizar ferramentas para facilitar 0 transporte entre associações, para que elas possam dividir os custos de transporte.

Foi mencionada uma preocupação com rastreabilidade dos alimentos. 
APÊNDICE B - Códigos das Ontologias EM Mídia Digital. 